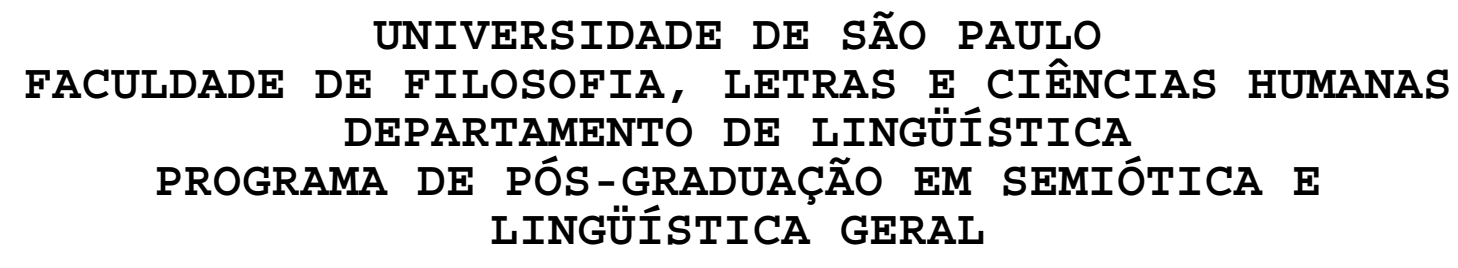

\title{
CONSTelação FôNICA E REDes NeURAis ARtificiais: APLICABILIDADE NA ANÁLISE COMPUTACIONAL DA PRODUÇÃO DA FALA
}

João Carlos Almeida Prado

Tese apresentada ao Programa de PósGraduação em Semiótica e Lingüística Geral, do Departamento de Lingǘstica da Faculdade de Filosofia, Letras e Ciências Humanas da Universidade de São Paulo, para obtenção do título de Doutor em Semiótica e Lingüística Geral.

Orientador: Profa. Dra. Claudia Regina Furquim de Andrade

\section{SÃO PAULO}




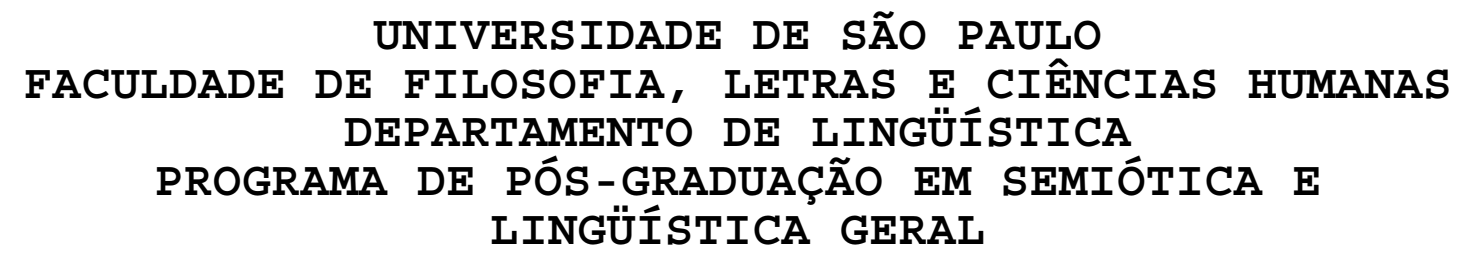

\section{CONSTelação FôNICA E REDes NeURAis ARtificiais: APLICABILIDADE NA ANÁLISE COMPUTACIONAL DA PRODUÇÃO DA FALA}

João Carlos Almeida Prado

Tese apresentada ao Programa de PósGraduação em Semiótica e Lingüística Geral, do Departamento de Lingǘstica da Faculdade de Filosofia, Letras e Ciências Humanas da Universidade de São Paulo, para obtenção do título de Doutor em Semiótica e Lingüística Geral.

Orientador: Profa. Dra. Claudia Regina Furquim de Andrade

\section{SÃO PAULO}

2007 
UNIVERSIDADE DE SÃO PAULO

FACULDADE DE FILOSOFIA, LETRAS E CIÊNCIAS HUMANAS

DEPARTAMENTO DE LINGÜÍSTICA

PROGRAMA DE PÓS-GRADUAÇÃO EM SEMIÓTICA E

LINGÜÍSTICA GERAL

CONStelaçÃo FôNICA E REDes NEURAis ARtificials: APLICABILIDADE NA ANÁLISE COMPUTACIONAL DA PRODUÇÃO DA FALA

João Carlos Almeida Prado

Orientador: Profa. Dra. Claudia Regina Furquim de Andrade

SÃO PAULO

2007 
P_C

Prado, João Carlos Almeida.

Constelação Fônica e Redes Neurais Artificiais: Aplicabilidade na análise computacional da produção da fala - João Carlos Almeida Prado. São Paulo: 2007. $173 \mathrm{f}$.

Orientação: Profa. Dra. Claudia Regina Furquim de Andrade Tese de Doutorado - Faculdade de Filosofia Letras e Ciências Humanas da Universidade de São Paulo, 2007.

Inclui anexo e bibliografia.

1. Redes Neurais Artificiais; Paraconsistente; Produção de Fala; Formantes; Fones; Análise de Fala; 


\section{DEDICATÓRIA}

À Minha esposa, por ter sido minha companheira, amiga e colaboradora deste trabalho, me incentivando, apoiando e acreditando em mim, mesmo quando até eu tive dúvidas. 


\section{AGRADECIMENTOS}

Agradeço a todos os colegas que, de forma direta ou indireta, colaboraram para que eu conseguisse concluir este trabalho, em especial à minha orientadora, Profa. Dra. Claudia Regina Furquim de Andrade, por nortear este trabalho com sua excepcional ética e competência profissional; e ao Prof. Jair Minoro Abe, que possibilitou esta parceria frutífera, entre a Lógica e a Medicina. 


\section{Sumário}

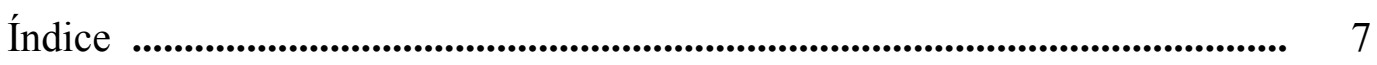

Índice das Tabelas ................................................................................... 9

Índice das Figuras .................................................................................................... 10

Resumo ............................................................................................................. 13

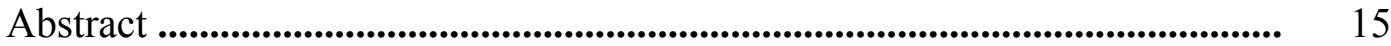

Referências Bibliográficas ................................................................................... 144

Apêndices:

A- Etapas da Criação do Sistema de Análise da Produção da Fala - SIAPF

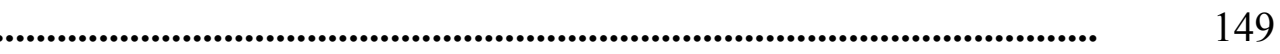

B- Autorização da AUTOBYTE para uso do Delphi ${ }^{\circledR}$ para o desenvolvimento do SIAPF ....................................................................................................... 151 Anexos:

A- Estudo do programa PRAAT .................................................................. 152

B- Aplicativo para visualização da série de Fourier .................................... 160

C- Séries de Fourier e Transformada rápida de Fourier ............................... 162

D- Média, Variância e Desvio Padrão .......................................................... 170

E- Funções Matemáticas ................................................................................. 172 


\section{ÍNDICE}

Apresentação

\section{Introdução}

I.1. As Ondas Sonoras: Definições .............................................................. 19

I.2. Conceitos de Fonética e Fonologia: Os Fonemas, Fones e os Traços Formantes 26

I.3. Analise quantitativa do sinal de voz: implicações na análise da produção da fala. 32

I.4. As Ondas Sonoras: Captação, Representação e Modelagem matemática 37

I.5. Algumas técnicas importantes no estudo, modelagem e reconhecimento da fala

II. Modelamento Matemático para análise computacional da produção da Fala

II.1. A criação do conceito de Constelação Fônica ....................................... 43

II.2. Constelação Fônica da Amplitude ............................................................ 49

II.3. Constelação Fônica da Freqüência ........................................................ 52

II.4. Fundamentos de Redes Neurais Artificiais ........................................ 55

II.5. Fundamentos da Lógica Paraconsistente ............................................ 58

II.6. A Lógica Paraconsistente aplicada às Redes Neurais Artificiais 66

II.7. Fundamentos das Redes Neurais Artificiais Paraconsistentes

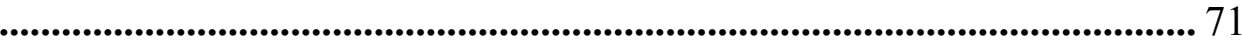

II.8. As Redes Neurais Artificiais Paraconsistentes usadas no reconhecimento de padrões .................................................................................................. 85

II.9. Criação das Unidades Neurais Artificiais Paraconsistentes para aprendizado e reconhecimento das constelações fônicas (UNAParcf) ... 112 
III.Método e Sistema de Análise da produção da Fala

III.1. SIAPF - Sistema de Análise da Produção da Fala ................................. 116

III.2. Testes funcionais do SIAPF …......................................................... 135

\section{Discussão e Considerações Finais}

IV.1. Discussão, Conclusões e Perspectivas de continuidade ........................... 141 


\section{Índice das Tabelas}

Tabela I.2.1 -Consoantes de acordo com seus Formantes .................................... 29

Tabela I.2.2 - Vogais de acordo com seus Formantes (abertura)......................... 30

Tabela I.2.3 - Vogais de acordo com seus Formantes (acústica).......................... 30

Tabela I.2.4 - Soantes de acordo com seus Formantes .......................................... 30

Tabela II.5.1 - Constantes anotacionais .................................................................. 63

Tabela II.5.2 - Interpretações. .............................................................................. 64

Tabela III.2.1 -Aprendizado e Reconhecimento .................................................... 136

Tabela III.2.2 - Reconhecimento (comparação) ...................................................... 137 


\section{Índice das Figuras}

Figura I.1.1 - Representação gráfica em plano cartesiano de uma oscilação...... 22

Figura I.1.2 - Representação da propagação do som no ar .................................. 25

Figura I.4.1 - Desenho representativo esquemático do microfone magnético ... 38

Figura I.4.2 - Forma de onda de uma senóide perfeita ................................... 38

Figura I.4.3 - Forma de onda amostrada em amplitude ...................................... 40

Figura II.1.1 - Representação ilustrativa da Constelação Fônica de freqüência e

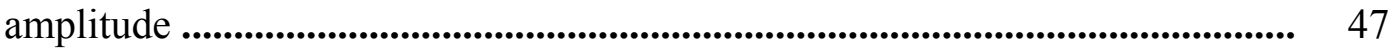

Figura II.2.1 - Representação ilustrativa de um sinal em amplitude ................. 49

Figura II.2.2 - Representação ilustrativa de um elemento da Constelação Fônica de

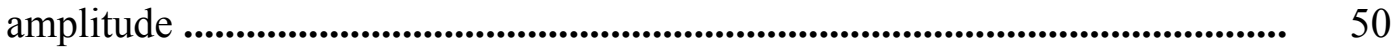

Figura II.3.1 - Representação gráfica ilustrativa do espectro em freqüência .... 52

Figura II.5.1 - Representação do reticulado associado a LPA2v ........................ 61

Figura II.5.2 - Plano cartesiano de evidência favorável e contrária .................... 62

Figura II.5.3 - Gráfico das constantes anotacionais .............................................. 62

Figura II.5.4 - Reticulado das constantes anotacionais ....................................... 64

Figura II.6.1 - Representação gráfica da transformação de uma onde em vetor . 66

Figura II.6.2 - Representação gráfica da seqüência de aprendizado da Rede ..... 67

Figura II.6.3 - Representação gráfica cartesiana dos vetores ................................ 68

Figura II.6.4 - Representação gráfica da Rede ...................................................... 70

Figura II.7.1 - Célula Artificial Paraconsistente básica ..................................... 72

Figura II.7.2 - CNAPca - Célula Neural Artificial Paraconsistente de conexão analítica

Figura II.7.3 - CNAPclsmax - Célula Neural Artificial Paraconsistente de conexão lógica simples para maximização ........................................................................ 75

Figura II.7.4 - CNAPclsmin - Célula Neural Artificial Paraconsistente de conexão lógica simples para minimização ...................................................................... 76

Figura II.7.5 - CNAPclsemax - Célula Neural Artificial Paraconsistente de conexão lógica seletiva para maximização ............................................................................. 77

Figura II.7.6 - CNAPclsemin - Célula Neural Artificial Paraconsistente de conexão lógica seletiva para minimização 
Figura II.7.7 - CNAPco - Célula Neural Artificial Paraconsistente complementação 79

Figura II.7.8 - CNAPd - Célula Neural Artificial Paraconsistente de decisão ... 80

Figura II.7.9 - CNAPadm - Célula Neural Artificial Paraconsistente de aprendizagem, desaprendizagem e memorização. ................................................ 81

Figura II.7.10 - Para-perceptron - UNAPb ...................................................... 83

Figura II.8.1 - CNAPp - Célula Neural Artificial Paraconsistente de passagem 86

Figura II.8.2 - Algoritmo de aprendizagem e desaprendizagem ........................... 88

Figura II.8.3 - CNAPadm - Célula Neural Artificial Paraconsistente de aprendizagem, desaprendizagem e memorização ............................................. 89

Figura II.8.4 - CNAPapm - Célula Neural Artificial Paraconsistente de ativação de padrão memorizado 90

Figura II.8.5 - CNAPrp - Célula Neural Artificial Paraconsistente de reconhecimento de padrão

Figura II.8.6 - Célula Neural Artificial Paraconsistente de reconhecimento de sinal 92

Figura II.8.7 - UNAParp - Unidade Neural Artificial Paraconsistente de aprendizado e reconhecimento de padrão 95

Figura II.8.8 - UNAPcaarp - Unidade Neural Artificial Paraconsistente de conexão analítica, aprendizado e reconhecimento de padrão 98 Figura II.8.9 - UNAPcaarpc - Unidade Neural Artificial Paraconsistente de conexão analítica, aprendizado e reconhecimento de padrão cíclica. 100 Figura II.8.10 - UNAPmax - Unidade Neural Artificial Paraconsistente de maximização 102

Figura II.8.11 - UNAPmin - Unidade Neural Artificial Paraconsistente de minimização 104

Figura II.8.12 - UNAPcmax - Unidade Neural Artificial Paraconsistente de contradição entre máximos 106 Figura II.8.13 - UNAPcmin - Unidade Neural Artificial Paraconsistente de contradição entre mínimos 108 Figura II.8.14 - SNAPdep - Sistema Neural Artificial Paraconsistente de decisão e execução de processos

Figura II.8.15 - Fluxograma funcional da Rede 
Figura II.9.1 - Célula Neural Artificial Paraconsistente de reconhecimento de sinal

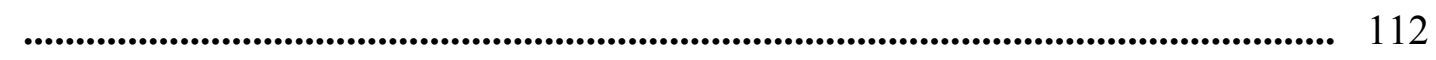

Figura III.1.1 - Esquema de blocos ............................................................... 117

Figura III.1.2 - Tela Principal .................................................................................... 122

Figura III.1.3 - Captura de uma fala ................................................................... 123

Figura III.1.4 - Capturando o sinal ................................................................. 124

Figura III.1.5 - Aviso ...................................................................................... 124

Figura III.1.6 - Tela de manipulação da fala. ........................................................... 126

Figura III.1.7 - Seleção de um arquivo ............................................................ 127

Figura III.1.8 - Faz corte inicial .............................................................. 127

Figura III.1.9 - Configuração do corte inicial ...................................................... 128

Figura III.1.10 - Normalização em amplitude ........................................................ 128

Figura III.1.11 - Recalculo de máximo ........................................................... 129

Figura III.1.12 - Gráfico normalizado ............................................................ 129

Figura III.1.13 - Gráfico completo .................................................................. 130

Figura III.1.14 - Dados da estrela Fônica ................................................................ 130

Figura III.1.15 - Constelação Fônica da freqüência ............................................ 131

Figura III.1.16 - Constelação Completa .................................................................. 132

Figura III.1.17 - Tabela de Reconhecimentos, após aprendizado .......................... 133

Figura III.1.18 - Tabela de Reconhecimentos ...................................................... 133

Figura III.2.1. - Manipulação do FA .................................................................... 136

Figura III.2.2. - Aprendizado do FA ................................................................ 137

Figura III.2.3. - Aprendizado do FA - Tabela de reconhecimento ....................... 137 


\section{Resumo}

Atualmente desenvolvem-se técnicas para a análise, identificação e o reconhecimento da fala. As mais eficientes mostram-se matematicamente complicadas, baseadas em análise estatísticas de dados, o que torna o sistema moroso, necessitando uma grande quantidade de dados para amostras.

Este trabalho tem como objetivo apresentar a possibilidade do uso de Estruturas Neurais Artificiais Paraconsistentes no aprendizado e reconhecimento de sinais de fala, independentemente de análise estatística, ou número de amostras.

A partir de um estudo piloto, identificou-se a necessidade de um aprofundamento no estudo dos Traços Formantes dos Fones. Com os Formantes dos Fones pode-se criar um sistema capaz de reconhecer sons produzidos em qualquer língua, pelas combinações da produção de sons através da emissão simultânea de um conjunto de Formantes.

Como possível solução para a identificação dos Formantes dos Fones propõe-se neste trabalho a criação do conceito de Constelação Fônica, que consiste no reconhecimento de combinações de características matemáticas identificadas nos sinais sonoros de fala. Como uma forma de reconhecer estas Constelações, apresentam-se as Redes Neurais Artificiais Paraconsistentes, eficientes no reconhecimento de padrões por proximidade e com capacidade para tratamento de sinais contraditórios e paracompletos.

Para a viabilização desta solução, criou-se um Programa de Computador (Sistema de Análise da Produção da Fala - SIAPF) capaz de promover os tratamentos necessários em um sinal falado, gerando assim a sua Constelação Fônica e sua respectiva Rede Neural Artificial Paraconsistente. A partir da Rede Neural Artificial Paraconsistente correspondente ao sinal em questão, pode-se estudá-lo de uma forma interpretativa, com menor acumulo de dados e tratamentos estatísticos do que com as ferramentas tradicionais.

O SIAPF passa a ser mais uma ferramenta para análise de produção de fala, viabilizando a criação de novas formas de medidas quantitativas e normatizadas para os Formantes da Fala. 
Palavras-Chave: Redes Neurais Artificiais; Paraconsistente; Produção de Fala; Formantes; Fones; Análise de Fala; 


\begin{abstract}
Currently, many diferent techniques are developing for the analysis identification and recognition of speech. The most efficient are shown mathematically complicated, based on analysis statistical of data, that actually makes systems very slow, creating the nessecity for a great amount of data for samples.

The aim of this work is to present the possibility of the use of Paraconsistent Artificial Neural Netwaork Structures, in the learnig and recognition of speech signals, independent of statistical analysis, or the number of samples.

Starting from a pilot study, the need of a deep study of the Formants of Phones was identified. With the Formants of Phones, a system capable to recognize sounds produced in any language, through conbinations of the production of sounds and simultaneous emission of a group of Formants was created.

A possible solution for the identification of Formants of Phones proposed in this work is the creation of Phonic Constellation concept, witch uses the recognition of combinations of identified mathematical characteristcs in the resoant signal of speech. As a form of recognizing these Constellation, this work present the Paraconsistent Artificial Neural Network, efficient in the recognition of patterns for proximity and with capacity to process contractory and paracomplet signals.

To develop this solution a Computer Program (System of Analysis of the Production of Speech - SIAPF) capable to process the necessary calculations of a speech signal, generating its Phonic Constelattion and its respective Paraconsistent Artificial Neural Network was created. The subject signal can be studied in an interpretative way using the Paraconsistent Artificial Neural Network with a minimal accumulation of data and statistical calculations compered to traditional tools.
\end{abstract}

The SIAPF is another new tool for analysis of speech production, creating new ways for quantitative and standard measures of Formants of Speech. 
Key Words: Artificial Neural Network; Paraconsistent; Speech Production; Formants; Phones; Speech Analysis; 


\section{Apresentação}

Durante a etapa inicial deste trabalho, procurou-se determinar caminhos para que se pudesse desenvolver uma técnica capaz de otimizar o tratamento do sinal sonoro captado a partir de um microfone conectado a um computador. Neste estudo inicial tomou-se conhecimento de um programa de computador denominado PRAAT, criado por um dos maiores especialistas em fonética acústica, Paul Boersma. No anexo A deste trabalho encontra-se um roteiro simplificado sobre a operação básica do PRAAT. Por se tratar de um programa muito sofisticado, é necessário um bom conhecimento de processos matemáticos para modelamento dos sinais acústicos para o completo entendimento do PRAAT, tornando seu uso efetivamente superficial para os fonoaudiólogos. Contatou-se então que a criação de uma nova ferramenta, mais objetiva e voltada para as necessidades do fonoaudiólogo, traria um grande beneficio na análise e quantificação de características da fala, podendo futuramente ser utilizada para estudos mais avançados, abrangendo velocidade e distúrbios de fala.

Com o apoio técnico e matemático do PRAAT, criou-se uma nova técnica para tratamento de sinais acústicos, diminuindo o volume de dados, e formatando as informações de uma forma mais compatível com estruturas Neurais.

Por se tratar de um estudo complexo, envolvendo diferentes áreas do conhecimento, constatou-se a necessidade do desenvolvimento de uma base teórica, denominada neste trabalho como INTRODUÇÃO.

Como segunda etapa do trabalho, apresenta-se o Modelamento MATEMÁtico PARA ANÁLISE COMPUTACIONAL DA PRODUÇÃO DA FALA, onde definem-se as técnicas matemáticas que permitem criar uma nova ferramenta de trabalho. 
$\mathrm{Na}$ terceira etapa desenvolveu-se um MÉTOdo E Sistema dE ANÁlise DA PRODUÇÃO DA FALA, culminando na criação do Sistema de Análise da Produção de Fala, o SIAPF.

Na última etapa do trabalho, encontra-se a DiscuSSÃO E CONSIDERAÇÕES FINAIS contendo os resultados, as conclusões e as perspectivas de continuidade. 


\section{I - Introdução}

\section{I.1. As Ondas Sonoras: Definições}

\section{I.1.1- Considerações iniciais}

Muitas definições são utilizadas de forma diferente nas diversas áreas de aplicação do conhecimento. Uma vez que este trabalho envolve fonética, fonologia, fonoaudiologia e computação, faz-se necessária uma unificação de conceitos, do ponto de vista matemático, físico, lingüístico e fonético. Para esta unificação, utilizam-se inicialmente os conceitos matemáticos, pois a matemática procura ser uma ferramenta estruturadora e embasadora de todas as ciências exatas, e daquelas que necessitam medir, representar ou avaliar com exatidão elementos diversos da natureza, a partir de modelos e representações.

É importante lembrar que muitas definições não são conceitos exatos (DA COSTA, 99). Isto parece um contra-senso, mas definir algo é sempre muito controverso. Para ilustrar o fato pode-se citar a definição de Lógica mais aceita: "Lógica é o que os lógicos fazem”. Desta forma, o objetivo destas definições é utilizar uma referência única para este trabalho, e se necessário ampliar ou ajustar esta definição.

Inicialmente apresentam-se os conceitos básicos de funções matemáticas, que têm como objetivo representar e modelar os elementos da natureza (MENDELSON, 97). Sem esta representação e sem este modelamento é impossível matematizar a natureza, pois muitos conceitos como o de igualdade, a rigor, nem podem ser utilizados (DA COSTA, 99). Muitas vezes estes conceitos são utilizados sem nenhuma exatidão. Pode-se utilizar como exemplo o abuso de linguagem aplicado para comparar duas cadeiras (DA COSTA, 99). Comumente afirma-se que duas cadeiras são iguais. Somente o fato delas estarem em lugares diferentes, pois não podem ocupar o mesmo lugar no espaço, não podem ser declaradas como iguais. Este abuso de linguagem aplicado ao mundo real não pode ser aplicado em ciências exatas, pois como o próprio nome diz, este tipo de ciência prima pela exatidão. Utilizando então uma entidade simbólica e ideal, que recebe o nome cadeira, identificada por algumas características 
deste elemento no mundo real, esta entidade ideal passa a representar a cadeira do mundo real. Pode-se então, a partir desta representação, criar modelos matemáticos que permitam calcular e inferir resultados que, uma vez interpretado o resultado da representação, pode-se novamente transferir esta informação para o mundo real.

Continuando a fundamentação teórica, apresentam-se as definições existentes dentro da física oscilatória, incluindo as ondas que são oscilações especiais, até chegar às ondas sonoras da fala.

Para que se possa deixar claro como se deve tratar as ondas sonoras da fala, apresenta-se a seguir os principais estudos existentes que permitem particularizar as ondas sonoras da fala, identificando do que se trata cada uma. Antes de estudar as ondas sonoras, é necessário a introdução de alguns conceitos matemáticos que são necessários como ferramenta de modelagem destas ondas.

É importante ressaltar que as ondas sonoras são elementos concretos da natureza e para que se possa estudá-las é necessário a definição de uma forma de representação destas ondas e a criação de um modelo matemático capaz de representar este fenômeno de forma eficaz para seu estudo matemático.

\section{I.1.2- Função matemática (ou simplesmente Função):}

Define-se Função como sendo qualquer relação binária que associa a cada elemento $\mathbf{x}$ de um conjunto $\mathbf{X}$ um único elemento $\mathbf{y}$ em um conjunto $\mathbf{Y}$ (ÁVILA, 94). $\mathrm{O}$ conjunto $\mathbf{X}$ é denominado domínio da Função, ou seja, valores para os quais a Função existe; e o conjunto Y é denominado contra-domínio da Função, ou seja, os valores que a Função pode assumir (mas não necessariamente assumirá todos). Os elementos do conjunto $\mathbf{Y}$ que efetivamente existam, dados por $\mathbf{f ( x )}$, são denominados conjunto Imagem da Função.

Considerando-se x como tempo, então uma Função que depende do instante temporal representado por $\mathbf{t}$ passa a ser modelada como $\mathbf{y}=\mathbf{f}(\mathbf{t})$. Como toda fala a ser captada pelo microfone tem seu inicio em $\mathbf{t}_{\mathbf{i}}=\mathbf{0}$ (o inicio do sinal é tomado como 
referencial inicial para todos os sons) então o primeiro ponto da Função é sempre $\mathbf{y}=$ $\mathbf{f}(\mathbf{0})$.

Note que a Função f não precisar ser uma Função contínua, ou determinada por uma relação matemática direta como, por exemplo, $\mathbf{y}=\mathbf{2} \mathbf{x}^{2}+\mathbf{x}-\mathbf{3}$ ou ainda $\mathbf{y}=\operatorname{sen}(\mathbf{x})$, ela pode ser simplesmente a relação direta entre dois números como, por exemplo, para $\mathbf{t}=\mathbf{0}=>\mathbf{y}=\mathbf{3 2}, \mathbf{t}=\mathbf{1}=\mathbf{y}=\mathbf{4 2}$, e assim por diante. É claro que, matematicamente, através de processos de aproximação em cálculo numérico, esta relação pode ser transformada em algo do tipo $\mathbf{y}=\mathbf{f}(\mathbf{x})$, por processos de aproximação sucessiva. Este processo será abordado quando tratarmos da transformada rápida de Fourier, utilizada nesta aplicação para conversão da onda sonora captada em espectro de freqüência.

\section{I.1.3- Oscilações:}

Qualquer movimento de um elemento (concreto ou não) é denominado Oscilação (PRADO, 50). Qualquer movimento que se repete, em intervalos de tempo iguais, constitui um movimento periódico, ou uma Oscilação Periódica (PRADO, 50). Todo movimento periódico pode, a partir de uma representação matemática correta, ser modelado matematicamente como sendo uma soma de senos e co-senos, através de uma operação matemática denominada série de Fourier (FOURIER, 1807). Por este motivo é denominado também de Movimento Harmônico. Um Movimento Harmônico é dito puro quando sua oscilação é representada por exatamente uma função seno, sem a necessidade da soma de outras funções. Diz-se também que este movimento puro não tem harmônico, possui apenas a freqüência fundamental, ou que se trata de uma senóide pura (isto porque as harmônicas causam ao ouvido Humano a impressão de que existe "algo a mais" no som, é a diferença que existe, por exemplo, entre a nota Lá de um diapasão e a nota Lá de um piano), ou ainda trata-se de um Movimento Harmônico Simples (PRADO, 50).

Considerando uma senóide pura, define-se $\mathbf{T}$ como período desta senóide, que é o tempo que o elemento leva para percorrer a trajetória do seno, até o ponto que o movimento inicia sua repetição (PRADO, 50). A freqüência $\mathbf{F}$ (não deve ser confundido com o f usado para denominar função anteriormente) é dada pelo inverso do período, ou seja, $\mathbf{F}=\mathbf{1} / \mathbf{T}$, e é medida em Hertz (Hz) (PRADO, 50). Define-se ainda $\lambda$ como 
comprimento de onda, determinado pela distância entre dois picos (ou vales) de uma oscilação (PRADO, 50). Na figura I.1.1 a seguir apresenta-se a representação gráfica, em plano cartesiano de uma oscilação com quatro períodos.

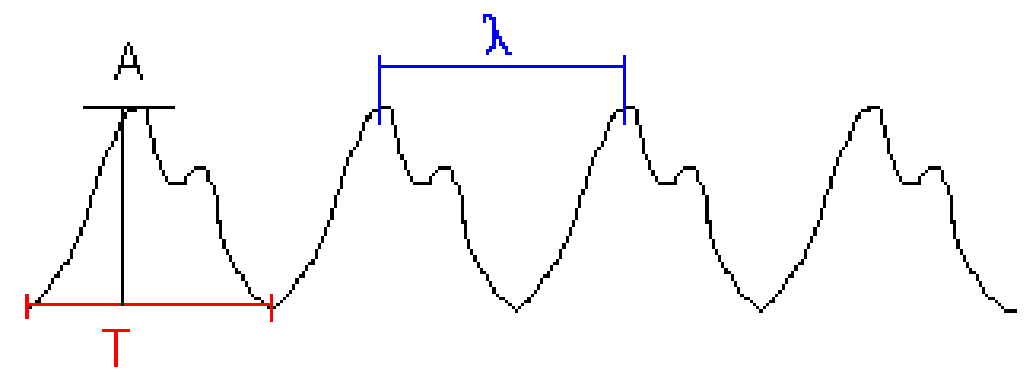

Figura I.1.1 - Representação gráfica em plano cartesiano de uma oscilação

Considerando-se um Movimento Harmônico Simples, denomina-se Amplitude como sendo o valor máximo que a função seno atinge, em módulo (PRADO, 50). Esta definição pode ser ampliada e aplicada em oscilações, como sendo o valor máximo de uma oscilação. Se esta oscilação for irregular (não harmônica), então a Amplitude será o valor máximo em um determinado intervalo de tempo. Fazendo este intervalor de tempo tender a zero, no limite, tem-se o valor da própria função, gerando assim uma igualdade entre amplitude e valor da função, pois no limite serão a mesma coisa. Do ponto de vista matemático este ajuste é correto e aplicável. O motivo de utilizar esta nomenclatura desta forma é que o sinal sonoro a ser captado e estudado, no seu estado natural, é normalmente captado por uma onda complexa, necessitando processos matemáticos para que se determine a função matemática do sinal complexo, ficando mais simples, portanto, tratar este sinal a partir de sua Amplitude, que passa a ser o valor instantâneo da onda, independentemente da função matemática usada para modelar a onda.

Neste trabalho, sempre que for citado o termo Amplitude, Esta Amplitude refere-se ao valor máximo de um sinal ou função, considerando-se um determinado intervalor de tempo infinitesimal. Esta definição é aplicável tanto a uma oscilação quanto a uma onda, complexa (com vários harmônicos) ou simples (somente uma freqüência). Uma forma mais rígida de se referir à Amplitude, seria dividir as definições em Amplitude de uma onda, Amplitude de uma oscilação ou Amplitude em um intervalo. Neste trabalho não é feita esta distinção, pois A Amplitude sempre se refere à Amplitude instantânea em um intervalo infinitesimal de tempo. 


\section{I.1.4- Ondas:}

Uma oscilação, ao se propagar em um meio elástico, recebe o nome de Onda (FRENCH, 74). Se a Onda for resultado de um Movimento Harmônico, é denominada Onda Harmônica. Se o meio elástico tiver resposta linear a esta oscilação, aplica-se o fato experimental que duas ou mais ondas podem cruzar-se na mesma região do espaço, independentemente uma da outra (FRENCH, 74). Desta forma, neste meio, o deslocamento do elemento passa a ser a soma dos deslocamentos que o mesmo teria para cada onda, de forma independente (FRENCH, 74). Isto, demonstrado matematicamente pelo Francês J. Fourier (FOURIER, 1807), resultou na operação inversa, onde uma onda qualquer pode ser representada pelos seus harmônicos simples, matematicamente modelada a partir de uma soma de senos e co-senos. Estes harmônicos simples também são chamados de componentes harmônicas, e a relação dessas componentes harmônicas, que contenham a informação de freqüência, amplitude e duração de cada componente recebem o nome de Espectro da Onda. No ANEXO C deste trabalho apresenta-se em detalhe o processo para o cálculo da série de Fourier. No ANEXO B, apresenta-se também um aplicativo para a visualização da série de Fourier.

Note que deste parágrafo anterior tiram-se duas informações importantes: A onda se "propaga" no meio de uma forma (soma dos deslocamentos) e pode ser "percebida" de outra (componentes harmônicos) (BEHLAU, 97). Isto explica a diferença entre captar uma onda sonora através de um microfone, e percebê-la através da audição. Vale ressaltar ainda que, se o meio elástico não tiver resposta linear, surge o que se chama de distorção, ou seja, a onda sofre alterações durante a sua propagação ou recepção (PRADO, 50). É importante notar que utilizam-se alguns abusos de linguagem, simplificando o entendimento para a conceituação da relação entre o real, a representação e o modelo matemático, visando facilitar o entendimento.

A intensidade da onda, que reflete a energia transmitida pela onda, é proporcional a amplitude de cada componente harmônica, uma vez que a amplitude de cada harmônica é proporcional a energia fornecida para que o elemento gerador da onda possa oscilar (TIPLER, 94). Como a onda pode possuir várias componentes harmônicas, Sua intensidade é dada por uma somatória de todas as componentes harmônicas. Para 
sinais onde o número das harmônicas tende a infinito (como pulsos isolados) a intensidade passa a ser uma integral matemática (TIPLER, 94)..

A intensidade da Onda também poderia ser calculada a partir da forma de onda resultante obtida através da sobreposição de suas componentes harmônica (TIPLER, 94). Neste caso a integral precisaria ser calculada para cada diferencial de valor da onda.

Caso, durante o percurso da onda no meio, exista perda desta energia, a onda passa a ser amortecida. Na natureza, normalmente, este amortecimento existe e pode ser modelado a partir de uma função exponencial.

Outra informação importante é que, caso duas ondas diferentes possuam componentes com mesma fase e freqüência, ou seja, existem componentes onde:

\section{- $\quad \operatorname{Ac1} 1 * \operatorname{sen}(t 1)=0$ e $\operatorname{Ac} 2 * \operatorname{sen} 2(t 1)=0$ e Fc1=Fc2);}

Haverá a chamada interferência, que resultará em:

\section{- $\quad \operatorname{fcr}(t)=(\operatorname{Ac} 1+\operatorname{Ac} 2) * \operatorname{sen}(t)$}

Ou seja, a componente resultante terá mesma freqüência e a amplitude será dada pela soma das componentes harmônicas.

\section{I.1.5- Ondas Sonoras:}

As ondas sonoras são ondas mecânicas (GRAWFORD, 96) (ondas onde os elementos são "físicos", ou seja, é necessário um meio "material” para a propagação desta onda) e longitudinais (movimento dos elementos se dá no mesmo sentido da propagação da onda). O intervalo considerado audível fica entre $20 \mathrm{~Hz}$ e $20.000 \mathrm{~Hz}$. As ondas de menor freqüência são denominadas infra-som (Ex: Terremotos) enquanto as de maior freqüência, ultra-som (Ex: usados em exames médicos) (GRAWFORD, 96).

As ondas sonoras consideradas "agradáveis" são aquelas de intensidade não muito grande (não pode gerar vibrações nos tímpanos onde a amplitude seja próxima à amplitude máxima no mesmo, perdendo a linearidade de resposta, causando, portanto distorção, sendo que no caso especifico do tímpano o mesmo poderá até ser lesado), e 
com poucas componentes harmônicas. Na figura I.1.2 a seguir pode-se visualizar uma dupla representação gráfica da onda sonora. A primeira representa a variação de pressão como pontos aglomerados, representando as partículas do ar: na formação mais densa (mais escura) representa as partículas posicionadas mais proximamente entre si, indicando maior pressão. A segunda representa a função matemática em plano cartesiano, usada como modelo da variação da pressão em função do tempo.

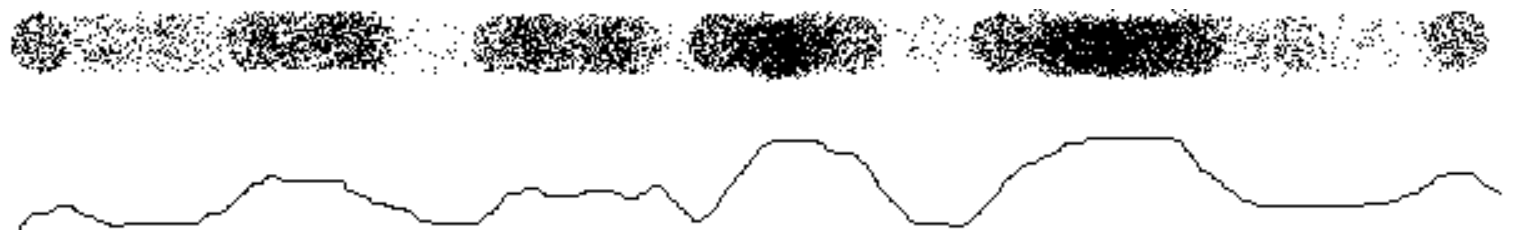

Figura I.1.2 - Representação da propagação do som no ar.

\section{I.1.6- Considerações finais:}

A matematização das ondas sonoras através de modelos adequados, permite que inferências quantitativas sejam produzidas, tornando o estudo das mesmas algo mais concreto e menos subjetivo. Nos capítulos seguintes são apresentados mais recursos matemáticos, de forma a otimizar o tratamento teórico do sinal, tornando este trabalho em uma ferramenta efetivamente concreta. 


\section{I.2. Conceitos de Fonética e Fonologia: Os Fonemas, Fones e os Traços Formantes}

\section{I.2.1- Considerações iniciais:}

Inicialmente é necessário que se entenda o conceito de segmentação da fala (FIORIN, 03).

Pode-se dividir a segmentação da fala em dois aspectos: os segmentais e os supra-segmentais. Para o estudo, os supra-segmentais não são de interesse, uma vez que se referem à fala de uma língua. Como exemplo pode-se citar a entonação utilizada na pergunta pelo português: as frases: - ele foi comprar - e - ele foi comprar? - são completamente iguais do ponto de vista da escrita (exceto pelo ponto de interrogação) e das palavras formantes, porém, através de uma entonação aplicada a toda frase, seu sentido passa de afirmação para interrogação (FIORIN, 03). Esta entonação atribuída à frase inteira consiste em um aspecto supra-segmental, pois não pode ser segmentada, ou seja, não se pode destacar a entonação de toda a frase como um segmento sonoro. Outra característica interessante é que, dentro do aspecto supra-segmental, não se define completamente e rigidamente os conceitos de forte, fraco, agudo ou outro aspecto qualquer, pois são interdependentes (FIORIN, 03). Vale ressaltar ainda que este tipo de entonação supra-segmental refere-se também a palavras como no caso de acentuação. Neste estudo destacam-se apenas os aspectos segmentais, ou seja, aqueles que podem ser claramente destacados de um som de fala emitido (FIORIN, 03).

O Fone, por ser considerado a unidade discreta e concreta, pois se trata da realização do Fonema. Um mesmo Fonema pode ser realizado de formas diferentes, de acordo com as circunstâncias da língua, podendo ser regional, e ainda sofrer interferência entre Fonemas de acordo com sua utilização e casos similares. Cada Fone é composto por Traços Formantes, ou simplesmente Formantes. Os Formantes são características não segmentáveis (não podem ser produzidos separadamente) dos Fones. Já os Fones são as menores partes dos sons produzidos na linguagem humana que podem ser produzidos separadamente, mas não simultaneamente (FIORIN, 03). Na 
figura 4 são apresentados os sons PA TA BA. Dentro da língua portuguesa são sílabas (grupos de fonemas) distintas e totalmente caracterizadas. Note que as três sílabas possuem dois Fones cada uma: $P-A, T-A, B-A$. Os Fones $P$ e $A$ não podem ser produzidos simultaneamente, isto caracteriza o Fone como menor unidade da linguagem falada. Outra análise importante a se fazer é que entre os Fones $P$ e $B$ existe uma diferença que é uma sonoridade na emissão do $B$. isto identifica o Formante, e diz-se que o $B$ é mais sonoro que o $P$. Esta característica é um dos Formantes do Fonema.

Pode-se definir três dimensões para a descrição dos sons (PAIS, 86):

a- Articulatória ou motora, que considera tudo que acontece com o aparelho fonador durante a produção do som;

b- Auditiva ou perceptual, que considera a percepção do ouvinte;

c- Acústica, que descreve as propriedades físicas da onda emitida.

A relação entre estas três dimensões define as características e aspectos segmentais e supra-segmentais sons (PAIS, 86).

Pode-se intuir ainda que um completo domínio relacional entre estas três dimensões seria suficiente para identificar de forma concreta e matemática qualquer som produzido pela fala humana. Isto equivale a dizer que tendo-se a exata matematização acústica dos Fones, relacionando claramente esta matematização às características auditivas e articulatórias, poder-se-ia construir um sistema capaz de, matematicamente, reconhecer um sinal de fala. É claro que isto não abrangeria a interpretação desta fala. É claro também que esta matematização deste sinal não é simples.

A partir deste trabalho, pretende-se identificar como resultado futuro, as diferenças espectrais entre os Formantes para que uma Rede Neural Artificial possa reconhecer estes Formantes, identificando assim cada Fone a partir da composição dos Formantes. 
Vale ressaltar que o alfabeto fonético internacional é baseado na obtenção de todos os Fones (possíveis ou não) obtidos através da associação de todos os Formantes possíveis, segmentais ou supra-segmentais.

É importante notar que algumas línguas são Fonéticas, ou seja, a escrita se baseia na produção dos Fonemas facilitando a alfabetização, uma vez que a produção do som é transcrita literalmente. No português (assim como nas línguas baseadas em Grafemas) nota-se uma grande diferença entre os sons falados e escritos, obrigando o leitor a interpretar a associação das letras.

\section{I.2.2- Fonema:}

Os Fonemas são considerados como sendo os sons da língua (PAIS, 86), pois são unidades mentais, abstratas, psíquicas, gerais, comuns a todos os falantes da referida língua. Para se chegar ao Fonema é preciso a produção concreta do som, que são os Fones.

\section{I.2.3- Fone:}

Os Fones são considerados os sons da fala, a produção concreta, particular, que considera as variações, diferentes de cada indivíduos e isento de interpretação.A produção correta dos Fones depende de uma correta articulação do aparelho fonador, aparelho este estudado pela fonética articulatória, responsável pela geração dos Formantes. Os Formantes, portanto, são os elementos fundamentais para a geração e determinação do Fone que se quer produzir sons (PAIS, 86).

Por este trabalho se tratar de um estudo e criação de uma ferramenta capaz de analisar a produção da fala, e não sua interpretação, pretende-se aprofundar o estudo na direção da identificação qualitativa e quantitativa dos Formantes, que são os elementos de base à produção da fala. 


\section{I.2.4- Formantes (Traços Formantes):}

Os Formantes são os elementos mais primitivos existentes no processo de produção do Fone, não tendo sentido sua produção individual. Todos os Formantes possuem características próprias, porém precisam ser associados para que possam produzir um determinado Fone (PAIS, 86).

A forma mais propícia para que se possa fazer um estudo claro dos Formantes é através da comparação de pares opositores, ou seja, pares que diferem apenas de um Formante entre si. Esta forma de análise será muito propicia neste trabalho, facilitando a identificação de elementos distintivos.

Para facilitar o estudo, pode-se dividi-lo em Consoantes, Vogais e Soantes. Para as Consoantes tem-se (PAIS, 86, p. 31):

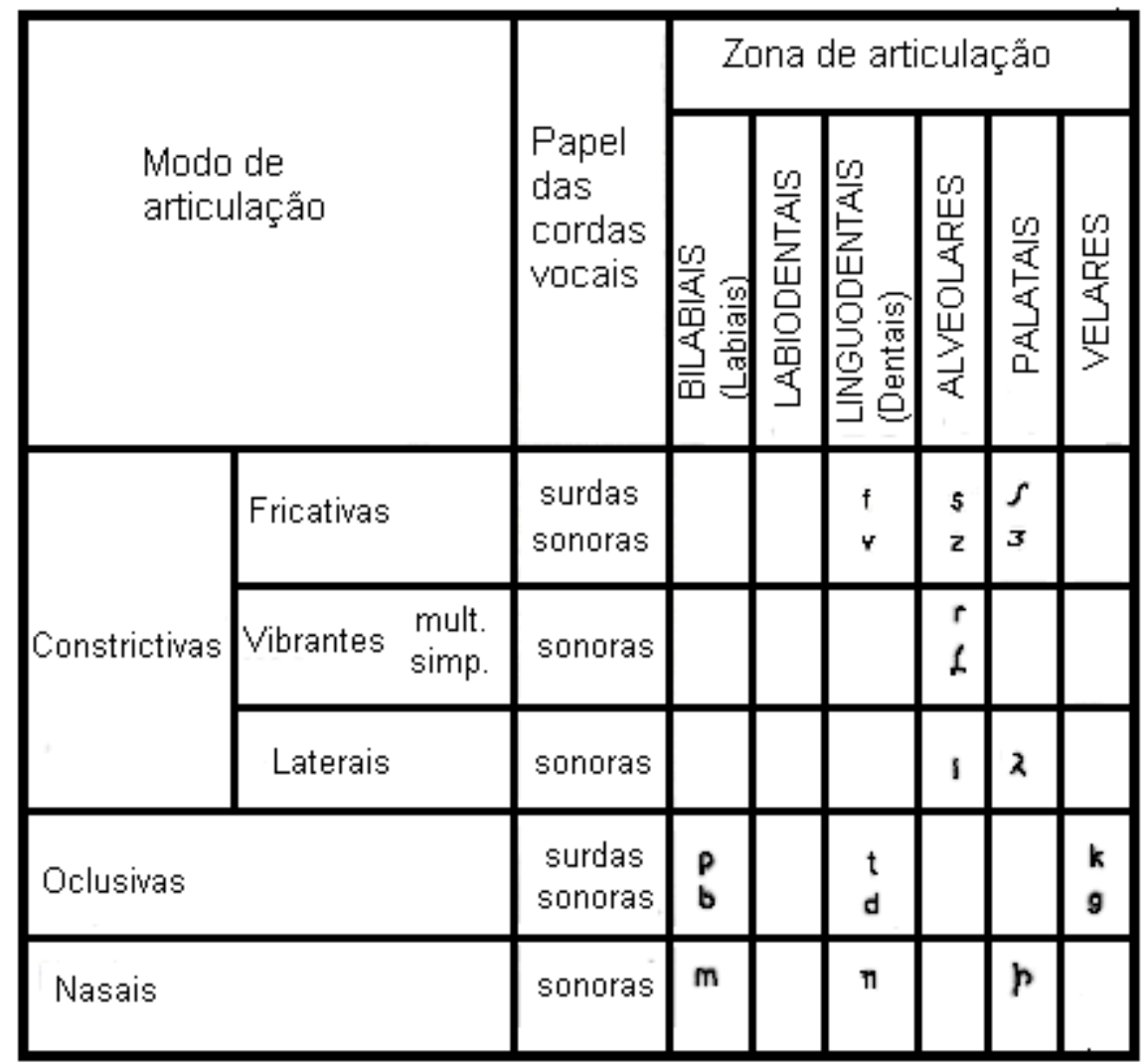

Tabela I.2.1 - Consoantes de acordo com seus Formantes 
Para as Vogais têm-se (PAIS, 86, p. 32):

\begin{tabular}{|c|c|c|c|c|}
\hline \multirow{2}{*}{ Grau de Abertura } & \multicolumn{2}{|c|}{ Orais } & \multicolumn{2}{|c|}{ Nasais } \\
\hline & Anteriores & Posteriores & Anteriores & Posteriores \\
\hline Fechadas & $\mathbf{i}$ & u & i & ũ \\
\hline semi-fechadas & e & 0 & \multirow{2}{*}{ ẽ } & \multirow{2}{*}{ õ } \\
\hline semi-abertas & $\varepsilon$ & 3 & & \\
\hline abertas & \multicolumn{2}{|c|}{ a } & \\
\hline
\end{tabular}

Tabela I.2.2 - Vogais de acordo com seus Formantes (abertura)

Tomando-se em consideração a classificação acústica, segundo os formantes, tem-se, por exemplo, para as vogais orais do português:

\begin{tabular}{|l|c|c|}
\hline Difusas & $\mathrm{i}$ & $\mathrm{u}$ \\
\hline Pouco difusas & $\mathrm{e}$ & $\mathrm{o}$ \\
\hline Pouco compactas & $\varepsilon$ & $\mathrm{J}$ \\
\hline Compacta & \multicolumn{2}{|c|}{ a } \\
\hline
\end{tabular}

Tabela I.2.3 - Vogais de acordo com seus Formantes (acústica)

Para as Soantes têm-se (PAIS, 86, p. 32):

\begin{tabular}{|c|c|c|c|c|}
\hline \multirow[b]{2}{*}{$\begin{array}{c}\text { MODO DE } \\
\text { ARTICULAÇAO }\end{array}$} & \multicolumn{2}{|c|}{$\begin{array}{l}\text { ZONA DE } \\
\text { ARTICULACÃO }\end{array}$} & \multirow[b]{2}{*}{$\begin{array}{c}\text { Quanto às } \\
\text { CORDAS } \\
\text { VOCAIS }\end{array}$} & \multirow[b]{2}{*}{$\begin{array}{l}\text { Quanto às } \\
\text { FOSSAS } \\
\text { NASAIS }\end{array}$} \\
\hline & $\begin{array}{c}\text { Anterior } \\
\text { ou } \\
\text { Palatal }\end{array}$ & $\begin{array}{c}\text { Posterior } \\
\text { ou } \\
\text { velar }\end{array}$ & & \\
\hline soantes & j & $w$ & sonoras & orais \\
\hline
\end{tabular}

Tabela I.2.4 - Soantes de acordo com seus Formantes 


\section{I.2.5- Considerações finais:}

A produção de todos os Formantes necessários à fala são baseados em freqüência, duração e intensidade. Estas características, atribuídas a cada Formante, passam a ser particulares de cada falante, quando avaliadas principalmente sob o aspecto da freqüência.

As características de duração e intensidade complementam a formação do Formante sendo, porém, menos particulares do ponto de vista do falante.

Para que se possa fazer um estudo detalhado destes Formantes, é necessária uma analise quantitativa do sinal de voz. No próximo capítulo apresentam-se os conceitos, técnicas, recursos e normatizações destinados e este tipo de estudo. 


\section{I.3. Análise quantitativa do sinal de voz: implicações na análise da produção da fala}

\section{I.3.1- Considerações iniciais:}

A análise da produção da fala permite avaliar o sinal de fala, suas características acústicas, identificando problemas em sua produção. Esta produção está diretamente ligada ao funcionamento do aparelho fonador e seu sistema neural de controle (ANDRADE, 04).

A análise da voz, identifica características particulares e específicas do falante, tendo implicações perceptuais e não só acústicas.

Como o objetivo principal deste trabalho é gerar um aplicativo capaz de contribuir com uma nova técnica de medida de sinais de fala, faz-se aqui uma referência aos principais pontos da análise quantitativa do sinal de voz, com implicações na produção da fala. Estes pontos foram retirados dos principais trabalhos de estudo de voz da atualidade.

A avaliação acústica de fala, para estudos clínicos, é recente, tendo sido introduzida na realidade brasileira apenas na década de noventa. A Avaliação acústica procura quantificar o sinal de fala, de forma a objetivar diagnósticos. A quantificação oferece vários benefícios (BEHLAU, 97) como:

- Uma maior compreensão acústica do sinal de fala;

- Promove dados normativos para diferentes realidades vocais;

- Oferece documentação suficiente para traçar a linha de base da voz do individuo;

- Monitora a eficácia de um tratamento, comparando resultados vocais de diferentes tratamentos terapêuticos;

- Acompanha o desenvolvimento de uma voz profissional ao longo de um período;

- $\quad$ Serve como instrumento de detecção precoce de problemas vocais; 
Apesar destes benefícios, pesquisas ainda confirmam que o ouvido parece ser mais confiável para avaliar vozes normais, cabendo a análise quantitativa apenas para refinamento do diagnóstico e tratamento (BEHLAU, 01).

A definição de parâmetros acústicos e o processo de normatização do uso de medidas quantitativas nos laboratórios de voz têm se tornado comum, apesar de ainda causarem um certo desconforto, pois estes parâmetros muitas vezes devem ser

questionados, ajustados e alterados, dependendo ainda do tipo de avaliação que se está fazendo. (TITZE, 95).

É importante que se entenda que na análise de voz, seja ela objetiva ou subjetiva, nenhuma medida oferece um diagnóstico definitivo, e por isso o emprego de computadores ou de instrumentos sofisticados, quando se é ciente de suas limitações, é um recurso poderoso. O valor da análise quantitativa está, em grande parte, nas habilidades associativas e no conhecimento prévio do avaliador, e não somente no instrumento que se utiliza (BEHLAU, 01).

Outro ponto importante a ressaltar é que a onda captada pelo microfone é sempre a onda complexa. Qualquer tratamento matemático que ela sofra, dependerá na boa qualidade de amostragem e captação do sinal.

\section{I.3.2- Cuidados especiais:}

Com base em (BEHLAU, 01), apresentam-se a seguir os principais cuidados na análise quantitativa da voz. Estes cuidados, segundo (BEHLAU, 01), estão agrupados em quatro categorias:

\section{I.3.2.1- Condições de registro:}

- A captação direta da voz é o ideal, utilizando uma placa de som para conversão analógico-digital com pelo menos 16 bits de resolução, em 6Volts, o que significa uma resolução de aproximadamente 15 microvolts.

- O ruído ambiental deve ser inferior a 50dB (decibéis)

- Os métodos de armazenamento e reprodução devem ser de alta qualidade, introduzindo ruídos e variações sempre menores do que a existente no 
equipamento de aquisição do sinal, ou seja, menor que 15 microvolts seria o ideal.

- Deve ser feita uma análise do nível de ruído em comparação com o sinal de fala, novamente o ideal seria abaixo da resolução de captação do sinal, caso contrário o erro será proporcional à relação sinal/ruído.

- O individuo falante deve ficar de pé no ato da gravação.

- A distância entre a boca do individuo e o microfone (que deve estar em pedestal fixo) deve ser de $10 \mathrm{~cm}$ permitindo a captação de falas genéricas (qualquer associação de vogais e consoantes), e a inclinação do microfone deve ser de $45^{\circ}$ em relação à reta formada pelo horizonte da boca do falante.

- A impedância do microfone deve ser compatível com a entrada do equipamento

I.3.2.2- Protocolos de gravação:

- Definição da produção de fala a ser estudada, e respectiva análise a ser utilizada. Isto significa definir palavras e frases de acordo com a necessidade do estudo, bem como o tipo de equipamento para captação, medição e análise quantitativa do sinal.

- Definição da duração, velocidade e entonação: normalmente utiliza-se o padrão habitual do falante.

- Definição do universo de pesquisa, abrangendo as características do falante de acordo com sexo, idade, região e demais características que podem alterar o padrão da fala.

I.3.2.3- Sistema de gravação: atualmente, uma vez que se utilizam técnicas de digitalização e produção de fala diretamente no microfone de um microcomputador, utiliza-se a gravação em meios digitais, fazendo com que, no momento da reprodução, introduza-se somente ruído do próprio sistema de reprodução. Como analiticamente os dados a serem utilizados estarão em formato digital, não existe perda ou distorção na análise, acima daquela já descartada no processo de amostragem e digitalização.

\section{I.3.2.4 - Análise qualitativa do sinal:}

- Tipo 1: sinal quase periódico, a somatória das magnitudes energética das freqüências harmônicas e sub-harmônicas é inferior a freqüência fundamental.

- Tipo 2: sinal acústico, que deve ser fracionado para ser estudado em partes que se encaixem no tipo um. A sua análise direta é visual e totalmente descritiva, 
- Tipo 3: Sinal sem nenhuma estrutura periódica aparente comporta-se como um sinal acústico distorcido, também deve ser analisado de forma segmentada. São os sinais atribuídos a vozes patológicas.

\section{I.3.3- Parâmetros acústicos e implicações Clínicas:}

Existem vários parâmetros acústicos que podem ser medidos, permitindo identificar anomalias no aparelho fonador. Nem todos parâmetros refletem especificamente uma anomalia. A seguir apresentam-se estes parâmetros, e algumas implicações clínicas específicas.

I.3.3.1 - Freqüência Fundamental (F0): É considerada a freqüência natural de vibração do aparelho fonador de um individuo. Do ponto de vista matemático é a primeira harmônica da série de Fourier que representa o sinal de fala de um individuo (apresentado no ANEXO C). Estudos exaustivos desta freqüência permitiram que se determinasse a faixa de freqüência esperada por idade e sexo.

I.3.3.2- Variabilidade da Freqüência Fundamental: $O$ estudo da variabilidade da freqüência fundamental permite, entre outras coisas, identificar patologias fonadoras no individuo falante. Esta variabilidade pode indicar também alteração no estado emocional do individuo.

I.3.3.3 - Harmônicas: São as freqüências que, associadas à fundamental, compõem o sinal complexo (e completo), segundo a transformada de Fourier (apresentada no Capitulo 5).

I.3.3.4 - Índices de perturbação: Os índices de perturbação refletem pequenas perturbações no aparelho fonador, possuindo grande importância clinica. Vale ressaltar que o maior interesse é pelo estudo dos índices de perturbação em curto prazo, e é esse que o presente estudo pretende, como pesquisa futura, identificar de forma quantitativa e objetiva, sem demasiado estudo estatístico da voz do falante. Os principais índices são: 
- Jitter - Perturbação de freqüência em curto prazo: identifica a diferença entre sucessivos períodos da freqüência fundamental. Se o aparelho fonador fosse ideal, esta perturbação seria zero.

- Shimmer - Perturbação de amplitude em curto prazo: identifica a diferença entre sucessivas amplitudes médias da onda fundamental. Se o aparelho fonador fosse ideal, esta perturbação seria zero.

- Tremor - Perturbação de freqüência em longo prazo: identifica a variação, durante a produção continua da fala, da freqüência fundamental. Divide-se em dois tipos, o vow, comum na fala de pacientes com esclerose múltipla, são de menor freqüência, e os flutter, de maior freqüência, comum em falantes com mal de Parkinson.

- Vibrato - Perturbação de amplitude em longo prazo: identifica a variação, durante a produção continua da fala, da amplitude média da fundamental. Muito utilizada por cantores para "enfeitar" o canto.

I.3.3.5 - Intensidade: reflete a energia com que o sinal é produzido. Trata-se de uma característica de amplo uso, necessária a identificação de todos os sinais medidos.

I.3.3.6 - Duração: Reflete o tempo de duração de cada evento acústico, sendo também uma característica de amplo uso para a caracterização dos sinais acústicos.

I.3.3.7 - Pré-sonorização: Importante no estudo de produção das consoantes plosivas, o estudo da pré-sonorização permite identificar falhas principalmente decorrentes da disfluência da fala.

\section{I.3.4- Considerações finais:}

A Análise quantitativa da voz permite criar medidas e normatizar resultados. Desta forma a análise de uma voz passa a ter um cunho exato, deixando de ser um estudo subjetivo e baseado em interpretações. No próximo capitulo são apresentados os processos de captação modelagem e representação das ondas sonoras, aumentando assim o universo de inferências exatas que se pode atribuir ao estudo da fala. 


\section{I.4. As Ondas Sonoras: Captação, Representação e Modelagem Matemática}

\section{I.4.1- Considerações iniciais:}

Neste capítulo pretende-se esclarecer como as ondas sonoras de uma fala podem ser captadas por um sistema eletro-eletrônico e introduzidas em um computador. A partir deste processo, usa-se uma modelagem matemática com o objetivo de uma boa representação quantitativa da onda, permitindo que se façam estudos e tratamentos que vão além das possibilidades estritamente perceptuais do ouvinte.

\section{I.4.2- Captação:}

Da mesma forma que o tímpano vibra em função da variação de pressão do ar (vibração esta que, caso não haja distorção do sinal, será proporcional a soma dos deslocamentos de pressão das harmônicas que compõem o sinal), e transforma esta vibração em sinais elétricos que se propagam pelo nervo auditivo, pode-se montar um artefato eletro-mecânico capaz de transformar a mesma onda sonora em um sinal elétrico. Este artefato chama-se microfone. Os microfones possuem uma membrana sujeita à vibração causada pela variação de pressão do ar. Atualmente pode-se construir microfones de cristais piezelétricos ou a partir de um sistema magnético (TIPLER, 94).

Os microfones piezelétricos possuem uma membrana presa a um cristal que, pressionado devido à vibração desta membrana, gera uma corrente proporcional à pressão.

Nos microfones magnéticos (apresentado esquematicamente na figura I.4.1) a membrana está presa a um enrolamento de fio de cobre esmaltado que possui como núcleo um imã permanente que, ao vibrar, produz uma variação do campo magnético no enrolamento proporcional à vibração. A variação do campo magnético gera no enrolamento uma corrente elétrica proporcional a esta variação. 


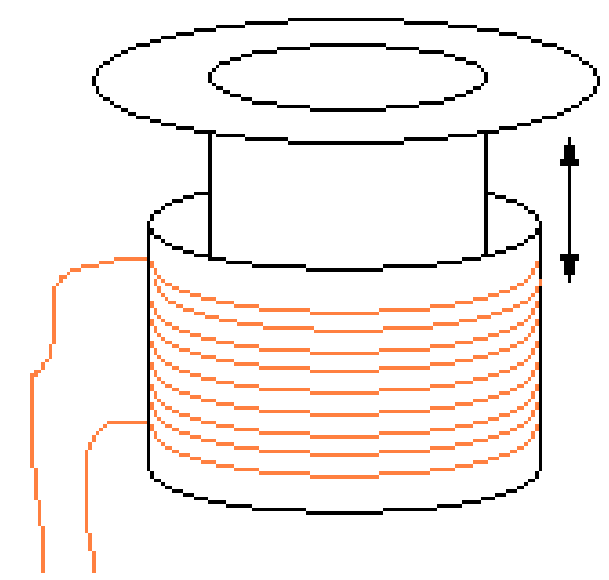

Figura I.4.1 - Desenho representativo esquemático do microfone magnético.

O sistema piezelétrico é mais eficaz nas altas freqüências e o magnético nas baixas.

\section{I.4.3- Representação:}

Independentemente do microfone usado, o sinal elétrico obtido, de uma senóide perfeita, (onda que possui somente um harmônico) tem como representação matemática o formato apresentado pela figura I.4.2 a seguir (PAIN, 68):

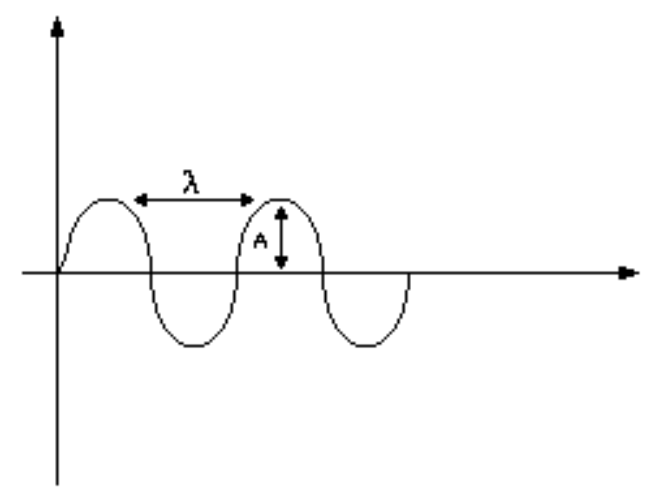

Figura I.4.2 - Forma de onda de uma senóide perfeita.

Para este sinal define-se $\lambda$ como sendo o comprimento da onda, que equivale a distância física de dois pontos da onda que determinam sua repetição ou ciclo. $\mathrm{O}$ número de ciclos por segundo (c/s) determina sua freqüência (f) (PRADO, 50). A 
amplitude (A) do sinal representa a sua variação entre a pressão natural do meio e o ponto de máximo, em módulo, como já apresentado anteriormente.

Considerando-se uma senóide perfeita, pode-se definir o ângulo em que se encontra o sinal como sendo a fase. A fase só tem utilidade quando utilizada para a comparação de dois sinais, com o objetivo de determinar a defasagem entre eles. Podese entender a fase do sinal, de uma forma simplificada, como sendo o momento de inicio da produção do sinal, quando comparado com outro sinal. Sabe-se que o ouvido humano não distingue a diferença de fase entre dois sinais isolados (TAFNER, 96), sendo que o reconhecimento de sinais se faz sempre se comparando dois sinais que estejam em fase.

Quase todos os sons na natureza não são senóides perfeitas, porém, como se tratam de oscilações, podem ser compostos a partir de seus harmônicos, conforme descrito anteriormente (FOURIER, 1807).

Por sua vez, os sons, ao se propagarem pelo ar, cuja resposta ao som é praticamente linear, a variação da pressão se dá de forma proporcional a soma das variações causadas por cada componente harmônica. Assim, o sinal captado pelo microfone corresponde a esta soma. Este sinal resultante é chamado de onda composta.

\section{I.4.4- Modelagem:}

Pode-se modelar matematicamente estas componentes harmônicas como várias senóides ou pedaços de senóides com amplitudes variadas: são as chamadas Séries de Fourier (PAIN, 68). Os componentes principais são as três primeiras freqüências.

Vale ressaltar que o ouvido humano consegue facilmente distinguir freqüências diferentes.

Todo som pode, conforme apresentado anteriormente, ser transformado em um sinal elétrico, proporcional a sua variação. Este sinal elétrico passa a ser um padrão que representa este som. Qualquer sistema que possa reconhecer este sinal elétrico, ou seja, este padrão, pode, por associação, reconhecer o som que o gerou. 
Padrão é, de um modo mais amplo, a descrição de um objeto (TOU, 74).

A seguir apresenta-se um método de modelagem matemática para a representação deste padrão.

Considere um sinal elétrico, obtido a partir de um sinal sonoro, que apresente o formato de onda da figura I.4.3:

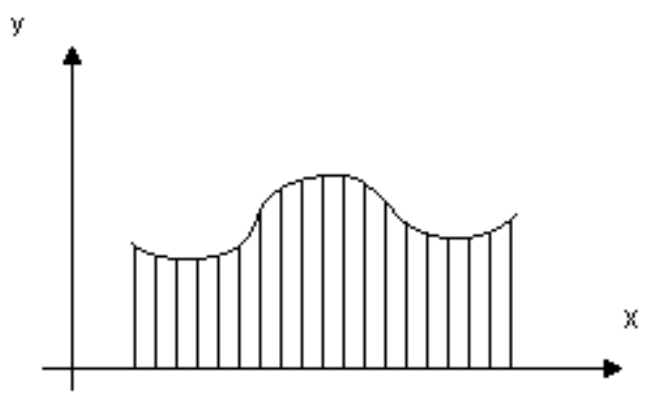

Figura I.4.3 - Forma de onda amostrada em amplitude.

No eixo $\mathbf{Y}$ tem-se a variação da amplitude do sinal, e no eixo $\mathbf{X}$, a variação do sinal na unidade de tempo. Para cada instante $i$ no eixo $\mathbf{X}$, tem-se uma amplitude $\mathbf{Y}$. Pode-se, então, representar essa onda como sendo uma seqüência de valores discretos, definidos por $\left(\mathbf{X}_{1}, \mathbf{X}_{2}, \mathbf{X}_{3}, \ldots, \mathbf{X}_{\mathbf{0}}\right)$, sendo $\mathbf{o}$ o número de elementos do vetor original.. Assim, o elemento identificado por $\mathbf{X}_{\mathbf{1}}$ possui valor $\mathbf{Y}_{\mathbf{1}}$, o elemento $\mathbf{X}_{\mathbf{2}}$ possui valor $\mathbf{Y}_{\mathbf{2}}$, e assim por diante.

Esta seqüência de valores é denominada vetor. Obtém-se então um vetor que representa um padrão (SKLANSKY, 73). Como este padrão está associado a um sinal sonoro, o reconhecimento deste vetor resulta no reconhecimento do padrão e, por conseqüência, no reconhecimento do sinal sonoro. O processo de conversão deste sinal analógico captado no microfone, para esta seqüência de valores denominada vetor, denomina-se digitalização.

O reconhecimento de um padrão representado por um vetor pode ser por igualdade ou similaridade (PRADO, 02a). 
Para o reconhecimento por igualdade basta que se comparem todos os elementos do vetor a ser reconhecido com um vetor pré-existente. Caso todos os elementos sejam iguais, diz-se que o padrão foi reconhecido por igualdade.

A similaridade entre os elementos é avaliada por um fator de reconhecimento de padrão (Frp), dado por um valor numérico de 0 a 1.

Diz-se que um vetor foi reconhecido por similaridade caso o grau de similaridade (Sm), entre o vetor em questão e o vetor ao qual ele está sendo comparado, seja maior ou igual que o fator de reconhecimento de padrão (Frp).

Existem várias formas de calcular o grau de similaridade (Sm) entre dois vetores. Neste trabalho são apresentadas as duas formas principais. A primeira forma é considerar o grau de similaridade como sendo o número de elementos iguais $\left(\mathbf{n}_{\mathbf{i}}\right)$ entre os dois vetores, dividido pelo número total de elementos do vetor $\left(\mathbf{n}_{\mathbf{t}}\right)$, ou seja:

\section{- $\mathbf{S m}=\mathbf{n}_{\mathbf{i}} / \mathbf{n}_{\mathbf{t}}$}

A segunda forma é considerar o grau de similaridade como sendo a unidade menos a somatória das distâncias relativas entre cada um dos elementos diferentes do vetor, dividida pelo número total de elementos diferentes, ou seja:

- $\mathbf{S m}=\mathbf{1}-\sum\left(\mid \mathbf{X}_{\mathbf{n}}-\mathbf{K}_{\mathbf{n}} / / \max \left(\mathbf{X}_{\mathbf{n}}, \mathbf{K}_{\mathbf{n}}\right)\right) / \mathbf{d}$ para $\mathbf{n}=1$ até $\mathbf{d}$, sendo $\mathbf{d}$ o número de elementos diferentes entre os dois vetores, e $\mathbf{X}_{\mathbf{n}}$ ou $\mathbf{K}_{\mathbf{n}}$ diferente de zero. Caso os dois vetores sejam idênticos, não haverá elementos diferentes, nem distancia entre eles, assim a similaridade será 1, ou seja, os vetores são iguais.

Nota-se que a diferença entre os dois métodos é que o primeiro é menos crítico: apenas identifica o nível genérico de diferença, pois não avalia a diferença entre cada elemento do vetor. O segundo método pondera as diferenças individuais. Dependendo do tipo de aplicação um método pode ser mais eficiente que o outro. Pode-se ainda associar os dois métodos, de forma a considerar o primeiro cálculo como grau de igualdade, e a complementação do segundo método como sendo o grau de diferença. Esta associação é muito útil se a ela aplicarmos o conceito da Lógica Paraconsistente, como será apresentado em capitulo posterior. 
Conforme descrito anteriormente, um sinal sonoro pode, a partir da sua digitalização da onda composta, ser transformado em um vetor. A partir desse vetor pode-se obter matematicamente sua representação no espectro de freqüência através da transformada rápida de Fourier. Este processo é explicado de forma detalhada no ANEXO C deste trabalho. Assim, obtêm-se a representação do sinal em amplitude e em freqüência.

\section{I.4.5- Considerações finais:}

Partindo-se de um sistema eficaz e preciso de captação e digitalização da fala, permitida, pode-se promover inúmeros tratamentos matemáticos, adequados às necessidades de estudos específicos. No próximo capítulo faz-se uma referência simplificada a algumas técnicas importantes do estudo modelagem e reconhecimento da fala, tomadas como norteadoras deste trabalho. 


\section{I.5. Algumas técnicas importantes no estudo, modelagem e reconhecimento da fala}

\section{I.5.1 - Considerações iniciais:}

Dedica-se este capítulo à citação das técnicas para modelagem e reconhecimento de fala, que mais interferiram na criação do modelo matemático aqui proposto. Além destas técnicas, outras foram utilizadas, mesmo que de forma conceitual, para aprimorar o funcionamento do aplicativo e estruturação da teoria. As outras técnicas estão relacionadas nas referências bibliográficas.

\section{I.5.2 - Identificação do final de fala:}

Existem vários processos para identificação de final de fala. Estes processos determinam em que pontos o sinal deve ser cortado para um efetivo estudo. Um processo possível é a partir da transformada do sinal para uma representação plana como apresentado em (RAJ \& SINGH, 03). De forma análoga à transformada de Fourier, este processo permite tratar matematicamente o sinal de fala e selecionar, de forma bem eficaz, pontos de final de fala. Estes cortes são necessários para isolar o objeto de estudo dentro do sinal de fala. Este processo se mostra tão eficiente quanto a seleção manual feita por um especialista. Neste trabalho foram usados estes conceitos para determinar, de forma discreta, o inicio e final do sinal de fala, permitindo também

que o sistema possa identificar rupturas internas na fala. Este processo é aplicado no programa de computador antes do cálculo das Constelações Fônicas (que serão apresentadas no momento oportuno). 


\section{I.5.3 - Decomposição temporal do espectro da fala:}

Em (NANDASENA \& AKAGI, 03) apresenta-se uma otimização da decomposição temporal do espectro de fala proposta por (ATAL, 83), aplicável também na decodificação fonético - acústica da fala (BIMBOT, 88). A filosofia dos processos utilizados em (NANDASENA \& AKAGI, 03) para esta otimização e simplificação de cálculos e algorítmos, foi utilizado neste trabalho para simplificar os processos de obtenção das Constelações Fônicas, uma vez que elas refletem um formato do sinal.

\section{I.5.4 - Fonologia Funcional - Modelo articulatório:}

Uma vez que este trabalho pretende criar uma nova ferramenta para análise de produção de fala, foi feito um estudo sobre modelos articulatório a partir do Livro de Fonologia Funcional (BOERSMA, 98), escrito por um dos maiores especialistas da atualidade neste assunto, Paulus P.G. Boersma, o criador do programa PRAAT, atualmente o mais utilizado para análise de produção da fala. Paralelamente a este estudo, fez-se também um estudo do PRAAT para a sua utilização e identificação de necessidades prévias. Este estudo do programa PRAAT encontra-se no ANEXO A.

\section{I.5.5 - Reconhecimento estatístico por segmentação:}

Uma das técnicas atualmente mais utilizadas para reconhecimento é o modelo HMM (Hidden Markov Model) (RABINER, 89). Este modelo pode ser mais eficiente ainda quando utilizado um processo de segmentação para reconhecimento (GLASS, 03). O processo de cálculo de parâmetros por trecho, também conhecido como segmentação, é utilizado neste trabalho para a definição dos elementos da constelação. Este processo serve para promover um ajuste fino do cálculo inicial. 


\section{I.5.6 - Paradigmas computacionais do modelamento acústico para reconhecimento}

de fala:

Os sistemas de reconhecimentos baseados em cálculos estatísticos são morosos e dependem de uma base de dados correta e eficiente. Além disso, são sensíveis a ruído, o que complica bastante o seu uso. Apesar do modelo HMM ser o mais utilizado, trás com ele os problemas citados anteriormente, fragilizando a sua aplicação e restringindo o seu uso. É importante que novas técnicas sejam desenvolvidas com o objetivo de completar e melhorar o sistema HMM (RUSSEL \& BILMES, 03).

\section{I.5.7 - Considerações finais:}

Os estudos aqui apresentados relatam técnicas avançadas e eficientes que contribuem para um estudo quantificado do sinal de fala de forma objetiva, mas não descartam a necessidade do desenvolvimento de novos estudos, pois ainda hoje o ouvido humano ainda não pode ser superado, validando a criação de novas técnicas, com enfoques diferenciados. No próximo capítulo introduz-se o conceito de Constelação Fônica. 


\section{II - Modelamento Matemático para análise computacional da produção da Fala}

\section{II.1. A criação do conceito de Constelação Fônica}

\section{II.1.1 - Considerações iniciais:}

Neste capítulo apresenta-se o conceito de Constelação Fônica, criado neste estudo, como uma nova ferramenta de representação do sinal de fala. A partir desta representação pretende-se criar um modelo capaz de inferir conclusões a partir da comparação com sinais posteriores.

\section{II.1.2 - O conceito:}

A partir das matematizações, anteriormente descritas, colhidas a partir do tratamento de um sinal de fala, pode-se montar uma coleção de pontos relacionados entre si que representam uma determinada fala.

Parte desta coleção de pontos, por ser estritamente particular, pode-se atribuir a um determinado fone, mesmo que obtidos com uma certa flutuação. A partir do desenvolvimento do próximo tópico pretende-se mostrar que é possível a criação de uma tabela que relacione diretamente uma coleção de pontos a um terminado fone. Com a identificação do fone, pretende-se, por diferença, detectar características de Formantes contrastantes.

A esta coleção de pontos dá-se o nome de Constelação Fônica. A cada elemento desta coleção, dá-se o nome de Estrela Fônica.

Define-se como Constelação de pontos de precisão $\mathbf{r}$ uma seqüência de m valores $\mathbf{C}_{\mathbf{r}}$, composta pelos elementos $\mathbf{e}_{\mathbf{0}}, \mathbf{e}_{\mathbf{1}}, \ldots, \mathbf{e}_{\mathbf{m}}$, com ordem $\mathbf{i}$, amplitude a e potência p, conforme representação a seguir:

\section{- $\quad \mathrm{Cr}=\left(\mathbf{e}_{0}[\mathbf{i}, \mathrm{a}, p], \mathrm{e} 1[\mathbf{i}, \mathrm{a}, \mathrm{p}], \ldots, \mathrm{e}_{\mathrm{m}}[\mathbf{i}, \mathrm{a}, \mathrm{p}]\right)$}


Uma constelação de pontos é uma representação simplificada de um vetor. Se este vetor representa um padrão de fala, a Constelação de pontos passa a se chamar Constelação Fônica. Esta Constelação Fônica pode ainda receber mais alguns elementos, representando características especificas complementares conforme será apresentado mais adiante.

Apenas de forma ilustrativa apresenta-se, na figura II.1.1 a seguir, um sinal em amplitude e sua respectiva constelação (pontos azuis) e o mesmo sinal representado em freqüência e suas respectiva constelação (pontos vermelhos).

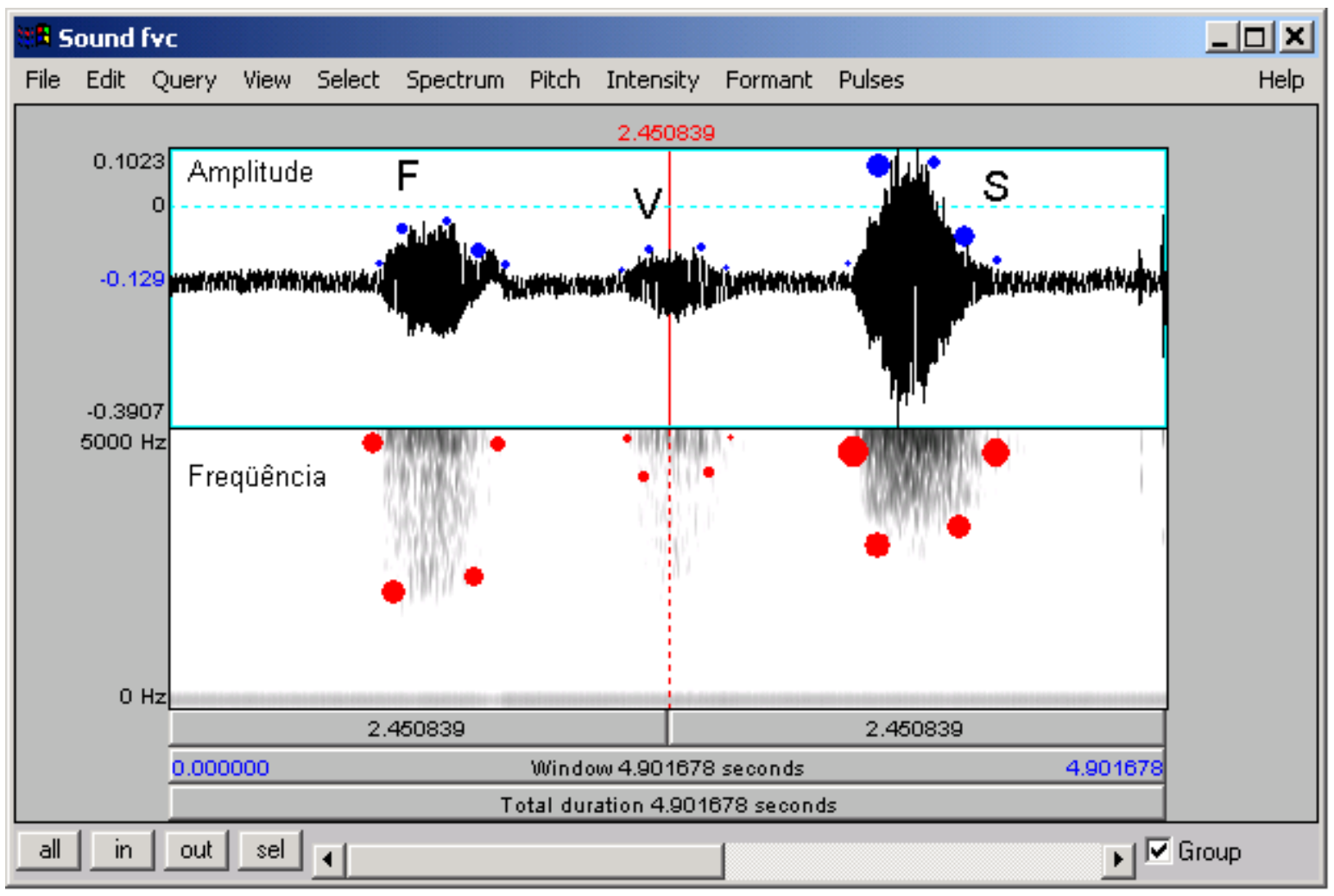

Figura II.1.1 - Representação ilustrativa da constelação fônica de freqüência e amplitude. 


\section{II.1.3- Considerações finais:}

Pretende-se utilizar o conceito de Constelação Fônica para a representação de um sinal de fala de uma forma reduzida, sem a perda de informação. Um sinal de fala passa a ser representado por um vetor de poucos elementos quando comparado com sua digitalização completa e tratamento de todos os valores obtidos desta digitalização. Partindo-se desta representação pretende-se mostrar, nos próximos capítulos, que é possível inferir análises eficazes mesmo quando trabalhando somente com a análise das Constelações obtidas. 


\section{II.2. Capítulo 8 - Constelação Fônica da Amplitude}

\section{II.2.1- Considerações iniciais:}

Se um vetor $\mathbf{V}\left(\mathbf{x}_{1}, \mathbf{x}_{2}, \ldots, \mathbf{x}_{\mathbf{n}}\right)$ foi obtido através da amostragem digital de um sinal sonoro, ele representa um sinal sonoro composto, e os valores dos elementos são proporcionais a amplitude do sinal composto, no momento de cada amostragem.

Denomina-se Constelação Fônica da Amplitude a Constelação de pontos de um vetor obtido a partir da representação em amplitude do um sinal composto de fala. Esta Constelação Fônica da Amplitude reflete as características de intensidade e duração do sinal sonoro, e cada elemento é obtido através de uma seqüência de cálculos.

$\mathrm{Na}$ figura II.2.1 a seguir apresenta-se uma representação gráfica do sinal, indicando cada elemento do vetor:

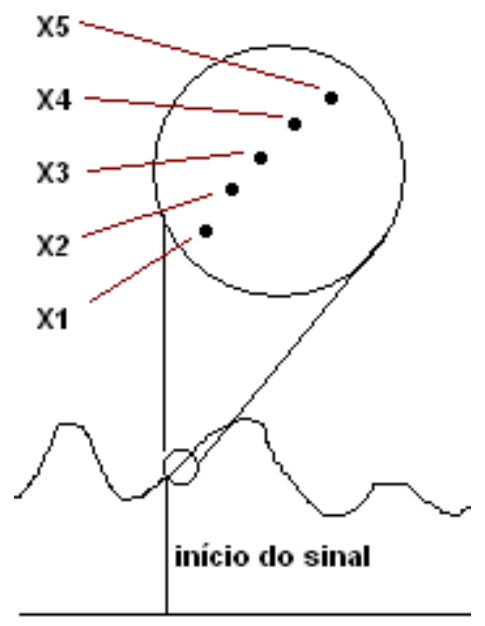

Figura II.2.1 - Representação ilustrativa de um sinal em amplitude. 


\section{II.2.2- Cálculo da Constelação Fônica da Amplitude}

Para o cálculo da Constelação Fônica da Amplitude, A partir do vetor original, obtém-se um sub-vetor, composto pelos $\mathbf{r}$ (precisão) primeiros, retirados do vetor original, mantendo-se o número de ordem do vetor original. Esta operação se repete até que o vetor original fique vazio. Para cada sub-vetor obtido, calcula-se:

- $\mathbf{e}_{\mathbf{m}}[\mathbf{i}, \mathbf{a}, \mathbf{p}]$, sendo:

o $\mathbf{m}=$ número seqüencial do elemento na constelação, iniciando por zero;

o $\mathbf{i}=$ número de ordem do bloco do elemento no vetor original (cada bloco possui 1024 elementos, e a taxa de amostragem é sempre um múltiplo deste valor, por definição);

o $\mathbf{a}=$ valor médio de todos os elementos do sub-vetor;

o $\mathbf{p}=$ constante (ajustado de acordo com a aplicação) $+\left|\mathbf{a}_{\mathbf{m}}-\mathbf{a}_{(\mathbf{m}-1)}\right|$ (diferença entre a amplitude de elementos seqüentes).

A representação gráfica do elemento é apresentada na figura II.2.2 a seguir:

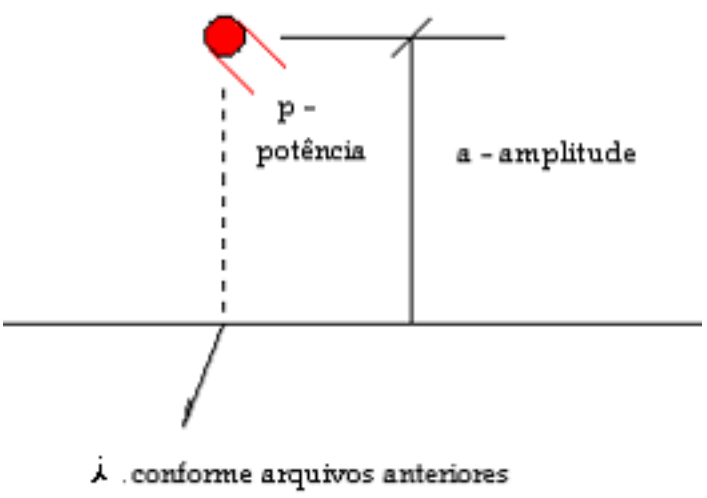

Figura II.2.2 - Representação ilustrativa de um elemento da Constelação Fônica de Amplitude.

Pode-se ainda agregar a esta constelação, mais uma característica importante no estudo do sinal de fala, o início de fala, representada por mais um elemento:

A Estrela Fônica P de pré sonorização (representa o inicio de fala, recebe a letra o nome pré-sonorização pois historicamente pretendia-se determinar efetivamente a présonorização do sinal. Como a determinação da pré-sonorização é bem complexa, optou pela simplificação do seu cálculo, obtendo-se assim apenas o inicio de fala, mas seu 
nome de pré-sonorização foi mantido) obtida pela duração do inicio do sinal, até sua efetiva produção. Os valores para a determinação são ajustáveis.

A Amplitude deste elemento é dada pelo valor máximo da amplitude do sinal, em todo trecho da pré-sonorização. A potência é a duração deste sinal. Este elemento é de ordem zero, apresentando-se sempre como primeira estrela da Constelação Fônica da Amplitude.

\section{II.2.3- Considerações Finais:}

Como resultado da forma de obtenção da Constelação fônica da Amplitude, temse uma relação de poucos pontos, mas com muita informação do sinal. Nos capítulos seguintes pretende-se mostrar que esta constelação Fônica consiste em uma nova e importante ferramenta de análise de sinal de voz. 


\section{II.3. Constelação Fônica da Freqüência}

\section{II.3.1 - Considerações iniciais:}

É importante ressaltar que, nos computadores atuais, as entradas de sinais sonoros sempre captam os sinais compostos, sendo que seria possível também captar o sinal a partir de filtros freqüenciais infinitos, que consistiria em uma transformada de Fourier direta. Como um sistema deste tipo seria extremamente dispendioso e complexo em sua implementação, a técnica normalmente utilizada consiste em captar o sinal composto e promover matematicamente a transformada de Fourier, obtendo-se, através de um cálculo matemático, e não captação direta, o espectro em freqüência, composto dos harmônicos do sinal.

Tratando-se matematicamente o vetor original obtido, através da transformada de Fourier, apresentada no ANEXO C, Obtém-se a relação de harmônicas que compõem o sinal sonoro. A relação de harmônicas do sinal pode ser expressa a partir de um vetor, como sendo uma seqüência de elementos $\mathbf{x}_{\mathbf{i}}\left[\mathbf{f}_{\mathbf{j}}\right]$, sendo $\mathbf{x}_{\mathbf{i}}$ a amplitude da harmônica $\mathbf{f}_{\mathbf{j}}$

A seguir, na figura II.3.1, encontra-se uma representação gráfica ilustrativa do vetor original do espectro em freqüência:

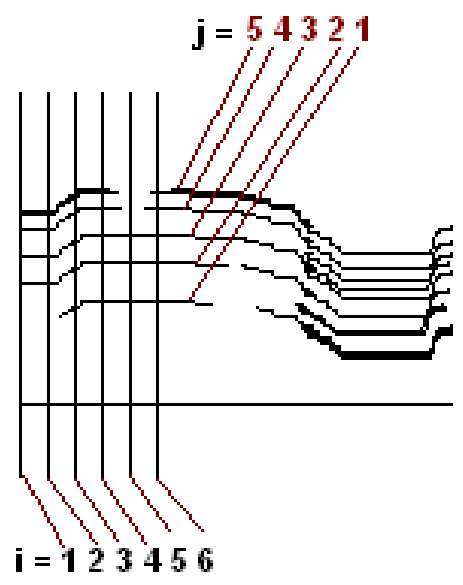

Figura II.3.1 - Representação gráfica ilustrativa do espectro em freqüência.

Para a representação da figura II.3.1, o vetor original do espectro em freqüência seria: $x_{1}\left[f_{2}\right], x_{1}\left[f_{3}\right], x_{1}\left[f_{4}\right], x_{1}\left[f_{5}\right], x_{2}\left[f_{2}\right], x_{2}\left[f_{3}\right], x_{2}\left[f_{4}\right], x_{2}\left[f_{5}\right], x_{3}\left[f_{1}\right], x_{3}\left[f_{2}\right], x_{3}\left[f_{3}\right], x_{3}\left[f_{4}\right]$, 
$\mathrm{x}_{3}\left[\mathrm{f}_{5}\right], \mathrm{x}_{4}\left[\mathrm{f}_{1}\right], \mathrm{x}_{4}\left[\mathrm{f}_{2}\right], \mathrm{x}_{4}\left[\mathrm{f}_{3}\right], \mathrm{x}_{4}\left[\mathrm{f}_{4}\right], \mathrm{x}_{4}\left[\mathrm{f}_{5}\right], \mathrm{x}_{5}\left[\mathrm{f}_{1}\right], \mathrm{x}_{5}\left[\mathrm{f}_{2}\right], \mathrm{x}_{5}\left[\mathrm{f}_{3}\right], \mathrm{x}_{6}\left[\mathrm{f}_{1}\right], \mathrm{x}_{6}\left[\mathrm{f}_{2}\right], \mathrm{x}_{6}\left[\mathrm{f}_{3}\right], \mathrm{x}_{6}\left[\mathrm{f}_{4}\right]$, $\mathrm{x}_{6}\left[\mathrm{f}_{5}\right]$.

\section{II.3.2 - Cálculo da Constelação Fônica da Freqüência:}

Para o cálculo da Constelação Fônica da Freqüência, A partir do vetor original, obtém-se um sub-vetor, composto pelos r (precisão) primeiros, retirados do vetor original, mantendo-se o número de ordem do vetor original. É importante ressaltar que os elementos retirados são baseados no índice $\mathbf{i}$, portanto, se existir $\mathbf{x}_{\mathbf{1}}\left[\mathbf{f}_{\mathbf{1}}\right], \mathbf{x}_{\mathbf{1}}\left[\mathbf{f}_{2}\right], \mathbf{x}_{\mathbf{1}}\left[\mathbf{f}_{3}\right]$, $\mathbf{x}_{\mathbf{1}}\left[\mathbf{f}_{\mathbf{4}}\right], \mathbf{x}_{\mathbf{1}}\left[\mathbf{f}_{\mathbf{5}}\right]$, etc.. todos elementos com mesmo $\mathbf{i}$ são pegos como elementos do subvetor, até que i atinja o valor de $\mathbf{r}$ (precisão). Vale lembrar que o vetor original é obtido a partir da aplicação da transformada rápida de Fourier, que em nossa aplicação foi utilizada de forma discreta, obtendo-se os elementos componentes dos harmônicos a partir de aproximação sucessiva.

Esta operação se repete até que o vetor original fique vazio. Para cada sub-vetor obtido, calcula-se:

- $\mathbf{e}_{\mathbf{m}}[\mathbf{i}, \mathbf{a}, \mathbf{p}]$, sendo:

o $\mathbf{m}=$ número seqüencial do elemento na constelação, iniciando por zero;

o $\mathbf{i}=$ número de ordem do bloco do elemento no vetor original (cada bloco possui 1024 elementos, e a taxa de amostragem é sempre um múltiplo deste valor, por definição);

o $\mathbf{a}=$ constante (ajustado de acordo com a aplicação) + número de harmônicas e freqüências, calculado como $\sum_{h=0}^{f} V_{h}^{*} 2^{h}$ sendo $V_{h}=1$ se a harmônica existe $\mathbf{e}_{\mathbf{n h}}=\mathbf{0}$ se não existe;

O $\mathbf{h}=$ o número da harmônica, numerada a partir de zero, a partir da menor freqüência usada para a escala em freqüência, até o ultimo harmônico possível, de número f;

o $\mathbf{p}=$ valor médio de todos os elementos do sub-vetor, independente da harmônica a que ele pertence, ou seja, soma de todos os $\mathbf{x}_{\mathbf{i}}$, dividido pelo número de $\mathbf{x}_{\mathbf{i}}$

Esta constelação reflete a freqüência (e características do espectro), duração das harmônicas e intensidade, sendo elas dispersas ou não. 
Pode-se ainda agregar a esta constelação, mais duas características no estudo do sinal de fala, o Jitter e o Shimmer, utilizados nos estudos de voz, mas de interesse na análise geral da fala, representada por mais dois elementos:

A estrela fônica $\mathbf{J}$ (representa o Jitter) será o desvio padrão, calculado para todos os elementos do vetor original com os valores de freqüência em torno da menor freqüência do sinal, que tenha a maior potência entre elas (portanto a fundamental). Assim esta estrela representa a variação do sinal em torno da freqüência fundamental. Conforme a definição, se o desvio padrão for zero, então o Jitter será zero.

A estrela fônica $\mathbf{S}$ (representa o Shimmer) será o desvio padrão, calculado para todos os elementos do vetor original com os valores de amplitude em torno da menor freqüência do sinal, que tenha a maior potência entre elas (portanto a fundamental). Assim esta estrela representa a variação do sinal em torno da Amplitude da Freqüência fundamental. Conforme a definição, se o desvio padrão for zero, então o Jitter será zero.

\section{II.3.3 - Considerações Finais:}

Como resultado da forma de obtenção da Constelação Fônica da Freqüência, tem-se uma relação de poucos pontos, mas com muita informação do sinal. Nos capítulos seguintes pretende-se introduzir os conceitos das Redes Neurais Artificiais Paraconsistentes, que associadas aos conceitos das Constelações Fônicas, permitirão uma eficiente representação e modelagem matemática permitindo conclusões quantitativas referentes aos sinais de fala captados. 


\section{II.4. Fundamentos de Redes Neurais Artificiais}

\section{II.4.1 - Considerações iniciais}

As Redes Neurais Artificiais (RNA's), muitas vezes consideradas uma subespecialidade de Inteligência Artificial, teve como característica principal o objetivo de criar elementos independentes que atuassem de forma similar aos neurônios humanos (SCHALKOFF, 97). Com o desenvolvimento desta teoria e a constatação da complexidade do neurônio humano, abandonou-se a idéia original do modelamento do neurônio humano, mas mantiveram-se as características que definem seus elementos.

As Redes Neurais Artificiais (RNA's), são compostas de elementos independentes, autônomos, interligados entre si, denominados Neurônios Artificiais (KOVACS, 96), em alusão às Redes Neurais Biológicas.

As RNA's mostram-se eficientes quando utilizadas no reconhecimento de padrões (LAU, 91), (SINENCIO; LAU, 92).

Existem vários tipos de Redes Neurais Artificiais (LAU, 91); (KOVACS, 96). Entre elas pode-se citar:

\section{II.4.2 - Rede Neural Artificial de Kohonen:}

Consiste em uma Rede de uma camada, na qual todas as entradas estão conectadas a todos os neurônios. Calcula-se a ativação dos neurônios a partir da distância euclidiana. Com este resultado, escolhem-se os neurônios vencedores e seus vizinhos. O cálculo se repete até que se obtenha um (ou mais) neurônio(s) vencedor(es). A relação de neurônios vencedores representa o sinal aprendido. 


\section{II.4.3 - Rede Neural Artificial de Rosenblatt:}

Também denominada de Perceptron, esta Rede é baseada em Neurônios Artificiais desenvolvidos por McCulloch e consiste na associação, por camadas, destes elementos. O resultado de saída se obtém através da somatória dos produtos entre os ganhos de cada entrada sináptica e a própria entrada. Matematicamente, é a representação mais simples e direta do neurônio biológico.

\section{II.4.4 - Rede Neural Artificial de Widrow:}

Esta Rede é baseada no modelo linear denominado ADALINE ou no modelo multidimensional denominado MADALINE, comporta-se de forma similar à Rede de Rosemblatt, recebendo um tratamento matemático diferenciado.

\section{II.4.5 - Rede Neural Artificial de Rummelhart, Hinton e Williams:}

Esta Rede é definida como o resultado da inclusão do algoritmo de backpropagation nas RNA's. O algoritmo de backpropagation é o processo utilizado para a atualização dos pesos de cada neurônio, caso a saída da Rede seja diferente da saída desejada.

\section{II.4.6 - Rede Neural Artificial de Hopfield:}

Esta Rede é caracterizada por sua forte supervisão, resultado da interdependência de todas as células e consiste em vários neurônios, interligados, sendo que sua estabilidade é atingida quando, após o recebimento do sinal, todos os neurônios atingem um estado estável. Cada neurônio tem sua saída em um, se a somatória das entradas for maior que zero, e em menos um, se a somatória das entradas for menor ou igual a zero. Uma das entradas serve para habilitar a rede (em um) e uma entrada de cada célula é externa, correspondendo ao sinal que se introduz na Rede. 


\section{II.4.7 - Considerações finais:}

Por se mostrar uma ferramenta eficiente quando utilizada para aprendizado e reconhecimento de padrões, pretende-se utilizar uma Rede Neural para a análise das Constelações. No próximo capítulo apresenta-se a Lógica Paraconsistente que, utilizada associada às Redes Neurais, aumenta a sua eficiência. Por se tratar de uma associação não trivial, apresenta-se no capítulo 12 uma aplicação simplificada, que permite entender o processo de associação e o beneficio que esta associação trás. 


\section{II.5. Fundamentos da Lógica Paraconsistente}

\section{II.5.1- Considerações iniciais:}

Com base na referência (DA COSTA, 99) faz-se neste capítulo um apanhado geral da Lógica Paraconsistente anotada de dois valores.

\section{II.5.2- Lógica Paraconsistente, Paracompleta, Não-Alética:}

Seja L uma lógica e L' a sua linguagem, que se supõe conter o símbolo de negação identificado por $\sim$. Uma teoria $\mathbf{T}$, que tem por base $\mathbf{L}$, é um conjunto de sentenças fechado pelas inferências aceitas por $\mathbf{L}$; ou seja, $\mathbf{T}$ contém todas as conseqüências (via $\mathbf{L}$ ) de suas sentenças. A sentenças de T são seus teoremas.

Diz-se que a teoria $\mathbf{T}$ é inconsistente, se existir uma sentença $\mathbf{A}$ tal que $\mathbf{A}$ e $\sim \mathbf{A}$ sejam teoremas de $\mathbf{T}$; caso contrário, denomina-se consistente. $\mathbf{T}$ é trivial, se qualquer sentença de L' for teorema; em hipótese contrária, $\mathbf{T}$ chama-se não-trivial.

Define-se Lógica Paraconsistente como uma lógica que serve de base para teorias que sejam inconsistentes e não-triviais.

A Paracompleteza define-se como sendo a inexistência de um teorema referente a $\mathbf{A}$ e a $\sim \mathbf{A}$, ou seja, a sentença $\mathbf{A}$ existe, mas nada se pode afirmar sobre ela.

Uma Lógica Paraconsistente e Paracompleta diz-se Não-Alética.

\section{II.5.3- A Lógica Paraconsistente Anotada de dois valores (LPA2v):}

As lógicas anotadas que são uma classe da Lógica Paraconsistente, Paracompleta e, portanto, Não-Alética, estão relacionadas a reticulados completos que desempenham um papel fundamental, como se apresentam a seguir.

Considerando-se o reticulado $\mathbf{R}=<([\mathbf{0 , 1}] \times[\mathbf{0 , 1}])^{\mathbf{2}}, \leq>$ onde $[\mathbf{0}, \mathbf{1}]$ é o intervalo real e $\leq$ é a ordem definida como $\left(\mathbf{u}_{1}, \mathbf{u}_{2}\right) \leq\left(\mathbf{p}_{1}, \mathbf{p}_{2}\right) \Leftrightarrow>\mathbf{u}_{1} \leq \mathbf{p}_{1} \mathbf{e} \mathbf{u}_{2} \leq \mathbf{p}_{2}$, um elemento 
do reticulado $\left(\mathbf{u}_{1}, \mathbf{u}_{2}\right)$ é interpretado como $\mathbf{u}_{1}=$ grau de evidencia favorável e $\mathbf{u}_{2}=$ grau de evidência contrária. Uma proposição p com grau de evidencia favorável $\mathbf{u}_{\mathbf{1}}$ e grau de evidência contrária $\mathbf{u}_{2}$ se anota como $\mathbf{p}\left(\mathbf{u}_{1}, \mathbf{u}_{2}\right)$; o reticulado $R$ se denomina reticulado de valores-verdade. Define-se também o operador $\sim: \mathbf{R} \rightarrow \mathbf{R}: \sim\left(\mathbf{u}_{1}, \mathbf{u}_{2}\right)=\left(\mathbf{1}-\mathbf{u}_{1}, \mathbf{1}-\right.$ $\left.\mathbf{u}_{2}\right)$.

A linguagem da LPA2v possui os seguintes símbolos primitivos:

1- Símbolos proposicionais representados por letras minúsculas;

2- Os conectivos de negação $(\sim)$, conjunção $\left({ }^{\wedge}\right)$, disjunção $(v)$ e implicação $(->)$;

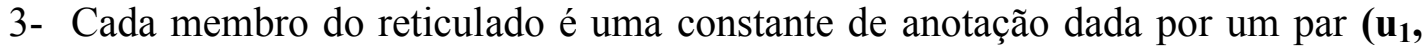
$\mathbf{u}_{2}$ ), podendo ser representado por $\mathbf{u}$;

4- E símbolos auxiliares, entre eles os parênteses;

Definições:

1- Expressão é qualquer seqüência finita de símbolos de seu vocabulário;

2- As fórmulas são obtidas pela seguinte definição indutiva generalizada:

2.1 - Se p é um símbolo proposicional e $\lambda \varepsilon \mathbf{R}$ é uma constante de anotação, então $\mathbf{p}_{\lambda}$ é uma fórmula atômica;

2.2 - Se $\mathbf{A}$ e $\mathbf{B}$ são fórmulas quaisquer, então $(\sim \mathbf{A}),\left(\mathbf{A}^{\wedge} \mathbf{B}\right),(\mathbf{A v B}),(\mathbf{A}->\mathbf{B})$ são fórmulas;

2.3 - Uma expressão constitui uma fórmula se e somente se for obtida por aplicação de uma das regras anteriores. 


\section{II.5.4- Interpretações:}

Seja $\mathbf{P}$ o conjunto dos símbolos proposicionais e $\mathbf{F}$ o conjunto das fórmulas da LPA2v. Uma interpretação para a LPA2v é uma função I: $\mathbf{P}->[\mathbf{1}, \mathbf{0}]^{2}$. Dada uma interpretação I , pode-se associar uma valoração $V_{\mathbf{I}}: \mathbf{F} \rightarrow\{\mathbf{0}, \mathbf{1}\}$ assim definida :

1- Se p $\varepsilon \mathbf{P}$ e u $\varepsilon|\tau|$, então :

$$
\begin{aligned}
& V_{\mathbf{i}}\left(\mathbf{p}_{\mathbf{u}}\right)=\mathbf{1} \text { se e somente se } \mathbf{I}(\mathbf{p}) \geq \mathbf{u} \text { e } \\
& \mathbf{V}_{\mathbf{i}}\left(\mathbf{p}_{\mathbf{u}}\right)=\mathbf{0} \text { se e somente se não é o caso que } \mathbf{I}(\mathbf{p}) \geq \mathbf{u}
\end{aligned}
$$

2- Se A é da forma $\sim^{k} \mathbf{p}_{\mathbf{u}}(\mathbf{k} \geq \mathbf{1})$, então $\mathbf{V}_{\mathbf{i}}\left(\sim^{\mathbf{k}}\left(\mathbf{p}_{\mathbf{u}}\right)\right)=\mathbf{V}_{\mathbf{i}}\left(\sim^{\mathbf{k}-1}\left(\mathbf{p}_{\sim \mathbf{u}}\right)\right)$

Sejam $A$ e $B$ fórmulas quaisquer. Então:

3- $\mathbf{V}_{\mathbf{i}}\left(A^{\wedge} B\right)=\mathbf{1}$ se e somente se $V_{\mathbf{i}}(A)=V_{i}(B)=\mathbf{1}$

4- $\quad V_{i}(A v B)=1$ se e somente se $V_{i}(A)=1$ ou $V_{i}(B)=1$

5- $\mathbf{V}_{\mathbf{i}}(\mathrm{A}->\mathrm{B})=\mathbf{1}$ se e somente se $\mathrm{V}_{\mathrm{i}}(\mathrm{A})=\mathbf{0}$ ou $\mathrm{V}_{\mathbf{i}}(\mathrm{B})=\mathbf{1}$

Se $A$ é uma fórmula complexa, então:

$$
\text { 6- } V_{i}(\sim A)=1-V_{i}(A)
$$

Pela condição 1 , tem-se que $\mathbf{V}_{\mathbf{i}}\left(\mathbf{p}_{\mathbf{u}}\right)=\mathbf{1}$ se e somente se $\mathbf{I}(\mathbf{p}) \geq \mathbf{u}$, ou seja, $\mathbf{p}_{\mathbf{u}}$ é verdadeira segundo a interpretação I se a interpretação dada a p, I(p), for maior ou igual a o valor de evidência u com respeito a proposição p. Ela é falsa, caso contrário.

Pode-se mostrar que há interpretações tais que $V_{\text {I }}\left(\mathbf{p}_{\mu}\right)=\mathbf{1}$ e $\mathbf{V}_{\text {I }}\left(\sim \mathbf{p}_{\mu}\right)=\mathbf{1}$, ou seja, nesta lógica, há contradições verdadeiras. 


\section{II.5.5- Representação do reticulado associado a LPA2v:}

A Lógica Paraconsistente Anotada pode ser representado, de modo particular, por meio de um diagrama de Hasse, conforme a figura II.5.1 a seguir:

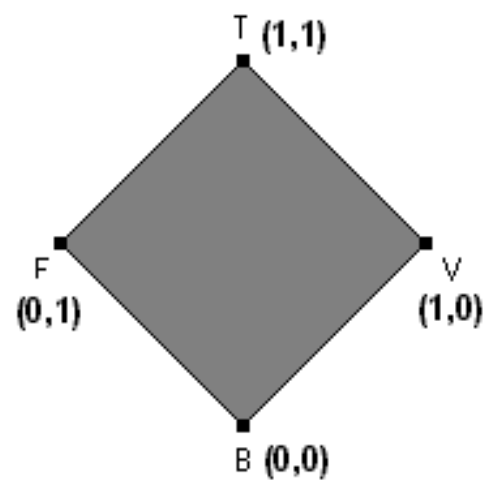

Figura II.5.1 - Representação do reticulado associado a LPA2v

Representa-se este reticulado por $|\mathbf{R}|=\{\mathbf{T}, \mathbf{V}, \mathbf{F}, \mathbf{B}\}$, no qual as constantes anotacionais representam: $\mathbf{T}=$ (top) inconsistente, $\mathbf{V}=$ Verdadeiro, $\mathbf{F}=$ Falso, $\mathbf{B}=$ (Bottom) indeterminado.

Este reticulado pode ser alterado e ajustado de acordo com a aplicação. A seguir, define-se o reticulado utilizado nesta aplicação.

\section{II.5.6- O grau de certeza e o grau de contradição:}

A partir do grau de evidência favorável e evidência contrária, determina-se o grau de certeza $\left(\mathbf{G}_{\mathbf{c}}\right)$ e o grau de contradição $\left(\mathbf{G}_{\mathbf{c t}}\right)$, através das formulas:

- $\quad \mathbf{G}_{\mathbf{c}}=\mathbf{u}_{1}-\mathbf{u}_{2}$

- $\quad \mathbf{G}_{\mathrm{ct}}=\mathbf{u}_{1}+\mathbf{u}_{2}-\mathbf{1}$.

Obtém-se assim, representado no plano cartesiano, o gráfico da figura II.5.2 a seguir: 


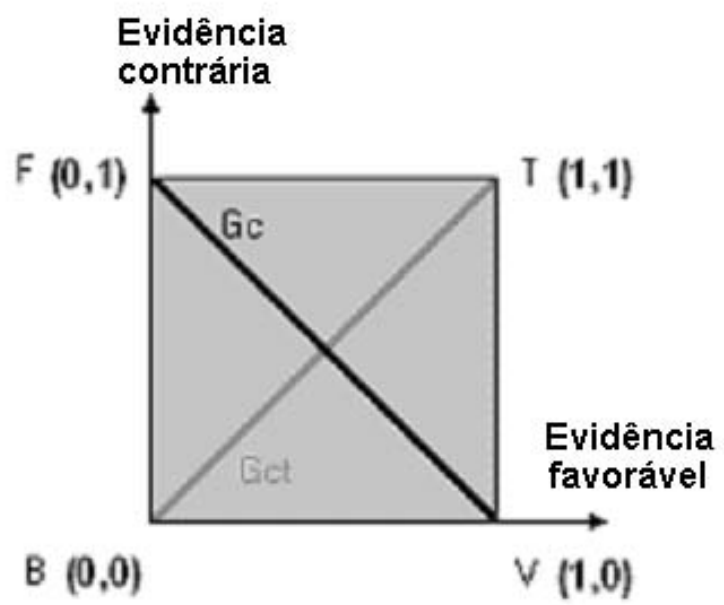

Figura II.5.2 - Plano cartesiano de evidência favorável e contrária

\section{II.5.7 Representação do reticulado no plano cartesiano:}

As constantes anotacionais $\mathbf{T}, \mathbf{V}, \mathbf{F}, B$, apresentadas anteriormente, não são discretas, ou seja, são determinadas por intervalos. Para o reticulado acima, cria-se então o gráfico a seguir (figura II.5.3):

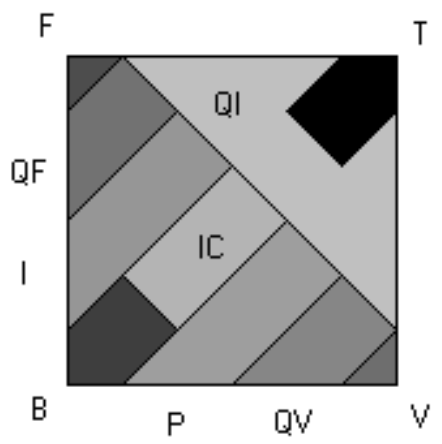

Figura II.5.3 - Gráfico das constantes anotacionais

Como se pode observar no gráfico acima, cada uma das constantes anotacionais apresentadas anteriormente, passa a ter uma faixa de validade, determinada pelos graus de certeza e contradição. 
Pode-se, a partir da determinação das faixas de validade de cada uma das constantes anotacionais definidas, montar uma tabela. Na tabela II.5.1 a seguir é apresentada uma tabela, que determina cada constante anotacional e sua saída $\mathbf{u}_{\mathbf{r}}$ :

\begin{tabular}{|l|l|l|l|} 
Constante Anotacional & Gct & Gc & $\mathbf{u}_{\mathbf{r}}$ \\
\hline $\mathrm{T}=$ inconsistente & $\geq+1 / 2$ & $\geq-1 / 6 \mathrm{e} \leq 1 / 6$ & $1 / 2$ \\
\hline $\mathrm{V}=$ verdadeiro & $\geq-1 / 6 \mathrm{e}<1 / 6$ & $>+5 / 6$ & 1 \\
\hline $\mathrm{QV}=$ quase verdade & $\geq-1 / 2 \mathrm{e}<1 / 6$ & $>1 / 2 \mathrm{e} \leq 5 / 6$ & $5 / 6$ \\
\hline $\mathrm{P}=$ provável & $\geq-5 / 6 \mathrm{e}<1 / 6$ & $>1 / 6 \mathrm{e} \leq 1 / 2$ & $2 / 3$ \\
\hline $\mathrm{IC}=$ incompleto & $\geq-1 / 2 \mathrm{e}<1 / 6$ & $>-1 / 6 \mathrm{e} \leq 1 / 6$ & $5 / 12$ \\
\hline $\mathrm{B}=$ indeterminado & $<-1 / 2$ & $>-1 / 6 \mathrm{e} \leq 1 / 6$ & $1 / 2$ \\
\hline $\mathrm{I}=$ improvável & $\geq-5 / 6 \mathrm{e}<1 / 6$ & $>-1 / 2 \mathrm{e} \leq-1 / 6$ & $1 / 3$ \\
\hline $\mathrm{QF}=$ quase falso & $\geq-5 / 6 \mathrm{e}<-1 / 2$ & $>-1 / 2 \mathrm{e} \leq 1 / 6$ & $1 / 6$ \\
\hline $\mathrm{F}=$ falso & $\geq-1 / 6 \mathrm{e}<1 / 6$ & $\leq-5 / 6$ & 0 \\
\hline $\mathrm{QI}=$ quase inconsistente & nda & nda & $7 / 12$ \\
\hline nda $=$ nenhuma das anteriores & & & \\
\hline
\end{tabular}

Tabela II.5.1 - Constantes anotacionais

Definindo-se, para a tabela II.5.1:

$\mathbf{V}_{\text {sct }} \mathbf{X}$ : Valor SUPERIOR do grau de CONTRADIÇÃO da constante anotacional $\mathbf{X}$ $\mathbf{V}_{\text {ict }} \mathbf{X}$ : Valor INFERIOR do grau de CONTRADIÇÃO da constante anotacional $\mathbf{X}$ $\mathbf{V}_{\mathbf{s c}} \mathbf{X}$ : Valor SUPERIOR do grau de CERTEZA da constante anotacional $\mathbf{X}$ $\mathbf{V}_{\mathbf{i c}} \mathbf{X}$ : Valor INFERIOR do grau de CERTEZA da constante anotacional $\mathbf{X}$

Pode-se fazer com que este sistema se ajuste de acordo com as necessidades, a partir da alteração dos valores limites descritos anteriormente. 


\section{II.5.8 Reticulado resultante da análise do plano cartesiano:}

Considerando-se que se pode definir um reticulado a partir do gráfico anteriormente apresentado, obtido através da definição de constantes anotacionais que são as interpretações para os valores resultantes referentes ao grau de certeza e contradição, visando a aplicação, o resultado é um reticulado como o apresentado a seguir, na figura II.5.4:

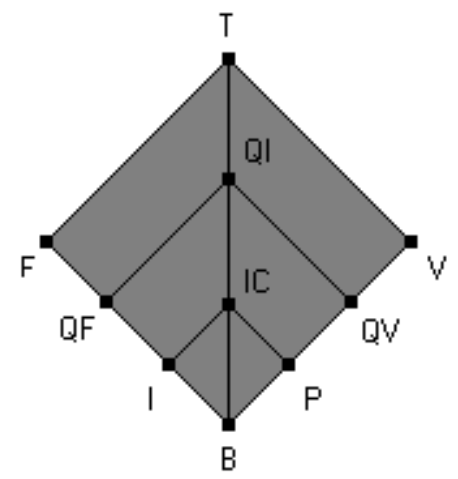

Figura II.5.4 - Reticulado das constantes anotacionais

Para este reticulado consideram-se suas constantes anotacionais como sendo as apresentadas na tabela da tabela II.5.2 , a seguir (Os nomes das interpretações podem ser alterados de acordo com a aplicação):

\begin{tabular}{|l|l|l|}
\hline$T(1,1)=$ inconsistente & $V(1,0)=$ verdadeiro & $F(0,1)=$ falso \\
\hline QI $(2 / 3,2 / 3)=$ quase inconsistente. & $Q V(2 / 3,0)=$ quase verdade & IC $(1 / 3,1 / 3)=$ incompleto \\
\hline QF $(0,2 / 3)=$ quase falso. & $P(1 / 3,0)=$ provável & I $(0,1 / 3)=$ improvável \\
\hline$B(0,0)=$ indeterminado. & & \\
\hline
\end{tabular}

Tabela II.5.2 - Interpretações. 


\section{II.5.9- Considerações finais:}

Utilizando-se a Lógica Paraconsistente conforme descrito neste capítulo, pode-se desenvolver um sistema capaz de aceitar contradições no seu processamento, permitindo a solução de problemas não-triviais. Associando-se às Redes Neurais apresentadas obtêm-se uma nova classe de Redes Neurais: As Redes Neurais Artificiais Paraconsistentes. 


\section{II.6. A Lógica Paraconsistente aplicada às Redes Neurais}

Artificiais

\section{II.6.1- Considerações iniciais:}

Apresenta-se, neste capítulo, um exemplo prático para elucidar o beneficio introduzido em uma Rede Neural quando associada com a Lógica Paraconsistente, sendo que os aspectos aqui referenciados foram publicados em (PRADO, 03a, 03b).

\section{II.6.2- Um exemplo Prático:}

Como exemplo prático para a apresentação da Lógica Paraconsistente aplica às Redes Neurais Artificiais, pode-se considerar uma onda sonora captada por um microfone. A partir da digitalização, transforma-se o sinal de áudio em um vetor. Veja, a seguir, a representação gráfica da transformação de uma onda em um vetor (figura II.6.1):

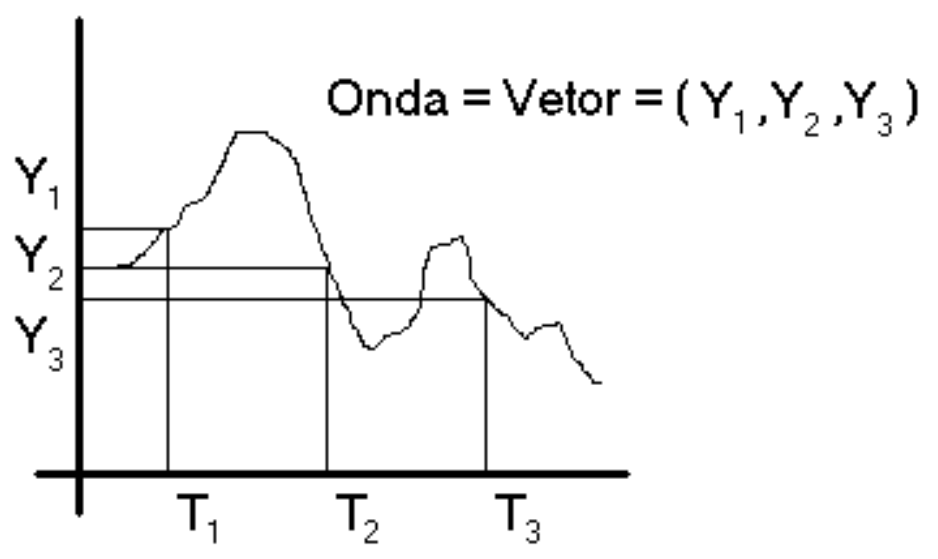

Figura II.6.1 - Representação gráfica da transformação de uma onde em vetor 
Para apresentar o processo de aprendizado da Rede, toma-se como exemplo o aprendizado de dois vetores, cada um com quatro elementos.

$\mathrm{V} 1=(3,2,1,7)$

$\mathrm{V} 2=(\mathbf{3 , 7 , 2 , 7 )}$

Inicialmente a Rede irá aprende o vetor $\mathbf{V 1}$, e em seguida o vetor V2, aproveitando, se possível, os elementos já aprendidos pelo aprendizado do vetor $\mathbf{V 1}$.

Veja a seguir, na figura II.6.2, a representação gráfica deste aprendizado:
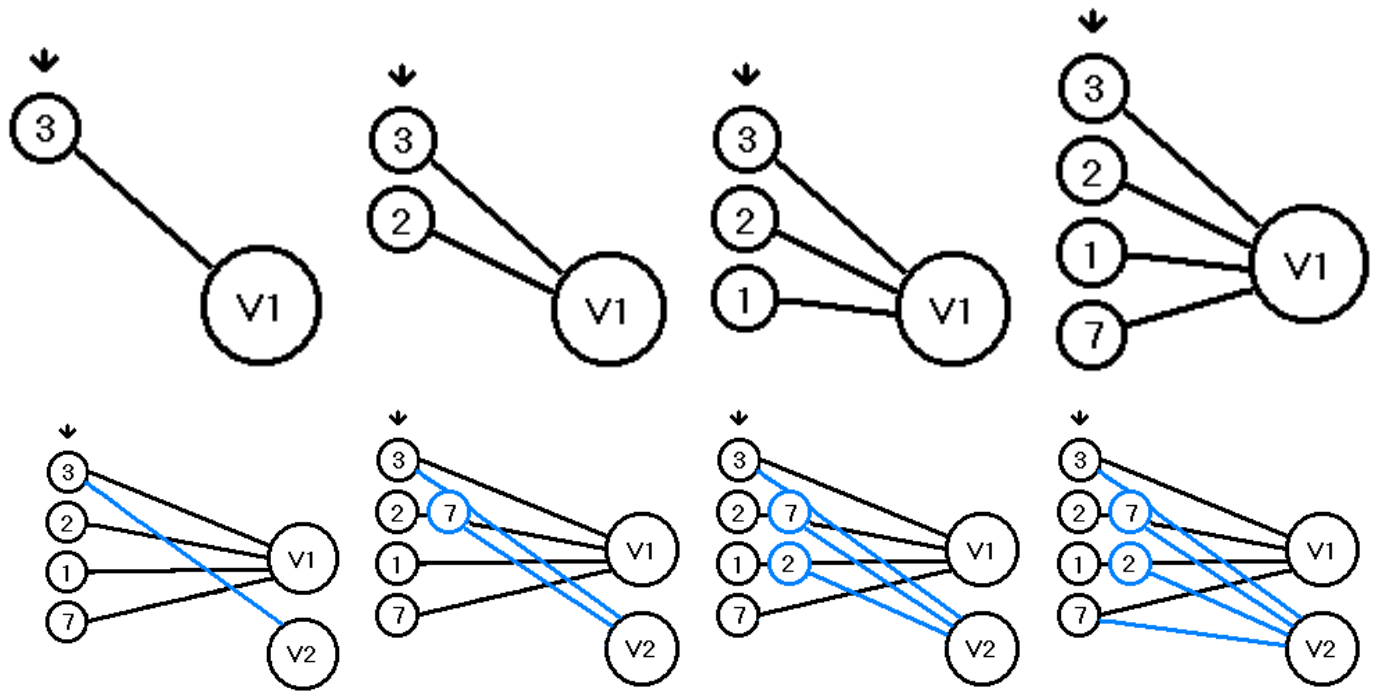

Figura II.6.2 - Representação gráfica da seqüência de aprendizado da Rede 
Para mostrar de forma simples que um cálculo paraconsistente é capaz de “enxergar" o vetor, são utilizados três vetores, com cinco elementos cada:

$\mathrm{V} 1=(2,1,2,7,2)$

$\mathrm{V} 2=(\mathbf{2}, 1,3,6,2)$

$\mathrm{V} 3=(2,1,1,5,2)$

Veja os respectivos gráficos cartesianos na figura II.6.3 a seguir:

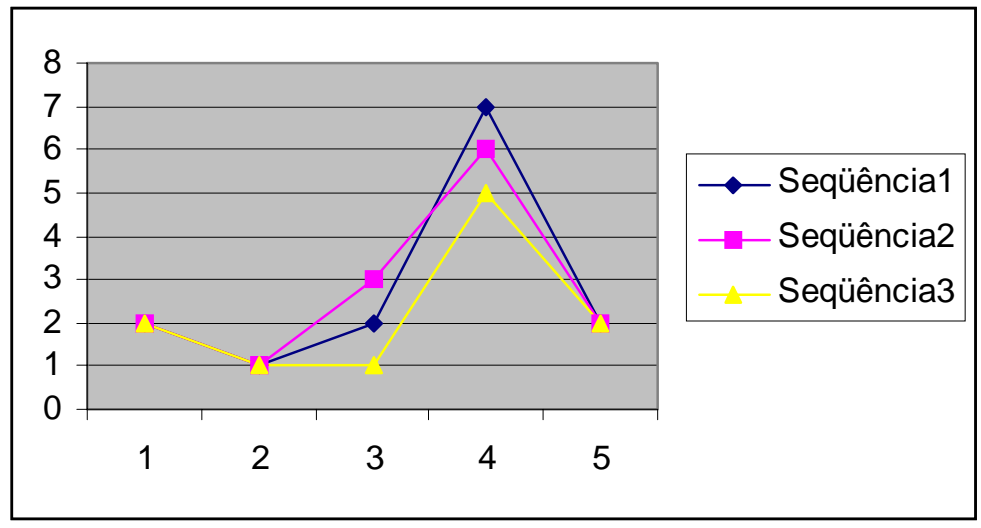

Figura II.6.3 - Representação gráfica cartesiana dos vetores

Utilizando um possível método para identificar as diferenças entre os vetores, baseado na Lógica Clássica, através da totalização relativa dos elementos iguais, atribuindo 1 a elemento igual e 0 a elemento diferente, tem-se:

Comparando V2 com V1 $=\mathbf{1}+\mathbf{1}+\mathbf{0}+\mathbf{0}+\mathbf{1}=\mathbf{3}$, em porcentagem: $(\mathbf{3} / \mathbf{5}) * \mathbf{1 0 0}=\mathbf{6 0} \%$

Comparando V3 com V1= $1+\mathbf{1}+0+0+1=3$, em porcentagem: $(3 / 5) * 100=60 \%$

Por este método conclui-se que o vetor V2 é tão próximo ao vetor V1, quanto o vetor V3.

Tranportando agora o raciocínio para a Lógica Paraconsistente. Considerando-se inicialmente este reconhecimento acima calculado como sendo o grau de evidência favorável, pode-se obter um grau de evidência contrária, a partir do cálculo das diferenças, em módulo, dos elementos não iguais. 
Tem-se então:

$$
\begin{aligned}
& \text { Comparando V2 com V1 }=\mathbf{0}+\mathbf{0}+\mathbf{1}+\mathbf{1}+\mathbf{0} \\
& \text { Comparando V3 com V1 }=\mathbf{0}+\mathbf{0}+\mathbf{1}+\mathbf{2}+\mathbf{0}
\end{aligned}
$$

É necessário ainda normalizar os totais obtidos em relação aos máximos, para obtermos um porcentual que não ultrapasse 100\%. Para isso cada diferença é dividida pela diferença máxima, somada ao resultado, e dividida o total pelo número de elementos, multiplicando-se por 100. No exemplo acima:

$$
\begin{aligned}
& \text { Comparando V2 com V1 }=0+0+1 / 8+1 / 8+0=(2 / 8) / 5=5 \% \\
& \text { Comparando V3 com V1 }=0+0+1 / 8+2 / 8+0=(3 / 8) / 5=7,5 \%
\end{aligned}
$$

Desta forma pode-se afirmar que o vetor V3 "é mais diferente" do vetor V1 do que o vetor V2 é do vetor V1. Note que visualmente pode-se "perceber" isto. Isto nos induz a afirmar que uma análise Paraconsistente permite que os vetores sejam “enxergados", pois identificam facilmente diferenças também facilmente identificadas pela visão.

Uma conclusão importante passa a ser que uma Rede Neural Artificial Paraconsistente poderia, além de aprender um vetor, "enxergá-lo".

Pode-se estender esta idéia, através da inclusão de mais uma camada, permitindo que o sistema monte blocos maiores a partir de sub-blocos. Assim pode-se agrupar Formantes em Fones. Como, sabidamente, existe um número limitado de Formantes, que estão intimamente ligados a cada Fone possível de ser produzido, Faz-se uma relação direta entre a fonética articulatória (produção dos Formantes) e a acústica (Fones produzidos, aquilo que o receptor percebe).

Usando o tipo de exemplo acima, considera-se agora o vetor $\mathbf{V 1}=$ $(\mathbf{0}, 3,7,2,0,2,5,1,0,3,2,3)$ e a separação dos Formantes como o elemento "0" (referência de separação identificada por uma camada independente com células especiais) a representação gráfica da Rede passa a ser a apresentada na figura II.6.4 apresentada a seguir: 


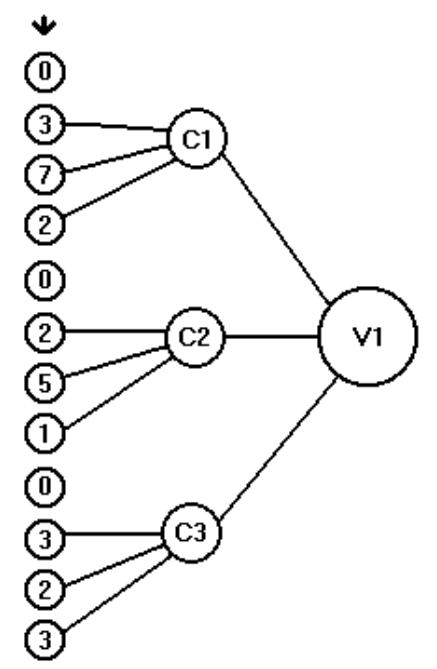

Figura II.6.4 - Representação gráfica da Rede

Portanto o Fone representado por V1 passaria a ser composto pelos Formantes C1, C2 e C3.

Para o reconhecimento de um Fone, basta repetir o processo de aprendizagem, anotando agora, em cada elemento, o quanto o valor do mesmo se aproxima do novo valor recebido. Fazendo o processo simultaneamente do aprendizado e do reconhecimento, o sistema sempre, além de aprender, apresentar o quanto se aproxima de cada vetor já existente. Note que o índice de proximidade se propaga pelas camadas da Rede, chegando até a camada dos vetores. A partir do reconhecimento de cada vetor, obtém-se uma tabela que será analisada por uma camada de decisão que apresenta o resultado definitivo do reconhecimento.

\section{II.6.3- Considerações finais:}

A partir do exemplo descrito, entende-se que a Rede Neural Artificial Paraconsistente mostra-se mais eficaz no aprendizado e reconhecimento de vetores que Redes baseadas em Lógica Clássica. Por isso, para o tratamento das Constelações Fônicas, utiliza-se, neste trabalho, este tipo de Rede Neural. 


\section{II.7. Fundamentos das Redes Neurais Artificiais Paraconsistentes}

\section{II.7.1 Considerações iniciais:}

Com base na referência (DA SILVA FILHO; ABE, 01) apresentam-se neste capítulo os componentes elementares das Redes Neurais Artificiais Paraconsistentes: as Células Neurais Artificiais Paraconsistentes (CNAP's), que tem como finalidade compor as Unidades Neurais Artificiais Paraconsistentes (UNAP's), com finalidades mais abrangentes, e que, por sua vez, também são associadas, dando origem aos Sistemas Neurais Artificiais Paraconsistentes (SNAP's).

As Redes Neurais Artificiais Paraconsistentes (RNAP's) são resultantes da associação de todos esses componentes.

\section{II.7.2 A Célula Neural Artificial Paraconsistente básica}

Denomina-se Célula Artificial Paraconsistente básica $(\mathrm{CAPb})$ o elemento capaz de, apresentado um par $\left(\mathbf{u}_{1 \mathbf{a}}, \mathbf{u}_{\mathbf{2}}\right)$ de evidência favorável e evidência contrária na sua entrada, fornecer um resultado na sua saída composto de uma tripla dada por $\mathbf{G}_{\mathbf{c t}}=\operatorname{grau}$ de contradição resultante, $\mathbf{G}_{\mathbf{c}}=$ grau de certeza resultante e $\mathbf{X}$ sendo umas das constantes anotacionais apresentadas anteriormente.

Esta célula é assim denominada por possui seu funcionamento baseado no conceito da Lógica Paraconsistente aplicada em um elemento Neural Artificial. 
A representação gráfica desta célula encontra-se na figura II.7.1 a seguir:

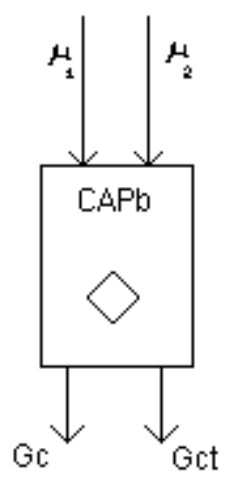

Figura II.7.1 - Célula Artificial Paraconsistente básica

À $\mathrm{CAPb}$, anteriormente descrita, agregam-se mais algumas características, criando assim a Célula Neural Artificial Paraconsistente (CNAP). A primeira característica a agregar é a normalização das saídas, pois, como se pode identificar, as saídas de grau de certeza $\left(\mathbf{G}_{\mathbf{c}}\right)$ e grau de contradição $\left(\mathbf{G}_{\mathbf{c t}}\right)$ pertencentes ao intervalo real $[\mathbf{- 1}, \mathbf{1}]$ e não podem ser utilizadas como entradas da próxima célula. Define-se então $\mathbf{u}_{\mathbf{r}}$ como sendo $\left(\mathbf{G}_{\mathbf{c}}+\mathbf{1}\right) / 2$, normalizando o grau de certeza. Define-se, então, a saída $\mathbf{u}_{\mathbf{r}}$ somente em função das entradas, chegando-se ao resultado:

$$
u_{r}=\left(u_{1}-u_{2}+1\right) / 2
$$

Outra característica que é preciso agregar a $\mathrm{CAPb}$ é a tolerância. Neste trabalho, os fatores de tolerância servem para simplificar o funcionamento da $\mathrm{CAPb}$, pois não são em todos os níveis da Rede Neural que se utiliza o reticulado completo. Em alguns níveis da Rede são necessárias apenas às respostas Verdadeiro (V), Falso (F) e Indefinida (I). No caso de indefinição, é necessário que se informe se a indefinição existe por insuficiência de informações, ou por alta contradição. Define-se então:

1- Fator de tolerância à contradição $\left(\mathbf{F t}_{\mathbf{c t}}\right)$ : Define a tolerância ao grau de contradição através de um valor normalizado: $\mathbf{0} \leq \mathbf{F t}_{\mathbf{c t}} \leq \mathbf{1}$. A partir disto, se $\left|\mathbf{G}_{\mathbf{c t}}\right|$ $<\mathbf{F t}_{\mathbf{c t}}$, então, $\mathbf{u}_{\mathbf{r}}=\left(\mathbf{u}_{1}-\mathbf{u}_{2}+\mathbf{1}\right) / \mathbf{2}, \boldsymbol{X}=$ constante anotacional e ainda o sinal de resposta à contradição é $\mathbf{S}_{\mathbf{c t}}=\mathbf{0}$; caso contrário, $\mathbf{u}_{\mathbf{r}}=\mathbf{1} / \mathbf{2}, \mathbf{X}=\mathbf{B}$ (indeterminado) e $\mathbf{S}_{\mathbf{c t}}=\left|\mathbf{G}_{\mathbf{c t}}\right|$. 
2- Fator de tolerância à certeza $\left(\mathbf{F t}_{\mathbf{c}}\right)$ : da mesma forma pode-se definir o fator de tolerância à certeza: $\mathbf{0} \leq \mathbf{F t}_{\mathbf{c}} \leq \mathbf{1}$. A partir disto se $\left|\mathbf{G}_{\mathbf{c}}\right|>\mathbf{F t}_{\mathbf{c}}$ então $\mathbf{u}_{\mathbf{r}}=\left(\mathbf{u}_{\mathbf{1}^{-}}\right.$ $\left.\mathbf{u}_{\mathbf{2}}+\mathbf{1}\right) / \mathbf{2}, \mathbf{X}=$ constante anotacional; caso contrário $\mathbf{u}_{\mathbf{r}}=\mathbf{1} / \mathbf{2}$.

3- Fator de tolerância à decisão $\left(\mathbf{F t}_{\mathbf{d}}\right)$ : este fator permite a célula definir se o resultado a ser apresentado deve ser falso ou verdadeiro. Isto permite uma correção de resultados, simplificando as possibilidades de respostas do sistema. Considerando-se $\mathbf{0} \leq \mathbf{F t}_{\mathbf{d}} \leq \mathbf{1}$, define-se $\mathbf{V l}_{\mathbf{f}}=\left(\mathbf{1}-\mathbf{F t}_{\mathbf{d}}\right) / \mathbf{2}$ e $\mathbf{V l}_{\mathbf{v}}=\left(\mathbf{1}+\mathbf{F t}_{\mathbf{d}}\right) / \mathbf{2}$. A partir daí, tem-se: se $\mathbf{u}_{\mathbf{r}} \geq \mathbf{V \mathbf { l } _ { \mathbf { v } }}$, então $\mathbf{u}_{\mathbf{r}}=\mathbf{1}$ e $\mathbf{X}=\mathbf{V}$, se $\mathbf{u}_{\mathbf{r}} \leq \mathbf{V} \mathbf{l}_{\mathbf{f}}$ então $\mathbf{u}_{\mathbf{r}}=\mathbf{0}$ e $\mathbf{X}$ $=\mathbf{F}$, caso contrário, $\mathbf{u}_{\mathbf{r}}=\left(\mathbf{u}_{\mathbf{1}}-\mathbf{u}_{\mathbf{2}}+\mathbf{1}\right) / \mathbf{2}$ e $\mathbf{X}=$ constante anotacional. Nota-se que, baseado no reticulado anteriormente apresentado, se $\mathbf{F t}_{\mathbf{d}}=\mathbf{2 / 3}$, o reticulado mantém-se como está.

A partir destes fatores apresentados, tem-se o controle completo da CNAP, simplificando ou mantendo o reticulado.

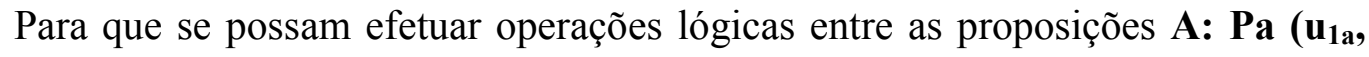
$\mathbf{u}_{2 \mathbf{a}}$ ), onde $\mathbf{u}_{1 \mathbf{a}}$ é o grau de evidência favorável da proposição $\mathbf{A}$, e $\mathbf{u}_{\mathbf{2 a}}$ é o grau de evidência contrária da proposição $\mathbf{A}$; e $\mathbf{B}: \mathbf{P b}\left(\mathbf{u}_{\mathbf{1 b}}, \mathbf{u}_{\mathbf{2 b}}\right)$ onde $u_{1 b}$ é o grau de evidência favorável da proposição $\mathbf{B}$, e $\mathbf{u}_{2 \mathbf{b}}$ é o grau de evidência contrária da proposição $\mathbf{B}$; e sendo $\mathbf{u}_{1 \mathbf{r}}$ o grau de evidência favorável resultante e $\mathbf{u}_{2 \mathbf{r}}$ o grau de evidência contrária resultante, definem-se:

1- Maximização (ou disjunção, OR, v) entre A e B:

Se $\mathbf{u}_{1 \mathbf{a}}<\mathbf{u}_{1 \mathrm{~b}}$ então $\mathbf{u}_{1 \mathbf{r}}=\mathbf{u}_{1 \mathbf{b}}$; caso contrário, $\mathbf{u}_{1 \mathbf{r}}=\mathbf{u}_{1 \mathbf{a}}$.

Se $\mathbf{u}_{2 \mathbf{a}}<\mathbf{u}_{2 b}$ então $\mathbf{u}_{2 \mathbf{r}}=\mathbf{u}_{2 \mathbf{b}}$; caso contrário, $\mathbf{u}_{2 \mathbf{r}}=\mathbf{u}_{2 \mathbf{a}}$.

2- Minimização (ou conjunção, $\mathrm{AND},{ }^{\wedge}$ ) entre A e B:

Se $\mathbf{u}_{1 \mathrm{a}}>\mathbf{u}_{1 \mathrm{~b}}$ então $\mathbf{u}_{1 \mathbf{r}}=\mathbf{u}_{1 \mathrm{~b}} ;$ caso contrário, $\mathbf{u}_{1 \mathrm{r}}=\mathbf{u}_{1 \mathrm{a}}$.

Se $\mathbf{u}_{2 \mathbf{a}}>\mathbf{u}_{2 b}$ então $\mathbf{u}_{2 \mathbf{r}}=\mathbf{u}_{2 b}$; caso contrário, $\mathbf{u}_{2 \mathbf{r}}=\mathbf{u}_{2 \mathbf{a}}$.

3- Negação (NOT, $\sim$ ) de $\mathbf{A}: \mathbf{u}_{1 \mathbf{r}}=\mathbf{u}_{2 \mathbf{a}}$ e $\mathbf{u}_{2 \mathbf{r}}=\mathbf{u}_{1 \mathbf{a}}$. (Vale a pena ressaltar que a negação de A também se poderia calcular por: $\mathbf{u}_{1 \mathbf{r}}=\mathbf{1 - \mathbf { u } _ { 1 \mathbf { a } }}$ e $\mathbf{u}_{\mathbf{2 r}}=\mathbf{1}-\mathbf{u}_{\mathbf{2 a}}$ )

4- O complemento (COMP) de A: $\mathbf{u}_{1 \mathbf{r}}=\mathbf{1}-\mathbf{u}_{1 \mathbf{a}}$ e $\mathbf{u}_{2 \mathbf{r}}=\mathbf{1}-\mathbf{u}_{2 \mathbf{a}}$ 
A partir deste estudo prévio, apresenta-se a família das Células Neurais Artificiais Paraconsistentes, simbolizadas por CNAP. A seguir apresentam-se, para cada uma das células suas entradas, que são os sinais recebidos, seus cálculos, que são efetuados internamente, e suas saídas, que são fornecidas para as células seguintes, ou interpretadas por camada de decisão final. São elas:

\section{II.7.3- Célula Neural Artificial Paraconsistente de conexão analítica:}

A Célula Neural Artificial Paraconsistente de conexão analítica (CNAPca) é a principal célula de toda RNAP, pois é responsável por todo cálculo fundamental da Lógica Paraconsistente, obtendo-se o grau de certeza $\left(\mathbf{G}_{\mathbf{c}}\right)$ e o grau de contradição $\left(\mathbf{G}_{\mathbf{c t}}\right)$ a partir das entradas e dos fatores de tolerância.

1- Entradas: $\mathbf{u}_{\mathbf{1}}$ (grau de evidência favorável da célula anterior 1), $\mathbf{u}_{2}$ (grau de evidência favorável anterior 2), $\mathbf{F t}_{\mathbf{c}}$ (fator de tolerância à certeza), $\mathbf{F t}_{\mathbf{c t}}$ (fator de tolerância à contradição).

2- Cálculos : $\mathbf{u}_{2 \mathrm{c}}=\mathbf{1}-\mathbf{u}_{2}, \mathbf{G}_{\mathrm{ct}}=\mathbf{u}_{1}+\mathbf{u}_{2 \mathrm{c}}-\mathbf{1}, \mathbf{G}_{\mathbf{c}}=\mathbf{u}_{1}-\mathbf{u}_{2 \mathrm{c}}, \mathbf{u}_{\mathrm{r}}=\left(\mathbf{G}_{\mathrm{c}}+\mathbf{1}\right) / 2$.

3- Saídas: se $\left|G_{c}\right|>F_{c}$ então $\mathbf{S}_{\mathbf{1}}=\mathbf{u}_{\mathbf{r}}$ e $\mathbf{S}_{\mathbf{2}}=\mathbf{0}$; Se $\left|\mathbf{G}_{\mathrm{ct}}\right|>\mathbf{F t}_{\mathrm{ct}}$ e $\left|\mathbf{G}_{\mathrm{ct}}\right|>\left|\mathbf{G}_{\mathbf{c}}\right|$ então $\mathbf{S}_{\mathbf{1}}=\mathbf{u}_{\mathrm{r}}$ e $\mathbf{S}_{\mathbf{2}}=\left|\mathbf{G}_{\mathrm{ct}}\right|$, caso contrário, $\mathbf{S}_{\mathbf{1}}=\mathbf{1} / \mathbf{2}$ e $\mathbf{S}_{\mathbf{2}}=\mathbf{0}$.

A representação gráfica desta célula encontra-se na figura II.7.2 a seguir:

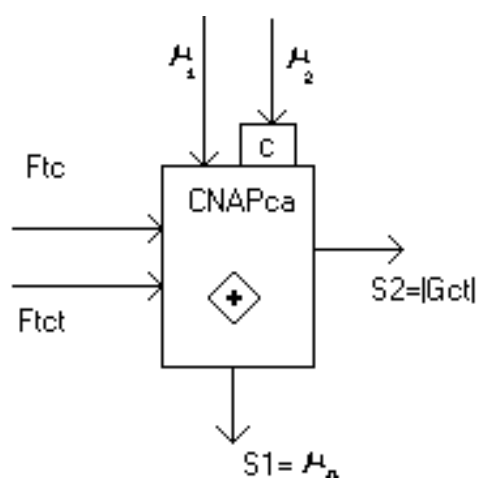

Figura II.7.2 - CNAPca - Célula Neural Artificial Paraconsistente de conexão analítica. 


\section{II.7.4- Célula Neural Artificial Paraconsistente de conexão lógica simples para maximização (operação lógica OU)}

A Célula Neural Artificial Paraconsistente de conexão lógica simples para maximização (CNAPclsmax) permite a seleção do valor máximo entre as entradas, sendo equivalente à operação lógica ou.

1- Entradas : $\mathbf{u}_{1}, \mathbf{u}_{2}$.

2- Cálculos: não possui.

3- Saídas: se $\mathbf{u}_{1}>\mathbf{u}_{2}=>\mathbf{S}_{1}=\mathbf{u}_{1}$, caso contrário, $\mathbf{S}_{1}=\mathbf{u}_{2}$

Sua representação gráfica encontra-se na figura II.7.3 a seguir:

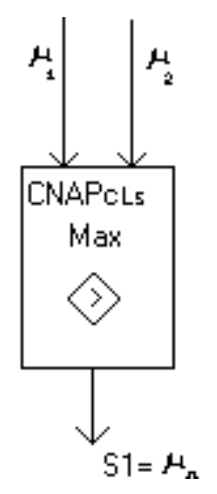

Figura II.7.3 - CNAPclsmax - Célula Neural Artificial Paraconsistente de conexão lógica simples para maximização 


\section{II.7.5 Célula Neural Artificial Paraconsistente de conexão lógica simples para minimização (operação lógica E)}

A Célula Neural Artificial Paraconsistente de conexão lógica simples para minimização (CNAPClsmin) permite a seleção do valor mínimo entre as entradas, sendo equivalente à operação lógica $E$.

1- Entradas: $\mathbf{u}_{1}, \mathbf{u}_{2}$

2- Cálculos: Não possui

3- Saídas : se $\mathbf{u}_{1}<\mathbf{u}_{2}=>\mathbf{S}_{\mathbf{1}}=\mathbf{u}_{\mathbf{1}}$, caso contrário, $\mathbf{S}_{\mathbf{1}}=\mathbf{u}_{\mathbf{2}}$

A representação gráfica desta célula encontra-se na figura II.7.4 a seguir:

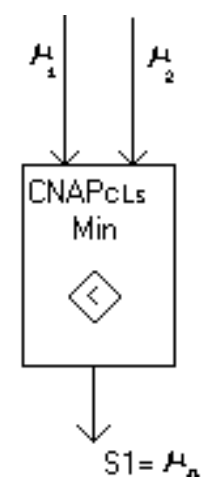

Figura II.7.4 - CNAPclsmin - Célula Neural Artificial Paraconsistente de conexão lógica simples para minimização 


\section{II.7.6- Célula Neural Artificial Paraconsistente de conexão lógica seletiva para maximização}

A Célula Neural Artificial Paraconsistente de conexão lógica seletiva para maximização (CNAPClsemax) permite, além da seleção do valor máximo entre as entradas, escolher o caminho que a informação segue, desviando o fluxo do processamento para uma camada diferente da Rede.

1- Entradas: $\mathbf{u}_{1}, \mathbf{u}_{2}$

2- Cálculos: Não possui

3- Saídas: se $u_{1}>u_{2}=>S_{1}=u_{1}$ e $S_{2}=1 / 2$, caso contrário, $S_{1}=1 / 2$ e $S_{2}=u_{2}$

A representação gráfica desta célula encontra-se na figura II.7.5 a seguir:

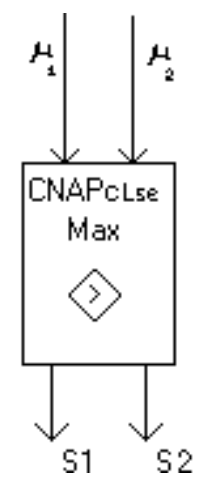

Figura II.7.5 - CNAPclsemax - Célula Neural Artificial Paraconsistente de conexão lógica seletiva para maximização 


\section{II.7.7- Célula Neural Artificial Paraconsistente de conexão lógica seletiva para minimização}

A Célula Neural Artificial Paraconsistente de conexão lógica seletiva para minimização (CNAPclsemin) permite, além da seleção do valor mínimo entre as entradas, escolher o caminho que a informação segue, desviando o fluxo do processamento para uma camada diferente da Rede.

1- Entradas: $\mathbf{u}_{1}, \mathbf{u}_{2}$

2- Cálculos: Não possui

3- Saídas : se $\mathbf{u}_{1}<\mathbf{u}_{\mathbf{2}}=>S_{1}=\mathbf{u}_{\mathbf{1}}$ e $\mathbf{S}_{\mathbf{2}}=\mathbf{1 / 2}$, caso contrário, $\mathbf{S}_{\mathbf{1}}=\mathbf{1 / 2}$ e $\mathbf{S}_{\mathbf{2}}=\mathbf{u}_{\mathbf{2}}$

Sua representação gráfica encontra-se na figura II.7.6 a seguir:

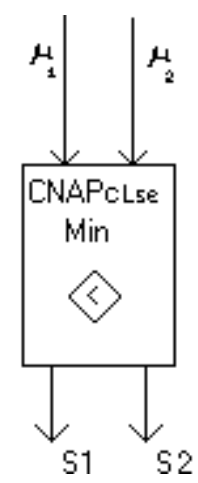

Figura II.7.6 - CNAPclsemin - Célula Neural Artificial Paraconsistente de conexão lógica seletiva para minimização 


\section{II.7.8- Célula Neural Artificial Paraconsistente de complementação}

A Célula Neural Artificial Paraconsistente de complementação (CNAPco) permite efetuar o cálculo do complemento da entrada, considerando o Fator de complementação $\left(F t_{c}\right)$ que define se a saída é indefinida ou pode conter o complemento da entrada.

1- Entradas : $\mathbf{u}_{\mathbf{1}}, \mathbf{F t}_{\mathbf{c}}$

2- Cálculos : $\mathbf{u}_{1 \mathrm{c}}=\mathbf{1 - \mathbf { u } _ { 1 }}$

3- Saídas: $\mathbf{u}_{r}=\left(\mathbf{u}_{1 \mathrm{c}}-\mathbf{u}_{\mathbf{1}}+\mathbf{1}\right) / 2$ se $\mathbf{u}_{\mathrm{r}} \geq \mathbf{F} \mathbf{t}_{\mathrm{c}}$, caso contrário, $\mathbf{u}_{\mathbf{r}}=\mathbf{1} / \mathbf{2}$.

A representação gráfica desta célula encontra-se na figura II.7.7 a seguir:

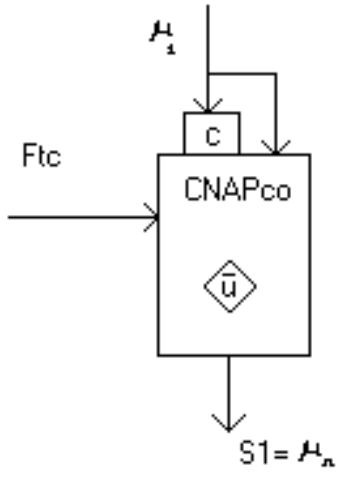

Figura II.7.7 - CNAPco - Célula Neural Artificial Paraconsistente complementação 


\section{II.7.9- Célula Neural Artificial Paraconsistente de decisão - CNAPd}

A Célula Neural Artificial Paraconsistente de decisão (CNAPd) permite identificar a interpretação do valor obtido, podendo ser verdadeiro, falso ou outro valor qualquer, de acordo com a tabela de constantes anotacionais definida.

1- Entradas : $\mathbf{u}_{\mathbf{1}}, \mathbf{u}_{\mathbf{2}}, \mathbf{F t}_{\mathbf{d}}$

2- Cálculos : $\mathbf{V l}_{\mathbf{f}}=\left(1-\mathbf{F t}_{\mathbf{d}}\right) / \mathbf{2}, \mathbf{V l v}=\left(1+\mathbf{F t}_{\mathbf{d}}\right) / 2, \mathbf{u}_{\mathbf{r}}=\left(\mathbf{u}_{1}-\mathbf{u}_{2}+1\right) / 2$

3- Saídas: se $\mathbf{u}_{\mathbf{r}} \geq V \mathbf{I}_{\mathbf{v}}$, então $\mathbf{S 1}=\mathbf{1}(\mathbf{V})$, se $\mathbf{u}_{\mathbf{r}} \leq \mathbf{V I}_{\mathbf{f}}$ então $S_{1}=\mathbf{0}(\mathbf{F})$, caso contrário, deve seguir a tabela de constantes anotacionais da figura 4.4 , do capítulo 4.

A representação gráfica desta célula encontra-se na figura II.7.8 a seguir:

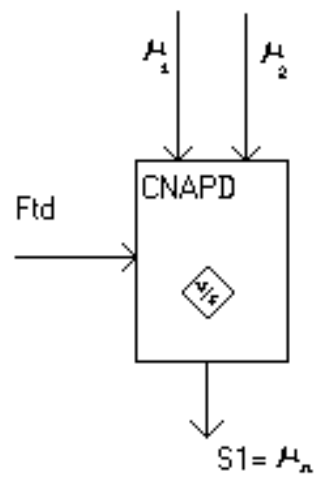

Figura II.7.8 - CNAPd - Célula Neural Artificial Paraconsistente de decisão 


\section{II.7.10 Célula Neural Artificial Paraconsistente de aprendizagem, desaprendizagem e memorização}

A Célula Neural Artificial Paraconsistente de aprendizagem, desaprendizagem e memorização (CNAPadm) foi criada de forma a poder aprender, desaprender ou memorizar um padrão. Discute-se seu funcionamento em capítulo posterior, pois esta célula teve seu funcionamento profundamente alterado em relação ao livro texto, devido à aplicação. Apresenta-se a seguir a sua representação gráfica (figura II.7.9):

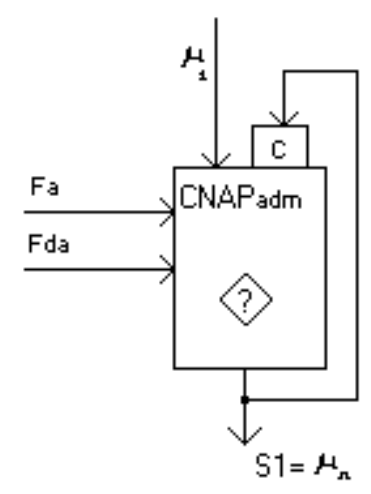

Figura II.7.9 - CNAPadm - Célula Neural Artificial Paraconsistente de aprendizagem, desaprendizagem e memorização.

Define-se a CNAPadm como sendo uma célula capaz de armazenar um sinal apresentado na entrada, se o Fator de aprendizagem $\left(\mathbf{F}_{\mathbf{a}}\right)$ for diferente de 0, e retornar para 0 , se o Fator de desaprendizagem $\left(\mathbf{F}_{\mathbf{d a}}\right)$ for diferente de zero; estes fatores nunca podem ser diferentes de zero simultaneamente. 


\section{II.7.11 - A Unidade Neural Artificial Paraconsistentes Básica}

As Unidades Neurais Artificiais Paraconsistentes (UNAP’s) são associações de CNAP's, visando um objetivo. Estas associações podem ter como objetivo a análise lógica, decisão, seleção, aprendizado, etc.

A seguir apresenta-se apenas a UNAPb, pois como o objetivo deste trabalho é o aprendizado e reconhecimento de vetores, as UNAP's utilizadas na aplicação são apresentadas em capítulo posterior. Por este motivo o estudo das UNAP's de uso geral serve apenas para esclarecer como se fazem as associações de células e apresentar a versatilidade gerada por esta associação.

A Unidade Neural Artificial Paraconsistente Básica (UNAPb) ou ParaPerceptron nada mais é que uma associação de CNAP's, de forma a obter um componente capaz de simular o funcionamento de um neurônio.

A diferença do Perceptron para o Para-perceptron é que o segundo tem comportamento paraconsistente, trabalhando com contradições e paracompletezas.

$\mathrm{Na}$ figura II.7.10 a seguir apresenta-se uma possível implementação para o Para-perceptron: 


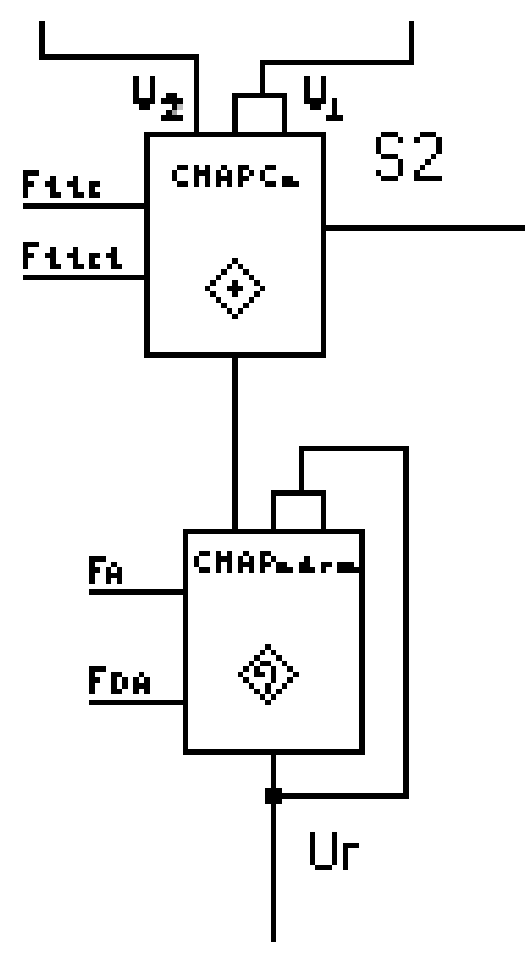

Figura II.7.10 - Para-perceptron - UNAPb

Esta associação permite comparar analiticamente dois sinais e em seguida aprendê-los. 


\section{II.7.12 - Os Sistemas Neurais Artificiais Paraconsistentes}

Os Sistemas Neurais Artificiais Paraconsistentes (SNAP's) são associações de UNAP's, visando um objetivo. Estas associações podem ter como objetivo a análise lógica, decisão, seleção, aprendizado, etc. Por se tratar de uma associação mais complexa e totalmente específica da aplicação, sua construção é apresentada em capítulo posterior oportuno, já visando a aplicação.

\section{II.7.13 - Considerações finais}

Neste capítulo foram apresentados todos os elementos necessários para a construção de uma RNAP. É importante destacar que a apresentação deles se fez necessária, para que haja uma familiarização com todos os processos de cálculo e comportamento dos elementos que compõem a RNAP. A possibilidade de associação destes elementos é infinita: comporta-se de forma similar a uma linguagem escrita, na qual seu alfabeto é composto pelas CNAP's, as palavras pelas UNAP's, e as SNAP's são as frases, que podem ser utilizadas de acordo com o contexto necessário. Assim sendo, pode-se compor a linguagem de acordo com a necessidade e a aplicação.

Outra consideração importante a fazer é que os elementos aqui apresentados são simbólicos e sua forma de concretização mais simples é através de um arquivo de computador, que armazena os valores existentes de cada elemento, seja ele uma célula, um Para-Perceptron, ou outro elemento qualquer. O comportamento funcional da célula é traduzido na prática como sendo um algorítmo, implementado através de um programa de computador. Poder-se-ia também materializar fisicamente os elementos aqui apresentados, como elementos físicos, porém, a versatilidade de uma implementação através de um software e arquivos de computador é muito maior, pois sua construção, alteração, destruição, conexão e demais operações atribuídas a uma rede neural é muito mais fácil. 


\section{II.8. As Redes Neurais Artificiais Paraconsistentes usadas no reconhecimento de padrões.}

\section{II.8.1 Considerações iniciais:}

Segundo a obra de Piaget (RICHMOND, 90), todo o desenvolvimento intelectual se dá através da organização, adaptação, esquemas, processos de assimilação e acomodação, de forma a atingir um equilíbrio entre o meio e a pessoa. Desta forma, sempre que se tem um estímulo desconhecido, cria-se um esquema. Este esquema consiste em uma combinação de estados de neurônios. Sempre que se recebe uma nova informação, esta é comparada com todos os esquemas próximos que se tem, associando partes destes esquemas, criando um novo esquema. Estas estruturas visam assimilar (gravar de forma coerente) as informações obtidas e acomodar todos os conhecimentos. Tudo isto cria um emaranhado de informações, que quanto mais interligado entre si, mais inteligente se torna. Para criar uma estrutura artificial que proceda desta forma, é preciso uma Rede que monte esquemas de acordo com as informações recebidas. Estes esquemas, a cada nova informação, se modificam ou se adaptam para absorverem a nova informação. Do ponto de vista da fala, estes esquemas se montam a partir da assimilação dos Formantes, que podem ser associados para a formação de Fones, que compõem a produção concreta de uma fala, conforme apresentado em capítulo anterior.

Este capítulo apresenta os elementos necessários para a aplicação prática desenvolvida, Elementos estes criados e testados em (PRADO, 02a, 02b, 03c): o aprendizado e reconhecimento de Constelações Fônicas para que, em um trabalho futuro possa-se, por diferença, aprender e reconhecer os Formantes de produções fônicas contrastantes.

Estes elementos são as CNAP's, UNAP's e SNAP's cuja versatilidade traduz-se em inúmeras adaptações possíveis de acordo com cada necessidade específica.

As CNAP's utilizadas para reconhecimento de padrões possuem algoritmos otimizados, permitindo respostas rápidas no aprendizado, desaprendizado, memorização, comparação e decisão referentes aos sinais que compõem os padrões a 
serem aprendidos e/ou reconhecidos. A seguir, são apresentadas as CNAP's, suas entradas, cálculos e saídas.

\section{II.8.2- Célula Neural Artificial Paraconsistente de passagem:}

A Célula Neural Artificial Paraconsistente de passagem (CNAPp) tem como finalidade principal permitir, ou não, a passagem de um sinal. Caso esteja desabilitada, seu sinal de saída é zero.

1- Entradas: $\mathbf{u}_{\mathbf{1}}, \mathbf{p}$.

2- Cálculos: nenhum

3- Saídas: $\mathbf{u}_{\mathbf{r}}=\mathbf{u}_{\mathbf{1}}$ se $\mathbf{p}=\mathbf{1}$, caso contrário, $\mathbf{u}_{\mathbf{r}}=\mathbf{0}$

Sua representação gráfica encontra-se na figura II.8.1, a seguir:

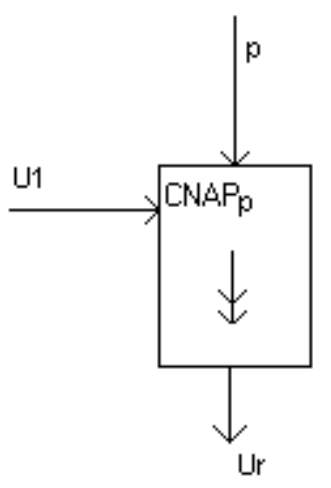

Figura II.8.1 - CNAPp - Célula Neural Artificial Paraconsistente de passagem 


\section{II.8.3- Célula Neural Artificial Paraconsistente de aprendizagem, desaprendizagem e memorização - CNAPadm:}

Criou-se a Célula Neural Artificial Paraconsistente de aprendizagem, desaprendizagem e memorização (CNAPadm) de forma a poder aprender, desaprender ou memorizar um padrão. Inicialmente, sua saída assume o valor $\mathbf{u}_{\mathbf{r}}=\mathbf{1 / 2}$, que significa que a célula não tem nada aprendido. Desta forma, considerando-se $\mathbf{u}_{1}$ como sendo sua entrada, a célula estará apta a aprender, ou manter seu estado indefinido. Note que esta célula tem um comportamento diferente das demais apresentadas, uma vez que pode aprender um valor no intervalo $[\mathbf{0}, \mathbf{1}]$, sem que este valor tenha um significado lógico. Assume-se desta forma, porque, diferentemente do proposto por (DA SILVA FILHO; $\mathrm{ABE}, 01)$, onde se considera que nas células primárias só dois tipos de padrões podem ser apresentados nas entradas: o padrão de VERDADE ou o padrão de FALSIDADE (DA SILVA FILHO; ABE, 01 - página 98, quarto parágrafo), neste trabalho a célula de aprendizagem armazena um valor analógico, facilitando sua aplicação para reconhecimentos de padrões.

É importante ressaltar que a saída, estando em $\mathbf{u}_{\mathbf{r}}=\mathbf{1} / \mathbf{2}$, não tem significado nenhum do ponto de vista lógico. Esta célula obrigatoriamente tem seu fator de aprendizagem $\left(\mathbf{F}_{\mathbf{a}}\right)$ diferente de zero, indicando que está virgem. Este parâmetro é responsável por permitir o inicio do aprendizado, bem como avisar às células seguintes que não possui nenhuma informação válida. Ao receber o sinal de entrada $\mathbf{u}_{\mathbf{1}}$, estando $\mathbf{F}_{\mathbf{a}}$ diferente de zero, a célula esta apta a aprender. Uma vez aprendido um padrão, a célula assume $\mathbf{F}_{\mathbf{a}}$ igual a zero, indicando que aprendeu um padrão. Caso esta célula possua um fator de desaprendizagem $\left(\mathbf{F}_{\mathbf{d a}}\right)$ diferente de zero, significa que está habilitada a desaprender, portanto ainda não possui uma saída válida. Somente $\operatorname{com} \mathbf{F}_{\mathbf{a}}$ igual a zero e $\mathbf{F}_{\mathrm{da}}$ igual a zero é que a saída é considerada válida, e permanece inalterada qualquer que seja $\mathbf{u}_{\mathbf{1}}$ na entrada, até que, externamente, se faça $\mathbf{F}_{\mathbf{a}}$ diferente de zero ou $\mathbf{F}_{\mathbf{d a}}$ diferente de zero.

Para que se possa utilizar esta célula, deve associá-la a outras, fazendo com que possa aprender, desaprender, memorizar e identificar um padrão, fornecendo um resultado lógico, compatível com a Lógica Paraconsistente. 
A seguir apresenta-se o algoritmo de aprendizagem, desaprendizagem e memorização desta célula na figura II.8.2:

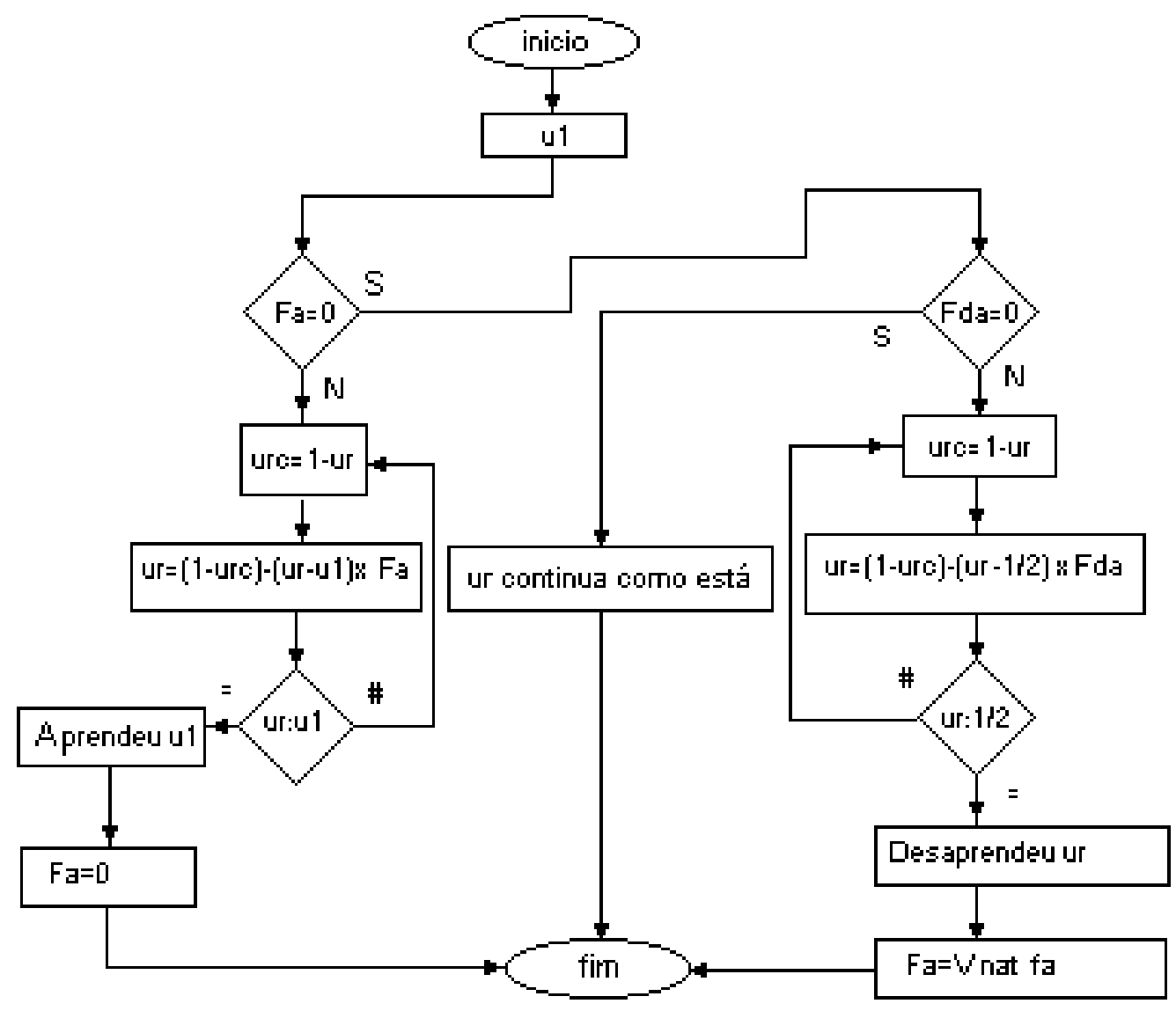

Figura II.8.2 - Algoritmo de aprendizagem e desaprendizagem

Nota-se que, no algoritmo da figura II.8.2 surge um novo valor, o Vnat fa, que significa valor natural do fator de aprendizagem.

Este valor natural é o valor inicial atribuído a esta célula. Comparado a um neurônio, isto equivale a dizer que um neurônio deve voltar ao seu estado inicial, esquecendo uma excitação elétrica que tenha sofrido. 
Sua representação gráfica encontra-se na figura II.8.3, a seguir:

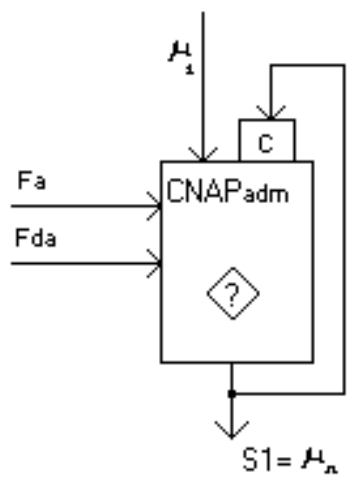

Figura II.8.3 - CNAPadm - Célula Neural Artificial Paraconsistente de aprendizagem, desaprendizagem e memorização.

Para a complementação do funcionamento da célula CNAPadm, criam-se dois novos tipos de células básicas: a CNAP de ativação de padrão memorizado e a CNAP de reconhecimento de padrão.

Neste estudo, a inclusão destas modificações se faz necessário para facilitar o processo de armazenagem e reconhecimento de padrões, diminuindo o número de camadas de células necessárias para a armazenagem e reconhecimento de um padrão. 


\section{II.8.4- Célula Neural Artificial Paraconsistente de ativação de padrão memorizado:}

A Célula Neural Artificial Paraconsistente de ativação de padrão memorizado (CNAPapm) permite consultar um padrão aprendido, fornecendo a saída indefinida $(1 / 2)$, caso esteja desativado.

1- Entradas: m, a.

2- Cálculos: nenhum

3- Saídas: se $\mathbf{a}=\mathbf{1}, \mathbf{u}_{\mathbf{r}}=\mathbf{m}$; caso contrário, $\mathbf{u}_{\mathbf{r}}=\mathbf{1} / \mathbf{2}$

A representação gráfica desta célula está apresentada a seguir, na figura II.8.4:

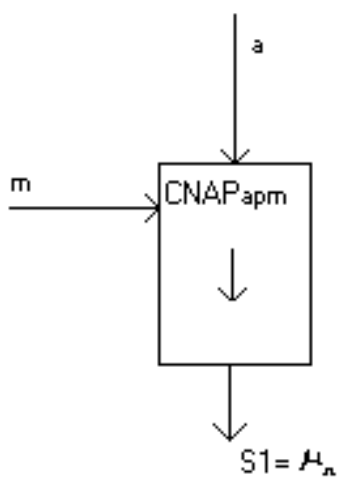

Figura II.8.4 - CNAPapm - Célula Neural Artificial Paraconsistente de ativação de padrão memorizado 


\section{II.8.5- Célula Neural Artificial Paraconsistente de reconhecimento de padrão:}

A Célula Neural Artificial Paraconsistente de reconhecimento de padrão (CNAPrp) permite, a partir de dois padrões comparados, retornar uma resposta que seja proporcional à igualdade dos padrões. Isto é necessário, para que a célula de aprendizagem possa armazenar um sinal que não seja uma crença, e sim um valor referente a um sinal de entrada. Esta célula transforma uma comparação de sinais num valor lógico, que é a similaridade entre dois elementos. Mais uma vez pode-se utilizar a tabela de constantes anotacionais para multivalorar o resultado. Considerando-se, como anteriormente descrito, o valor $\mathbf{1 / 2}$ como indefinição, o padrão pode ser reconhecido (1) não reconhecido (0) ou apresentar um fator de similaridade, sendo que 1/2 significa indefinido. Tem-se então:

1- Entradas : $\mathbf{u}_{\mathbf{1}}, \mathbf{u}_{\mathbf{2}}, \mathbf{F}_{\mathbf{r p}}$

2- Cálculos: $\mathbf{V s}_{\mathrm{rp}}=\left(\mathbf{1}+\mathbf{F t}_{\mathrm{rp}}\right) / \mathbf{2}, \mathbf{V \mathbf { i } _ { \mathrm { rp } }}=\left(\mathbf{1}-\mathbf{F t}_{\mathrm{rp}}\right) / \mathbf{2}, \mathbf{u}_{\mathrm{r}}=1-\left|\mathbf{u}_{1}-\mathbf{u}_{2}\right|$

3- Saídas: se $\mathbf{u}_{\mathbf{r}} \geq \mathbf{V} \mathbf{s}_{\mathbf{r p}}$, então $\mathbf{S}_{\mathbf{1}}=\mathbf{1}(\mathbf{V})$, o padrão foi reconhecido; se $\mathbf{u}_{\mathbf{r}} \geq \mathbf{V} \mathbf{i}_{\mathbf{r p}}$ então $\mathbf{S}_{1}=\mathbf{u}_{\mathbf{r}}$, seguindo a tabela de constantes anotacionais (note que se pode assumir $\mathbf{u}_{\mathbf{r}}=\mathbf{1} / \mathbf{2}$, indicando indefinição); caso contrário $\mathbf{S}_{\mathbf{1}}=\mathbf{0}(\mathbf{F})$, o padrão não foi reconhecido.

A representação gráfica desta célula encontra-se na figura II.8.5, a seguir:

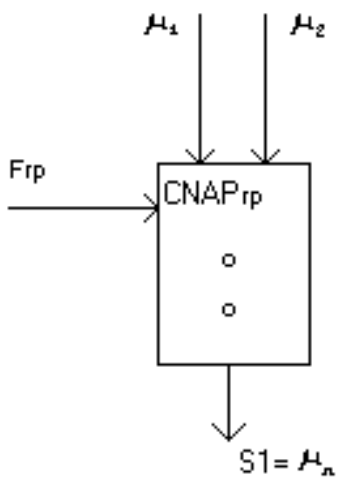

Figura II.8.5 - CNAPrp - Célula Neural Artificial Paraconsistente de reconhecimento de padrão 


\section{II.8.6- Célula Neural Artificial Paraconsistente de reconhecimento de sinal:}

Conforme apresentado anteriormente, é necessária a identificação de início e fim de fala. Para isso utiliza-se uma célula capaz de reconhecer o inicio e fim de um sinal, podendo ser ajustada inclusive para secionar um sinal de fala em partes menores, antes de ser analisado. Para uma seqüência de elementos do vetor que representa o sinal de fala, a reta determinada pelo par $\left(\mathbf{x}_{\mathbf{i}-1}, \mathbf{x}_{\mathbf{i}+1}\right)$ recebe o nome de $\mathbf{r}_{\mathbf{i}}$. A inclinação desta reta é dada por $\operatorname{tg}\left(\alpha_{\mathbf{i}}\right)=\left(\mathbf{x}_{\mathbf{i}+\mathbf{1}}-\mathbf{x}_{\mathbf{i}-1}\right) / 3$. Considerando-se já normalizados os valores de $\mathbf{x}_{\mathbf{i}}$, se $\operatorname{tg}\left(\alpha_{i}\right) \geq \mathbf{0 , 2 5}$ (valor ajustável na aplicação), tem-se o início de um fonema que recebe um número k. Identifica-se o final de uma fala por duas condições: proximidade do sinal zero (psz) durante um número de elementos (nmez), e inversão da derivada.

Para este processo de cálculo e reconhecimento do inicio e fim de fala cria-se uma nova célula, denominada Célula Neural Artificial Paraconsistente de reconhecimento de sinal (CNAPrs).

1- Entradas: lis - liberado para encontrar início do sinal, psz - proximidade do sinal zero, nmez - número máximo de elementos zerados, $\mathbf{u}_{\mathbf{i}}-$ entrada iésima.

2- Cálculos : $\operatorname{tg}\left(\alpha_{i}\right)=\left(\mathbf{u}_{i+1}-\mathbf{u}_{\mathbf{i}-1}\right) / 3$, se $\operatorname{tg}(\quad$ i $)>0$ e Lis $=\mathbf{S}$ e $\mathbf{u}_{\mathbf{i}}>\mathbf{0}$ então $\mathbf{u}_{\mathbf{i}}=$ elemento inicial, se $\operatorname{tg}\left(\alpha_{\mathbf{i}}\right)<0$ e elemento inicial já encontrado e entraram $\mathbf{n m e z}$ elementos $\leq \mathbf{p s z}$, então $\mathbf{u}_{\mathbf{i}}=$ elemento final, fazer $\mathbf{u}_{\mathbf{r s}}=\mathbf{1}$; caso contrário, $\mathbf{u}_{\mathrm{rs}}=\mathbf{0}$

Sua representação gráfica é apresentada na figura II.8.6, a seguir:

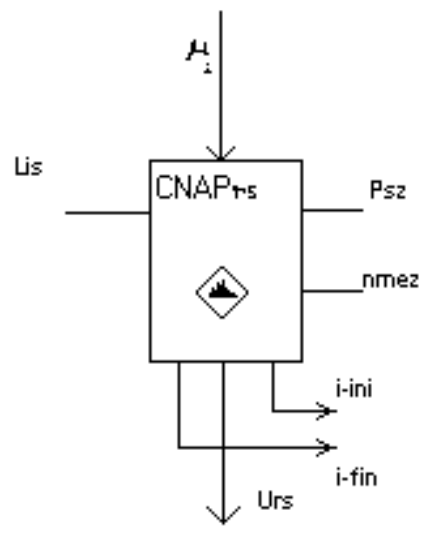

Figura II.8.6 - Célula Neural Artificial Paraconsistente de reconhecimento de sinal 


\section{II.8.7- UNAP's para reconhecimento de padrões:}

Para a obtenção das Unidades Neurais Artificiais Paraconsistentes (UNAP's), associam-se CNAP's de forma a introduzir uma estrutura que se comporte de forma similar ao neurônio. As características do neurônio são:

1- Entradas múltiplas e ponderadas: recebe a informação de vários outros neurônios e apresenta um sinal resultante;

2- Armazenamento: de acordo com o sinal resultante, armazena-o;

3- Saída única: dependendo do sinal de entrada, mesclado com o sinal armazenado, apresenta um resultado na saída. Note que esta saída pode estar conectada a vários outros neurônios;

4- Possibilidade de aprendizado efêmero: no neurônio existe a possibilidade de um armazenamento temporário através de um sinal elétrico, terminada a excitação, o mesmo muda seu estado de acordo com a nova entrada, de forma proporcional a excitação.

É imediato entender que, neste trabalho, UNAP, perceptron e neurônio são apresentações diferentes do mesmo elemento. O objetivo é apresentar uma Rede Neural Artificial Paraconsistente, ou ainda, uma Rede de UNAP's para o reconhecimento de padrão.

Uma característica importante das UNAP's aqui introduzidas é que, ao contrário do cérebro humano que já nasce com o número máximo de neurônios, estas UNAP's apenas passam a existir quando necessário. Durante o processo de aprendizado, o sistema computacional desenvolvido (programa de computador) se encarrega de criar as UNAP's conforme necessário. É necessário então incluir nas UNAP's elementos capazes, através de um simples gerenciamento funcional, de criar novas UNAP's.

Vale ressaltar que, de forma similar ao cérebro humano, as UNAP's devem ter a capacidade de acomodar as suas sinapses (conexões) de acordo com o aprendizado contínuo do sistema.

Outra observação importante é que deve existir um sistema gerenciando o funcionamento das UNAP's. Este gerenciamento é um programa de computador pré- 
existente. No caso do cérebro humano, as funções metabólicas vitais, conexões a órgãos, aos sentidos, e demais funções básicas, praticamente confundem-se com o gerenciamento funcional dos neurônios, que pode ser exercido também pelos próprios neurônios. Portanto, no cérebro humano, até o programa de gerenciamento dos neurônios é parte aprendida, parte inerente. $\mathrm{Na}$ verdade, todo estes gerenciamentos e supervisões dos neurônios ainda não são de domínio humano, sendo que muitos processos são desconhecidos.

Na aplicação aqui desenvolvida, o gerenciamento é externo às UNAP's, cabendo às mesmas apenas armazenar as informações, efetuar operações lógicas e apresentar resultados. O comportamento do sistema que gerencia as UNAP's pode ser alterado através de parâmetros, modificados pela SNAPdep, responsável pela decisão final da Rede.

A aplicação é válida, mesmo considerando-se que se desenvolveu, através de programação convencional, um sistema gerenciador e supervisor das UNAP's. Este sistema consiste em introduzir os elementos nas UNAP's, acionar a criação de novas UNAP's e propagar a informação pela Rede. Os resultados apresentados pelas UNAP's são os responsáveis por nortearem os resultados apresentados pelo sistema.

Segue, então, a apresentação de cada UNAP criada, utilizada nesta aplicação.

\section{II.8.8- Unidade Neural Artificial Paraconsistente de aprendizado e reconhecimento de padrão:}

A Unidade Neural Artificial Paraconsistente de aprendizado e reconhecimento de padrão (UNAParp) tem como finalidade receber um sinal analógico e armazená-lo, permitindo a comparação de padrões. Tem também a capacidade de apresentar algumas saídas complementares, necessárias à composição da Rede, que é expandida a cada processo de aprendizagem e reconhecimento de padrão. Neste trabalho, esta UNAP serve para armazenar os elementos de um fonema e o próprio fonema.

A UNAParp é composta por:

1- uma CNAPadm, com a finalidade de aprender, desaprender ou memorizar um padrão; 
2- uma CNAPClsmax, com a finalidade de somente liberar o reconhecimento de um padrão quando a UNAP não estiver programada nem para aprender nem para desaprender;

3- uma CNAPCo, para complementar o valor obtido da saída da CNAPlsmax;

4- uma CNAPapm, que libera a passagem do sinal de reconhecimento de um padrão. Como esta célula é acionada pela CNAPCo, a UNAP somente reconhece um padrão, caso não esteja habilitada nem para aprender, nem para desaprender um padrão;

5- uma CNAPrp, que compara o padrão aprendido pela CNAPadm com o padrão apresentado na entrada;

6- uma $C N A P d c$, que identifica a necessidade ou não da criação de uma nova camada;

A representação gráfica está apresentada na figura II.8.7 a seguir:

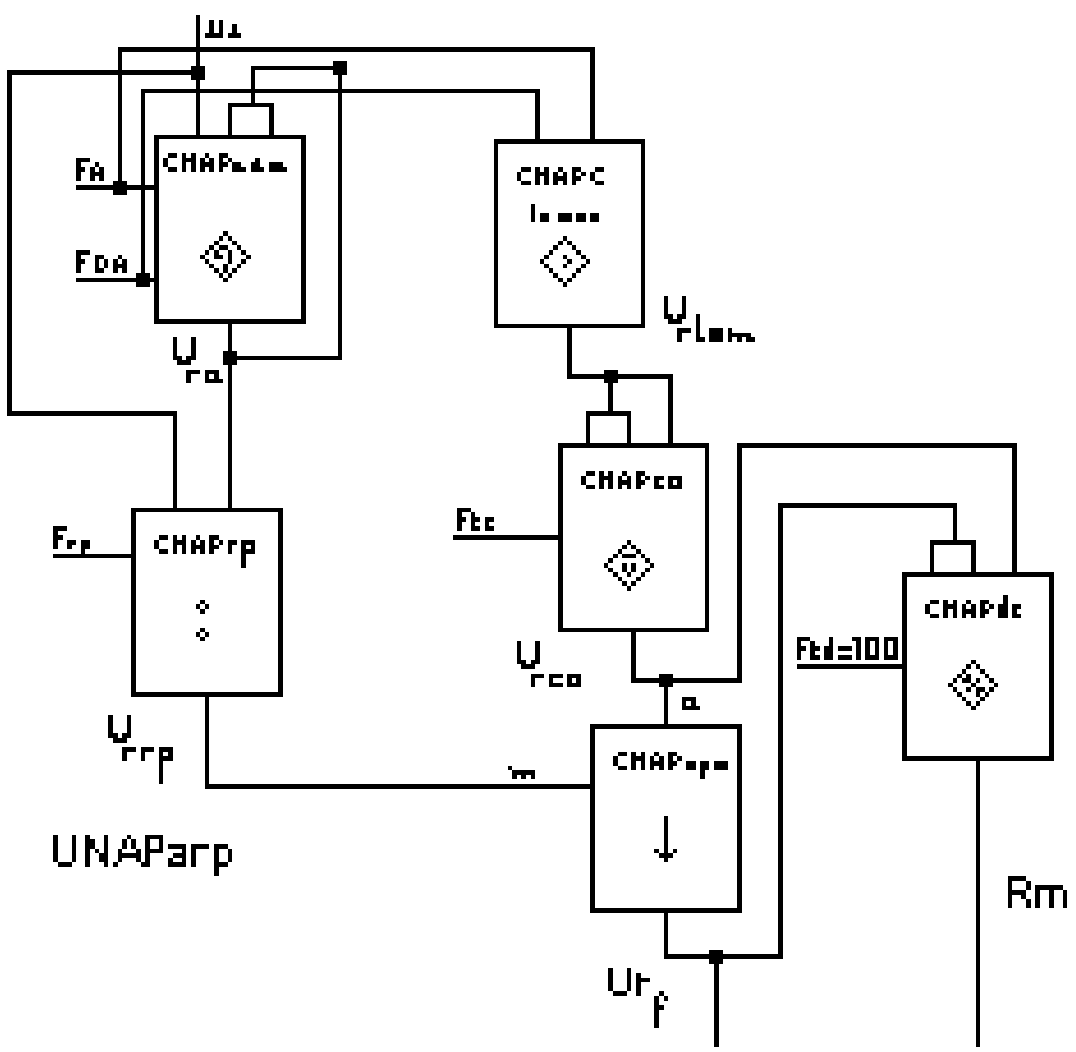

Figura II.8.7 - UNAParp - Unidade Neural Artificial Paraconsistente de aprendizado e reconhecimento de padrão

Entradas desta UNAP:

1- fator de aprendizado $\left(\mathbf{F}_{\mathbf{a}}\right)$ : que no momento de sua criação é 1;

2- fator de desaprendizado $\left(\mathbf{F}_{\mathbf{d a}}\right)$ : que no momento de sua criação é 0;

3- fator de contradição (Ft $\mathbf{c}_{\mathbf{c}}$ ): que define o limite de complementação da CNAPco; 
4- fator de reconhecimento de padrão (Frp): que permite identificar o grau de reconhecimento do padrão, definindo automaticamente os limites para $U_{r f}=\mathbf{0}, \mathbf{1}$ ou um valor proporcional ao reconhecimento;

5- fator de decisão $\left(\mathbf{F t}_{\mathbf{d}}\right)$ : que nesta UNAP recomenda-se 1, fazendo com que o reconhecimento máximo $\left(\mathbf{R}_{\mathbf{m}}\right)$ somente seja 1 com as entradas da CNAPdc iguais a 1 . Caso contrário, a saída será 1/2 (indefinido), indicando que deve ser criada uma nova camada, pois o reconhecimento não foi máximo.

Saídas desta UNAP:

1- saída resultante aprendida $\left(\mathbf{U}_{\mathbf{r a}}\right)$ : que é o padrão armazenado pela UNAParp, inicialmente é $\mathbf{1 / 2}$ (indefinido);

2- saída resultante final $\left(\mathbf{U}_{\mathbf{r f}}\right)$ : que indica o quanto foi reconhecido do sinal aplicado na entrada;

3- reconhecimento máximo $\left(\mathbf{R}_{\mathbf{m}}\right)$ : que indica que o reconhecimento do sinal foi de 100\%, não sendo necessário a criação de uma nova camada.

Durante o funcionamento da UNAParp, ainda geram-se os resultados:

1 - $\mathbf{O K}=$ 'S' - indica que a UNAParp existe;

2- Sinapses: indicam as conexões entre as diversas UNAP's. As UNAParp da camada de entrada e apontam para uma ou mais UNAParp da camada seguinte, que aponta para uma UNAPcaarp da camada seguinte.

É importante observar que a UNAParp pode ser representada conforme a descrição a seguir:

UNAParp $=\left[O K,\left(F_{a}, F_{d a}, F_{c}, F_{r p}, F_{d}\right), U_{r a}, U_{r f}, R_{m},\left(\right.\right.$ sinapse $_{1}, \operatorname{sinapse}_{2}, \ldots$, sinapse $\left.\left._{n}\right)\right]<-U_{i}$

Ou seja, uma ênupla resultante da aplicação de uma entrada $\mathbf{U}_{\mathbf{i}}$, dados os parâmetros $\left(\mathbf{F}_{\mathbf{a}}, \mathbf{F}_{\text {da }}, \mathbf{F t}_{\mathbf{c}}, \mathbf{F}_{\mathbf{r p}}, \mathbf{F t}_{\mathbf{d}}\right)$. 


\section{II.8.9- Unidade Neural Artificial Paraconsistente de conexão analítica, aprendizado e reconhecimento de padrão:}

A Unidade Neural Artificial Paraconsistente de conexão analítica, aprendizado e reconhecimento de padrão (UNAPcaarp) agrupa elementos da camada anterior, aprende o sinal referente a este agrupamento e aponta para um rótulo. $\mathrm{Na}$ aplicação prática, ela agrupa fonemas e rotula este agrupamento como sendo uma palavra.

A UNAPcaarp é composta por:

1- várias CNAPca's, que identificam as várias sinapses das camadas anteriores, decidindo de acordo com o resultado de camadas anteriores;

2- várias CNAPClsmax's, que fornecem na saída o maior grau de contradição encontrado nas entradas;

3- uma CNAPadm, que aprende, desaprende ou memoriza um padrão;

4- uma CNAPClsmax, que libera o reconhecimento de um padrão quando a UNAP não está programada nem para aprender nem para desaprender;

5- uma CNAPCo, que complementa o valor obtido da saída da CNAPlsmax;

6- uma CNAPp, que libera a passagem do sinal de reconhecimento de um padrão. Como esta célula é acionada pela CNAPco, o UNAP somente reconhece um padrão caso não esteja habilitada nem para aprender, nem para desaprender um padrão;

7- uma CNAPrp, que serve para comparar o padrão aprendido pela CNAPadm com o padrão apresentado na entrada;

Na figura II.8.8, apresentada a seguir, encontra-se a representação gráfica: 


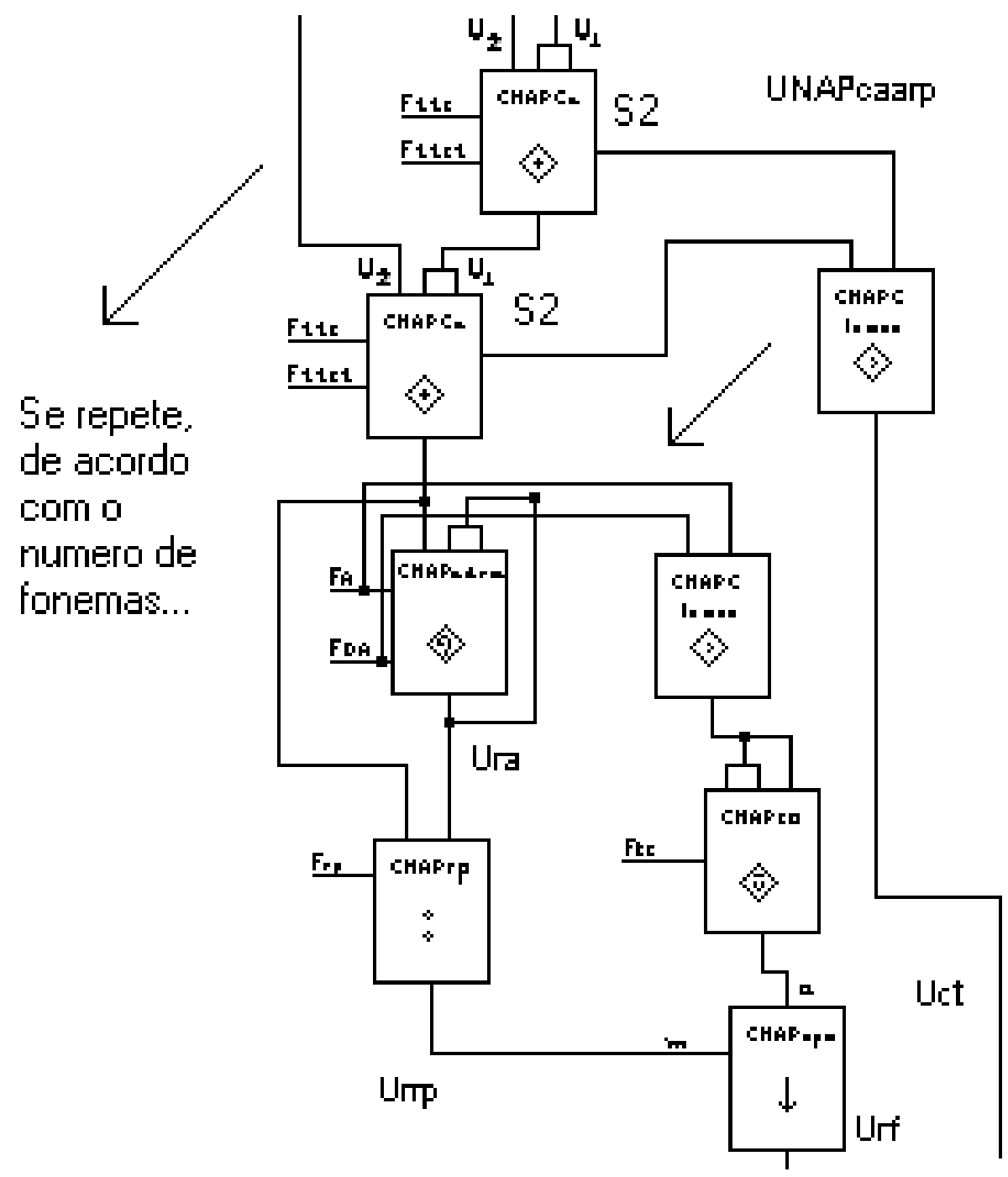

Figura II.8.8 - UNAPcaarp - Unidade Neural Artificial Paraconsistente de conexão analítica, aprendizado e reconhecimento de padrão

Entradas desta UNAP:

1- fator de tolerância à certeza $\left(\mathbf{F t}_{\mathbf{t c}}\right)$ : que define os limites para a identificação de 1 e 0 para todas as CNAPca's;

2- fator de tolerância à contradição $\left(\mathbf{F t}_{\mathbf{t c t}}\right)$ : que define os limites para a identificação de 100 e 0 para todas as CNAPca's;

3- fator de aprendizado $\left(F_{a}\right)$ : que no momento de sua criação é 1;

4- fator de desaprendizado ( $\left.F_{d a}\right)$ : que no momento de sua criação é 0 ;

5- fator de contradição $\left(F t_{c}\right)$ : que define o limite de complementação da CNAPco;

6- fator de reconhecimento de padrão $\left(\mathbf{F}_{\mathbf{r p}}\right)$ : que identifica o grau de reconhecimento do padrão, definindo automaticamente os limites para $\mathbf{U}_{\mathbf{r f}}=\mathbf{0}, \mathbf{1}$ ou um valor proporcional ao reconhecimento; 
7- fator de decisão $\left(\mathbf{F t}_{\mathbf{d}}\right)$ : que define o nível de reconhecimento do sinal;

8- CNAPca: que indica todos os fonemas que compõem a palavra em ordem, testados pela CNAPca para o reconhecimento.

Saídas desta UNAP:

1- saída resultante aprendida (Ura): que é o padrão armazenado pela UNAParp, sendo inicialmente $1 / 2$ (indefinido);

2- saída resultante final $\left(\mathbf{U}_{\mathbf{r f}}\right)$ : que indica o quanto foi reconhecido o sinal aplicado na entrada. Quando se cria a UNAPcaarp, vale 1; quando a reinicia para reconhecimento, vale -1 , indicando que se considera o primeiro reconhecimento como sendo a $\mathbf{U}_{\mathbf{r f}}$ de reconhecimento da palavra;

3- saída de contradição $\left(\mathbf{U}_{\mathbf{c t}}\right)$ que indica o grau de contradição das entradas.

A UNAPcaarp é uma chamada cíclica da UNAParp, fazendo sempre os cálculos:

1- $\quad u_{1 c}=1-U r f, G_{c t}=U 2+u_{1 c}-1, G_{c}=U 2-u_{1 c}, u r=\left(G_{c}+1\right) / 2$;

2- $\quad$ se $\left|\mathbf{G}_{\mathbf{c}}\right|>\mathbf{F t}_{\text {tc }}$, então $\mathbf{U}_{\mathbf{r f}}=\mathbf{u}_{\mathbf{r}} \mathbf{e} \mathbf{U}_{\mathbf{c t}}=\mathbf{0} ; \operatorname{Se}\left|\mathbf{G}_{\mathbf{c t}}\right|>\mathbf{F t}_{\text {tct }}$ e $\left|\mathbf{G}_{\mathbf{c t}}\right|>\left|\mathbf{G}_{\mathbf{c}}\right|$, então $\mathbf{S}_{\mathbf{1}}=\mathbf{u}_{\mathrm{r}}$ e $\mathbf{S}_{\mathbf{2}}=\left|\mathbf{G}_{\mathrm{ct}}\right|$, caso contrário, $\mathbf{S}_{\mathbf{1}}=\mathbf{1} / \mathbf{2}$ e $\mathbf{S}_{\mathbf{2}}=\mathbf{0}$

Durante o funcionamento da UNAPcaarp, ainda são gerados os resultados:

$1-O K=$ ' $S$ ' - indica que a UNAPcaarp existe.

2- Sinapses: palavra aprendida.

Nota-se que a UNAPcaarp pode ser implementada através de um processo cíclico, podendo ser representada pela UNAPcaarpc (cíclica). Na figura II.8.9 encontrase a representação gráfica: 


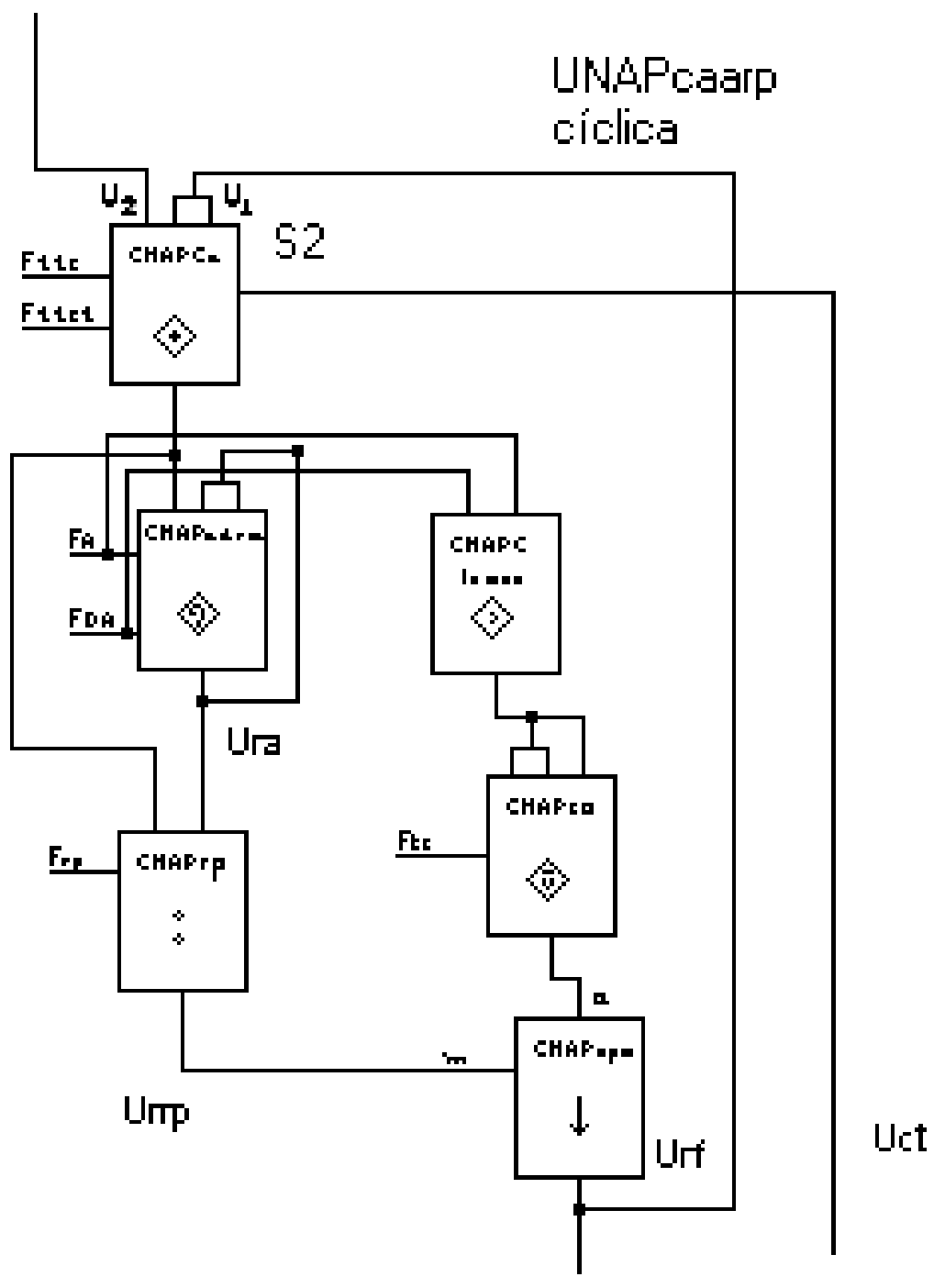

Figura II.8.9 - UNAPcaarpc - Unidade Neural Artificial Paraconsistente de conexão analítica, aprendizado e reconhecimento de padrão cíclica. 


\section{II.8.10- Unidade Neural Artificial Paraconsistente de maximização (UNAPmax):}

A Unidade Neural Artificial Paraconsistente de maximização (UNAPmax) tem como finalidade reconhecer, numa seqüência de valores, qual o valor máximo entre eles, armazenando-o.

A UNAPmax é composta por:

1- uma CNAPClsmax, que identifica quando na entrada existir um sinal maior do que o já aprendido;

2- uma CNAPrp, que gera um sinal diferente de 100\%, sempre que na entrada surgir um valor diferente do já aprendido. Nota-se que, se o valor é diferente, significa que é maior que o já aprendido;

3- uma CNAPCO, que apresenta 0 na sua saída se o sinal for $100 \%$ reconhecido, e um valor diferente de 0 , se o sinal não for $100 \%$ reconhecido;

4- uma CNAPapm, que apresenta o resultado da CNAPco na sua saída, quando o reconhecimento (sinal de controle a) for $\mathbf{1}$; neste caso, a sua saída é $\mathbf{0}$ (complementação de 1, também introduzido na CNAPco); neste caso, a CNAPadm mantém o último valor aprendido. Caso o reconhecimento não seja 100\% (o valor entrado difere do gravado e é maior que o mesmo) na saída da CNAPp tem-se 1/2 (independentemente da entrada $\mathrm{m}$ ), que é o fator de aprendizado para a CNAPadm; 5- uma CNAPadm, que armazena o valor máximo entre todas as entradas apresentadas.

A representação gráfica encontra-se na figura II.8.10 a seguir: 


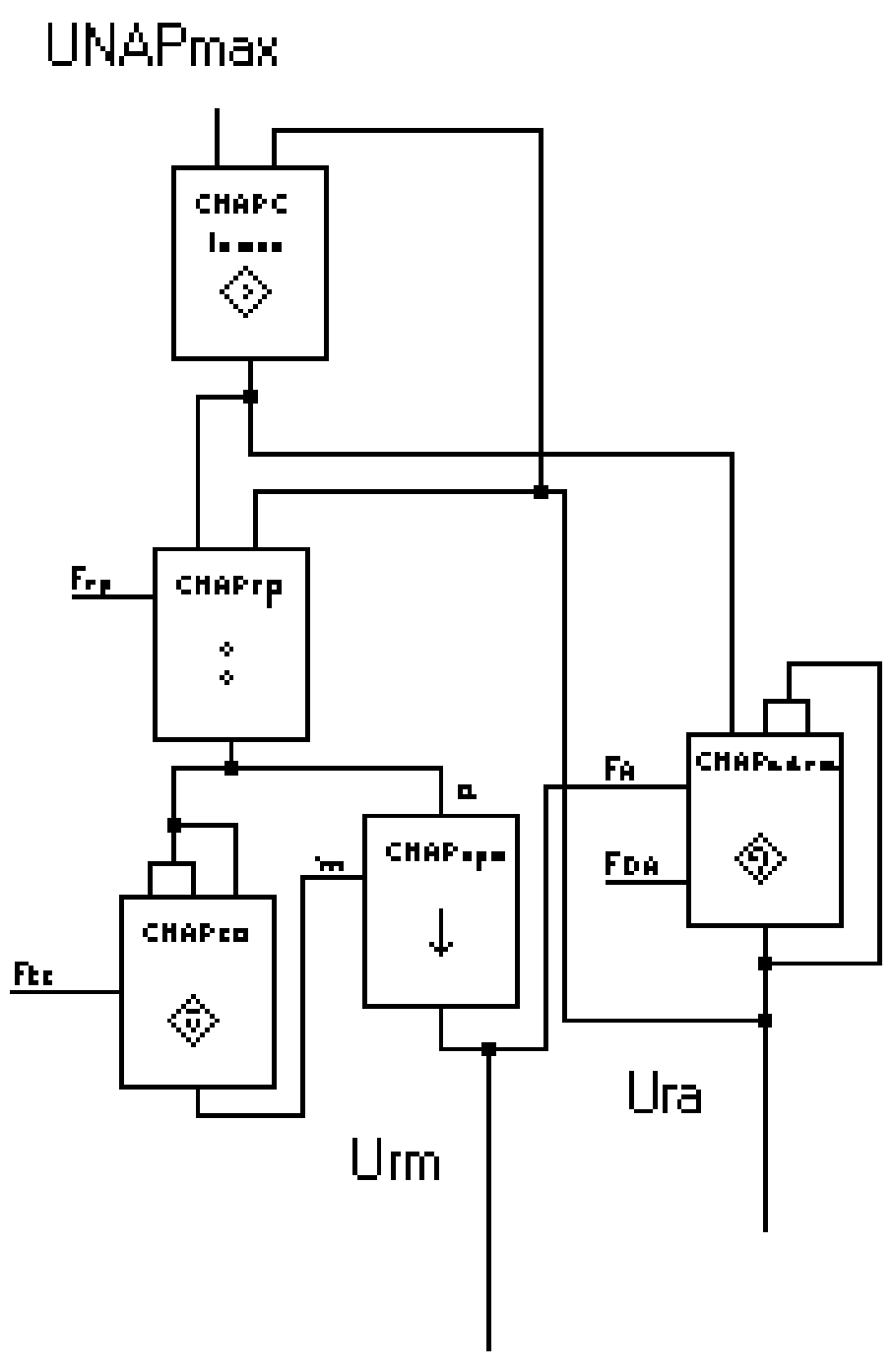

Figura II.8.10 - UNAPmax - Unidade Neural Artificial Paraconsistente de maximização

Entradas desta UNAP:

1- fator de aprendizado $\left(\mathbf{F}_{\mathbf{a}}\right)$ : que no momento de sua criação é $\mathbf{1}$;

2- fator de desaprendizado $\left(\mathbf{F}_{\mathbf{d a}}\right)$ : que no momento de sua criação é $\mathbf{0}$;

3- fator de contradição $\left(\mathbf{F t}_{\mathbf{c}}\right)$ : que define o limite de complementação da CNAPco;

4- fator de reconhecimento de padrão $\left(\mathbf{F}_{\mathbf{r p}}\right)$ : que identifica o grau de reconhecimento do padrão, definindo automaticamente os limites para $\mathbf{U}_{\mathbf{r f}}=\mathbf{0}, \mathbf{1}$ ou um valor proporcional ao reconhecimento.

Saídas desta UNAP:

1- saída resultante aprendida $\left(\mathbf{U}_{\mathbf{r a}}\right)$ : que é o padrão armazenado pela UNAPmax, que inicialmente é 0 (sem padrão); 
2- saída de reconhecimento de máximo $\left(\mathbf{U}_{\mathbf{r m}}\right)$ : que indica que o elemento atual foi reconhecido como máximo (1/2) ou não (0).

\section{II.8.11- Unidade Neural Artificial Paraconsistente de minimização:}

A Unidade Neural Artificial Paraconsistente de minimização (UNAPmin) tem como finalidade reconhecer, numa seqüência de valores, qual o valor mínimo entre eles, armazenado-o.

A UNAPmin é composta por:

1- uma CNAPClsmin, que identifica quando na entrada existir um sinal menor do que o já aprendido;

2- uma CNAPrp, que gera um sinal diferente de 100\%, sempre que na entrada surgir um valor diferente do já aprendido. Note que se o valor é diferente, significa que é menor que o já aprendido;

3- uma CNAPco, que apresenta 0 na sua saída, se o sinal for 100\% reconhecido, e um valor diferente de $\mathbf{0}$, se o sinal não for $100 \%$ reconhecido;

4- uma CNAPapm, que apresenta o resultado da CNAPCo na sua saída, quando o reconhecimento ( (complementação de 1, também introduzido na CNAPco); neste caso a CNAPadm mantém o último valor aprendido. Caso o reconhecimento não seja 100\% (o valor entrado difere do gravado e é menor que o mesmo) na saída da CNAPp tem-se 1/2 (independentemente da entrada $\mathbf{m}$ ), que é o fator de aprendizado para a CNAPadm; 5- uma CNAPadm, que armazena o valor mínimo entre todas as entradas apresentadas;

A representação gráfica encontra-se na figura II.8.11 a seguir: 


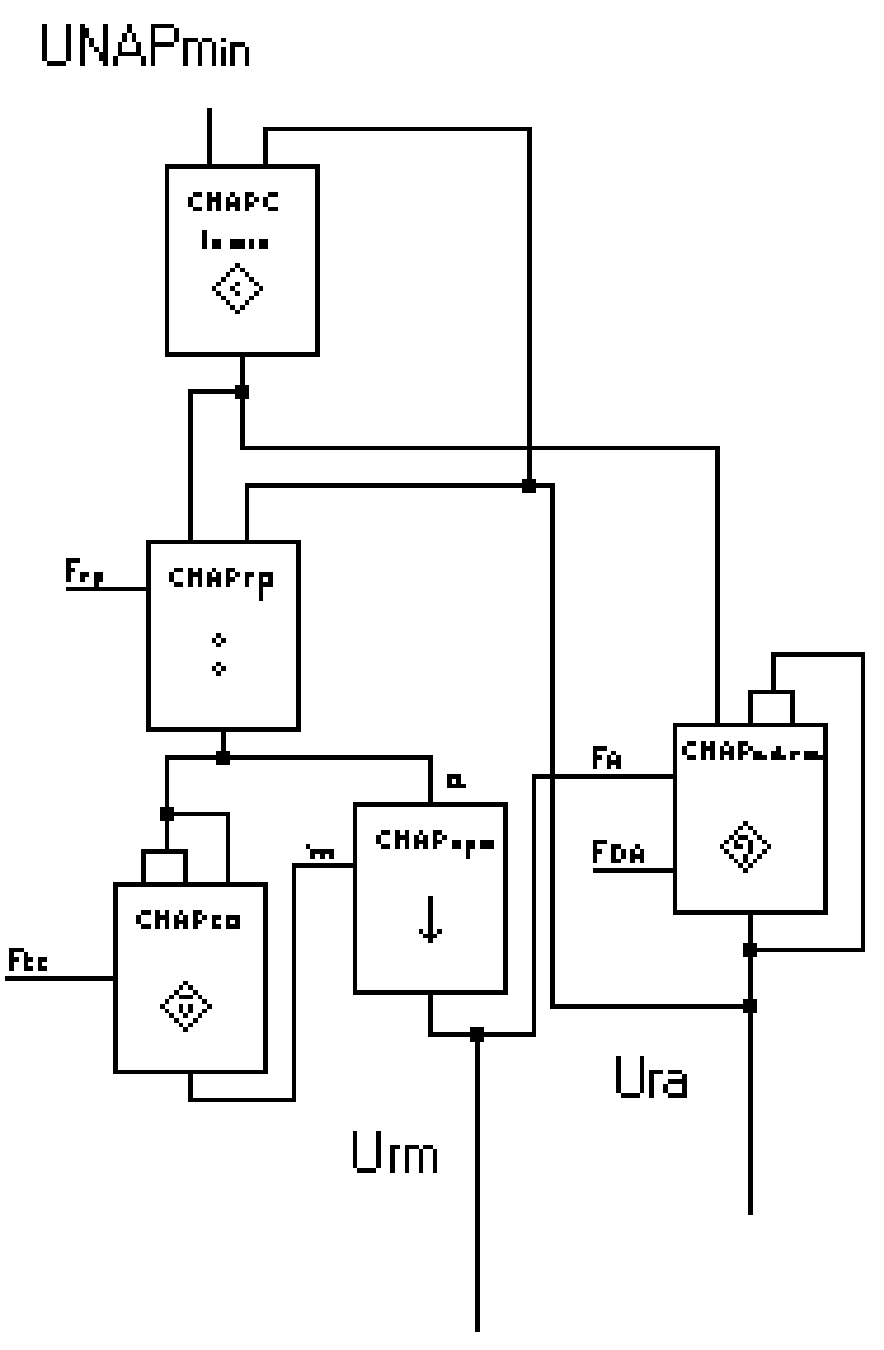

Figura II.8.11 - UNAPmin - Unidade Neural Artificial Paraconsistente de minimização

Entradas desta UNAP:

1- fator de aprendizado $\left(\mathbf{F}_{\mathbf{a}}\right)$ : que no momento de sua criação é 1;

2- fator de desaprendizado $\left(\mathbf{F}_{\mathbf{d a}}\right)$ : que no momento de sua criação é $\mathbf{0}$;

3- fator de contradição ( $\left.\mathbf{F t}_{\mathbf{c}}\right)$ : que define o limite de complementação da CNAPco;

4- fator de reconhecimento de padrão $\left(\mathbf{F}_{\mathbf{r p}}\right)$ : identifica o grau de reconhecimento do padrão, definindo automaticamente os limites para $\mathbf{U}_{\mathbf{r f}}=\mathbf{0}, \mathbf{1}$ ou um valor proporcional ao reconhecimento.

Saídas desta UNAP:

1- saída resultante aprendida $\left(\mathbf{U}_{\text {ra }}\right)$ : que é o padrão armazenado pela UNAPmax, que inicialmente é $\mathbf{1}$ (sem padrão); 
2- saída de reconhecimento de mínimo $\left(\mathbf{U}_{\mathbf{r m}}\right)$ : que indica que o elemento atual foi reconhecido como mínimo (1/2) ou não (0).

\section{II.8.12- Unidade Neural Artificial Paraconsistente de contradição entre máximos}

A Unidade Neural Artificial Paraconsistente de contradição entre máximos (UNAPcmax) tem por finalidade reconhecer, numa seqüência de valores, se existe mais de um valor máximo, calculando o valor de certeza para cada máximo e a contradição entre eles.

\section{A UNAPcmax é composta por:}

1- uma CNAPrp, que compara um resultado obtido, com o valor de máximo já armazenado;

2- uma CNAPCo na entrada, que libera a comparação, somente se o elemento que se está comparando não é o próprio elemento que determinou o máximo, eliminando assim este elemento da verificação. Isto é óbvio, pois não se pode considerar inconsistente a comparação entre um elemento e ele mesmo;

3- uma CNAPp, que libera a comparação caso o elemento não seja o próprio máximo;

4- uma CNAPca, que compara o último resultado armazenado com o próximo, apresentando duas respostas: uma que indica a certeza em apontar um ou mais elementos como resposta final, e uma que indica o nível de contradição entre as palavras testadas. Nota-se que, nesta CNAPca, o $\mathbf{U}_{2}$ não se inverte antes de introduzir-se como entrada;

5- uma CNAPadm, que armazena o resultado obtido para operação futura. Particularmente, o valor inicial é 0;

6- uma CNAPCo, que inverte o sinal de certeza no resultado obtido. Este valor é proporcional ao número de elementos contados.

A seguir, na figura II.8.12, tem-se a representação gráfica desta UNAP: 


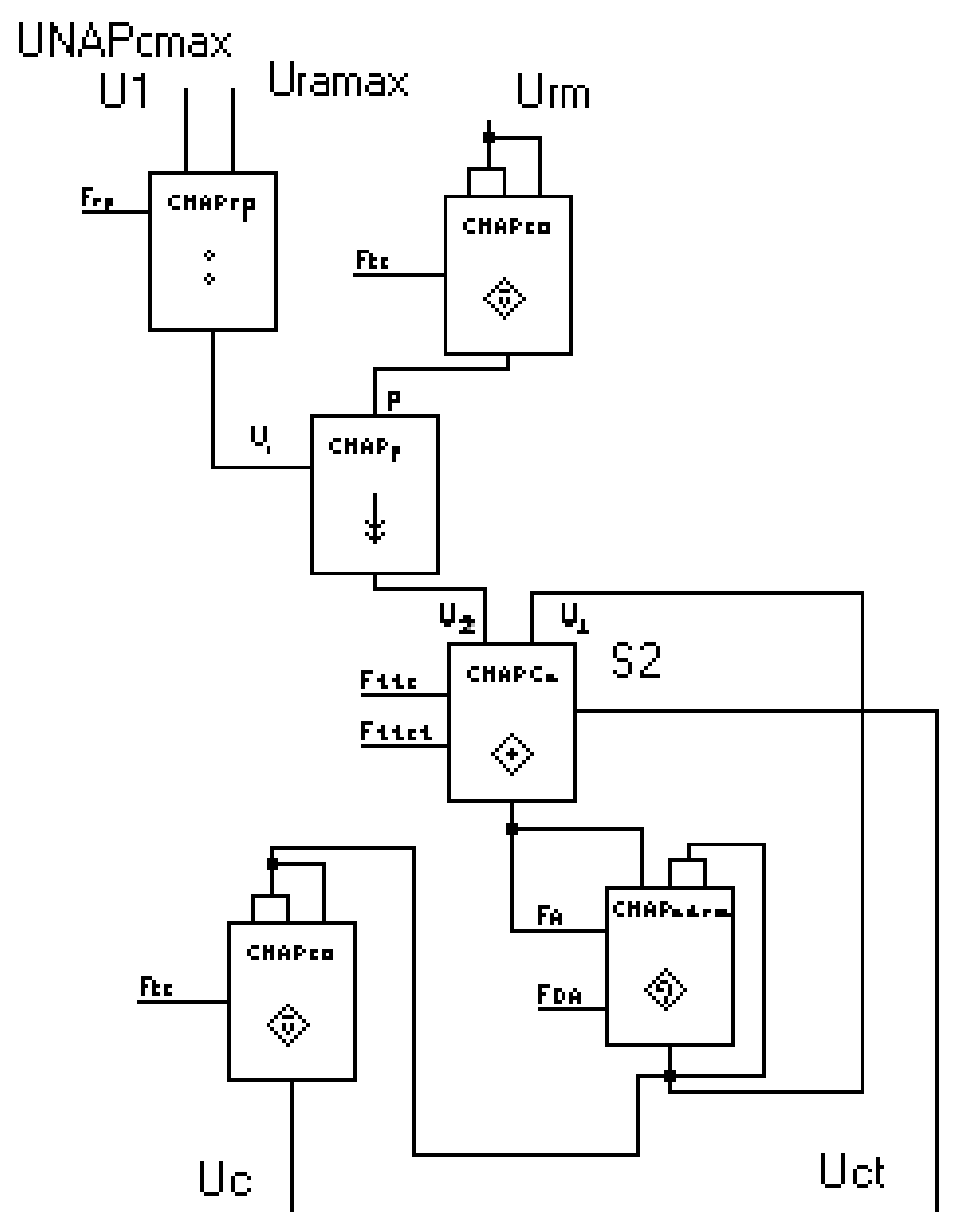

Figura II.8.12 - UNAPcmax - Unidade Neural Artificial Paraconsistente de contradição entre máximos

Entradas desta UNAP:

1- fator de aprendizado $\left(\mathbf{F}_{\mathbf{a}}\right)$ : que no momento de sua criação é 1;

2- fator de desaprendizado $\left(\mathbf{F}_{\mathbf{d a}}\right)$ : que no momento de sua criação é $\mathbf{0}$;

3- fator de contradição ( $\left.\mathbf{F t}_{\mathbf{c}}\right)$ : que define o limite de complementação da CNAPco;

4- fator de reconhecimento de padrão $\left(\mathbf{F}_{\mathbf{r p}}\right)$ : que identifica o grau de reconhecimento do padrão, definindo automaticamente os limites para $\mathbf{U}_{\mathbf{r f}}=\mathbf{0}, \mathbf{1}$ ou um valor proporcional ao reconhecimento;

5- fator de tolerância à certeza $\left(\mathbf{F t}_{\mathbf{t c}}\right)$ : que define os limites para a identificação de $\mathbf{1}$ e 0 para todas as CNAPca;

6- fator de tolerância à contradição $\left(\mathbf{F t}_{\mathbf{t c t}}\right)$ : que define os limites para a identificação de 1 e 0 para todas as CNAPca.

Saídas desta UNAP: 
1- saída resultante de certeza $\left(\mathbf{U}_{\mathbf{c}}\right)$ : que indica qual a certeza nos elementos apontados como resultado. Vale 1 caso exista somente um resultado;

2- saída resultante de contradição $\left(\mathbf{U}_{\mathbf{c t}}\right)$ : que indica qual a contradição nos elementos apontados como resultado. Vale $\mathbf{0}$ caso exista somente um resultado.

\section{II.8.13- Unidade Neural Artificial Paraconsistente de contradição entre mínimos}

A Unidade Neural Artificial Paraconsistente de contradição entre mínimos (UNAPcmin) tem por finalidade reconhecer, numa seqüência de valores, se existe mais de um valor mínimo, calculando o valor de certeza para cada mínimo e a contradição entre eles.

\section{A UNAPcmin é composta por:}

1- uma CNAPrp, que compara um resultado obtido, com o valor de mínimo já armazenado;

2- uma CNAPCo na entrada, que libera a comparação, somente se o elemento que se está comparando não é o próprio elemento que determinou o mínimo, eliminando assim este elemento da verificação. Isto é óbvio, pois não se pode considerar inconsistente a comparação entre um elemento e ele mesmo;

2- uma CNAPapm, que libera a comparação caso o elemento não seja o próprio mínimo;

3- uma CNAPca, que compara o último resultado armazenado com o próximo, apresentando duas respostas: uma que indica a certeza em apontar um ou mais elementos como resposta final, e uma que indica o nível de contradição entre as palavras testadas. Nota-se que, nesta CNAPca, não se inverte o $\mathbf{U}_{\mathbf{2}}$ antes de introduzir-se como entrada;

4- uma CNAPadm, que armazena o resultado obtido para operação futura. Particularmente, o valor inicial é 0;

5- uma CNAPCO, que inverte o sinal de certeza no resultado obtido. Este valor é proporcional ao número de elementos contados.

A representação gráfica encontra-se na figura II.8.13 a seguir: 


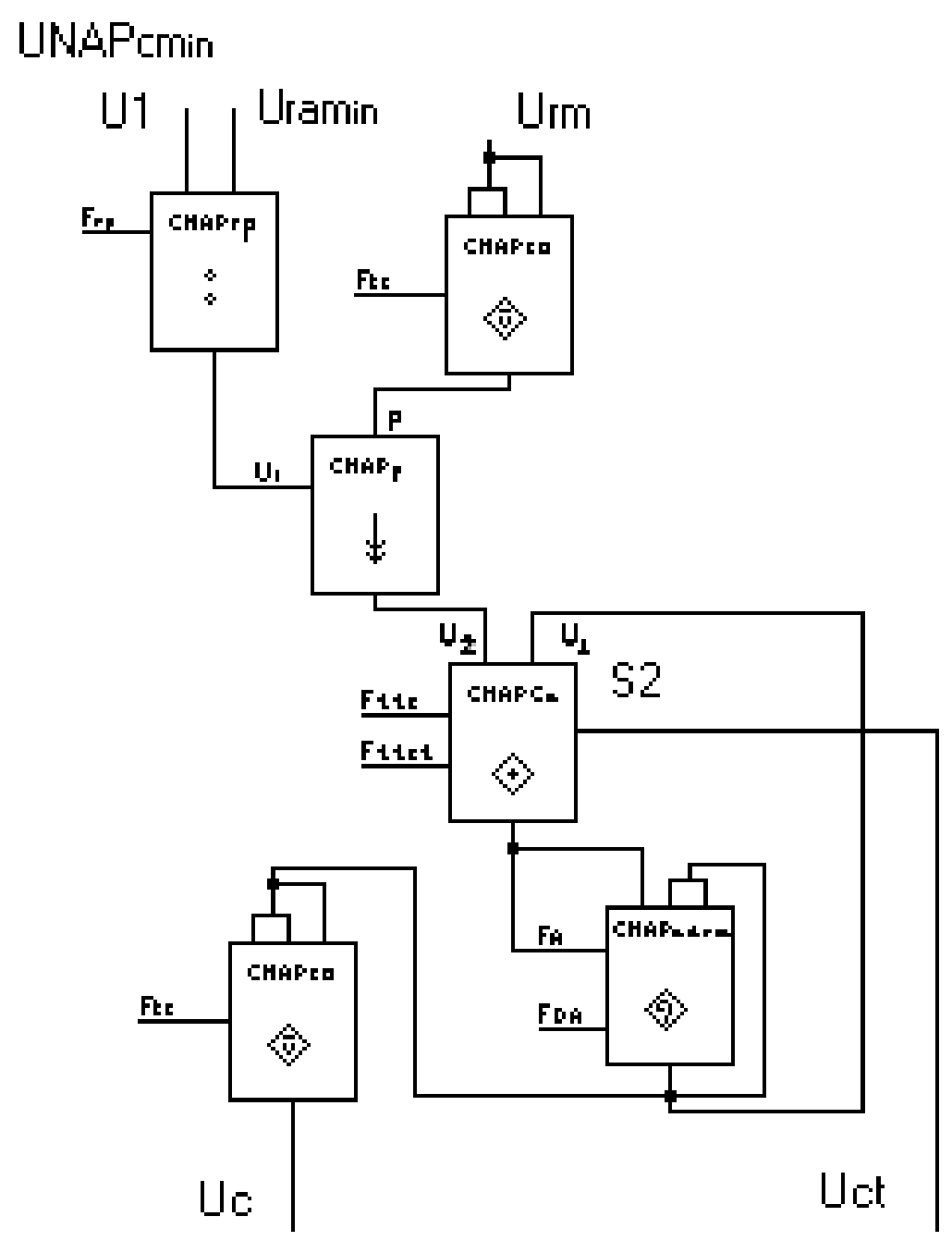

Figura II.8.13 - UNAPcmin - Unidade Neural Artificial Paraconsistente de contradição entre mínimos.

Entradas desta UNAP:

1- fator de aprendizado $\left(\mathbf{F}_{\mathbf{a}}\right)$ : que no momento de sua criação é 1;

2- fator de desaprendizado $\left(\mathbf{F}_{\mathbf{d a}}\right)$ : que no momento de sua criação é $\mathbf{0}$;

3- fator de contradição ( $\mathbf{F t}_{\mathbf{c}}$ ): define o limite de complementação da CNAPco;

4- fator de reconhecimento de padrão $\left(\mathbf{F}_{\mathbf{r p}}\right)$ : que identifica o grau de reconhecimento do padrão, definindo automaticamente os limites para $\mathbf{U}_{\mathbf{r f}}=\mathbf{0}, \mathbf{1}$ ou um valor proporcional ao reconhecimento;

5- fator de tolerância à certeza $\left(\mathbf{F t}_{\mathbf{t c}}\right)$ : que define os limites para a identificação de $\mathbf{1}$ e 0 para todas as CNAPca's;

6- fator de tolerância à contradição $\left(\mathbf{F t}_{\mathbf{t c t}}\right)$ : que define os limites para a identificação de $\mathbf{1}$ e $\mathbf{0}$ para todas as CNAPca's. 
Saídas desta UNAP:

1- saída resultante de certeza $\left(\mathbf{U}_{\mathbf{c}}\right)$ : que indica qual a certeza nos elementos apontados como resultado. Vale 1, caso exista somente um resultado; 2- saída resultante de contradição $\left(\mathbf{U}_{\mathbf{c t}}\right)$ : que indica qual a contradição nos elementos apontados como resultado. Vale $\mathbf{0}$ caso exista somente um resultado.

\section{II.8.14- SNAP's para reconhecimento de padrões:}

Os Sistemas Neurais Artificiais Paraconsistentes nada mais são do que associações das Unidades Neurais Artificiais Paraconsistentes. Esta associação é feita de forma a se obter um resultado único, a partir dos resultados parciais de cada Unidade. Neste trabalho, utiliza-se apenas um SNAP: O Sistema Neural Artificial Paraconsistente de decisão e execução de processos. Sua finalidade é apresentar os resultados obtidos a partir da análise dos resultados da penúltima camada da Rede, além de definir qual procedimento será realizado, caso exista inconsistência, contradição, paracompleteza, indefinição ou outra situação que não represente um resultado objetivo. Estes resultados são: identificação do reconhecimento máximo (UNAPmax), identificação do reconhecimento mínimo (UNAPmin), que se fazem na primeira etapa; cálculo do grau de certeza e de contradição do reconhecimento máximo (UNAPcmax) e cálculo do grau de certeza e de contradição do reconhecimento mínimo (UNAPcmin), na segunda etapa. Usam-se também duas CNAPapm, cuja finalidade é liberar os sinais máximos e mínimos para a segunda etapa do SNAPdep. Vale ressaltar que é possível suprimir esta célula caso se opere de forma cíclica, utilizando um processo por vez.

A representação gráfica está apresentada na figura II.8.14 a seguir: 


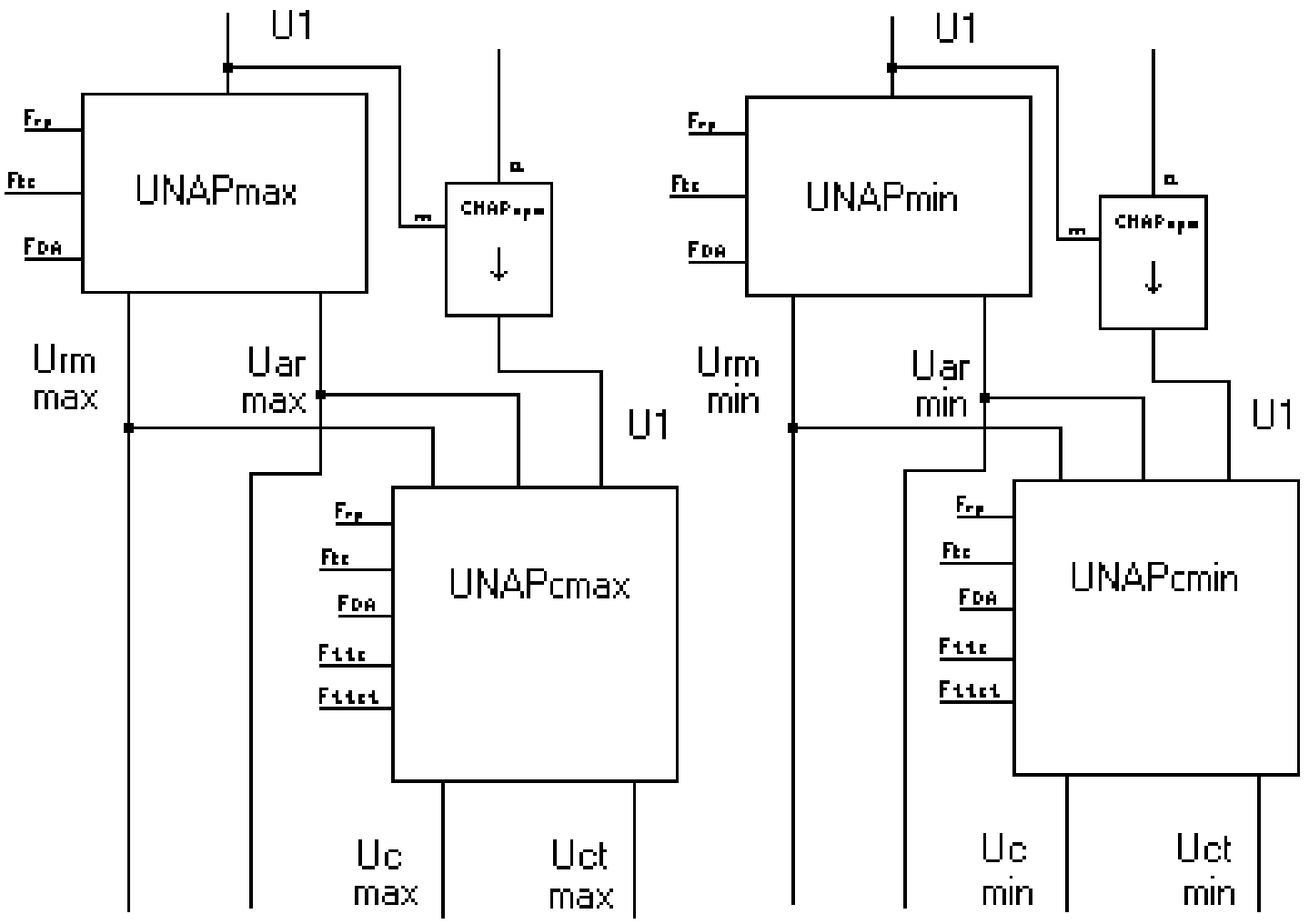

Figura II.8.14 - SNAPdep - Sistema Neural Artificial Paraconsistente de decisão e execução de processos.

Nota-se que este sistema apresenta como saídas:

1- $\mathbf{U}_{\text {rmmax }}$ : indica se foi reconhecido um sinal de máximo;

2- $\mathbf{U}_{\text {armax}}$ : apresenta o valor do sinal de máximo reconhecido;

3- $\mathbf{U}_{\text {cmax }}$ : grau de certeza do sinal de máximo;

4- $\mathbf{U}_{\text {ctmax }}$ : graus de contradição do sinal de máximo;

5- $\mathbf{U}_{\text {rmmin: }}$ indica se foi reconhecido um sinal de mínimo;

6- $\mathbf{U}_{\text {armin }}$ : apresenta o valor do sinal de mínimo reconhecido;

7- $\mathbf{U}_{\text {cmin }}$ : grau de certeza do sinal de mínimo;

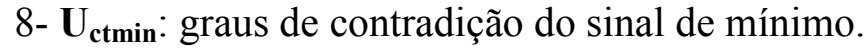

Utilizam-se estes sinais para determinar o processo a executar-se. Para descrever um algoritmo geral de uma Rede Neural artificial, define-se um "NEURÔNIO 
ARTICIAL" que armazenará o elemento do sinal a ser aprendido. A partir do processo definido acima, monta-se o algoritmo da figura II.8.15 a seguir:

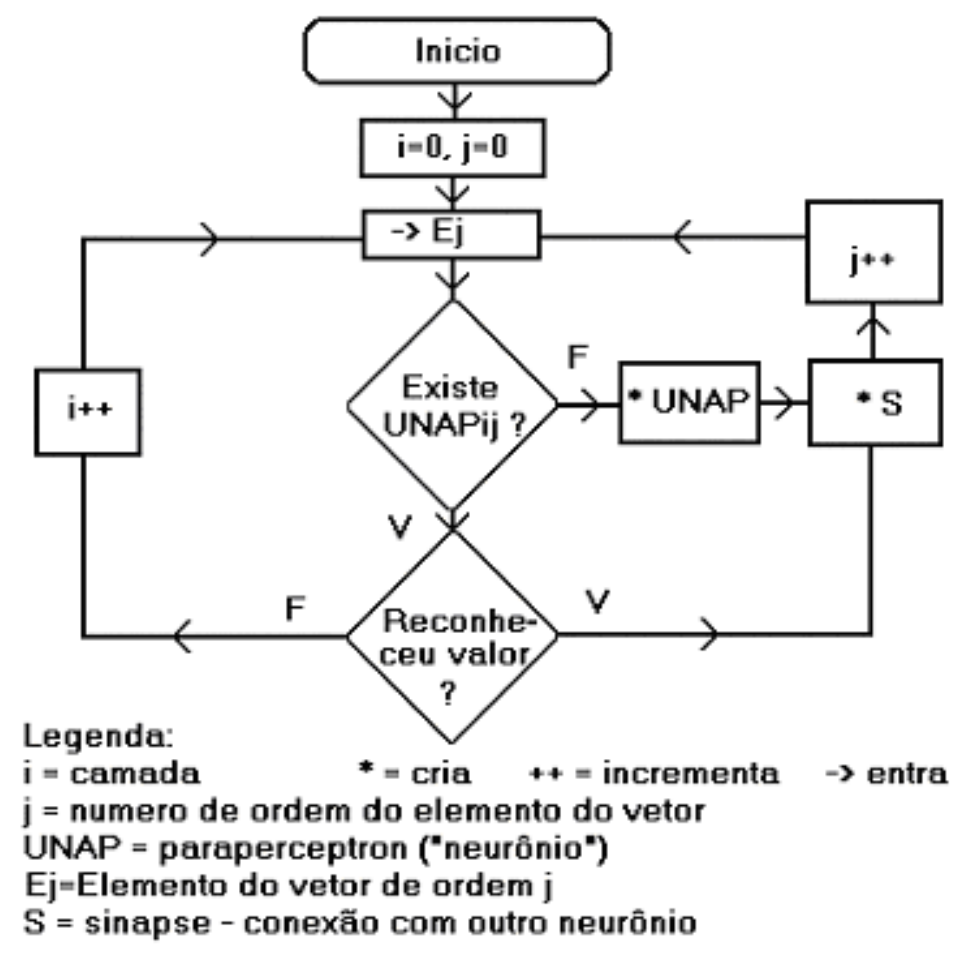

Figura II.8.15 - Fluxograma funcional da Rede.

\section{II.8.15- Considerações finais:}

Como se pode constatar, as RNAP's tornam-se extremamente versáteis pelo fato de possuírem elementos facilmente adaptáveis. Estas adaptações podem seguir as necessidades de cada aplicação. A criação de um sistema multicamadas paraconsistente permite que se implementem sistemas complexos que podem resolver problemas dos mais variados tipos. No próximo capítulo são apresentados os elementos da Rede que foram especialmente criados para o desenvolvimento deste trabalho. 


\section{II.9. Criação das Unidades Neurais Artificiais Paraconsistentes para aprendizado e reconhecimento das constelações fônicas (UNAParcf).}

\section{II.9.1- Considerações iniciais:}

Conforme apresentado em capítulos anteriores, as Unidades Neurais Artificiais Paraconsistentes são compostas por Células Neurais Artificiais Paraconsistentes. Sendo assim, é necessário que se apresente as Células que foram criadas, exclusivamente para esta aplicação, para depois associá-las, criando assim as Unidades destinadas ao aprendizado e reconhecimento das Constelações Fônicas.

\section{II.9.2- Célula Neural Artificial Paraconsistente de cálculo de Estrela Fônica:}

A Célula Neural Artificial Paraconsistente de cálculo de Estrela Fônica (CNAPcef), foi criada para a obtenção das Estrelas Fônicas, a partir da entrada de um vetor de valores:

1- Entradas: $\mathbf{r}$ - precisão; $\mathbf{u}_{\mathbf{i}}$ - entrada iésima; $\mathbf{C}$ - constante de cálculo

2- Cálculos: $\mathbf{m}=$ número seqüencial do elemento na constelação, iniciando por zero; $\mathbf{a}=$ amplitude; $\mathbf{p}=$ potência.

Sua representação gráfica é apresentada na figura II.9.1, a seguir:

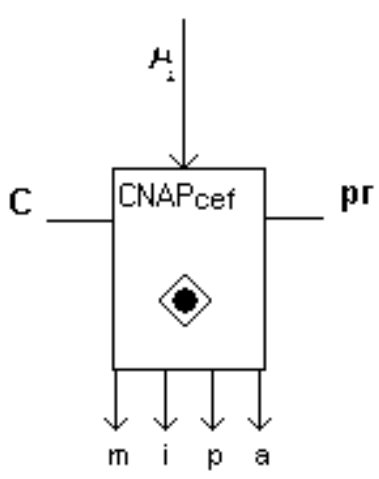

Figura II.9.1 - Célula Neural Artificial Paraconsistente de reconhecimento de sinal 


\section{II.9.3- Célula Neural Artificial Paraconsistente de cálculo de Estrela Fônica de amplitude:}

A partir da Célula Neural Artificial Paraconsistente de cálculo de Estrela Fônica (CNAPcef), obtém-se a de Célula Neural Artificial Paraconsistente de cálculo de Estrela Fônica de Amplitude (CNAPcefa), definindo a forma de cálculo da amplitude e potência da Estrela como sendo:

$\mathbf{a}($ amplitude $)=$ valor médio de todos os elementos do sub-vetor;

$\mathbf{p}($ potência $)=\mathbf{C}+\left|\mathbf{a}_{\mathbf{m}}-\mathbf{a}_{(\mathbf{m}-\mathbf{1})}\right|$

\section{II.9.4- Célula Neural Artificial Paraconsistente de cálculo de Estrela Fônica de Pré-sonorização:}

A partir da Célula Neural Artificial Paraconsistente de cálculo de Estrela Fônica (CNAPcef), obtém-se a de Célula Neural Artificial Paraconsistente de cálculo de Estrela Fônica de Pré-sonorização (CNAPcefps), agregando-se as seguintes condições e características:

1- Entradas: $\mathbf{F i}=$ Fator de inicio. É a amplitude média do sinal esperada para considerar o inicio da pré-sonorização, de acordo com a precisão.

2- $\mathbf{F d}=$ Fator de diferença. É a diferença esperada entre a média anterior e a média posterior para considerar o final da pré-sonorização.

3- Cálculos: $\mathbf{a}=$ amplitude máxima; $\mathbf{p}=\mathbf{C}+$ número de elementos.

\section{II.9.5- Célula Neural Artificial Paraconsistente de cálculo de Estrela Fônica de freqüência:}

A partir da Célula Neural Artificial Paraconsistente de cálculo de Estrela Fônica (CNAPcef), obtém-se a de Célula Neural Artificial Paraconsistente de cálculo de Estrela Fônica de freqüência (CNAPceff), definindo a forma de cálculo da amplitude da Estrela como sendo:

$\mathbf{a}=$ constante (ajustado de acordo com a aplicação) + número de harmônicas e freqüências, calculado como $\mathbf{V} * \mathbf{2}^{\mathrm{h}}$ sendo $\mathbf{V}=\mathbf{1}$ se a harmônica existe e $\mathbf{V}=\mathbf{0}$ se não existe, h o número da harmônica, numerada a partir de zero, a partir da menor 
freqüência usada para a escala em freqüência; $\mathbf{p}=$ valor médio de todos os elementos do sub-vetor.

\section{II.9.6- Célula Neural Artificial Paraconsistente de cálculo de Estrela Fônica de Jitter:}

A partir da Célula Neural Artificial Paraconsistente de cálculo de Estrela Fônica (CNAPcef), obtém-se a de Célula Neural Artificial Paraconsistente de cálculo de Estrela Fônica de Jitter (CNAPcefj), definindo a amplitude da Estrela como sendo:

$\mathbf{a}=$ freqüência fundamental;

E a potência da estrela como sendo:

$\mathbf{p}=$ desvio padrão da freqüência fundamental.

\section{II.9.7- Célula Neural Artificial Paraconsistente de cálculo de Estrela Fônica de Shimmer:}

A partir da Célula Neural Artificial Paraconsistente de cálculo de Estrela Fônica (CNAPcef), obtém-se a de Célula Neural Artificial Paraconsistente de cálculo de Estrela Fônica de Shimmer (CNAPcefs), definindo a amplitude da Estrela como sendo: $\mathbf{a}=$ freqüência fundamental;

E a potência da estrela como sendo:

$\mathbf{p}=$ desvio padrão da amplitude da harmônica fundamental.

\section{II.9.8- Unidade Neural Artificial Paraconsistente para aprendizado e reconhecimento das Constelações Fônicas:}

A partir das células anteriores, capazes de obter as Estrelas Fônicas, aprender e comparar um sinal, compõe-se a Unidade Neural Artificial Paraconsistente para aprendizado e reconhecimento das Constelações Fônicas (UNAParcf). Além de uma de cada das células anteriores, ela contém uma Unidade Neural Artificial Paraconsistente de aprendizado e reconhecimento de padrão (UNAParp) para cada uma dessas células. 


\section{II.9.9- Considerações finais:}

Uma vez criados todos os elementos necessários, passa-se a descrição do SIAPF - Sistema de análise da produção da fala. 


\section{III - Método e Sistema de Análise da Produção da Fala}

\section{III.1. SIAPF - Sistema de Análise da Produção da Fala}

\section{III.1.1- Considerações iniciais:}

Este capítulo destina-se a descrição completa do sistema SIAPF - Sistema de Análise de Produção de Fala, Desenvolvido em DELPHI 7 ®, ferramenta de desenvolvimento criada pela BORLAND ${ }^{\circledR}$, Baseada em linguagem object pascal. $\mathrm{O}$ DELPHI ${ }^{\circledR}$ utilizado para o desenvolvimento pertence a AUTOBYTE comercio e informática, sendo que no ANEXO D deste trabalho encontra-se a declaração da empresa autorizando seu uso.

Este sistema tem por objetivo principal determinar as Constelações Fônicas de um sinal de fala, permitir seu aprendizado e reconhecimento a partir de Redes Neurais Artificiais Paraconsistentes e futuramente determinar diferenças entre Constelações de forma a identificar os Formantes de uma fala. Nesta primeira versão deste sistema, todo processo de determinação das Constelações Fônicas, seu aprendizado e reconhecimento foi desenvolvido da forma mais simples e objetiva possível, facilitando a operação por parte do usuário.

Como continuidade deste trabalho, pretende-se ampliar os recursos do aplicativo, permitindo que se extraia o máximo de resultados que a teoria aqui criada permitir. A otimização dos recursos de análise também será necessária para facilitar o uso futuro deste aplicativo como ferramenta quantitativa em análise da produção de fala. Os módulos deste aplicativo que não foram concluídos estão aqui descritos para implementação futura, bem como seus resultados esperados. 


\section{III.1.2- Descrição geral:}

O programa de computador desenvolvido, doravante denominado Sistema SIAPF - Sistema de Análise de Produção de Fala, tem por objetivo permitir a captura de uma fala, sua manipulação para obtenção das representações matemáticas necessárias, bem como os gráficos destas representações, determinar a Constelação fônica de um sinal e seu gráfico, criando-se uma Rede Neural Artificial Paraconsistente, capaz de apresentar interpretações do sinal quando comparada com sinais prévios. As Estrelas Fônicas das Constelações possuem características individuais decorrente das características do sinal representado. Este programa de computador pretende ser mais uma ferramenta para análise quantitativa da produção da fala.

\section{III.1.3- Esquema de blocos do SIAPF:}

A seguir, na figura III.1.1, apresenta-se o esquema de blocos do sistema.

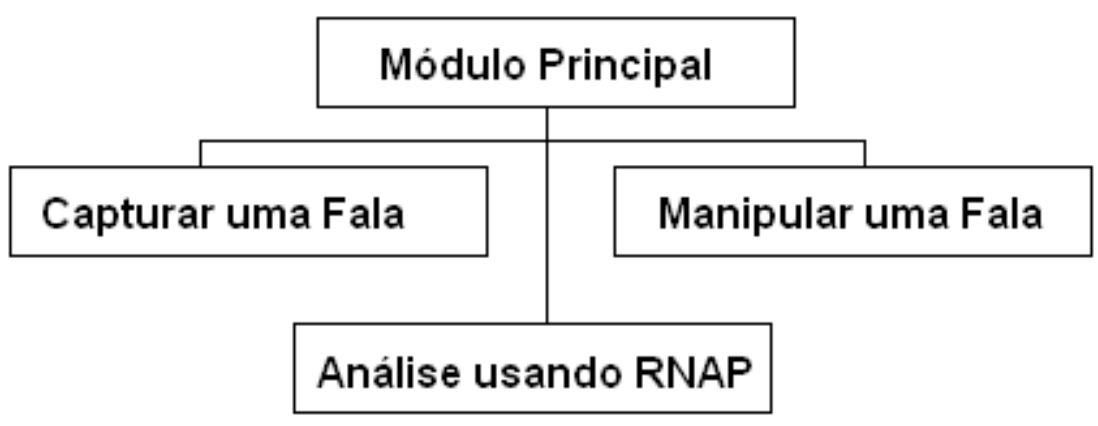

Figura III.1.1 - Esquema de blocos

\section{III.1.4- Descrição simplificada de cada bloco do SIAPF:}

Descreve-se neste tópico, de forma simplificada, cada um dos blocos existentes na aplicação:

- Módulo Principal: Contém as funções genéricas do sistema, e permite acessar os demais blocos.

- Capturar uma fala: Permite capturar uma fala, a partir de um microfone, conectado à placa de som do computador. 
- Manipular uma fala: Permite que o sistema apresente a representação de amplitude em função do tempo e freqüência em função do tempo do sinal de fala composto. Possui opção para visualizar, através de gráficos cartesianos os resultados obtidos. Permite ainda:

o A normalização de sinais

o A determinação da Constelação Fônica da Amplitude e sua visualização

o A determinação da Constelação Fônica da Freqüência e sua visualização

- Análise usando a RNAP: Permite que o sistema analise e apresente resultados a partir de sinais previamente tratados, através dos processos:

o Aprendizado e reconhecimento das Constelações de um sinal de fala: o reconhecimento só é possível caso a analise se já feita de duas produções de fala iguais, ou caso se faça o aprendizado isolado de diferentes produções do mesmo Fone.

o Determinação de diferenças entre Constelações: esta operação serve para determinar Formantes quando comparados Fones com apenas um Formante contrastante. Esta diferença caracteriza um determinado par contrastante de Formantes. Este módulo não foi implementado na aplicação.

\section{III.1.5- Descrição dos arquivos de dados do SIAPF:}

O sistema SIAPF utiliza arquivos textos para seu processamento. Estes arquivos textos são descritos a seguir:

III.1.5.1-som_cap.tmp - Arquivo temporário: ao finalizar a captura o sistema cria este arquivo. Ao final da gravação, re-nomeia este arquivo para o arquivo de som capturado. III.1.5.2- som_capturado<n>.som - Ao ser finalizado, o som gravado recebe este nome, sendo $<\mathbf{n}>$ um número seqüencial a partir de 0 . Seu conteúdo está apresentado a seguir: 


\section{$V[\mathbf{i}, \mathbf{j}]=$ valor $x$ vezes}

- Onde:

O $\mathbf{i}=$ numero do bloco lido, cada bloco pode ter até 1024 elementos;

$0 \mathbf{j}=$ numero de ordem do elemento;

o valor $=$ valor em amplitude do elemento;

o vezes $=$ número de vezes que ele aparece, usado como forma de compactação.

Exemplo:

$\mathrm{V}[0,0]=114 \times 1$

$\mathrm{V}[0,1]=113 \times 1$

$\mathrm{V}[0,2]=114 \times 1$

$\mathrm{V}[0,3]=115 \times 1021$

$\mathrm{V}[1,0]=115 \times 2$

$V[1,2]=114 \times 1022$

$\mathrm{V}[2,0]=114 \times 1024$

III.1.5.3- < nome>.som - este arquivo é igual ao anterior, porém agora ele está gravado com o nome definido pelo operador. Após a gravação do arquivo, o SIAPF cria uma copia reserva automaticamente, denominada <nome>_res.som

III.1.5.4- < nome>.nor - este arquivo é igual ao anterior, normalizado em amplitude.

III.1.5.5- <nome>.cam - este arquivo contém a Constelação Fônica da Amplitude do sinal falado. Sua estrutura é apresentada a seguir:

\section{$\mathbf{V}[\mathbf{i}]=\mathbf{a}|\mathbf{p}|$}

- Onde:

o $\mathbf{i}=$ numero do bloco inicial para calculo da estrela (cada bloco pode ter até 1024 elementos, mas não será necessariamente igual a precisão);

o $\mathbf{a}=$ amplitude, conforme definição e cálculo apresentado no Capítulo 8;

o $\mathbf{p}=$ =potência, conforme definição e cálculo apresentado no Capítulo 8. 
Exemplo:

$V[44]=-161|161|$

$\mathrm{V}[46]=-189|28|$

$\mathrm{V}[48]=-161|28|$

$\mathrm{V}[50]=-366|205|$

$\mathrm{V}[52]=-91|275|$

$\mathrm{V}[54]=-111|20|$

$\mathrm{V}[56]=-201|90|$

$\mathrm{V}[58]=-\mathbf{1 4 8}|53|$

III.1.5.6- <nome>.fre - a partir do arquivo normalizado em amplitude, <nome>.nor, é gerado o arquivo do espectro em freqüência. Obtém-se este arquivo calculando as harmônicas necessárias para a composição do sinal. Representando assim cada elemento do sinal através do formato a seguir:

$V[i, j]=A * \operatorname{sen}\left(F^{*} 1\right)\left|A * \cos \left(F^{*} 1\right)\right| A / 2 * \operatorname{sen}\left(F^{*} 2\right)\left|A / 2 * \cos \left(F^{*} 2\right)\right| \ldots$

$A / n * \operatorname{sen}\left(F^{*} n\right)\left|A / n * \cos \left(F^{*} n\right)\right|$

- Onde:

o cada elemento separado por | é uma componente harmônica do sinal;

o $\mathbf{F}=$ menor freqüência, ou freqüência fundamental do sinal;

O A=amplitude de cada harmônica;

o $\quad \mathrm{N}=$ número da harmônica.

Exemplo:

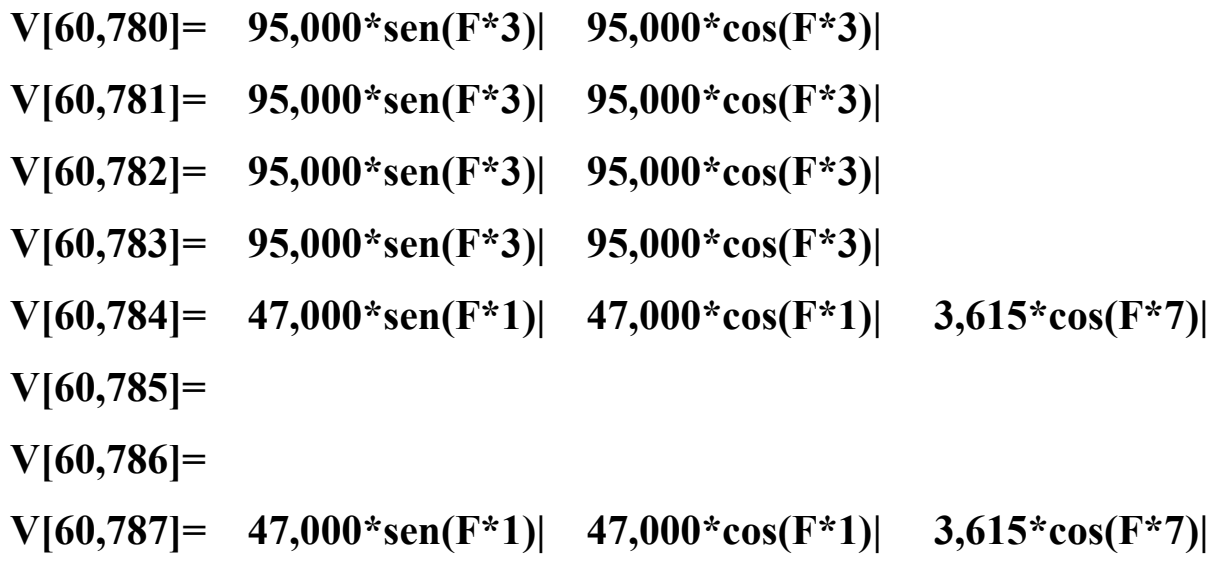


III.1.5.7- <nome>.cfe - este arquivo contém a Constelação Fônica da Freqüência, obtida a partir do espectro em freqüência armazenado no arquivo anterior.

\section{$\mathbf{V}[\mathbf{i}]=\mathbf{a}|\mathbf{p}|$}

- Onde:

o $\mathbf{i}=$ numero do bloco inicial para calculo da estrela;

o $\mathbf{a}=$ amplitude, conforme definição e cálculo apresentado no Capítulo 9;

o $\mathbf{p}=$ =potência, conforme definição e cálculo apresentado no Capítulo 9.

Exemplo:

$\mathrm{V}[4]=-61|31|$

$\mathrm{V}[6]=-90|18|$

$\mathrm{V}[8]=-16|10|$

$\mathrm{V}[20]=-36|45|$

$\mathrm{V}[30]=-41|75|$

$\mathrm{V}[44]=-71|89|$

$\mathrm{V}[46]=-101|19|$

III.1.5.8- <nome>.def - arquivo que contém as demais Estrelas Fônicas calculadas. Sua estrutura é apresentada a seguir:

$\mathrm{V}[\mathrm{P}]=\mathrm{a}|\mathrm{p}|$ - Estrela Fônica de Pré-sonorização (conforme descrita no capítulo 8)

$\mathrm{V}[\mathrm{J}]=\mathrm{a}|\mathrm{p}|$ - Estrela Fônica de Jitter (conforme descrita no capítulo 9)

$\mathrm{V}[\mathrm{S}]=\mathrm{a}|\mathrm{p}|$ - Estrela Fônica de Shimmer (conforme descrita no capítulo 9) 
III.1.6- Telas da aplicação e descrição detalhada de cada recurso do SIAPF:

III.1.6.1- Principal: Permite a seleção da operação a ser efetuada. Está apresentada na figura III.1.2 a seguir:

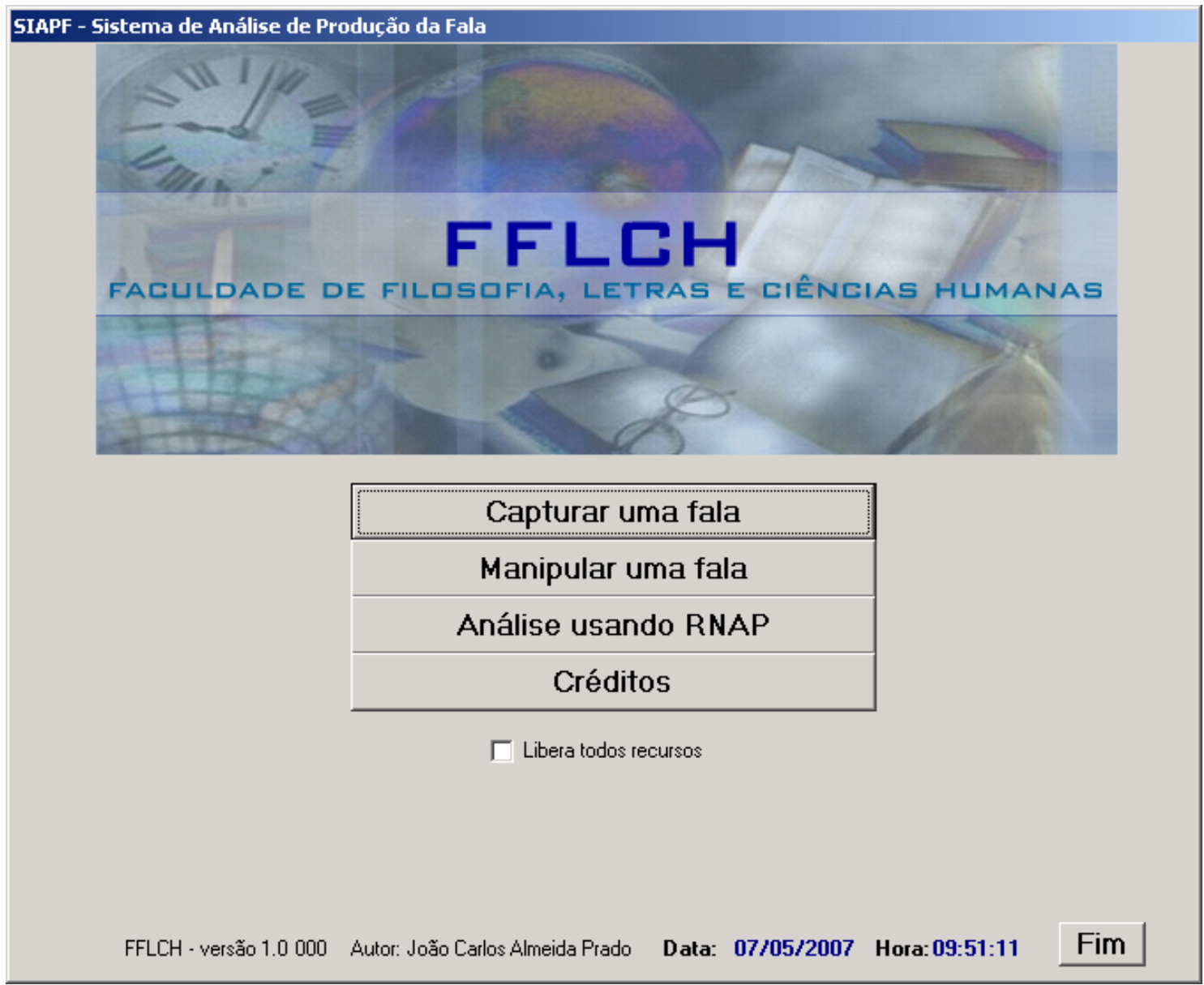

Figura III.1.2 - Tela Principal

A partir desta tela principal, é possível capturar uma fala; manipular uma fala ou fazer análise usando RNAP.

Para que se possa promover um teste mais completo e detalhado da aplicação, nesta tela existe a opção libera todos recursos. Habilitando-se esta opção, todos os processos de cálculo, manipulação e análises ficam totalmente disponíveis para que, mesmo fora da ordem convencional, o operador possa refazer passos ou antecipá-los, avaliando o comportamento da aplicação. 
III.1.6.2- Capturar uma fala: permite capturar uma fala a partir da tela apresentada na figura III.1.3 a seguir:

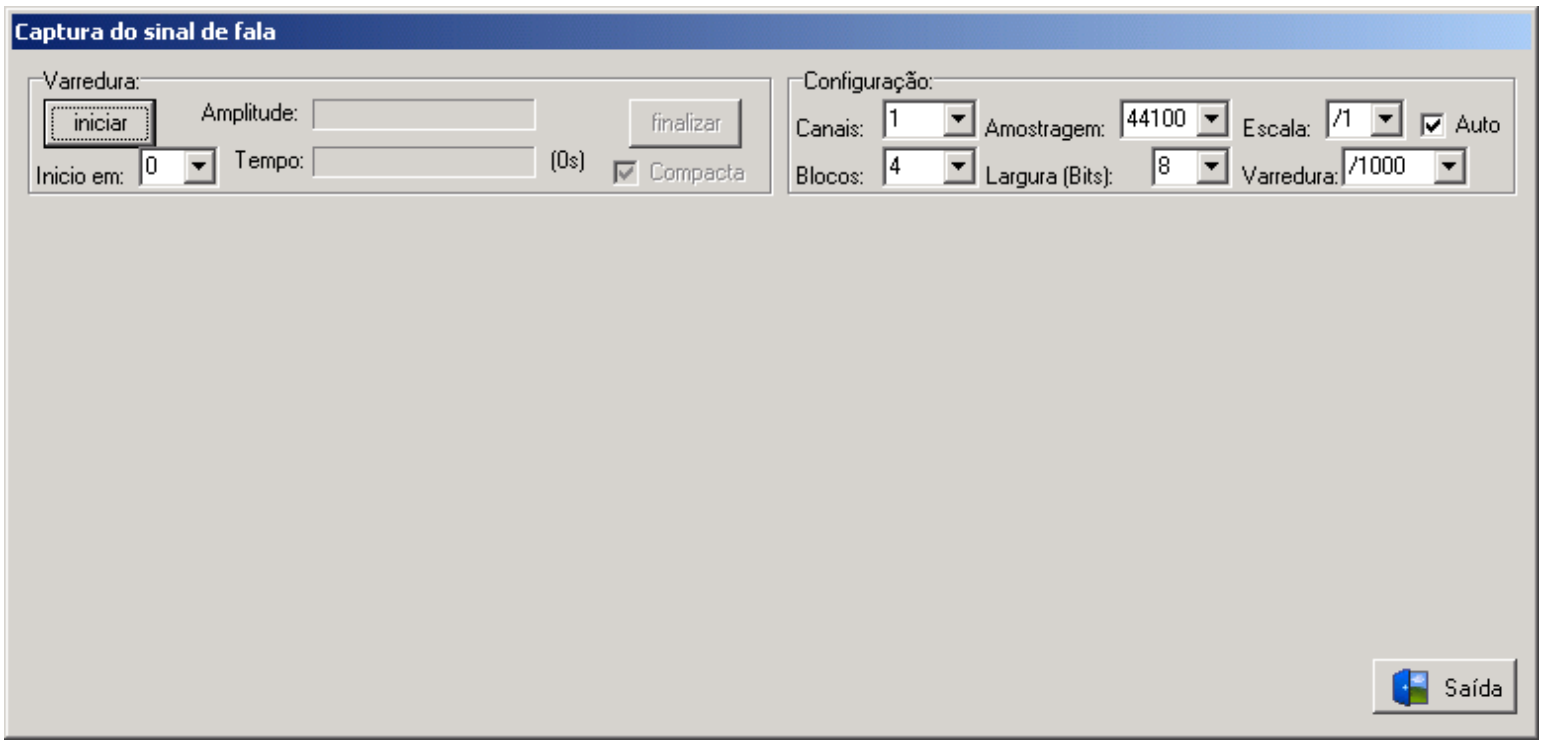

Figura III.1.3 - Captura de uma fala

Descreve-se a seguir a finalidade de cada componente desta tela:

- Varredura: inicia e finaliza a captura, mostrando seu andamento. Neste grupo existem os componentes:

o Botão iniciar: inicia a captura de um sinal a partir das configurações existentes na tela. Esta captura do sinal é feita através de um microfone conectado à placa de som do computador. O resultado obtido a partir deste processo está apresentado na figura III.1.4 a seguir: 


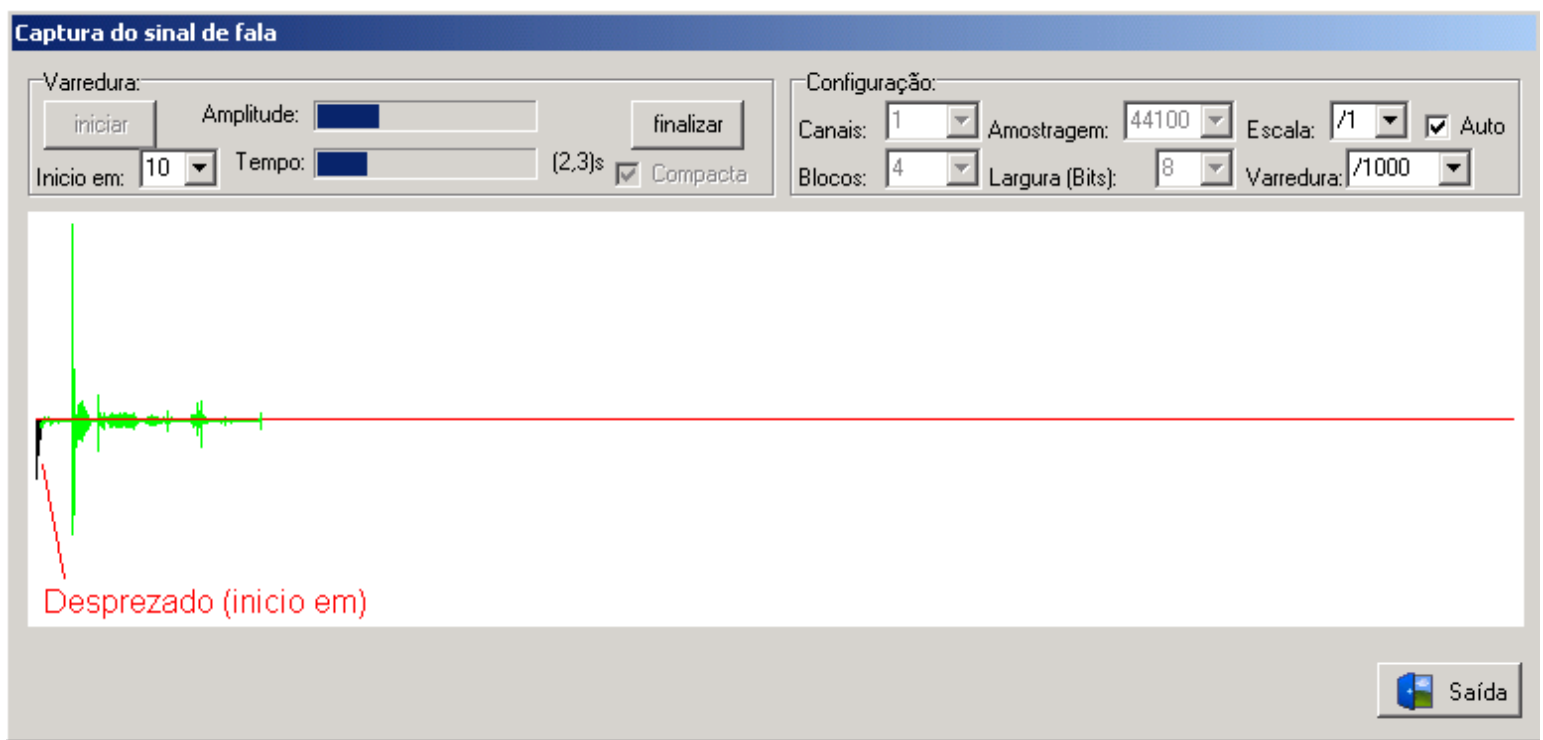

Figura III.1.4 - Capturando o sinal

o Inicio em: Permite cortar um determinado número de blocos iniciais (parâmetro i nas descrições anteriores). Cada bloco equivale a um centésimo de segundo. Recomenda-se cortar pelo menos dez blocos, pois sempre que a placa é acionada, existe um ruído de estabilização. Este ruído, caso não seja excluído, faz com que o corte automático na manipulação de uma fala não funcione.

o Amplitude: mostra a amplitude do sinal;

o Tempo: mostra o tempo de varredura;

o Botão Finalizar (só fica habilitado se o sistema estiver capturando sinal): finaliza a captura permitindo sua gravação. O sistema pergunta ao usuário se o mesmo deseja gravar a captura ou ignorar (figura III.1.5 a seguir):

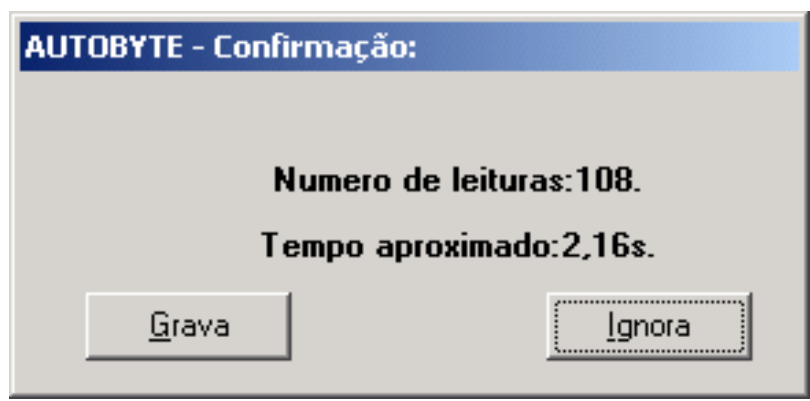

Figura III.1.5 - Aviso 
o Compacta: fica sempre ativado. O arquivo descompactado passou a não ser mais utilizado pois através do formato compactado fica mais fácil eliminar ruídos e identificar vazios.

- Configuração: permite definir o modo de varredura. O sistema sempre inicia no modo mais conveniente. É importante ressaltar que a alteração destas configurações pode distorcer a interpretação dos sinais pelo sistema. Estas configurações devem ser ajustadas de acordo com a resolução da interface de som utilizada. As configurações possíveis são:

o Canais: número de canais use 2 caso a placa seja estéreo;

o Blocos: número de blocos por amostragem;

o Amostragem: taxa de amostragem;

o Largura (bits): precisão da amplitude;

o Escala: escala para visualização;

o Auto: habilita a auto-escala;

o Varredura: diminuiu a velocidade de varredura para confecção do gráfico.

- Grava arquivo no... como: o sistema sempre numera seqüencialmente as capturas, e grava em um arquivo temporário. Este arquivo temporário pode ser renomeado (ou numerado seqüencialmente caso já exista) para o nome que o usuário desejar;

- Grava: use este botão para confirmar a gravação do arquivo com o novo nome escolhido. O sistema avisa o resultado da gravação;

- Saída: retorna a tela principal do sistema. 
III.1.6.3- Manipular uma fala: Esta tela permite manipular uma fala. Veja sua apresentação na figura III.1.6 a seguir:

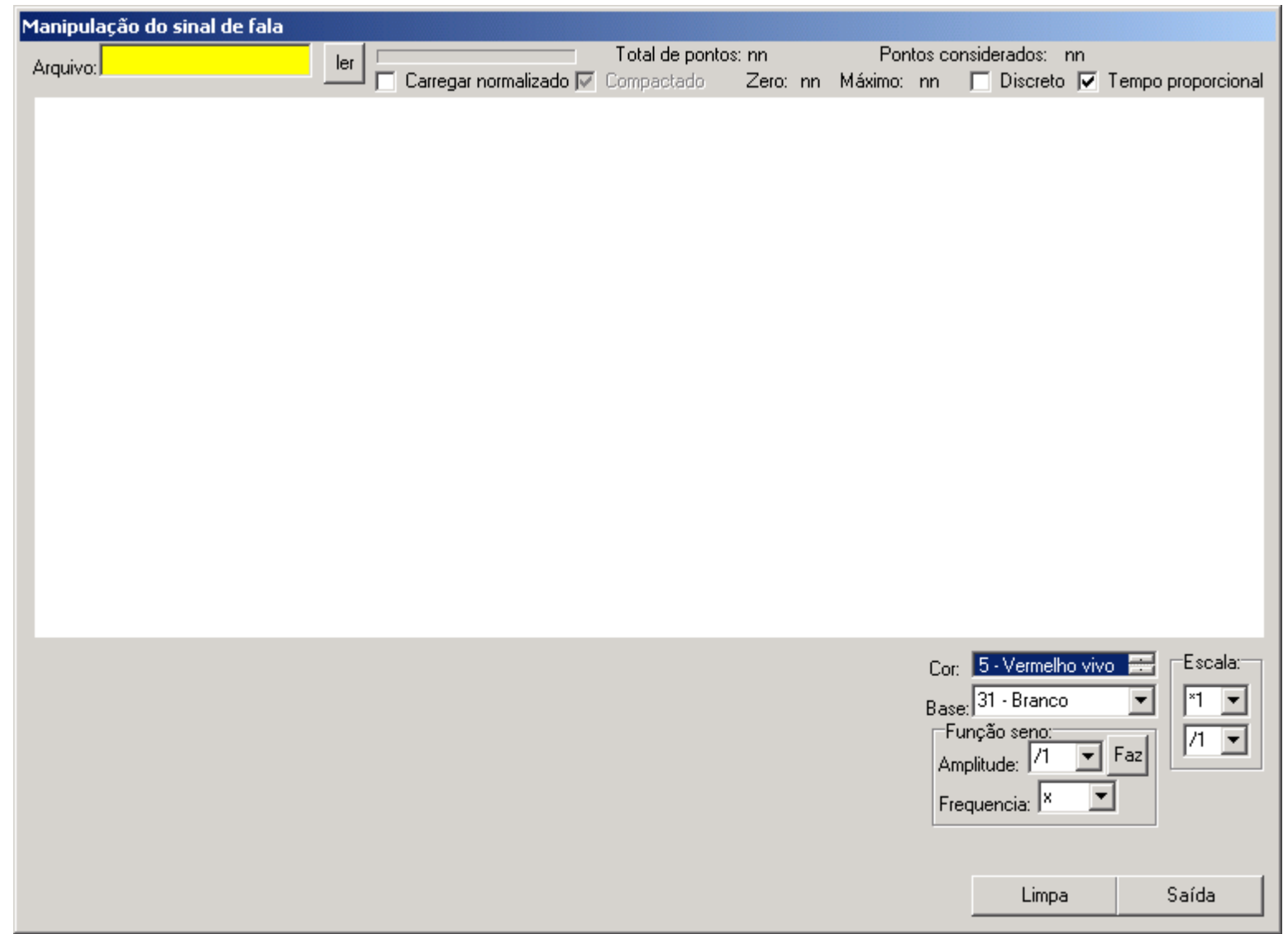

Figura III.1.6 - Tela de manipulação da fala.

O sistema percorre automaticamente passo a passo todos os processos que devem ser feitos. Sempre que for necessária a digitação de dados, seleção de parâmetros, ou intervenção do operador onde valores possam ser digitados, o sistema aguarda esta intervenção, indicando o local de digitação através da cor amarela. (veja figura III.1.6).

Para a seleção do arquivo a ser manipulado, o operador pode digitar o nome do arquivo, ou procurá-lo a partir de uma lista determinada pelo sistema, a partir de sons já capturados. Usando o Duplo clique do mouse no campo Arquivo, o sistema apresenta uma lista de arquivos conforme apresentado na figura III.1.7 a seguir: 


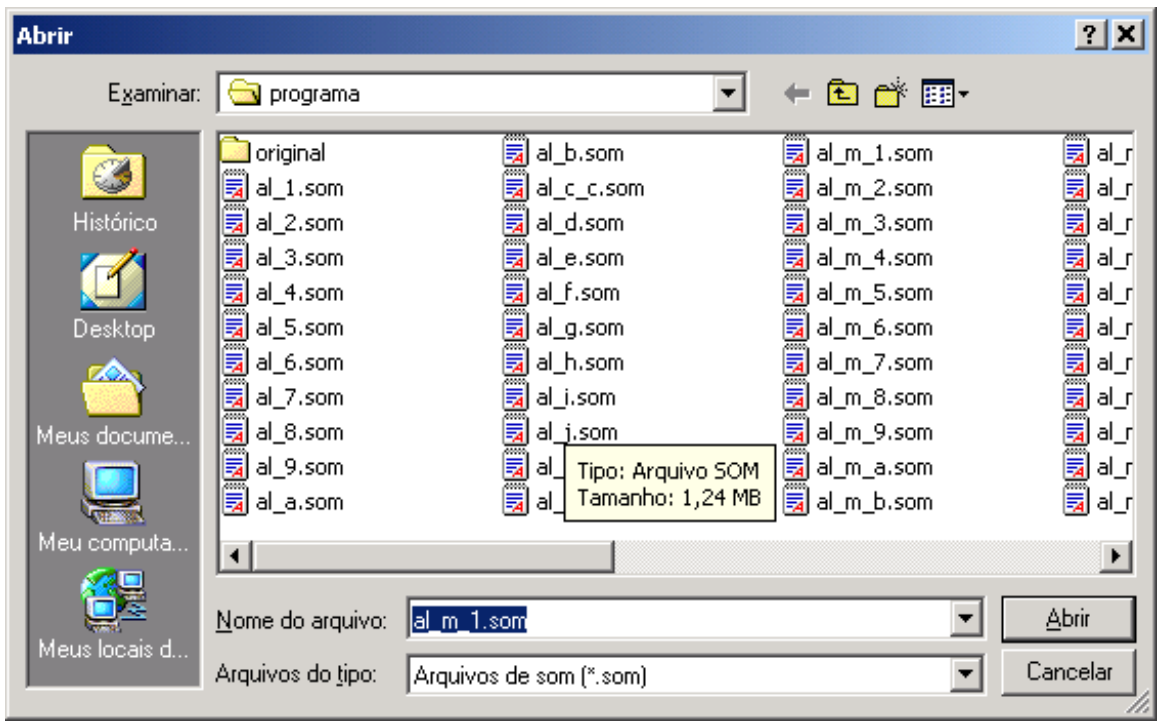

Figura III.1.7 - Seleção de um arquivo

Uma vez selecionado o arquivo da lista, o operador pode utilizar a tecla ENTER do computador e o sistema automaticamente executa o próximo passo: a leitura do arquivo. Durante o processo de leitura, é possível o corte automático inicial (pergunta feita ao operador, conforme figura III.1.8 a seguir):

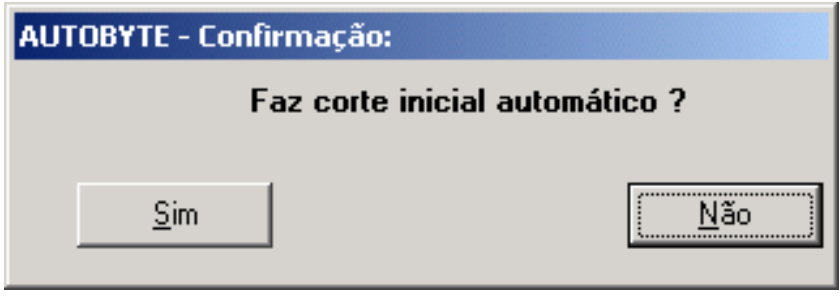

Figura III.1.8 - Faz corte inicial.

Caso seja selecionado o corte inicial automático, o sistema corta ruídos iniciais que não fazem parte da fala propriamente dita, a partir da definição de alguns parâmetros, conforme apresentado na figura III.1.9 a seguir: 


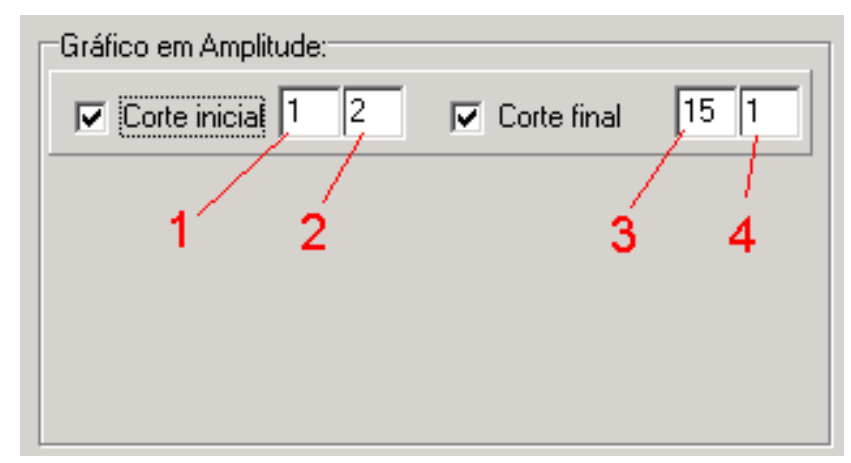

Figura III.1.9 - Configuração do corte inicial.

Para definição dos parâmetros a serem utilizados para o corte inicial, e/ou final (que pode ser habilitado ou não através do mouse), é necessário definir os campos 1, 2, 3 e 4 (veja figura III.1.9). o campo 1 define o número de blocos com valor maior que o campo 2 que deve ocorrer, para que se considere como iniciado o sinal. O campo 3 define o número de blocos com valor menor que o campo 4 que deve ocorrem, para que se considere como finalizado o sinal.

Caso o operador opte por não fazer o corte inicial e final automático, O sistema solicita que o operador defina o corte com o mouse. Visualmente, o operador deve clicar no inicio, e em seguida (após a aplicação ter atualizado a tela), no final.

O trecho escolhido pelo operador é o trecho a ser analisado.

Concluído o corte inicial e final, o sistema habilita os passos para normalização (figura III.1.10 a seguir). Use o ENTER para efetuar o processo.

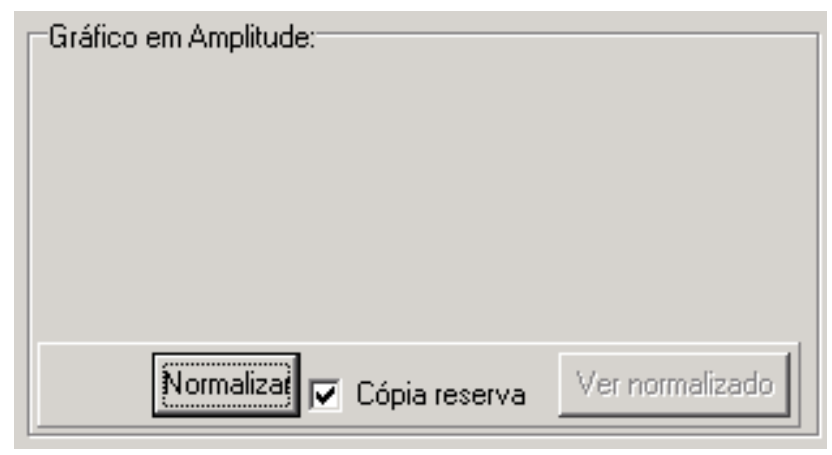

Figura III.1.10 - Normalização em amplitude. 
Iniciado o processo de Normalização, o sistema pergunta se é para recalcular o máximo do trecho selecionado. É aconselhável que esta resposta sempre seja afirmativa (figura III.1.11 a seguir):

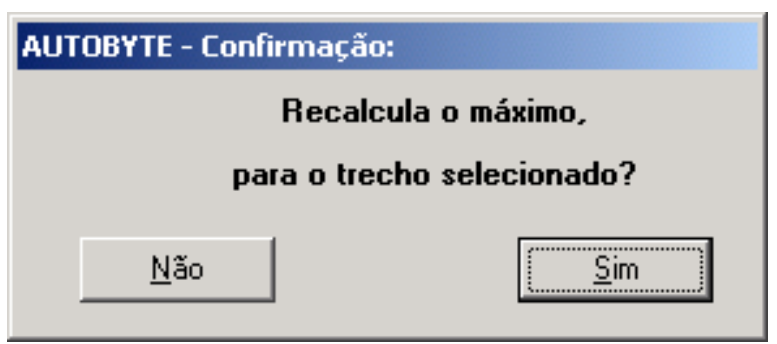

Figura III.1.11 - Recalculo de máximo

Terminada a Normalização, o sistema mostra o resultado e habilita a tela de cálculo da Constelação Fônica da Amplitude (figura III.1.12 a seguir).

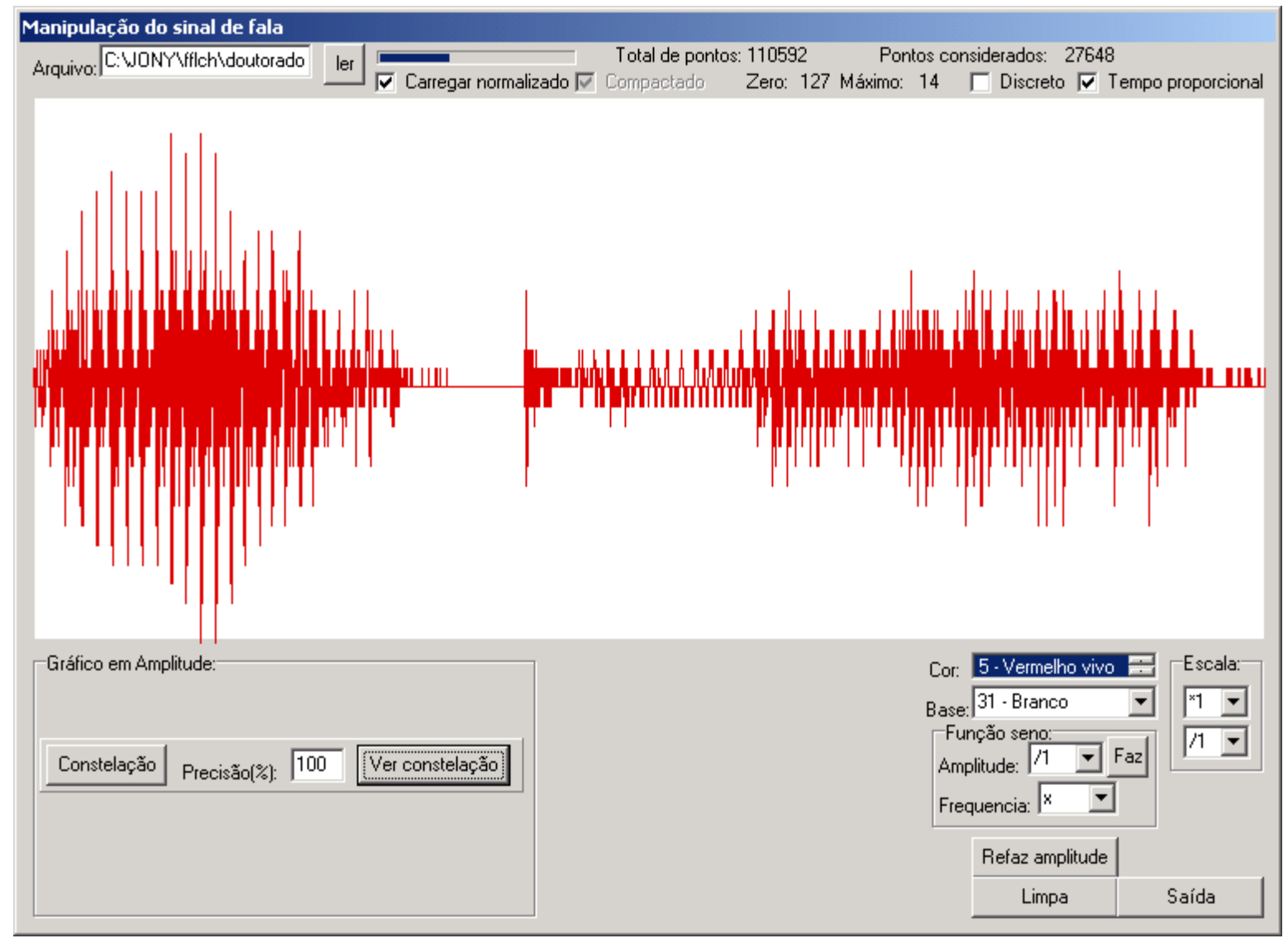

Figura III.1.12 - Gráfico normalizado 
Concluído o cálculo da Constelação Fônica, o sistema Apresenta o resultado final (figura III.1.13 a seguir), permitindo que o operador passe agora a efetuar os tratamentos no espectro de freqüência.

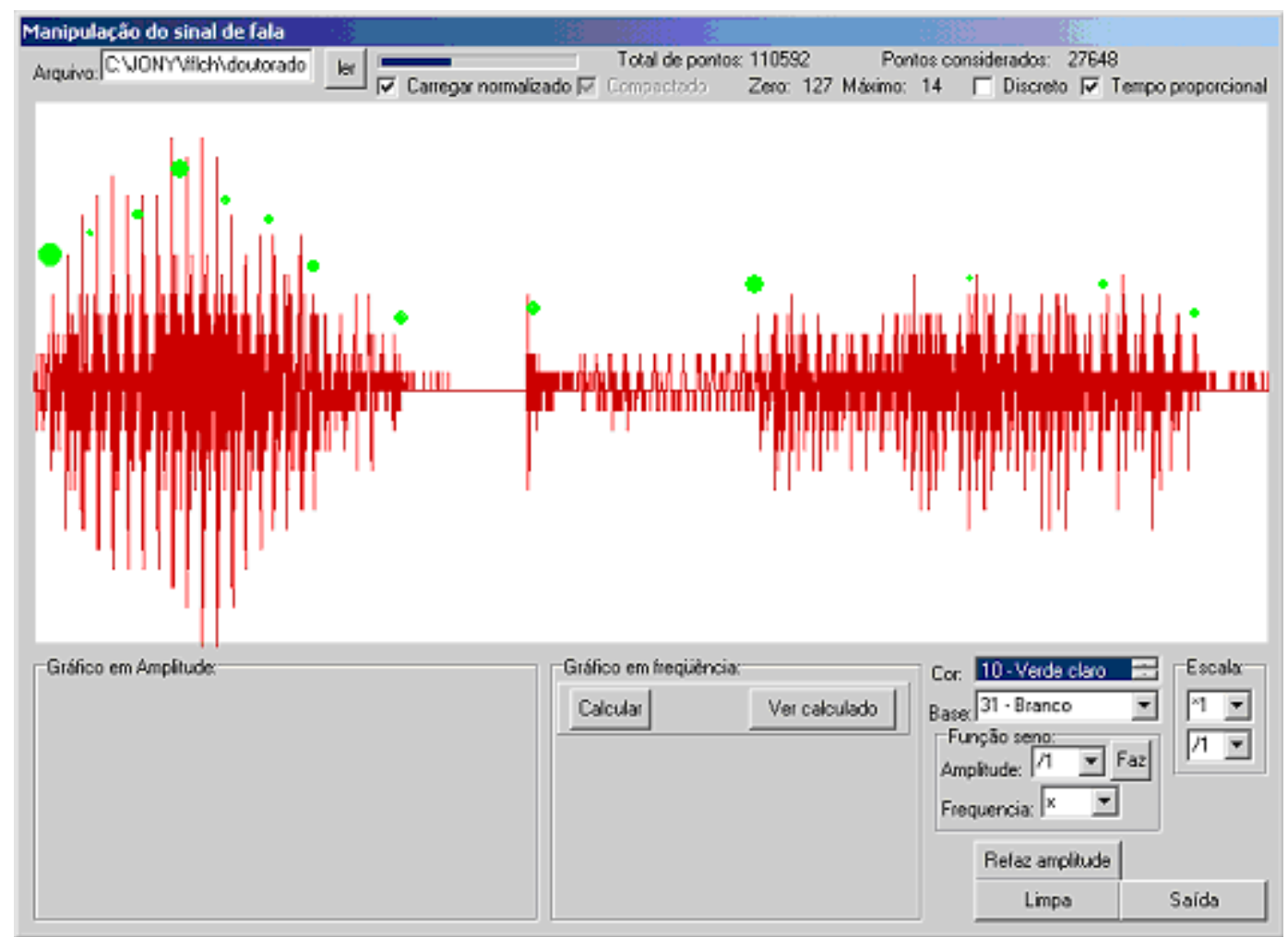

Figura III.1.13 - Gráfico completo.

Para saber os dados de cada componente da Constelação, clique na Estrela Fônica, com o botão direito do mouse e o sistema apresentará todos os dados desta Estrela (figura III.1.14 a seguir).

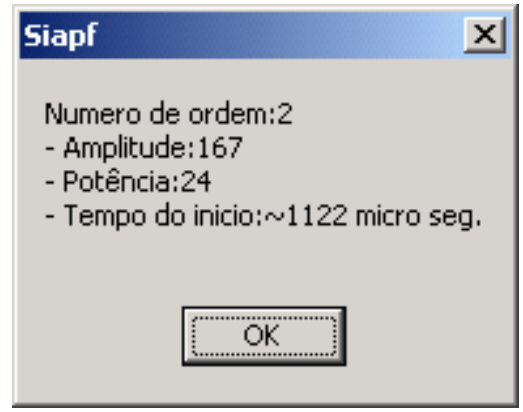

Figura III.1.14 - Dados da estrela Fônica.

Após o cálculo do espectro em freqüência, o sistema apresenta o gráfico e sua respectiva Constelação(figura III.1.15 a seguir): 


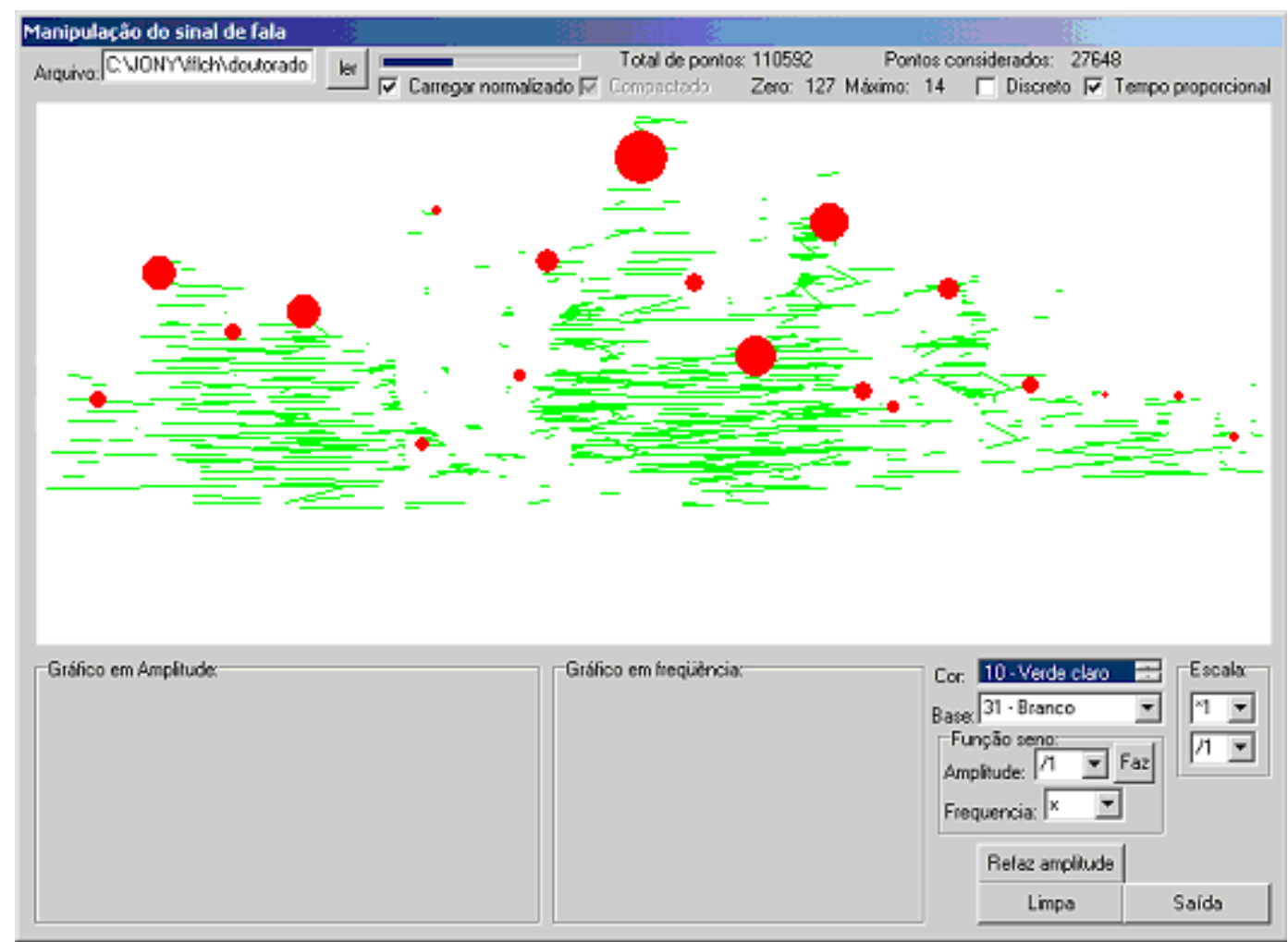

Figura III.1.15 - Constelação Fônica da Freqüência

Finalizado os dois processos principais, é possível completar o cálculo das estrelas, incluindo A pré-sonorização, o Jitter e o Shimmer. Todas as Constelações e estrelas calculadas ficam arquivas, podendo ser utilizadas no modulo de análise usando RNAP. 
III.1.6.4- Análise usando a RNAP: Esta tela permite Aprender ou reconhecer, comparar através das Redes Neurais Artificiais Paraconsistentes todos os sinais obtidos, e obter as tabelas de análise referente a estes processos.

Uma vez selecionado o arquivo que se deseja aprender (e reconhecer) ou comparar, o sistema apresenta a sua Constelação completa, incluindo Amplitude e Freqüência, bem como as demais estrelas complementares (figura III.1.16 a seguir). A Constelação completa, após a confirmação do usuário, pode ser aprendida ou somente comparada Pela Rede Neural Artificial Paraconsistente (RNAP).

Para o aprendizado é possível escolher como qual fala a constelação será aprendida, ou se consiste em um novo aprendizado, de uma para que não existe na RNAP ainda.

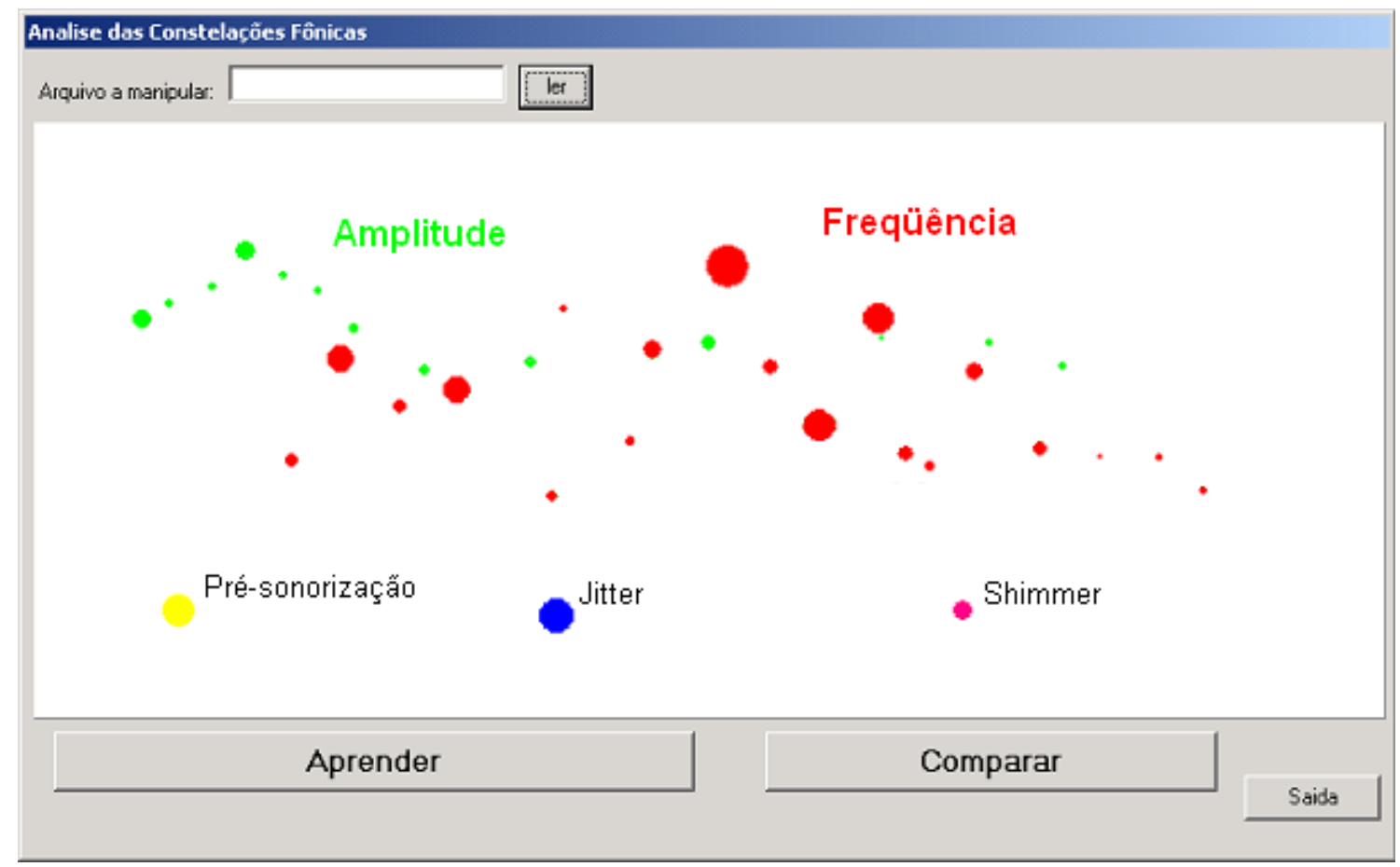

Figura III.1.16 - Constelação Completa

O processo de aprendizado, automaticamente passa pelo reconhecimento, sendo que o sistema apresenta uma tabela contendo todos os reconhecimentos da Constelação que está sendo aprendida (figura III.1.17 a seguir). 


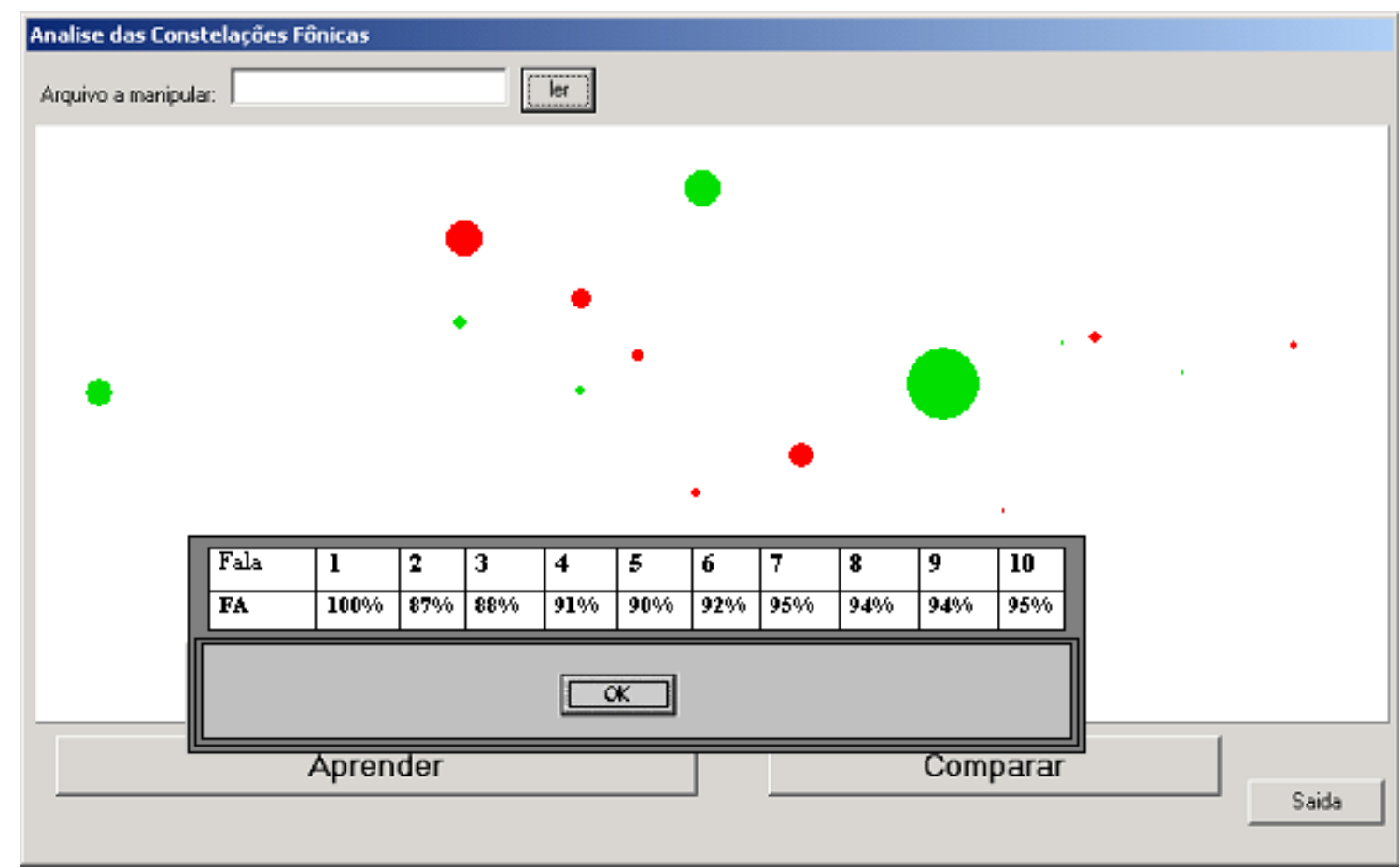

Figura III.1.17 - Tabela de Reconhecimentos, após aprendizado.

Caso o operador tenha escolhido somente o processo de comparação, o sistema pergunta com qual constelação o operador quer que o arquivo em questão seja comparado, apresentando em seguida uma tabela contendo todos os índices de comparação já obtidos (figura III.1.18 a seguir).

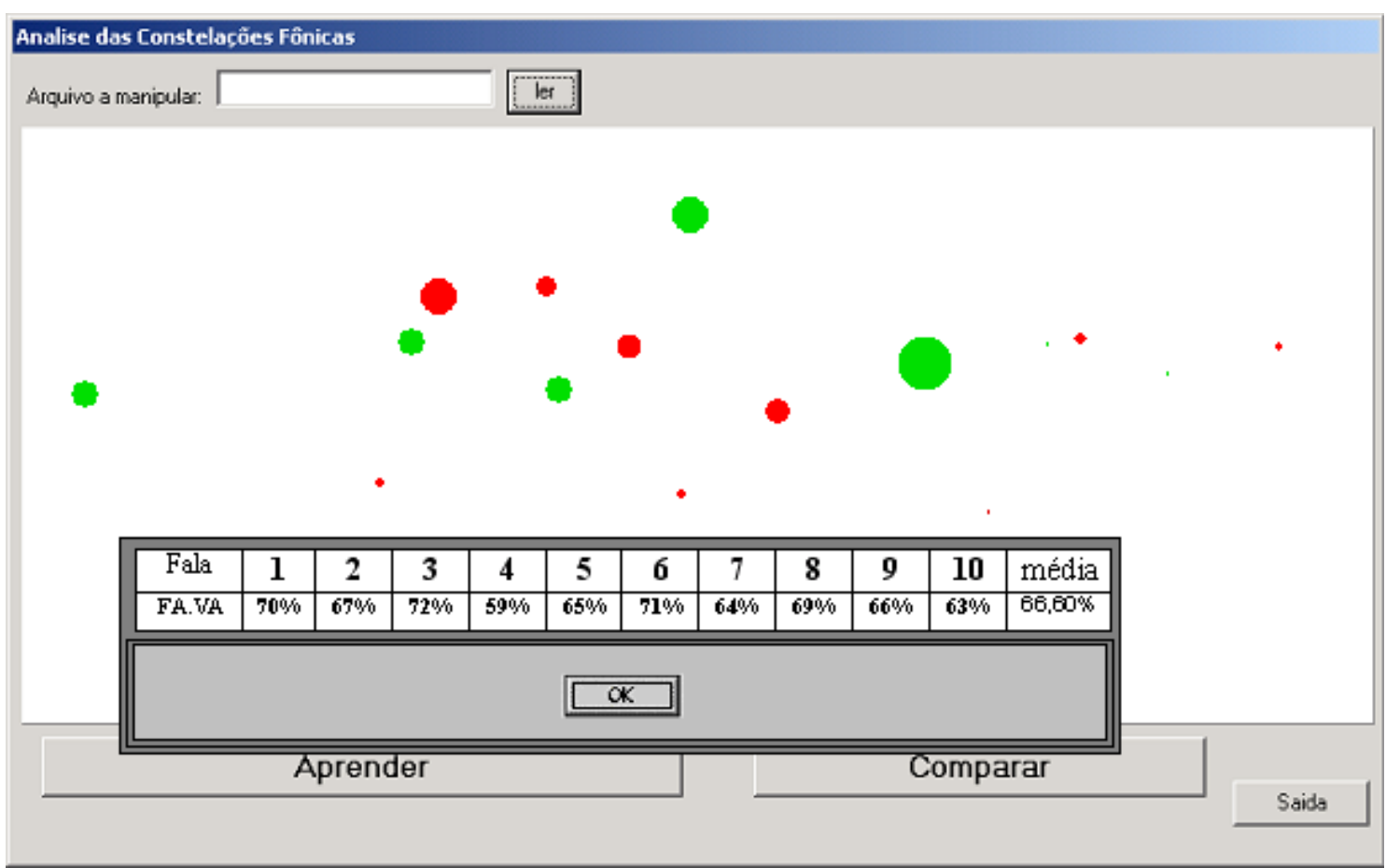

Figura III.1.18 - Tabela de Comparação. 


\section{III.1.7- Considerações finais:}

O sistema mostrou-se eficiente e prático, podendo ainda ser melhorado, incluindo mais recursos.

A Determinação de diferenças entre Constelações não foi implementada, ficando como proposta de continuidade. 


\section{III.2. Testes funcionais do SIAPF}

\section{III.2.1- Introdução:}

Para uma análise concreta do sinal capturado pelo programa, fez-se a captura de vozes de mulheres, Nível universitário, na faixa de 20 a 25 anos, sem distinção de região (sotaque de fala), utilizando-se a frase: BARCO NA AGUA. O resultado obtido mostrou a necessidade da normalização em amplitude, pois a diferença de potência apresentada no sinal existe, é grande, principalmente em decorrência da diferença de microfones utilizados. Outra dificuldade constatada foi em relação ao sistema operacional do computador: quando utilizado o WINDOWS XP ${ }^{\circledR}$ o sistema não respondia ao comando de finalização da captura, tornando necessário um corte final manual no sinal capturado.

A partir deste teste inicial ficou clara a necessidade de refinar parâmetros de ajuste, sendo assim, decidiu-se promover testes considerando apenas um falante.

O Objetivo deste capítulo é apresentar os testes feitos com o sistema para análise da produção da fala. Para estes testes utilizou-se o português brasileiro, da cidade de São Paulo, produzido por um falante homem de 40 anos.

Nestes testes foram utilizados os pares contrastantes FA-VA PA-BA e CA-GA, a partir de sílabas, pois assim a sua produção seria mais regular, diminuindo as variações das produções das falas a serem analisadas. A primeira etapa foi fazer com que o sistema aprendesse cada uma das primeiras silabas. A segunda etapa consistiu em introduzir na Rede cada um dos respectivos pares contrastantes, avaliando o reconhecimento comparativo entre as constelações de cada silaba. Assim, as igualdades e diferenças constatadas, podem ser atribuídas aos Fones com Formantes contrastantes, uma vez que o A foi introduzido apenas para facilitar a produção dos Formantes objeto de estudo.

A seguir são apresentados os resultados obtidos de acordo com cada processo efetuado, publicado em (PRADO, 06). Vale ressaltar que, independente da utilização ou 
não da constelação fônica, destaca-se a eficiência e versatilidade da Rede Neural Artificial Paraconsistente.

\section{III.2.2- Descrição do método utilizado para o aprendizado do "FA PA CA":}

Respeitando-se os padrões para captura de sinal de fala, conforme descrito em capitulo anterior, foram feitos dez aprendizados para cada uma das silabas-alvo, FA, PA, CA. Cada processo de aprendizado respeitou a seguinte seqüência, para n de 1 até 10:

III.2.2.1- Usando a opção Capturar uma fala do SIAPF, O falante produz a silabaalvo. A silaba é capturada e salva com o numero n (no caso da silaba FA, primeiro aprendizado, o arquivo recebe o nome de FA1)

III.2.2.2- Usando a opção Manipular uma fala do SIAPF, É obtida a constelação fônica em amplitude e freqüência da silaba produzida (para o exemplo, será manipulada a primeira silaba, portanto o arquivo FA1 - Figuras III.2.1 a seguir)

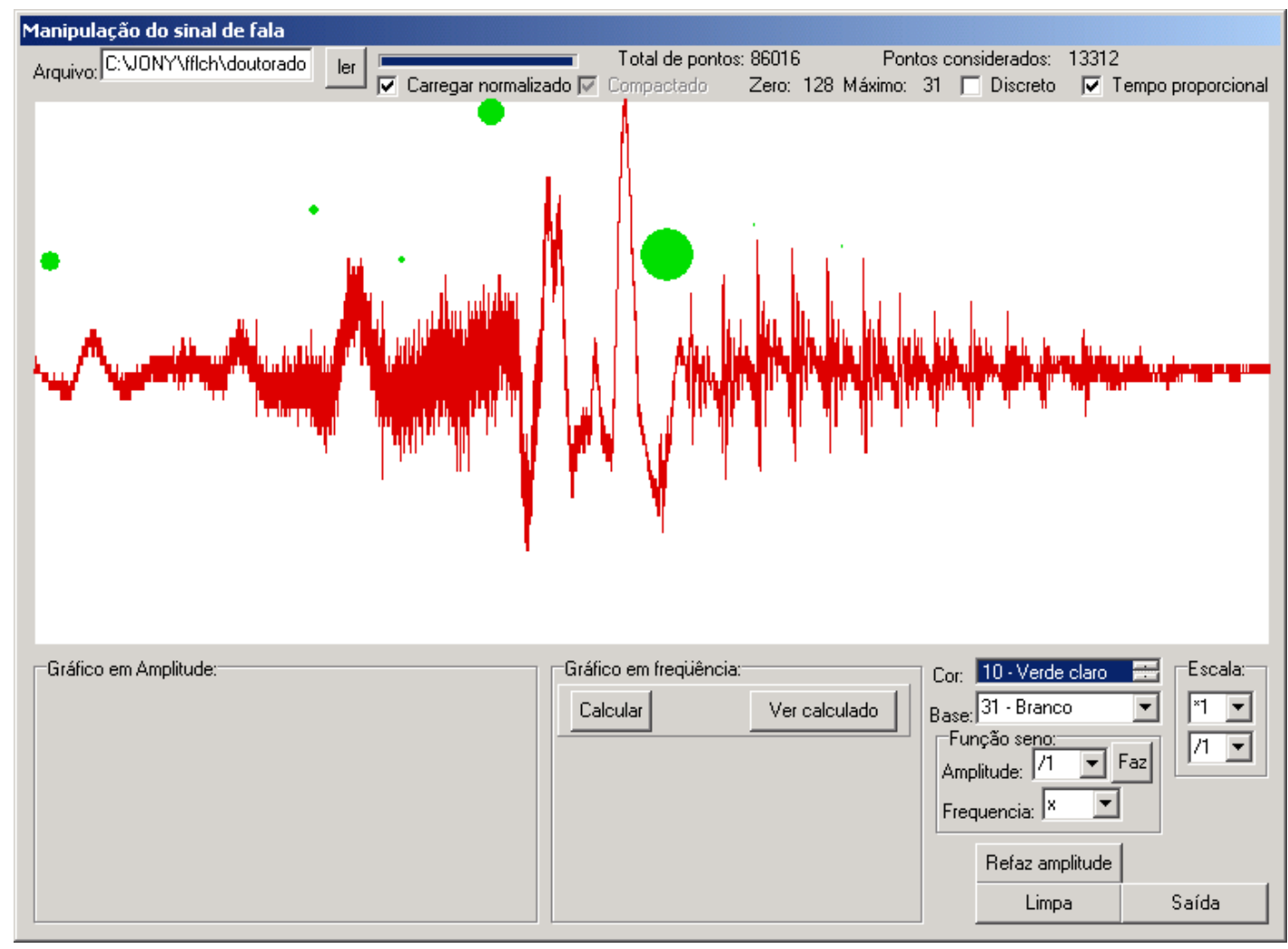

Figura III.2.1 -Manipulação do FA 
III.2.2.3- Usando a opção Análise usando a RNAP do SIAPF, através do botão Aprender, A silaba é aprendida (Figura III.2.2 a seguir), e o SIAPF apresenta a Tabela de Reconhecimento, após o aprendizado (Figura III.2.3 a seguir - para o primeiro aprendizado, a tabela só tem a primeira coluna)

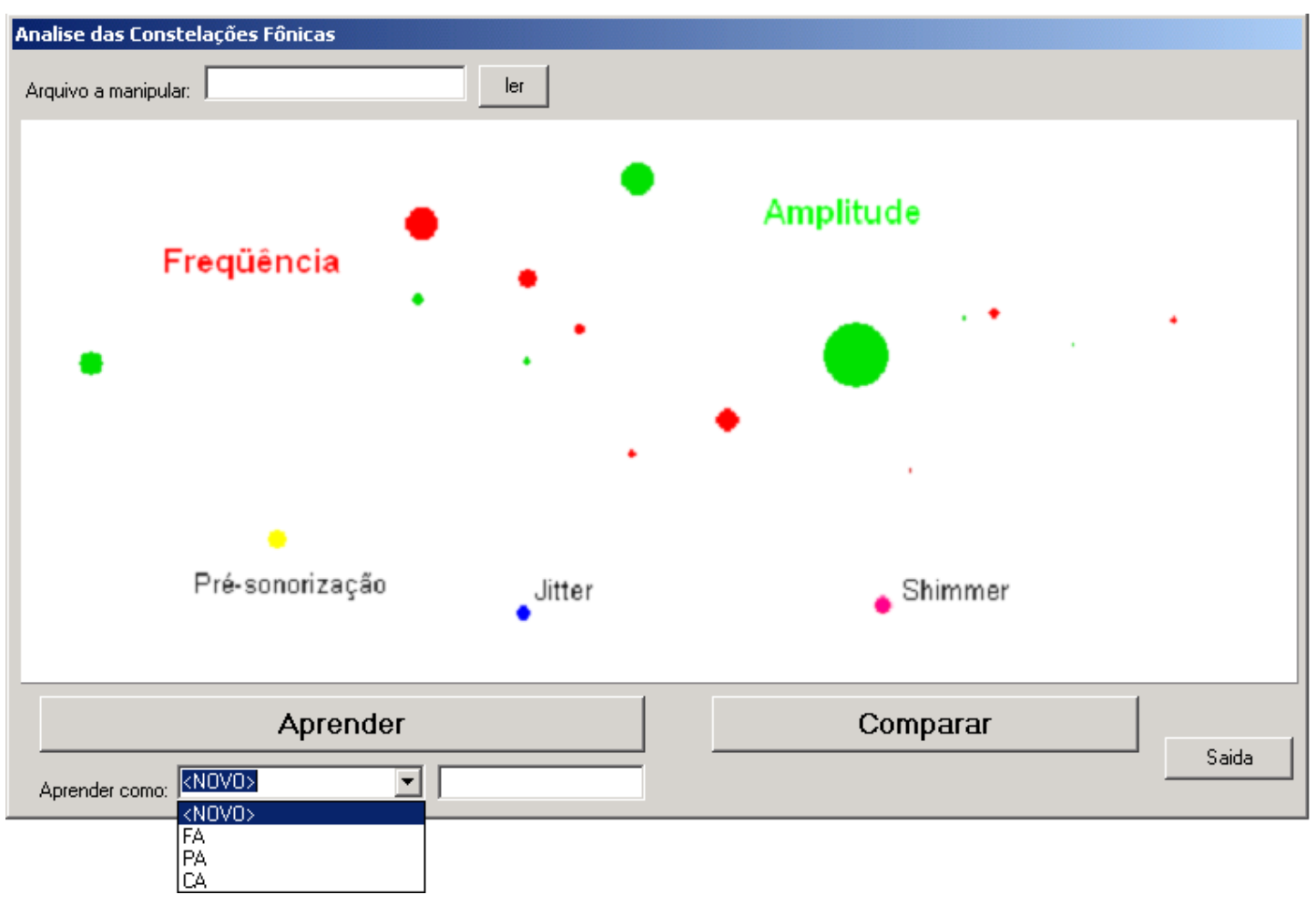

Figura III.2.2 -Aprendizado do FA

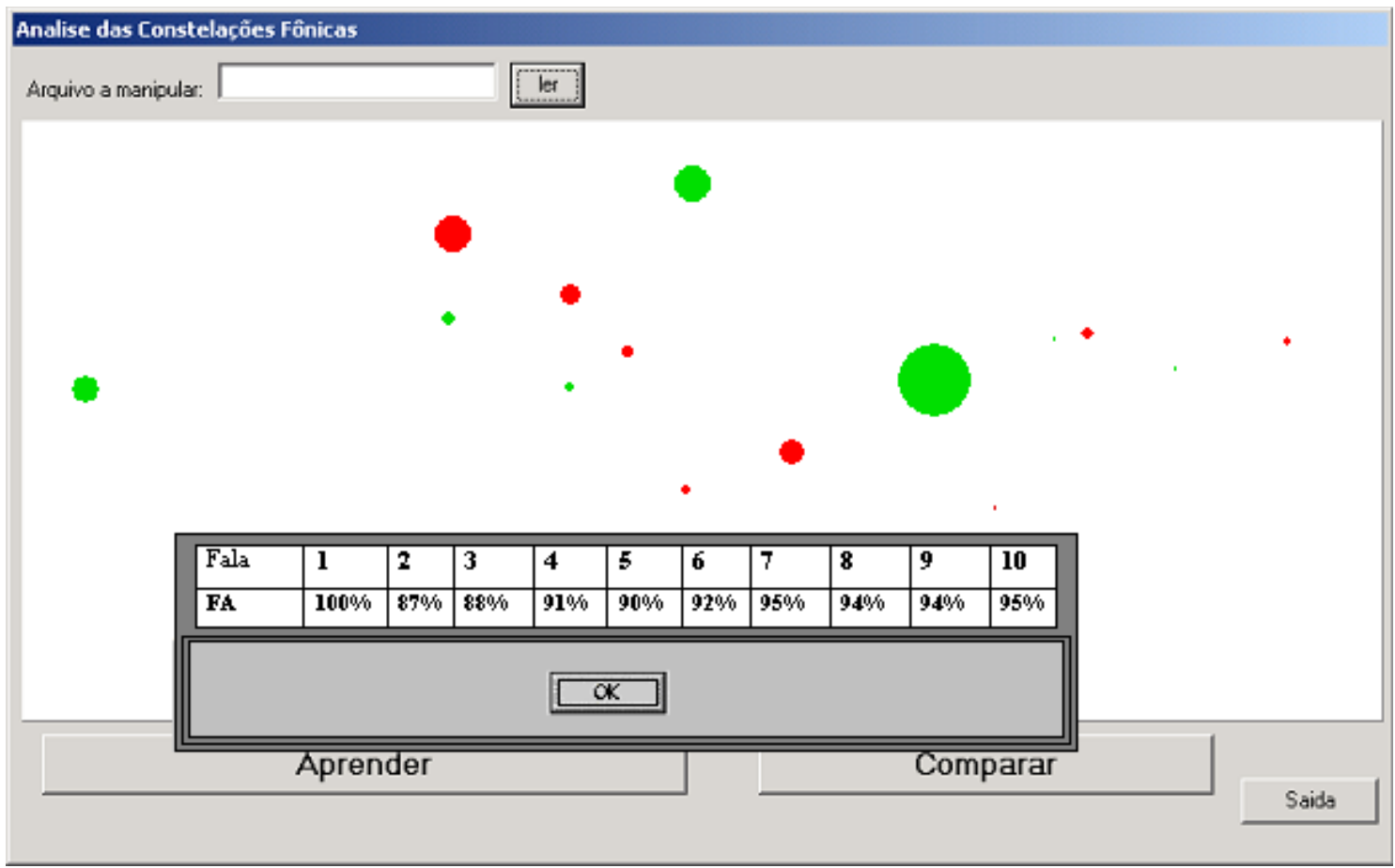

Figura III.2.3 -Aprendizado do FA - Tabela de reconhecimento 
III.2.2.4- se não for o décimo processo, repita desde III.2.2.1.

\section{III.2.3- Analisando o aprendizado do "FA PA CA":}

A Tabela III.2.1 a seguir mostra a capacidade de reconhecimento de um mesmo falante. O porcentual de reconhecimento na primeira coluna é sempre $100 \%$ porque a RNAP está vazia, e a silaba é comparada com ela mesma.

A partir da segunda coluna até a ultima, a Rede aprende e ajusta-se simultaneamente: este é o motivo pelo qual o reconhecimento aumenta. Pode-se definir que, depois da sexta repetição, a Rede é capaz de reconhecer o sinal eficientemente com um fator acima de $90 \%$. Todos os sinais que estiverem abaixo deste fator são considerados como não reconhecidos. Uma observação importante é que, após estes testes, é possível ajustar a tolerância da Rede, permitindo que sua eficiência de $90 \%$ seja atingida já no quarto aprendizado. Outra constatação importante é que, devido ao tratamento das paracompletezas contradições e redundâncias do sinal, sem a trivialização dos dados, a Rede atinge os valores constatados de forma muito eficiente, principal contribuição da Lógica Paraconsistente quando associada à Rede. Este porcentual de reconhecimento é incomum nas Redes Neurais (TAFNER, 96).

\begin{tabular}{|l|l|l|l|l|l|l|l|l|l|l|}
\hline Fala & 1 & 2 & 3 & 4 & 5 & 6 & 7 & 8 & 9 & 10 \\
\hline FA & $100 \%$ & $87 \%$ & $88 \%$ & $91 \%$ & $90 \%$ & $92 \%$ & $95 \%$ & $94 \%$ & $94 \%$ & $95 \%$ \\
\hline PA & $100 \%$ & $82 \%$ & $86 \%$ & $90 \%$ & $88 \%$ & $93 \%$ & $93 \%$ & $94 \%$ & $94 \%$ & $95 \%$ \\
\hline CA & $100 \%$ & $82 \%$ & $87 \%$ & $89 \%$ & $88 \%$ & $92 \%$ & $91 \%$ & $94 \%$ & $92 \%$ & $95 \%$ \\
\hline
\end{tabular}

Tabela III.2.1 -Aprendizado e Reconhecimento

\section{III.2.4- Descrição do método utilizado para a comparação com "VA BA GA":}

Respeitando-se os padrões para captura de sinal de fala, conforme descrito em capitulo anterior, foram feitos dez comparações para cada uma das silabas-alvo, FA, PA, CA. A silaba FA foi comparada com a sílaba VA, A silaba PA foi comparada com a sílaba BA, A silaba CA foi comparada com a sílaba GA, Cada processo de comparação respeitou a seguinte seqüência, para n de 1 até 10: 
III.2.4.1- Usando a opção Capturar uma fala do SIAPF, O falante produz a silabaalvo de comparação. A silaba é capturada e salva com o numero n (no caso da silaba FA, a silaba de comparação foi a VA, e para o primeiro aprendizado, o arquivo recebe o nome de VA1)

III.2.4.2- Usando a opção Manipular uma fala do SIAPF, É obtida a constelação fônica em amplitude e freqüência da silaba produzida (para o exemplo, será manipulada a primeira silaba, portanto o arquivo VA1)

III.2.4.3- Usando a opção Análise usando a RNAP do SIAPF, através do botão Comparar, A silaba é compara com FA, e o SIAPF apresenta a Tabela de Comparação, após o aprendizado (Figura III.1.18 - para o primeiro aprendizado, a tabela só tem a primeira coluna)

III.2.4.4- se não for o décimo processo, repita desde III.2.4.1.

A seguir apresenta-se a análise dos resultados da comparação.

\section{III.2.5- Analisando a comparação com o "VA BA GA":}

A tabela III.2.2 mostra o porcentual de reconhecimento, quando a Rede recebe uma sílaba com apenas um Formante contrastante. Como se pode constatar, quando a Rede aprende intensivamente a silaba FA (10 vezes), e recebe a silaba VA para reconhecimento, o fator de reconhecimento nunca é maior que $72 \%$. Para os outros pares contrastantes este fator é menor. Isto mostra um nível de diferença satisfatório entre Fones de produção tão próxima. Esta diferença permite, como continuidade futura do trabalho, desenvolver o processo de Determinação de Diferenças entre Constelações, resultando na identificação dos formantes.

\begin{tabular}{|c|c|c|c|c|c|c|c|c|c|c|c|}
\hline FALA & $\mathbf{1}$ & $\mathbf{2}$ & $\mathbf{3}$ & $\mathbf{4}$ & $\mathbf{5}$ & $\mathbf{6}$ & $\mathbf{7}$ & $\mathbf{8}$ & $\mathbf{9}$ & $\mathbf{1 0}$ & média \\
\hline FA.VA & $\mathbf{7 0 \%}$ & $\mathbf{6 7 \%}$ & $\mathbf{7 2 \%}$ & $\mathbf{5 9 \%}$ & $\mathbf{6 5 \%}$ & $\mathbf{7 1 \%}$ & $\mathbf{6 4 \%}$ & $\mathbf{6 9 \%}$ & $\mathbf{6 6 \%}$ & $\mathbf{6 3} \%$ & $66,60 \%$ \\
\hline PA. BA & $\mathbf{5 1 \%}$ & $\mathbf{5 9 \%}$ & $\mathbf{4 9 \%}$ & $\mathbf{5 3 \%}$ & $\mathbf{4 8 \%}$ & $\mathbf{5 2} \%$ & $\mathbf{4 6 \%}$ & $\mathbf{4 7 \%}$ & $\mathbf{5 2 \%}$ & $\mathbf{4 8 \%}$ & $50,50 \%$ \\
\hline CA.GA & $\mathbf{6 2} \%$ & $\mathbf{5 9 \%}$ & $\mathbf{6 1 \%}$ & $\mathbf{6 2} \%$ & $\mathbf{5 8 \%}$ & $\mathbf{5 9 \%}$ & $\mathbf{6 0 \%}$ & $\mathbf{4 9 \%}$ & $\mathbf{6 3 \%}$ & $\mathbf{5 7 \%}$ & $59,00 \%$ \\
\hline \multicolumn{10}{|c|}{ Tabela III.2. - Comparação }
\end{tabular}




\section{III.2.6- Outras constatações:}

A partir dos testes efetuados, constatou-se uma variabilidade na obtenção das demais Estrelas da Constelação do sinal: Pré-Sonorização, Jitter e Shimmer. Essa variação, constatada apenas de forma perceptiva, parece estar ligada efetivamente a variações na produção da fala, merecendo um aprofundamento do estudo da constelação visando quantificar melhor esta variabilidade. Esta melhor quantificação aponta para uma possível constatação de distúrbios de fala, caso esta teoria seja aplicada também no cálculo de outras características do sinal, como o Tremor (Perturbação de freqüência em longo prazo) dividido em vow e flutter, facilitando o diagnóstico de esclerose múltipla e mal de Parkinson, respectivamente. 


\section{IV- Discussão e Considerações Finais}

\section{IV.1. Discussão, Conclusões e Perspectivas de continuidade}

Tendo em vista as características funcionais do SIAPF apresentam-se a seguir os tópicos mais relevantes a serem avaliados:

\section{IV.1.1- Eficiência da Rede:}

A eficiência da Rede pode ser constatada, através do comportamento do reconhecimento dos padrões nela aplicados, que atingiu um nível ótimo após 10 repetições, sem a trivialização de resultados. Este tipo de resultado em Redes Neurais Artificiais seria considerado ideal caso estivesse sendo utilizada técnicas convencionais. Para atingir esta eficiência é necessário o ajuste de parâmetros fortemente empíricos, o que força a necessidade de maiores estudos sobre o comportamento da Rede, objetivando uma maior exatidão na configuração do SIAPF. Numa perspectiva futura, faz-se necessário quantificar exatamente a eficiência da Rede, quando comparada com os métodos tradicionalmente mais utilizados para análise de produção de fala, justificando seu uso de forma mais abrangente. Isto ajudará a determinar limitações de uso para esta técnica.

\section{IV.1.2- Velocidade da Rede:}

Com relação à velocidade da Rede, tendo em vista as técnicas convencionais, é suficientemente rápida para o reconhecimento do sinal falado, aparentemente superior a Redes convencionais. Esta velocidade permite implementar um sistema que seja capaz de atingir resultados em tempo real, de forma simultânea à produção da Fala. A velocidade da Rede pode ser melhorada, para futuras análises em tempo real, utilizando ferramentas de banco de dados ao invés de arquivos texto, que são didáticos, porém morosos. 


\section{IV.1.3- Interpretação dos sinais:}

Considerando a interpretação dos sinais a variação dos valores dos elementos dos vetores é avaliada corretamente e o ajuste automático da Rede é eficiente para um bom reconhecimento. A boa resposta aos sinais contraditórios, redundantes e paracompletos são eficientemente tratados pela Rede em decorrência da sua construção embasada na Lógica Paraconsistente. Por se tratar de um sistema Paraconsistente, a Rede pode reconhecer pequenas variações mesmo que haja contradição, sem ter a necessidade do descarte de valores, sem a trivialização dos resultados. Este processo trás um enorme ganho aos resultados, diminuindo também o volume necessário para ajuste e

aprendizado da Rede. Como perspectiva de continuidade, é possível quantificar de forma mais exata as respostas da Rede, tornando o SIAFP em uma aplicação com uma interface mais acessível ao operador. Uma linguagem menos matemática e mais médica tornaria o aplicativo em algo mais fácil de se utilizar.

\section{IV.1.4- Eficiência da Técnica criada:}

As Constelações Fônicas se apresentam como uma nova técnica de estudo de sinais de fala, permitindo um amplo estudo sem a necessidade de acúmulos excessivos de dados. Como continuidade do trabalho aqui apresentado, deve-se sujeitar o aplicativo a uma bateria de testes, envolvendo faixas etárias de falantes, sexo, região, condição sócio-econômica entre outras características; avaliando as dificuldades que surgirem decorrente de uma base de dados mais abrangente. 


\section{IV.1.5- Motivação para estudos futuros:}

Em decorrência dos resultados obtidos, as Constelações Fônica, aliadas às Redes Neurais Artificiais Paraconsistentes aparecem como uma nova ferramenta para análise da produção de fala, merecendo uma atenção especial.

A ferramenta aqui apresentada pode ser aplicada a outros estudos importantes, entre eles:

- $\mathrm{O}$ estudo de Velocidade da Fala, permitindo identificar e diagnosticar distúrbios de Disfluência da Fala;

- O estudo de Flutuação na Produção da Fala, incluindo a determinação por exemplo do Tremor da Fala (Perturbação de freqüência em longo prazo) dividido em vow e flutter, facilitando o diagnóstico de esclerose múltipla e mal de Parkinson, respectivamente.

- Um aprofundamento na análise quantitativa das demais Estrelas da Constelação do sinal como Pré-Sonorização, Jitter e Shimmer pode permitir a normatização de mais características de fala, estreitando a distância existente entre a Fonética Articulatória, Acústica e Perceptual.

- O corte automático mostrou-se um recurso importante para o estudo da produção da fala facilitando a análise do sinal, evitando variações importantes nos resultados devido a flutuações de velocidade e intensidade do sinal. Uma maior eficiência neste recurso trará maior precisão em análises futuras.

- O ajuste de contantes das estrelas de forma empírica, mostrou que este processo necessita ser automatizado de forma a tornar o aplicativo mais eficaz e com menor influência externa. 


\section{Referências Bibliográficas}

ALBANO, E.C. \& Aquino, P. A. Linguistic criteria for building and recording units for concatenative speech synthesis in Brazilian Portuguese. Proceedings of Eurospeech'97, v. 2, p. 725-728. Rhodes, Grecia, 1997.

ALBANO, E.C. and Moreira, A.A., Archisegment-based letter-to-phone conversion for concatenative speech synthesis in Portuguese. Proceedings of the ICSLP'96, October 3-6, v. 3, p. 1708-1711, 1996.

ALlEN, J., S. Hunnicutt \& D. Klatt From text to speech: the MITalk system. Cambridge: Cambridge University Press, 1987.

Andrade, C. R. F. de - Abordagem neurolingüística e motora da gagueira. In: Tratado de Fonoaudiologia. Org. Leslie P. Ferreira; Débora M. Befi-Lopes; Suelly C.O Limongi. Roca. São Paulo. 2004. p. 1001-1026. ISBN 85-7241-550-5 (1076 pag.).

ATAL, B.S.; Efficient coding of LPC parameters by temporal decomposition, Proceedings of the international Conference on Acoustics, Speech, and Signal Processing, p. 81-84. 1997.

ÁVILA, Geraldo S.S. - Introdução às funções e à Derivada. São Paulo: Atual, 1994.

BARBOSA, P. A., Syllable-timing in Brazilian Portuguese: uma crítica a Roy Major. São Paulo: D.E.L.T.A., 2. ed., p. 369-402, 2000.

BARBOSA, P. A. Revelar a estrutura rítmica de uma língua construindo máquinas falantes: pela integração de ciência e tecnologia de fala. In: Estudos de Prosódia. Scarpa, E. (org.). Campinas: Editora da Unicamp. p. 21-52, 1999.

BATSCHELET, E. - Introdução à Matemática para Biocientistas. São Paulo: EDUSP, 1978.

BOURLARD, H., H.Hermansky \& N. Morgan Towards increasing speech recognition error rates. Speech Communication v. 3, 18 p.,1996.

BECCHETTI, C.; RICOTTI, L.P. Speech Recognition Theory and C++ implementation. 3. ed., New York: Jhon Wiley \& Sons 1td, 2000. 
BEHLAU, Maria; Considerações sobre a análise acústica em laboratórios computadorizados de voz. Fonoaudiologia Atual, p. 93-115 - Rio de Janeiro: Editora Revinter, 1997.

BEHLAU, Maria et al; Voz, O livro do Especialista, v. 1, p. 138-179; São Paulo: Editora Revinter, 2001.

BIMBOT, F.; CHOllet,G.; DELEGlise,P.; MONTACIE,C.; Temporal decomposition and acoustic-phonetic decoding of speech, Proceedings of the international Conference on Acoustics, Speech, and Signal Processing, p. 81-84.

BOERSMA, Paulus P.G.; Functional Phonology - Formalizing the interactions between articulatory and perceptual drives. 509 p. Netherlands: Holland Academic Graphics, 1998.

BOERSMA, Paulus P. G.; Cinteraction between Glottal and Vocal-Tract Aerodynamics in a Comprehensive Model of the Speech Apparatus - Institute of phonetic Science, Amsterdam, Netherlands: Holland Academic Graphics, 2003.

DA COSTA, N.C.A. et al., Lógica Paraconsistente Aplicada. 1. ed., São Paulo: Editora Atlas, 1999.

DA SILVA FILHO, J.I.; ABE, J.M. Fundamentos das Redes Neurais Artificiais destacando aplicações em Neurocomputação. 1. ed., São Paulo: Editora Villipress, 2001 .

FIORIN, José Luiz et al., Introdução a Lingüística - I. Objetos teóricos. 2. ed., São Paulo: Editora Contexto, 2003.

FIORIN, José Luiz et al., Introdução a Lingüística - II. Princípios de análise. 2. ed., São Paulo: Editora Contexto, 2003.

FOURIER, Jean Baptiste Joseph - Descoberta das Séries de Fourier, Paris: Academia de Paris, 1807.

FRENCH, A. P.; Vibraciones Y Ondas, 1. ed., Barcelona: Ed. Reverte, 1074.

GLASS, James R.; CA probabilistic framework for segment-based speech recognition - Computer Speech and Language v. 17, p. 137-152, MA-USA: Academic Press, 2003.

GRAWFORD, F. S. JUNIOR; Waves, 1.ed., USA: Mc Graw Hill , 1968.

HUCKVALE, Mark; FANG, Alex Chengyu; Using phonologically-constrained morphological analysis in continuous speech recognition - Computer Speech and Language v. 16, p. 165-181, MA-USA: Academic Press, 2002. 
JOHNSON, K, Acoustic and Auditory Phonetics. Oxford: Blackwell Publishers Ltd, 1997.

KENT, R. \& READ, C. The Acoustic Analysis of Speech. San Diego: Singular Publishing Group Inc., 1992.

KOVACS, Z.L. Redes Neurais Artificiais, 1.ed., São Paulo: EDUSP, 1996.

LAU, C.G.Y. Neural Network - Theoretical foundations and analysis. 1.ed., USA: IEEE press, 1991.

LEVELT, W. Speaking. From intention to articulation. Cambridge: MIT Press, 1989. LADEFOGED, P. Elements of Acoustic Phonetics. 2. ed, Chicago: University of Chicago Press, 1996.

MADUREIRA, S. Entoação e síntese da fala: Modelos e Parâmetros. In: Estudos de Prosódia. Scarpa, E. (org.). Campinas: Editora da Unicamp, 1999.

MENDELSON, Elliott - Introduction to Mathematical Logic, $4^{\mathrm{a}}$ ed. USA: Chapman \& Hall/CRC, 456 p. 1997.

MOREIRA, José dos Santos, Elementos de Estatística, 1. ed., São Paulo: Atlas, 1970. NANDASENA, A.C.R.;NGUYEN, P.C.;AKAGI,M. Spectral stability based event localizing temporal decomposition - Computer Speech and Language v.15, p. 381401, Japam Advanced Institute of Science and Tecnology, Ishikawa, Japão, Academic Press, 2001.

NEWMEYER, F. J. (Ed.) Linguistics: The Cambridge Survey. Linguistics Theory: Foundations v. 1, Cambridge: Cambridge University Press, 1988.

PAIN, H.J. The Physics of Vibrations and Waves. 1. ed., Inglaterra: W.B. Ltd., 1968. PAIS, CIDMAR TEODORO; BARBOSA, MARIA APARECIDA; PONTES, EUNICE et. al; Manual de Lingüística, 2. ed., São Paulo: global editora, 1986.

PRAAT, a system for doing phonetics by computer, version 3.4. 1996.

PRADO, L.C. Curso de Física Geral - As Oscilações, São Paulo, s.ed., 1950.

PRADO, João Carlos A. Redes Neurais Artificiais Paraconsistentes utilizadas no reconhecimento de padrões -São Paulo, 2002202 p., Dissertação (Mestrado), Escola Politécnica da Universidade de São Paulo.

PRADO, João Carlos A; Abe, Jair Minoro; THE 6TH WORLD MULTICONFERENCE ON SYSTEMICS, CYBERNETICS AND INFORMATICS - 14 - 18 DE JULHO, 2002 - Flórida - USA. Proccedings; Titulo: "Paraconsistent Artificial Neural Network and its application on Pattern Recognition" 
PRADO, João Carlos A; Abe, Jair Minoro; THE 7TH WORLD MULTICONFERENCE ON SYSTEMICS, CYBERNETICS AND INFORMATICS - 14 - 18 DE JULHO, 2003 - Flórida - USA. . Proccedings; Titulo: "Aspects of Paraconsistent Artificial Neural Networks"

PRADO, João Carlos A; III Congresso Brasileiro de Computação - 25 a 29 de AGOSTO, 2003 - UNIVALI - Itajaí - Brasil - Artigos: Titulo: “Alguns Aspectos Práticos da Lógica Paraconsistente aplicados à Rede Neural Artificial”.

PRADO, João Carlos A; III Congresso Brasileiro de Computação 25 a 29 de AGOSTO, 2003 - UNIVALI - Itajaí - Brasil - Artigos: Titulo: “As Redes Neurais Artificiais Paraconsistentes Utilizadas no Aprendizado e Reconhecimento de Padrões". PRADO, João Carlos A; Abe, Jair Minoro; Nakamatsu, Kazumi: Paraconsistent Artificial Neural Network: Applicability in Computer Analysis of Speech Productions. KES - 2006 p. 844-850 (http://www.informatik.unitrier.de/ ley/db/conf/kes/kes2006-2.html\#AbePN06) - 07/10/2006.

RABINER,L.; A tutorial on hidden Markov models and selected applications in speech recognition. Proc. IEEE 77 v. 2, p. 257-286

RABINER, L. \& Biing-Hwang Juang, Fundamentals of Speech Recognition. Prentice-Hall, 1993.

RAJ, BHIKSHA; SINGH, RITA; Classifier-based non linear projection for adaptive endpointing of continuous speech - Computer Speech and Language v.17, p. 5-26, MA-USA: Academic Press, 2003.

RICHMOND, P.G. Piaget - Teoria e Prática. 1. ed. São Paulo: IBRASA, 1990.

ROSEN, Kenneth H. Rosen, Discrete Mathematics and Its Applications 6.ed., USA: Mc Graw Hill , 2006.

RUSSEL, Martin J. e BILMES, Jeff A; Introduction to the special issue on new computational paradigms for acoustic modeling in speech recognition, Computer Speech and Language - v. 17, p. 107-112, 2003

SCHALKOFF, R.J. Artificial Neural Network. 1.ed., USA: Mc Graw Hill , 1997.

SINENCIO, E.S.; LAU, C. G. Y. Artificial Neural Networks Paradigms. 1. ed., USA: IEEE press, 1992.

SILVA, Thais Cristófaro, Exercícios de Fonética e Fonologia. 1. ed., São Paulo: Editora Contexto, 2003. 
SKLANSKY, J. Pattern Recognition: introduction and foundations, 1.ed., Sklansky, Dowdon, Hutchinson; Ross, inc, 1973.

TAFNER, M.A. Reconhecimento de palavras faladas isoladas usando redes neurais artificiais, Santa Catarina, 1996, 170 p. Dissertação (Mestrado) - Universidade Federal de Santa Catarina.

TIPLER, Paul A. Física para cientistas e engenheiros: gravitacão, ondas e termodinâmica, 3. ed., Rio de Janeiro: Guanabara Koogan, 1994.

TITZE, I.; Towards standars in acoustic analisys, National Center for Voice and Speech; Denver, Universit of Lowa, USA: NCVS library - 1989.

TOU, J.T.; GONZALEZ, R.C. Pattern Recognition Principles, 1.ed., USA: AddisonWesley Publishing Company, 1974.

VARONA, A.; TORES, I.; Ck-TSS language models in speech recognition systems Computer Speech and Language v.15, p. 127-149, MA-USA: Academic Press, 2001.

ZHENG, JING; FRANCO, HORACIO; STOLCKE, ANDREAS; Modeling word-level rate-of speech variation in large vocabulary conversational speech recognition Speech Communication v. 41, p. 273-285, MA-USA: Academic Press, 2003.

ZITOUNI, UMED; SMAILI,KAMEL; HATON, JEAN PAUL; Statistical Language modeling based on variable-length sequences Computer Speech and Language v., p. 27- 41, MA-USA: Academic Press, 2003.

ZWEIG, GEOFFREY; Cbayesian network structures and inference techniques for automatic speech recognition - Computer Speech and Language v.17, p. 173-193, MA-USA: Academic Press, 2003.

Apêndices 
A- Etapas da Criação do Sistema de Análise da Produção da Fala

Etapa 1 - Base teórica - período pré-qualificação

\begin{tabular}{|c|c|c|c|c|c|c|c|c|c|c|c|c|}
\hline Descrição & $\begin{array}{l}\text { mês } \\
\text { ano }\end{array}$ & $\begin{array}{l}02 \\
04\end{array}$ & $\begin{array}{l}03 \\
04\end{array}$ & $\begin{array}{l}04 \\
04\end{array}$ & $\begin{array}{l}05 \\
04\end{array}$ & $\begin{array}{l}06 \\
04\end{array}$ & $\begin{array}{l}07 \\
04\end{array}$ & $\begin{array}{l}08 \\
04\end{array}$ & $\begin{array}{l}09 \\
04\end{array}$ & $\begin{array}{l}10 \\
04\end{array}$ & $\begin{array}{l}11 \\
04\end{array}$ & \begin{tabular}{|l|}
12 \\
04
\end{tabular} \\
\hline A representação matemática de sinais sonoros & & $\mathrm{x}$ & $\mathrm{x}$ & & & & & & & & & \\
\hline Os Traços, Fones e os Fonemas & & $\mathrm{x}$ & $\mathrm{x}$ & $\mathrm{x}$ & & & & & & & & \\
\hline Os programas PRAAT e GRAM & & $\mathrm{x}$ & & & & & & & & & & \\
\hline $\begin{array}{l}\text { Um estudo superficial da possibilidade de } \\
\text { identificação dos Traços através dos } \\
\text { programas PRAAT e GRAM }\end{array}$ & & $\mathrm{x}$ & $\mathrm{x}$ & & & & & & & & & \\
\hline $\begin{array}{l}\text { Um estudo completo sobre o programa } \\
\text { PRAAT }\end{array}$ & & $\mathrm{x}$ & $\mathrm{x}$ & $\mathrm{x}$ & $\mathrm{x}$ & $\mathrm{x}$ & $\mathrm{x}$ & & & & & \\
\hline $\begin{array}{l}\text { A utilização do PRAAT para uma análise de } \\
\text { processos de matematização dos sons da fala }\end{array}$ & & & & $\mathrm{x}$ & $\mathrm{x}$ & $\mathrm{x}$ & $\mathrm{x}$ & $\mathrm{x}$ & & & & \\
\hline A criação do conceito de constelação fônica & & & & & & & & $\mathrm{x}$ & $\mathrm{x}$ & & & \\
\hline $\begin{array}{l}\text { Criação de um programa de computador } \\
\text { capaz de captar o sinal e obter os elementos } \\
\text { necessários à criação da Constelação Fônica } \\
\text { - SIAPF }\end{array}$ & & & & & & & & & $\mathrm{x}$ & $\mathrm{x}$ & $\mathrm{x}$ & $\mathrm{x}$ \\
\hline
\end{tabular}

Etapa 2 - Base teórica - período pós-qualificação 


\section{Etapa 3 - Aplicação}

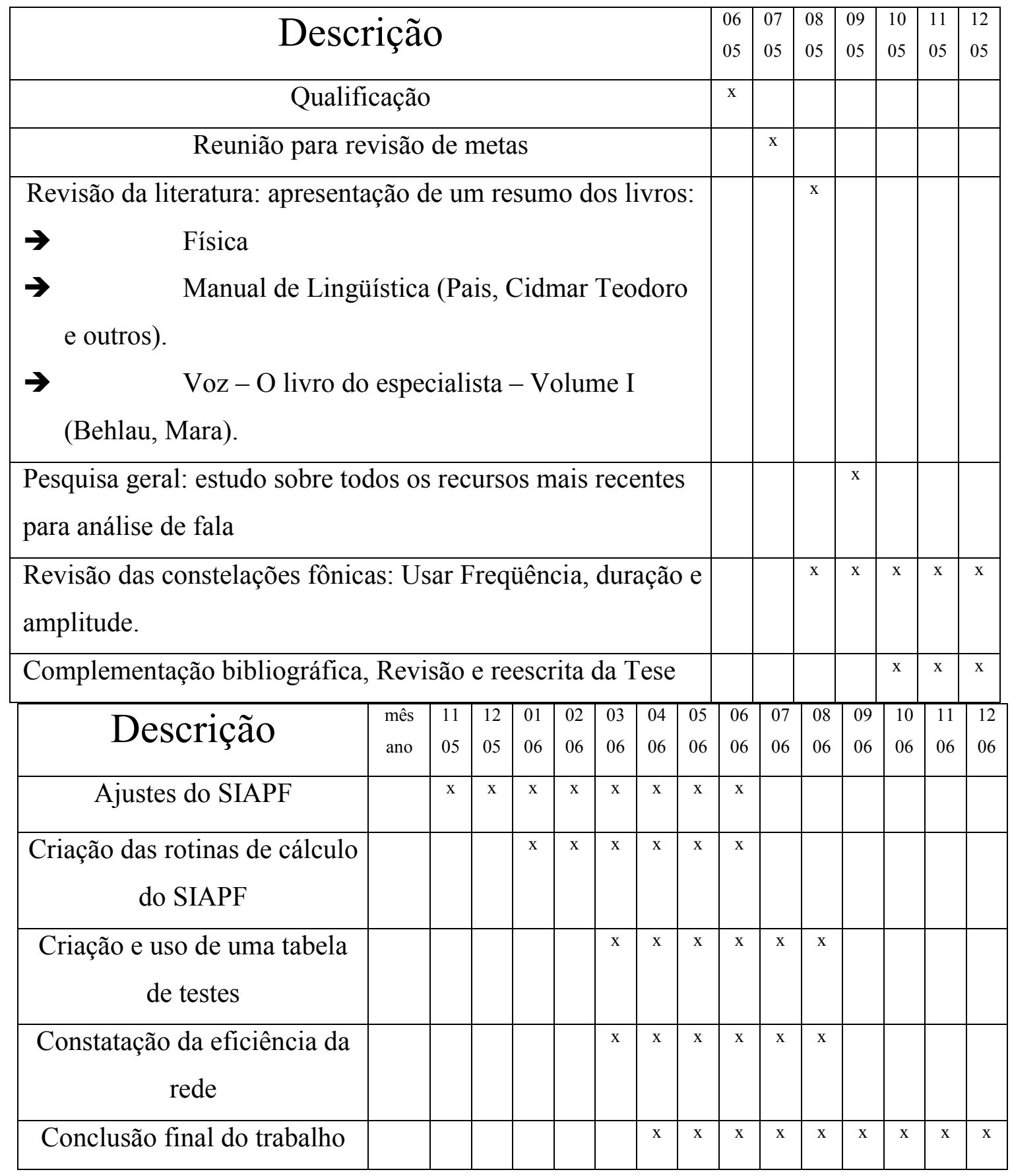

\section{B- Autorização da AUTOBYTE para uso do Delphi ${ }^{\circledR}$ para o desenvolvimento do SIAPF}




\section{DECLARAÇÃo}

A AUTOBYTE - COMÉRCIO E INFORMÁTICA LTDA - ME, com sede social na cidade de São Paulo, estado de São Paulo, localizada a Av. Gal Ataliba Leonel, 459, tendo inscrição no CNPJ sob no 62.204.821/0001-05 e Inscrição Estadual sob no 113.113.858.117, aqui representada por seu diretor no final assinado, declara ser responsável pelo desenvolvimento do SIAPF (Sistema de análise de produção de fala) através do uso do DELPHI ${ }^{\circledR}$, adquirido regularmente da BORLAND $\AA$ do BRASIL.

\section{AUTOBYTE - COMÉRCIO E INFORMÁTICA LTDA - ME JOÃO CARLOS ALMEIDA PRADO SÓCIO - DIRETOR}

\section{Anexos}

\section{A-Estudo do programa PRAAT}


O programa PRAAT (Disponível através do link:

http://www.fon.hum.uva.nl/paul/) consiste em um aplicativo destinado a transformar um sinal de áudio digitalizado em uma representação matemática disponível, desenvolvido por:

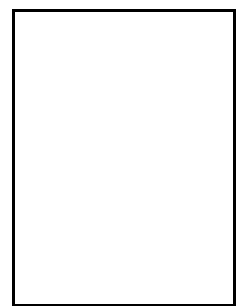

$\underline{\text { Paul }}$
Paul Boersma and David Weenink Institute of Phonetic Sciences (http://www.fon.hum.uva.nl/) University of Amsterdam

Herengracht 338 1016CG Amsterdam

The Netherlands

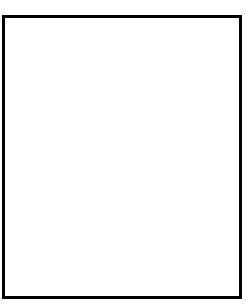

David

Esta representação matemática pode ser em amplitude em função do tempo, em freqüência em função do tempo, ou ainda de várias outras formas que não serão aqui abordadas. As representações em amplitude e freqüência são obtidas através de séries matemáticas, permitindo ao operador visualizar estes gráficos (conforme apresentado anteriormente). Depois de instalado em plataforma WINDOWS ${ }^{\circledR}$ o PRAAT pode ser acessado a partir do ícone a seguir:

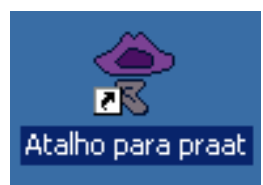

Uma Vez acessado, o PRAAT apresenta sua tela inicial:

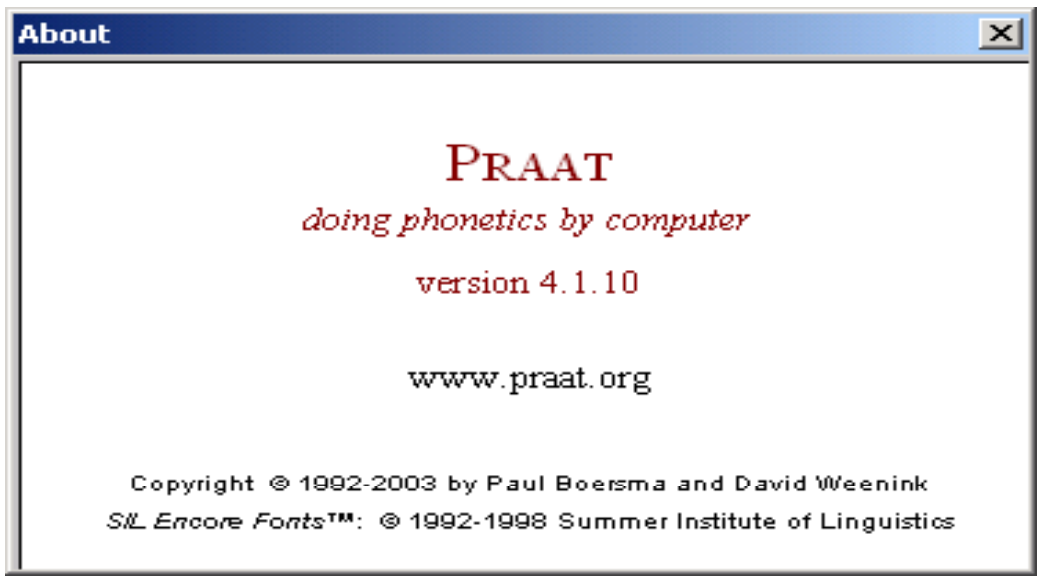


Apresenta também as telas de manipulação de sons, composta por duas janelas, sendo uma com a relação de objetos (PRAAT objects) existentes já gravados pelo PRAAT que podem ser manipulados, através da tela de figuras (PRAAT pictures).

Veja a sua apresentação na figura a seguir:

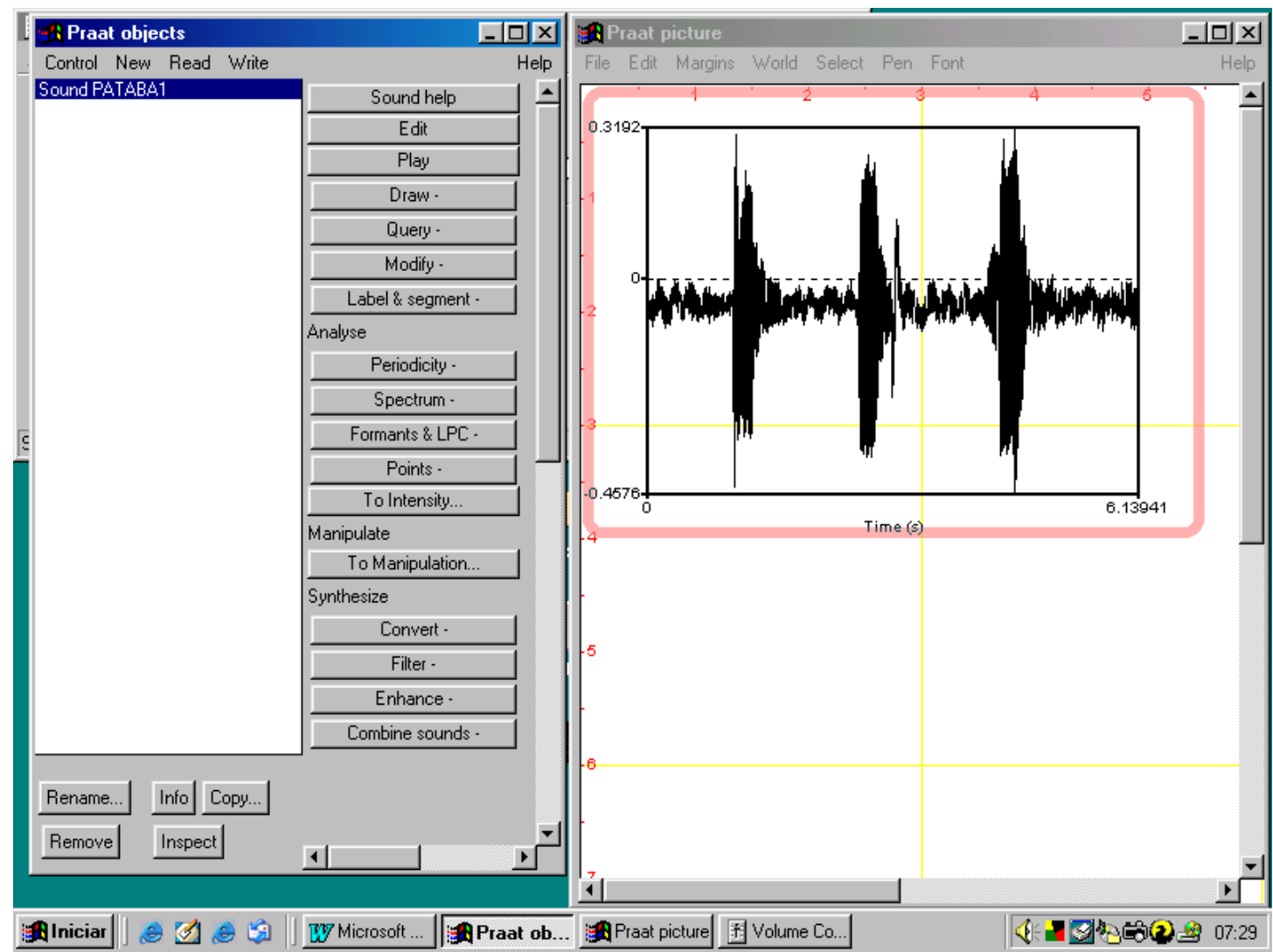

PA, TA BA no espectro em amplitude - programa PRAAT.

A partir da tela de Objetos é possível capturar um sinal de fala e manipula-lo das mais diversas formas possíveis.

A seguir apresentam os um roteiro bem simplificado para o uso básico do PRAAT. 
Para gravar uma fala, estando o computador com microfone e caixas de som devidamente configurados, usando a janela PRAAT Objects, selecione a opção New e em seguida Record mono Sound, conforme a figura a seguir:

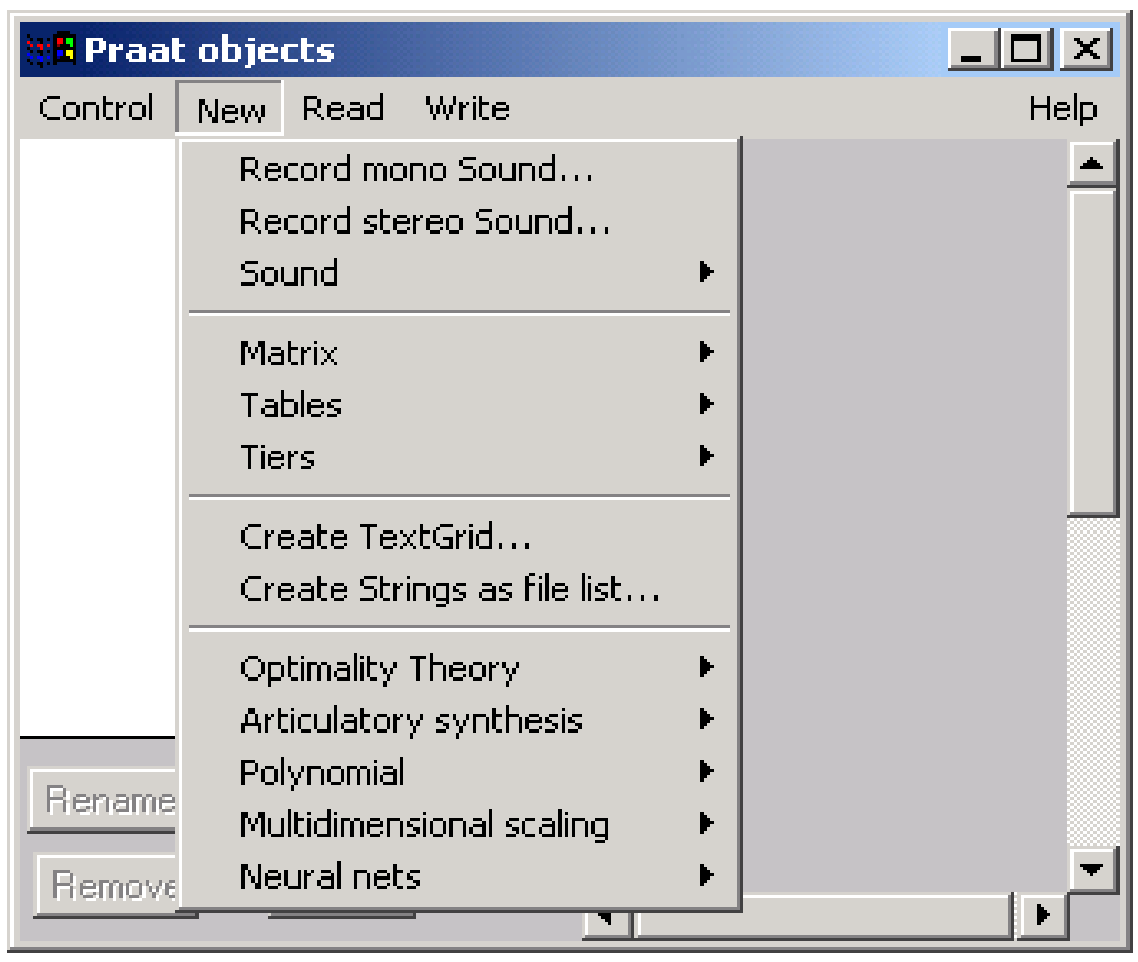

O PRAAT apresentará a tela de captura de sinal, conforme a figura a seguir:

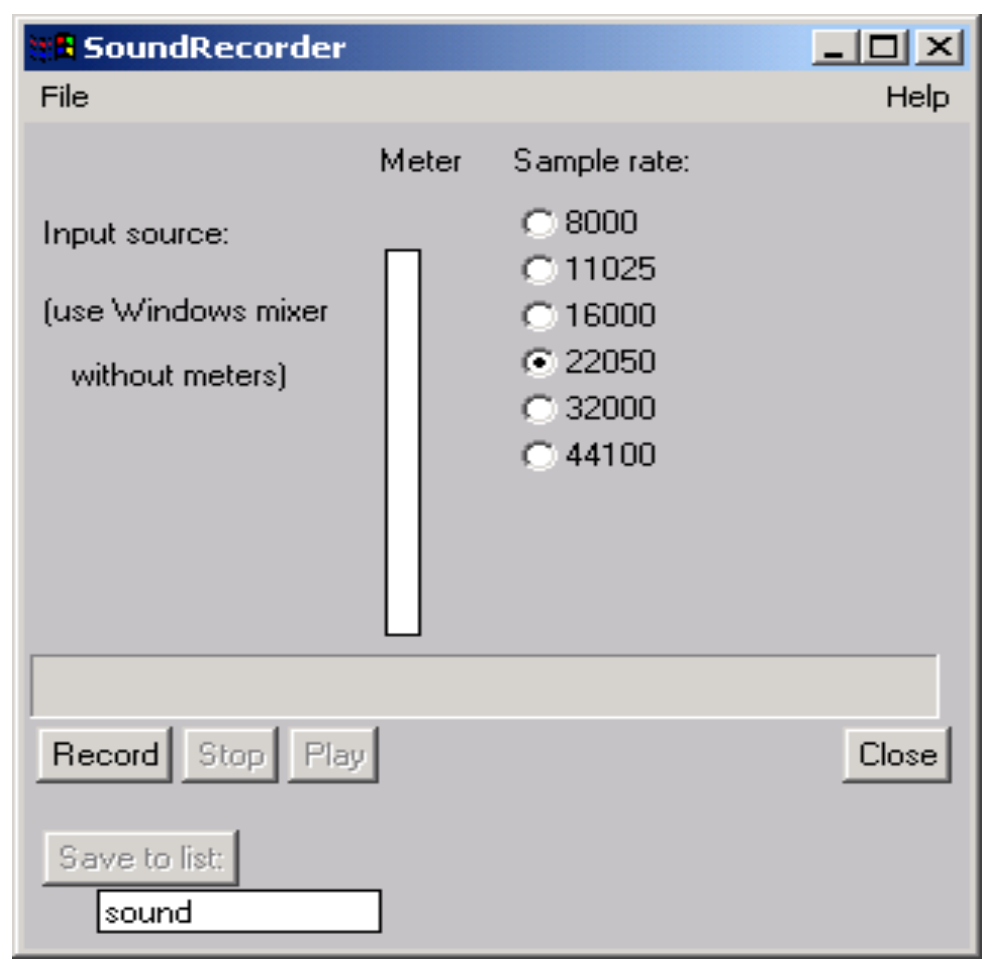


Uma Vez gravado o sinal de voz, a Janela PRAAT Objects irá disponibilizar todas as operações aplicáveis a este sinal de voz. Use o botão Edit, para manipular o sinal. Veja a tela a seguir:

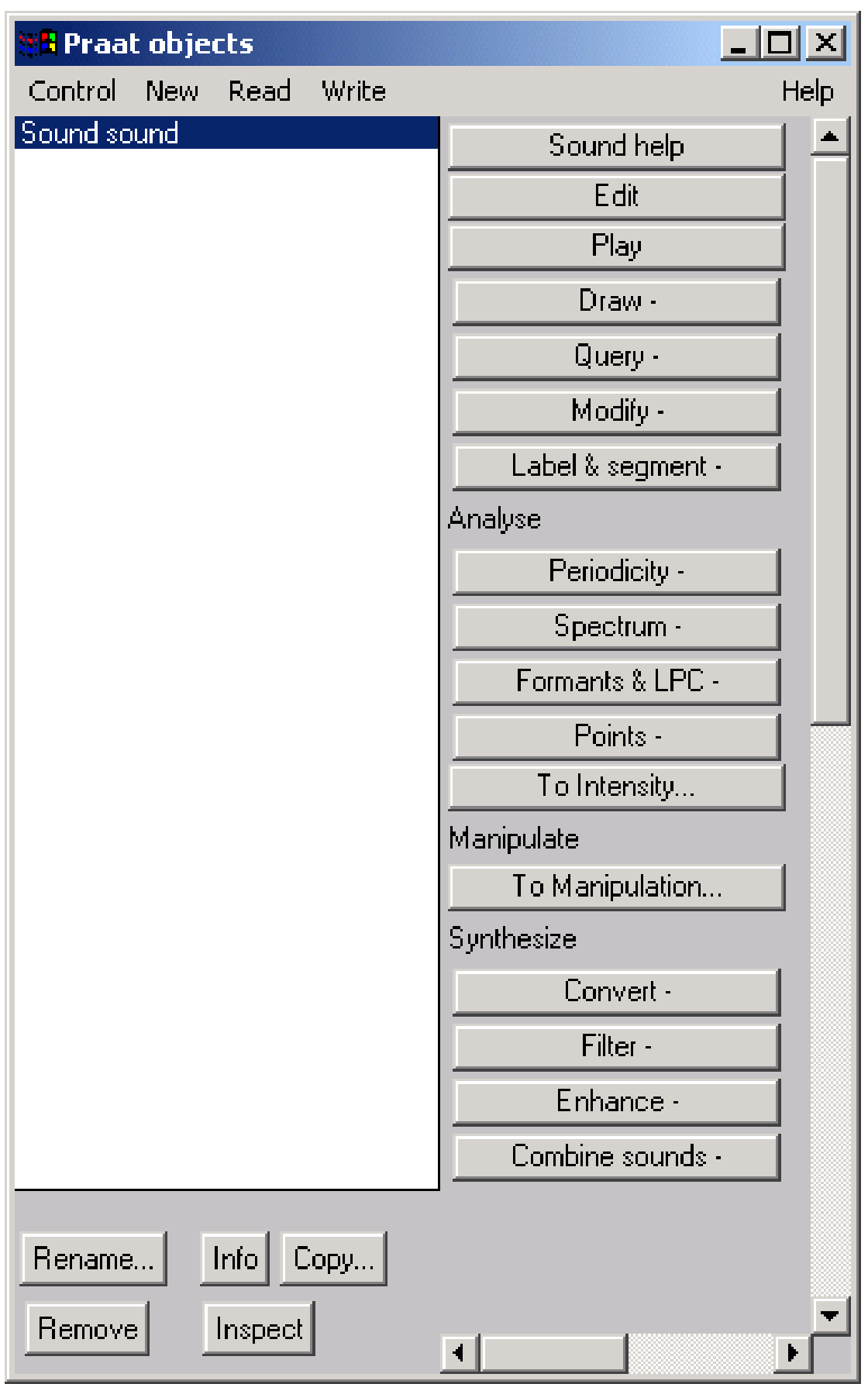

Ativado o botão Edit, o PRAAT transfere, para a janela PRAAT Pictures o sinal falado, apresentando sua representação carteziana da amplitude do sinal composto em função do tempo. Veja a figura exemplo a seguir: 


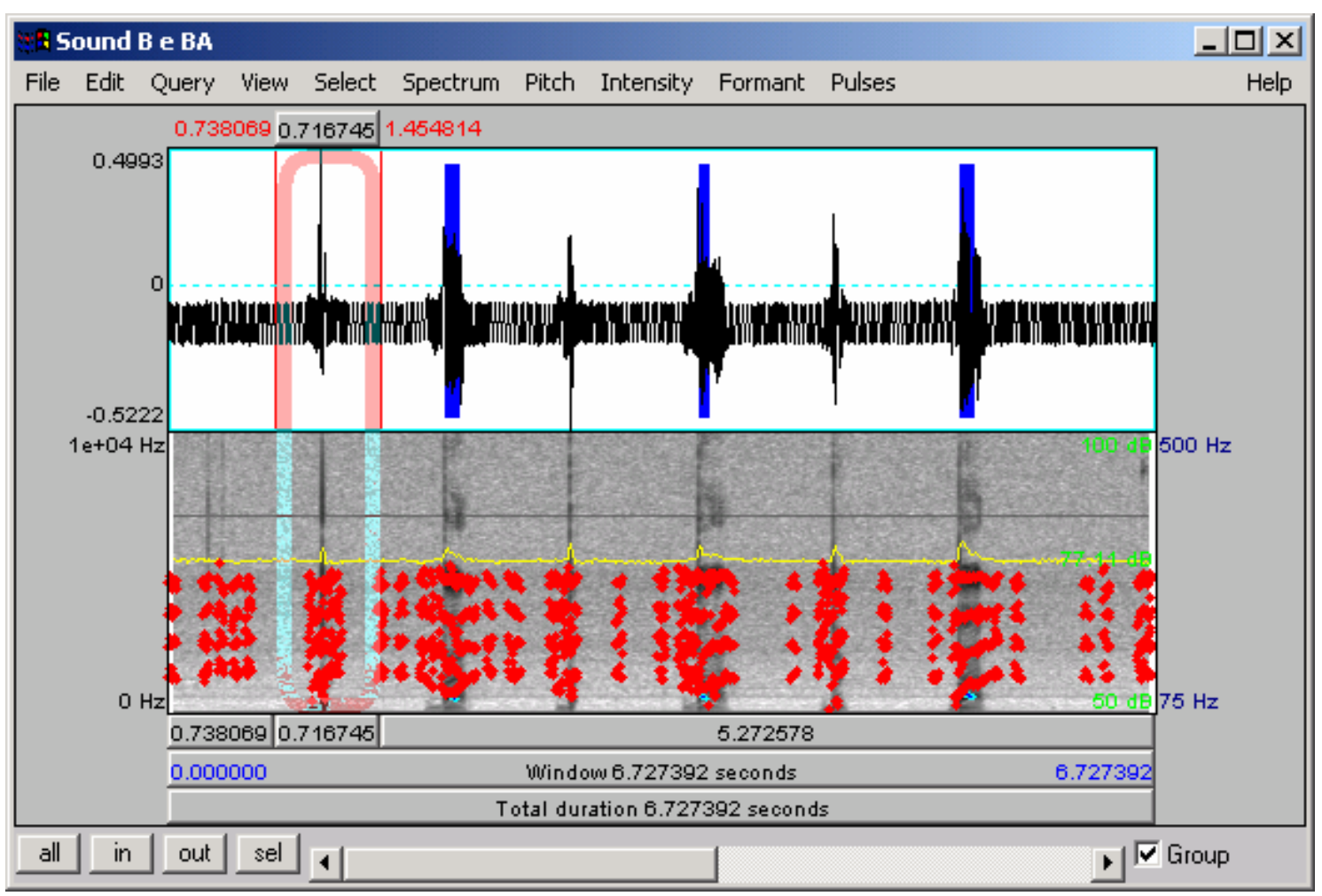

Para editar uma parte do sinal, use o Mouse, clicando e arrastando para selecionar o trecho desejado. Note que as barras na parte superior e inferior que aparassem indicam o tempo do trecho selecionado. Para o trecho selecionado, é possível aplicar um Zoom, conforme indicado a seguir:

\begin{tabular}{|c|c|c|c|}
\hline Yiew & Select Spectrum & Pitch & Inten \\
\hline \multicolumn{4}{|c|}{$\checkmark$ Sound autoscaling } \\
\hline \multicolumn{4}{|c|}{ Analysis vindow: } \\
\hline \multicolumn{4}{|c|}{ Show analyses... } \\
\hline \multicolumn{4}{|c|}{ Time step settings... } \\
\hline \multicolumn{4}{|c|}{ Time domain: } \\
\hline \multicolumn{4}{|c|}{ Zoom... } \\
\hline & ow all & Ctrl-A & \\
\hline & om in & Ctrl-I & \\
\hline & om out & Ctrl-O & \\
\hline & om to selection & $\mathrm{Ctrl}-\mathrm{N}$ & \\
\hline
\end{tabular}

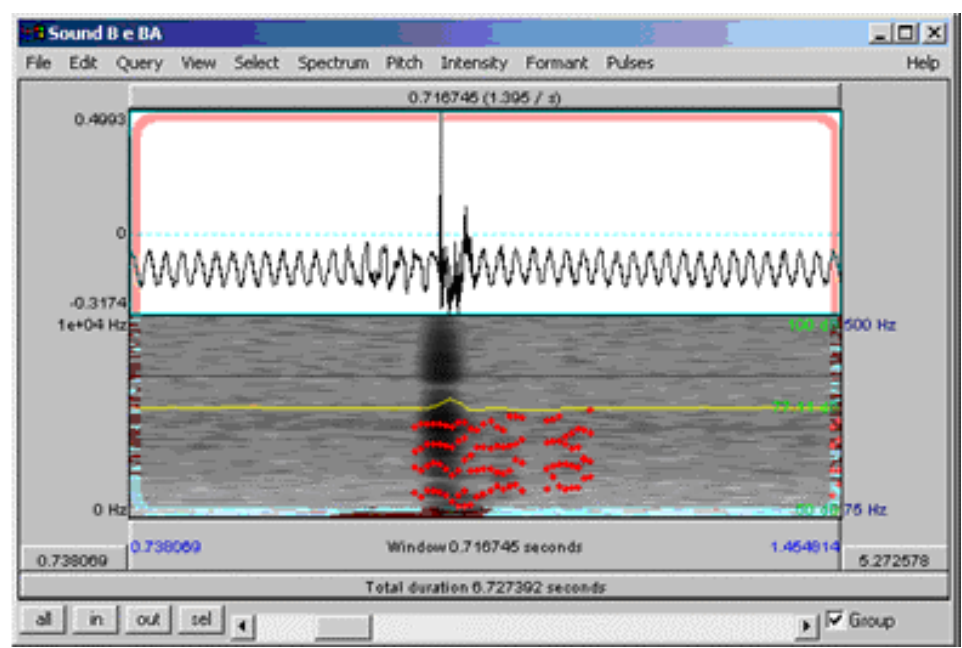


O trecho anteriormente selecionado pode ser extraído como um novo objeto, permitindo novos tratamentos apenas para este trecho do sinal de fala. Veja o trecho extraído a seguir:
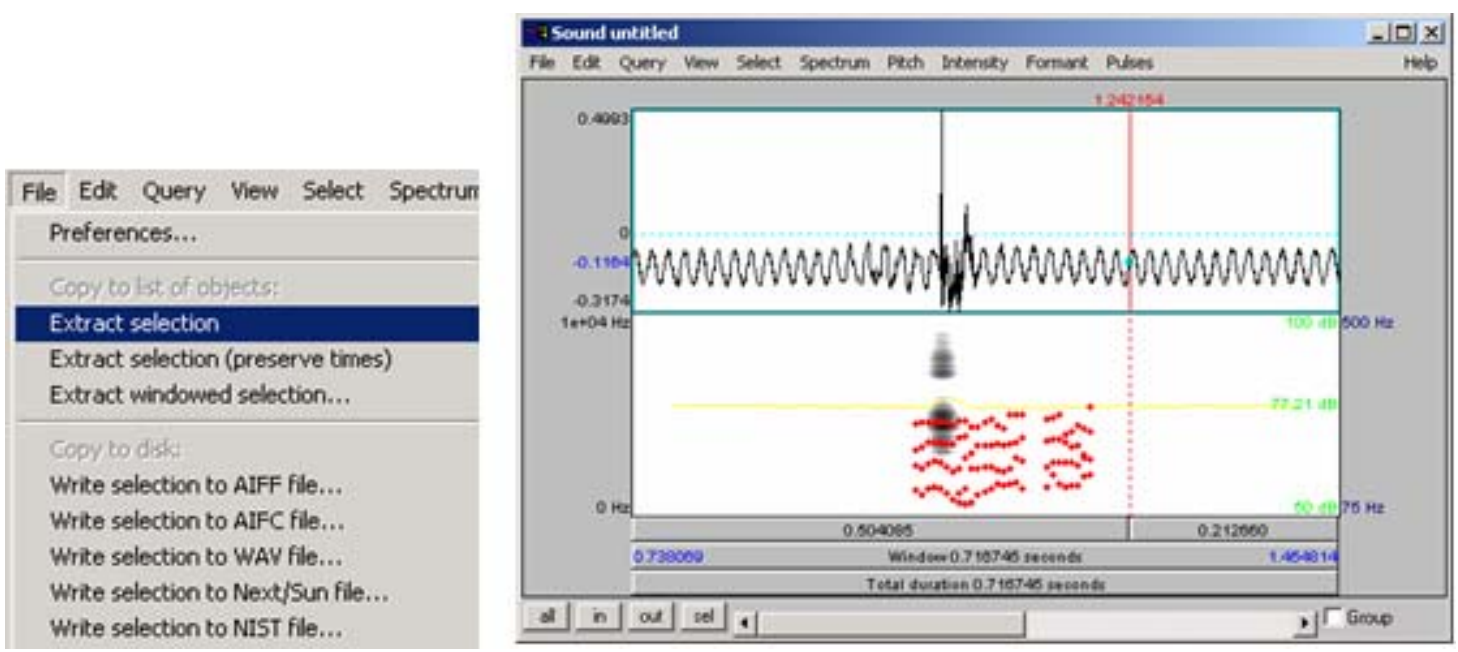

O PRAAT permite também criar sons a partir de formulas matemáticas através da opção indicada a seguir:

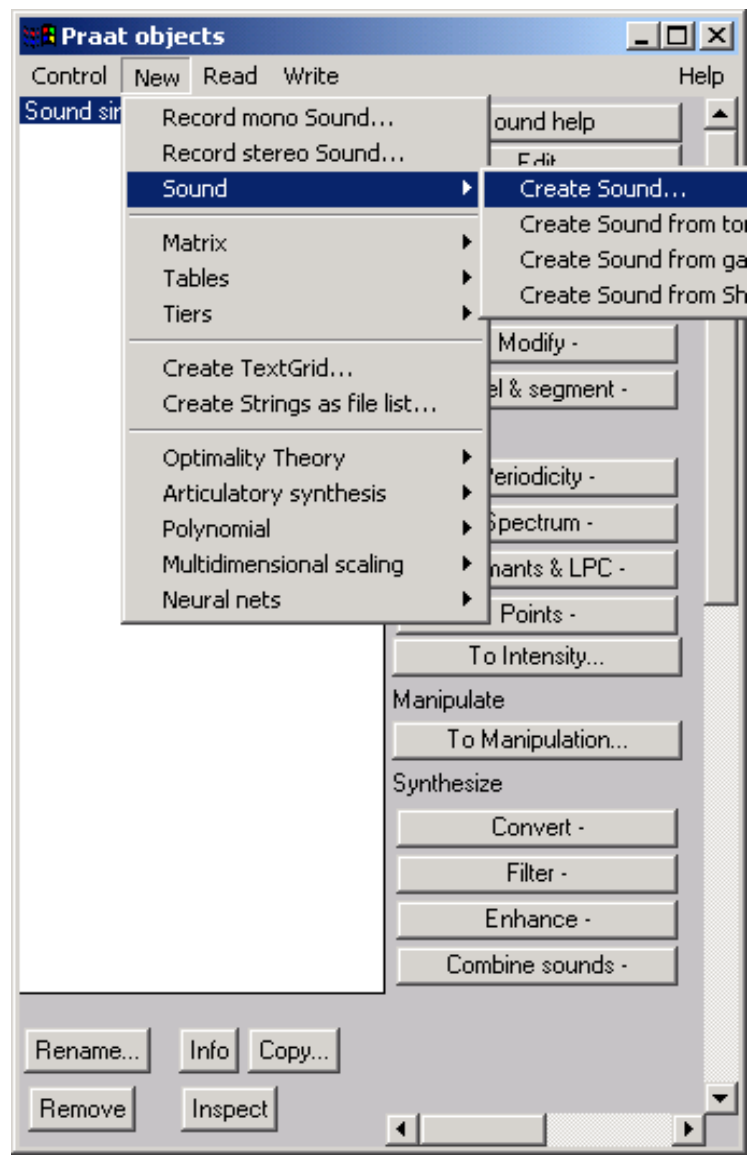


Ao selecionar a opção para criação de som, o PRAAT disponibiliza a fórmula, de acordo com o selecionado, possibilitando ainda alterar esta formula e seus parâmetros. Veja esta tela a seguir:

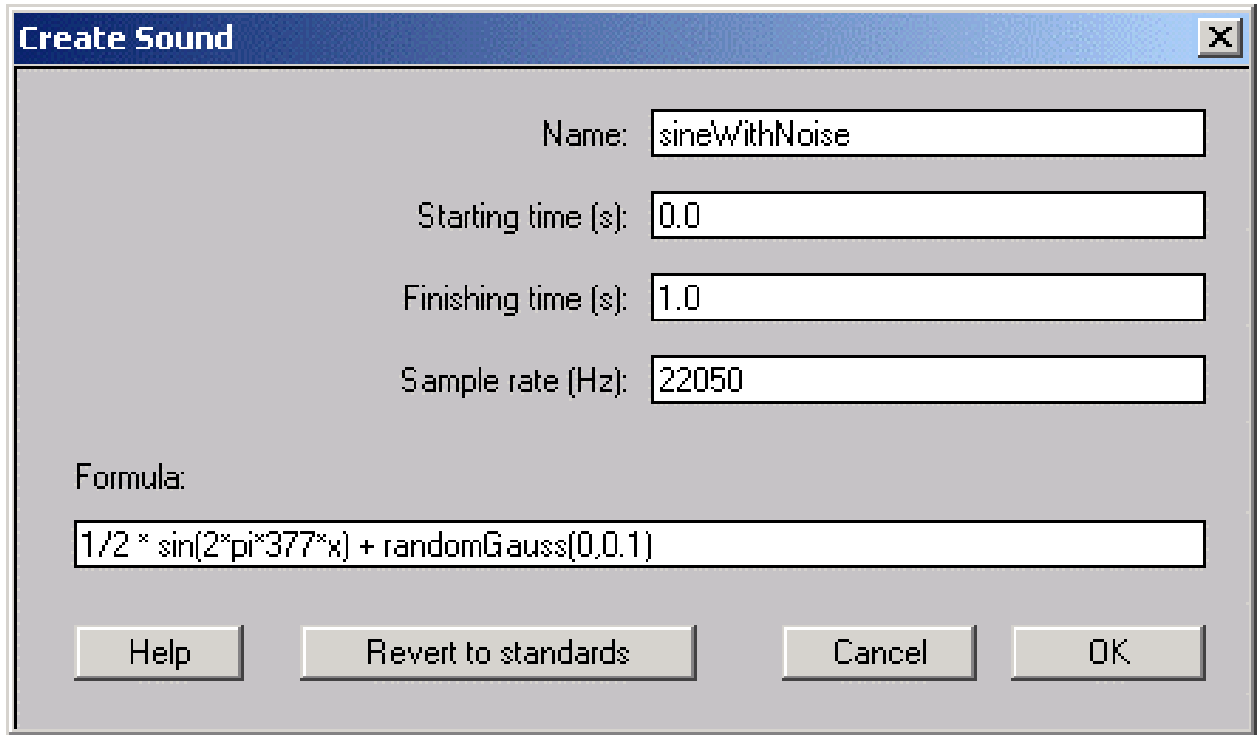

A seguir apresenta-se o sinal obtido a partir da formula selecionada:

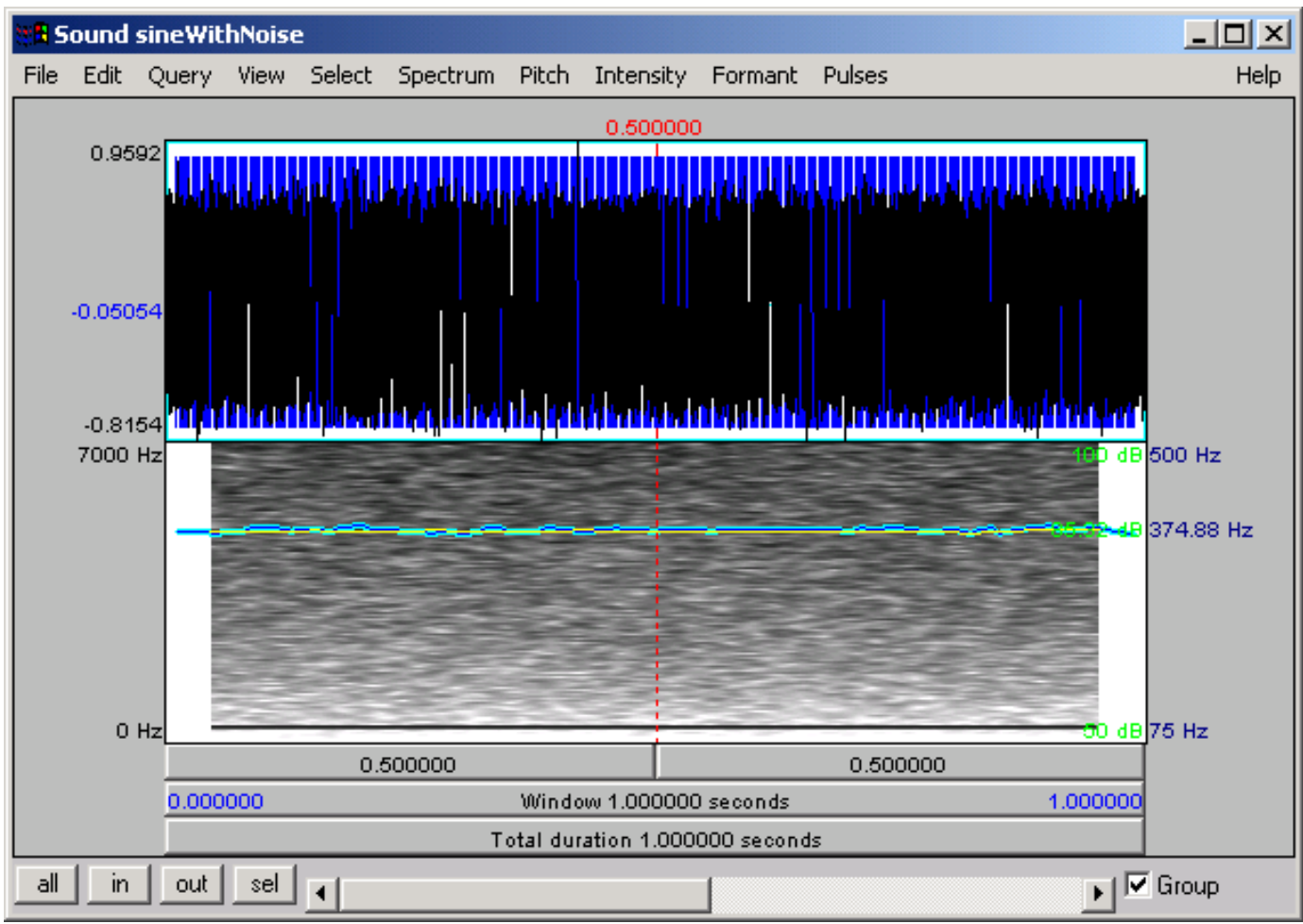




\section{B- Aplicativo para visualização da série de Fourier}

Durante a pesquisa sobre séries de Fourier, através do link:

http://www.edu.aytolacoruna.es/aula/fisica/applets/Hwang/ntnujava/sound/sound_s.htm

Obteve-se o acesso à um aplicativo para a visualização da série de Fourier. As telas deste aplicativo e alguns exemplos de ondas estão apresentados a seguir (por se tratar de um aplicativo sem referencias ao autor do mesmo, sua referencia bibliográfica não conta neste trabalho):

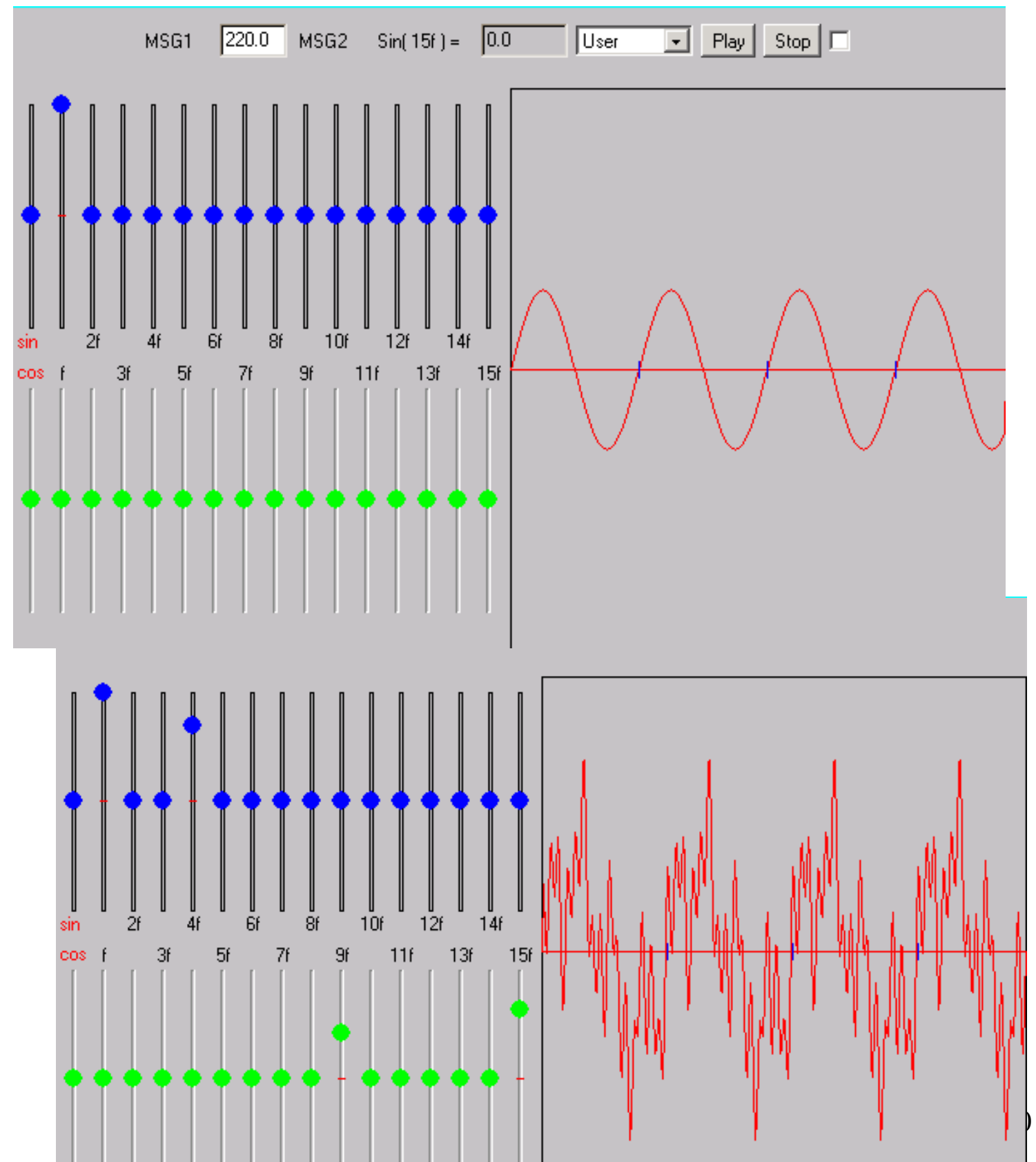


Por se tratar de um recurso excepcionalmente didático, desenvolveu-se um aplicativo, a partir do ambiente de desenvolvimento DELPHI (mesma ferramenta utilizada para o desenvolvimento do SIAPF), que possui os mesmos recursos do aplicativo apresentado anteriormente.

\section{C- Séries de Fourier e Transformada rápida de Fourier}

As séries de Fourier, Descobertas no Século dezenove (FOURIER, 1807), são de extrema importância para o estudo de sinais compostos.

É importante ressaltar que, nos computadores atuais, as entradas de sinais sonoros sempre captam os sinais como onda composta, sendo que seria possível também captar o sinal a partir de filtros freqüenciais infinitos, que consistiria em uma transformada de Fourier direta.

Como, na prática, a obtenção destes filtros infinitos torna-se inviável, a transformação do sinal para uma somatória de senóides é obtida através de processos matemáticos. Este processo matemático denomina-se transformada rápida de Fourier. Esta representação consiste em relacionar, para cada unidade de tempo, uma freqüência e sua respectiva potencia.

Para se obter o sinal completo, representado por uma composição de senóides, representando assim o espectro em freqüência do sinal sonoro captado, utiliza-se a transformada rápida de Fourier, a partir de uma interpretação continua do sinal, usando a seguinte fórmula:

$$
X(f)={ }_{0} \int T(t) \mathrm{e}^{-2 \pi i f t} d t
$$

Onde T é a duração do som, e t é a tomada relativa do som, associada à primeira amostragem, ou seja, ao inicio do sinal. Desta forma calcula-se então todas as 
componentes existentes, considerando-se todas as freqüências que se "encaixam" em uma determinada senóide.

Esta representação também é denominada de representação por harmônicos, que nada mais são que múltiplos a partir de uma freqüência base. Este tipo de representação do sinal sonoro parece estar mais próximo do sistema utilizado pelo ouvido humano que consegue facilmente diferenciar "timbres", se são diferenças entre sinais sonoros a partir da segunda harmônica. Este conceito pode ser facilmente entendido quando se ouve a nota dó de uma flauta e a mesma nota dó de um violão: a freqüência fundamental é a mesma, o que difere são as demais componentes, ou seja, o timbre.

A seguir apresenta-se um estudo geral sobre a transformada de Fourier. De uma forma objetiva a série de Fourier é dada por:

- $f(t)=a_{0} / 2+\Sigma_{k=1, \infty} a_{k} \cos k t+\Sigma_{k=1, \infty} b_{k}$ sen $k t$

Sendo os coeficientes calculados por:

- $a_{k}=(1 / \pi) \int_{0,2 \pi} f(t) \cos k t d t$ e $b_{k}=(1 / \pi) \int_{0,2 \pi} f(t)$ sen $k t$ dt

Como foi apresentado anteriormente, uma função $\mathbf{f}(\mathbf{x})$ pode ser "expandida" em uma série de Fourier onde a função é aproximada pela soma de senos e co-senos do seguinte modo:

- $f(x)=a_{0}+a_{1} \operatorname{sen}(x)+a_{2} \operatorname{sen}(2 x)+a_{3} \operatorname{sen}(3 x)+\ldots+b_{1} \cos (x)+$ $b_{2} \cos (2 x)+\ldots$

Fourier conseguiu achar uma forma simples de calcular esses coeficientes $\mathbf{a}_{0}, \mathbf{a}_{1}$, $\mathbf{a}_{2}, \ldots, \mathbf{b}_{1}, \mathbf{b}_{2}$ e assim por diante, conforme processo apresentado a seguir.

Para exemplificar, segue-se o método para a obtenção do coeficiente $\mathrm{a}_{3}$. 
Inicialmente, multiplica-se os dois lados da equação que define a série por $\operatorname{sen}(3 x)$. Obtêm-se, assim:

- $f(x) \operatorname{sen}(3 x)=a_{0} \operatorname{sen}(3 x)+a_{1} \operatorname{sen}(x) \operatorname{sen}(3 x)+a_{2} \operatorname{sen}(2 x)$ $\operatorname{sen}(3 x)+a_{3} \operatorname{sen}^{2}(3 x)+\ldots+b_{1} \cos (x) \operatorname{sen}(3 x)+\ldots$

A seguir, tomam-se as MÉDIAS de cada termo dessa equação:

- $<f(x) \operatorname{sen}(3 x)>=<a_{0} \operatorname{sen}(3 x)>+<a_{1} \operatorname{sen}(x) \operatorname{sen}(3 x)>+<a_{2}$ $\operatorname{sen}(2 x) \operatorname{sen}(3 x)>+<a_{3} \operatorname{sen}^{2}(3 x)>+\ldots+<b_{1} \cos (x) \operatorname{sen}(3 x)$ $>+\ldots$

Surge uma particularidade: todas as médias do lado direito da equação são nulas, menos a média do termo correspondente $a \mathbf{a}_{3}$. Isto é:

$$
<f(x) \operatorname{sen}(3 x)>=\frac{1}{2} a_{3}
$$

Isso acontece porque cada termo da esquerda (menos o termo de $\mathbf{a}_{3}$ ) contém a média de um seno ou um co-seno em um período, que é zero, como apresentado antes. Mas, o termo de $\mathbf{a}_{3}$ contém a média de $\operatorname{sen}^{2}(\mathbf{3 x})$, que vale $\mathbf{1 / 2}$, como também foi visto. Portanto:

$$
\text { - } a_{3}=2<f(x) \operatorname{sen}(3 x)>
$$

Portanto, o coeficiente $\mathbf{a}_{3}$ é duas vezes a média do produto de $\mathbf{f}(\mathbf{x})$ por $\operatorname{sen}(\mathbf{3 x})$. 
Fazendo-se o mesmo para todos os valores de $\mathbf{n}$ em $\operatorname{sen}(\mathbf{n x})$ e $\cos (\mathbf{n x})$, verifica-se, portanto, que:

- $a_{0}=<f(x)>=$ média de $f(x)$.

- $a_{n}=2<f(x) \operatorname{sen}(n x)>=2$ vezes a média de $f(x) \operatorname{sen}(n x)$.

- $b_{n}=2<f(x) \cos (n x)>=2$ vezes a média de $f(x) \cos (n x)$.

Sabendo-se calcular essas médias, acham-se os coeficientes da série de Fourier.

Como apresentado anteriormente, uma função periódica $\mathrm{f}(\mathrm{x})$ pode ser aproximada por uma série de Fourier do seguinte modo:

- $f(x)=a_{0}+a_{1} \operatorname{sen}(x)+a_{2} \operatorname{sen}(2 x)+a_{3} \operatorname{sen}(3 x)+\ldots+b_{1} \cos (x)+b_{2}$ $\cos (2 x)+\ldots$

Os coeficientes de Fourier $\mathrm{a}_{0}, \mathrm{a}_{1}, \mathrm{a}_{2}, \ldots, \mathrm{b}_{1}, \mathrm{~b}_{2}$ etc são dados por:

- $a_{0}=\langle f(x)>=$ média de $f(x)$ em um período;

- $a_{n}=2<f(x) \operatorname{sen}(n x)>=2$ vezes a média de $f(x) \operatorname{sen}(n x)$ em um período;

- $b_{n}=2<f(x) \cos (n x)>=2$ vezes a média de $f(x) \cos (n x)$ em um período.

Para ilustrar esse resultad, faz-se a seguir o desenvolvimento em série de Fourier de uma função periódica simples: a chamada "onda quadrada", ou "função degrau", cujo gráfico é mostrado na figura a seguir. Essa função é muito utilizada devido a sua aplicabilidade em computação, pois pode ilustrar uma sucessão de "bits" com valores 1 e 0 .

No primeiro período, ela pode ser escrita como sendo:

- $f(x)=1$ (de 0 a $\pi)$

- $f(x)=0$ (de $\pi a 2 \pi)$. 


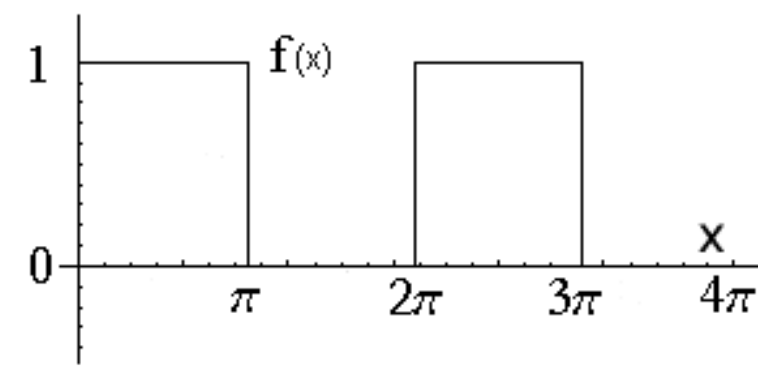

O mesmo se repete para os demais períodos. Essa é a vantagem de uma função periódica: basta ver o que acontece em um período para saber o que acontece nos demais.

Para expressar essa função "onda quadrada" em séries de Fourier, calcula-se os coeficientes da série, conforme segue.

O primeiro coeficiente, $\mathrm{a}_{0}$, é a média de $\mathrm{f}(\mathrm{x})$ no período. Graficamente, pela figura a seguir, constata-se que esse valor médio é $1 / 2$.

- $a_{0}=1 / 2$.

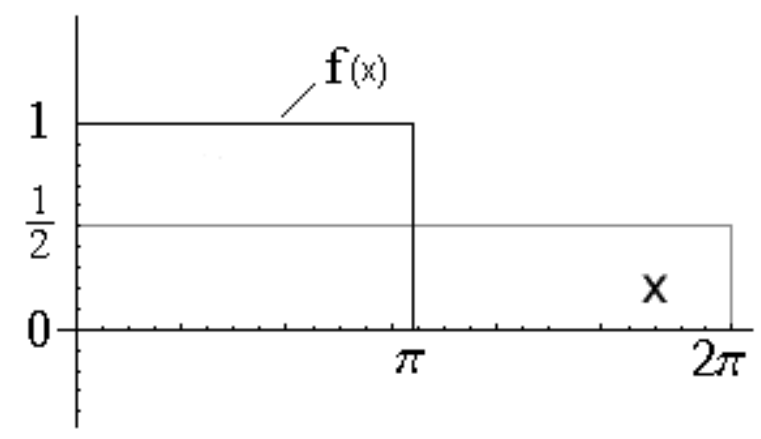

Para obter o coeficiente $a_{1}$, primeiro multiplica-se $\mathbf{f}(\mathbf{x})$ por sen(x). Obtêm-se a curva a seguir, que é a meia onda de uma senóide. Como apresentado anteriormente, a área sob essa meia onda é $\mathbf{S}=\mathbf{2}$. Logo, a altura do retângulo,que é o valor médio do produto $\mathbf{f}(\mathbf{x}) \operatorname{sen}(\mathbf{x})$, deve ser $1 / \pi$. (Pois, $(1 / \pi) \times 2 \pi=2$.) Portanto:

- $a_{1}=2<f(x) \operatorname{sen}(x)>=2 / \pi$. 


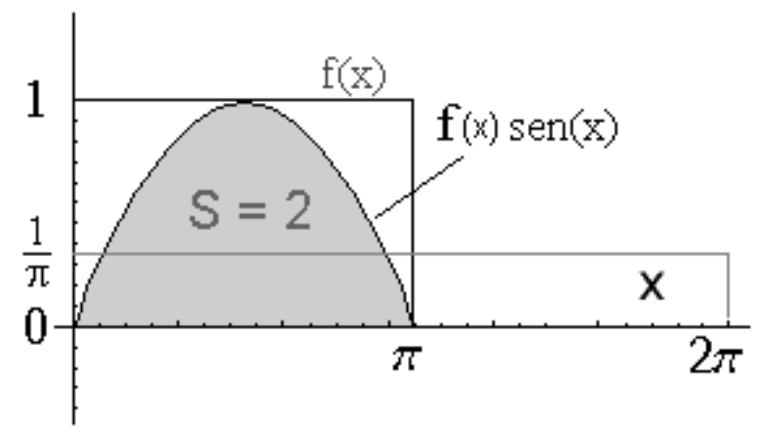

O coeficiente $\mathbf{a}_{2}$ é duas vezes a média de $\mathbf{f}(\mathbf{x}) \operatorname{sen}(\mathbf{2 x})$ no período. Pela figura, esse valor médio é zero. Logo:

- $a_{2}=0$.

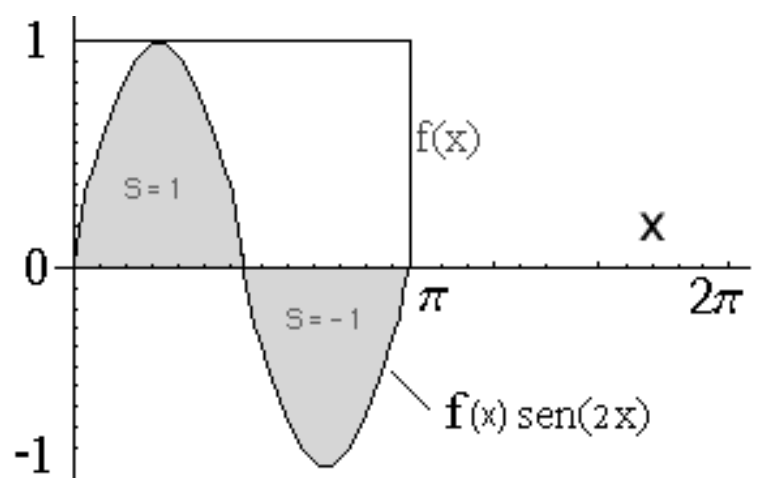

$\mathrm{O}$ coeficiente $a_{3}$ é duas vezes a média de $\mathbf{f}(\mathbf{x}) \operatorname{sen}(3 \mathbf{x})$. Na figura apresentada, constata-se que as partes sombreadas desse produto se anulam, e sobrando apenas uma onda cuja área é $2 / 3$. Logo, o valor médio do produto $\mathbf{f}(\mathbf{x}) \operatorname{sen}(3 \mathbf{x})$ vale $1 / 3 \pi$, e o coeficiente fica valendo:

- $\quad \mathbf{a}_{3}=2 / 3 \pi$.

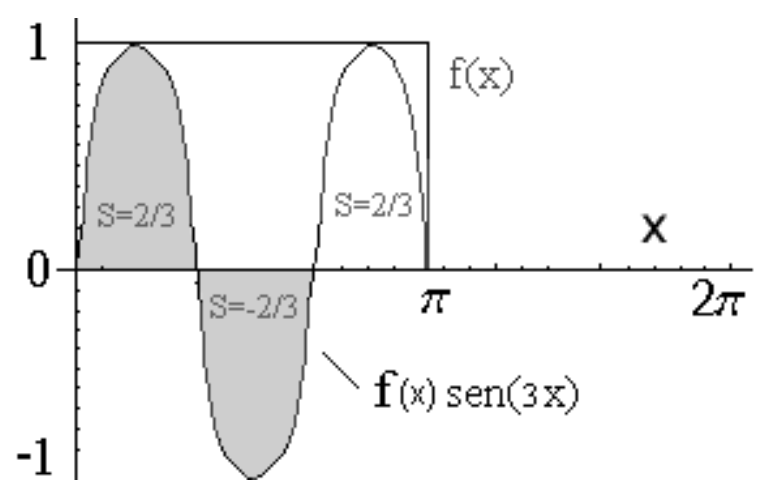

- $\mathbf{a}_{\mathbf{n}}=0$ - para todo $\mathrm{n}$ PAR; 
- $a_{n}=2 / n \pi$ - para todo $n$ ÍMPAR.

A partir deste cálculo, constata-se que todos os coeficientes dos termos em $\cos (\mathbf{x})$, isto é, os $\mathbf{b}_{\mathbf{n}}$, são nulos. Portanto, a série de Fourier para a onda quadrada é:

- $f(x)=1 / 2+(2 / \pi) \operatorname{sen}(x)+(2 /(3 \pi)) \operatorname{sen}(3 x)+(2 /(5 \pi)) \operatorname{sen}(5 x)+(2 /(7 \pi))$ $\operatorname{sen}(7 x)+\ldots$

A figura a seguir mostra um gráfico da onda quadrada juntamente com o gráfico da expansão com os primeiros 5 termos da série de Fourier, isto é, com os termos explicitados na equação acima.

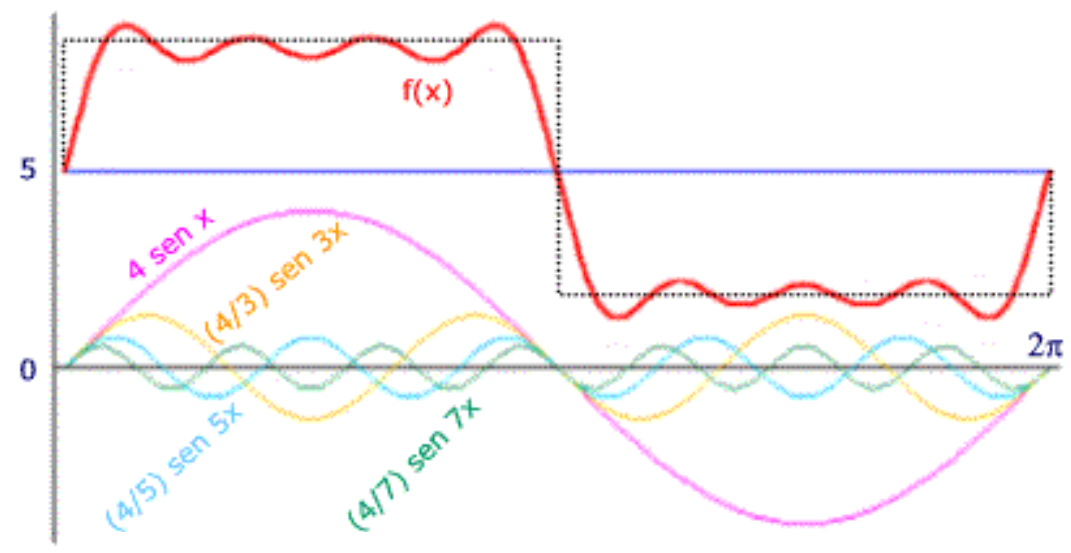

A motivação de Fourier, ao desenvolver a série que imortalizou seu nome, estava ligada a um problema físico: a propagação do calor em um sólido. Com seu livro Teoria Analítica do Calor, conseguiu fama e prestígio, além de receber um prêmio da Academia de Ciências da França.

A importância do trabalho de Fourier ultrapassou por completo seu uso na termodinâmica. Como apresentado anteriormente, uma série de Fourier pode 
representar uma função periódica. $\mathrm{Na}$ verdade, ela pode representar qualquer função, periódica ou não.

Como apresentado, os termos da série são:

- $\mathbf{a}_{0}, \mathbf{a}_{1} \operatorname{sen}(x), \mathbf{a}_{2} \operatorname{sen}(2 x)$ etc.

Isto é, as fases $(\mathbf{x}, \mathbf{2 x}, \mathbf{3 x}$ etc) se diferenciam por valores inteiros. Isso não é necessário e pode ser modificado. As diferenças poderiam, por exemplo, ser fracionárias, por exemplo, $\mathbf{x}, \mathbf{0 , 1 x}, \mathbf{0 , 2 x}, \mathbf{0 , 3 x}$ etc. Essa diferença pode até ser infinitesimal. Com essa generalização, é possível achar uma expansão de Fourier para (praticamente) qualquer função.

Em 1924, em sua tese de doutoramento, o francês Louis De Broglie apresentou a revolucionária idéia de associar propriedades ondulatórias a partículas como o elétron. Segundo sua sugestão, o comportamento de um elétron (ou qualquer outra partícula) seria governado por uma "onda piloto" que se deslocaria junto com o elétron e teria uma forma parecida com essa que é vista na figura abaixo.

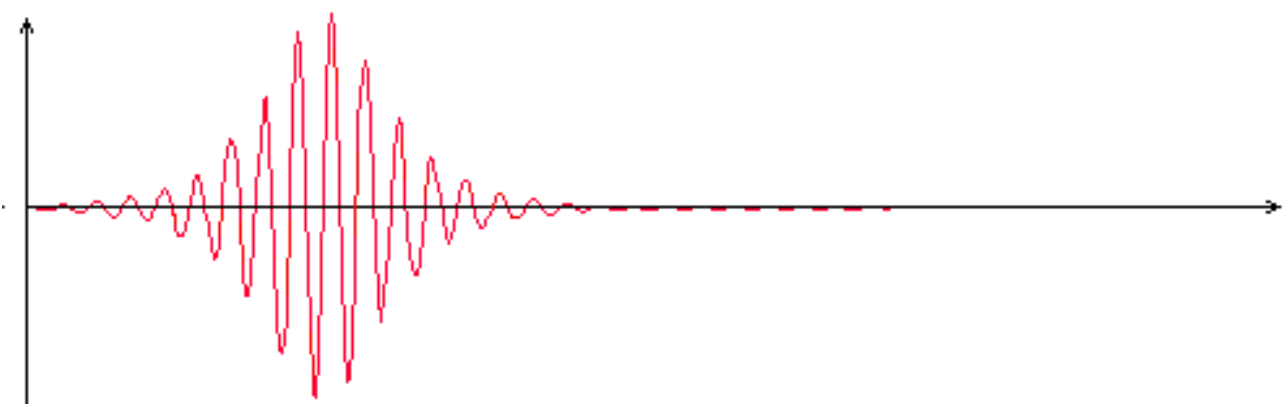

A melhor maneira de se descrever essa "onda piloto", ou "pacote de onda", como se chama hoje em dia, utiliza uma expansão de Fourier com diferenças de fase 
infinitesimais. Isto fez com que trabalho de Fourier tivesse grande utilidade no desenvolvimento da física moderna do século 20 e do atual.

\section{D- Média, Variância e Desvio Padrão}

A Média, Variância e Desvio Padrão, são cálculos utilizados para a análise de relação de valores discretos (MOREIRA, 70).

Para resumir dados quantitativos aproximadamente simétricos, é usual calcular a média aritmética como uma medida de locação. Se $\mathbf{x}_{1}, \mathbf{x}_{2}, \ldots, \mathbf{x}_{\mathbf{n}}$ são os valores dos dados, então pode-se escrever a média como:

$$
\bar{x}=\frac{x_{1}+x_{2}+\ldots+x_{n}}{n}=\frac{\sum_{i=1}^{n} x_{i}}{n}
$$


A variância, identificada por $\mathbf{s}^{2}$, é definida como o desvio quadrático médio da média, e é calculada de uma amostra de dados como:

$$
s^{2}=\frac{\sum_{i=1}^{n}\left(x_{i}-\bar{x}\right)^{2}}{n-1}
$$

A segunda versão é mais fácil de ser calculada, embora muitas calculadoras têm funções prontas para o cálculo de variâncias, e é raro ter que realizar todos os passos manualmente. Comumente as calculadoras fornecem a raiz quadrada da variância, o desvio padrão, i.e.:

$$
s=\sqrt{s^{2}}
$$

a qual é medida nas mesmas unidades dos dados originais.

Uma informação útil é que para qualquer conjunto de dados, pelo menos $75 \%$ deles fica dentro de uma distância de 2 desvio padrão da média, ou seja, entre $\overline{\mathrm{x}}-2 \mathrm{~s} \quad \mathrm{e}^{\overline{\mathrm{x}}+2 \mathrm{~s}}$ 


\section{E- Funções Matemáticas}

Apresenta-se a seguir um resumo das definições formais relativas às funções matemáticas (ÁVILA, 94).

\section{C.1 - Definição}

Dados dois conjuntos A e B não vazios, chama-se função (ou aplicação) de A em $B$, representada por $\mathbf{f}: \mathbf{A} \rightarrow \mathbf{B} ; \mathbf{y}=\mathbf{f}(\mathbf{x})$, a qualquer relação binária que associa a cada elemento de $\mathrm{A}$, um único elemento de B.

Portanto , para que uma relação de A em B seja uma função, exige-se que a cada $x \in A$ esteja associado um único $y \in B$, podendo entretanto existir $y \in B$ que não esteja associado a nenhum elemento pertencente ao conjunto A. 


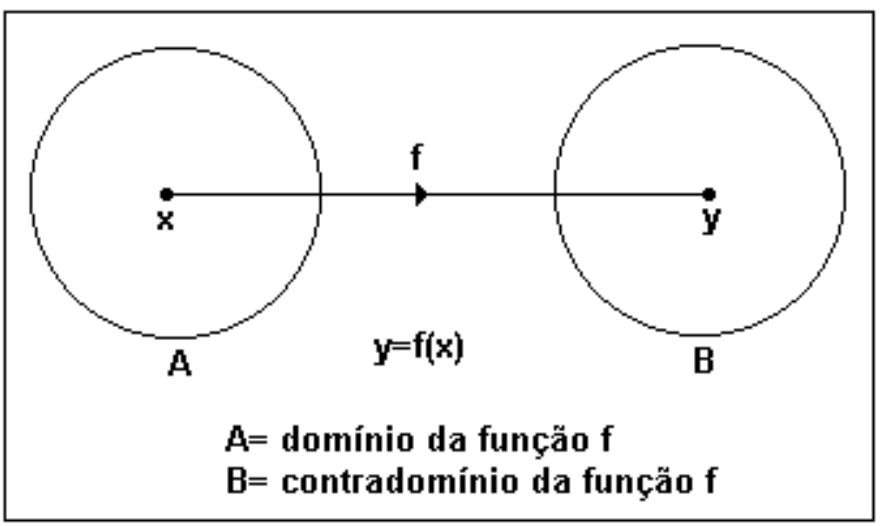

Obs: na notação $\mathbf{y}=\mathbf{f}(\mathbf{x})$, entende-se que y é imagem de $\mathrm{x}$ pela função $\mathrm{f}$, ou seja: $\mathrm{y}$ está associado a $\mathrm{x}$ através da função $\mathrm{f}$.

Para definir uma função, necessitamos de dois conjuntos (Domínio e Contradomínio) e de uma fórmula ou uma lei que relacione cada elemento do domínio a um e somente um elemento do contradomínio.

Quando $\mathbf{D}(\mathbf{f}) \subset \mathbf{R}$ e $\mathbf{C D}(\mathbf{f}) \subset \mathbf{R}$, sendo $\mathbf{R}$ o conjunto dos números reais, diz-se que a função f é uma função real de variável real . Na prática, costuma-se considerar uma função real de variável real como sendo apenas a lei $\mathbf{y}=\mathbf{f}(\mathbf{x})$ que a define, sendo o conjunto dos valores possíveis para $\mathbf{x}$, chamado de domínio e o conjunto dos valores possíveis para y, chamado de conjunto imagem da função. Assim, por exemplo, para a função definida por $\mathbf{y}=\mathbf{1} / \mathbf{x}$, tem-se que o seu domínio é $\mathbf{D}(\mathbf{f})=\mathbf{R}^{*}$, ou seja, o conjunto dos reais diferentes de zero (lembre-se que não existe divisão por zero), e o seu conjunto imagem é também $R^{*}$, já que se $y=1 / x$, então $x=1 / y$ e, portanto $y$ também não pode ser zero.

Dada uma função $\mathbf{f}: \mathbf{A} \rightarrow \mathbf{B}$ definida por $\mathbf{y}=\mathbf{f}(\mathbf{x})$, pode-se representar os pares ordenados $(\mathbf{x}, \mathbf{y}) \in \mathbf{f}$ onde $\mathbf{x} \in \mathbf{A}$ e $\mathbf{y} \in \mathbf{B}$, num sistema de coordenadas cartesianas .O gráfico obtido será o gráfico da função f.

Assim, por exemplo, sendo dado o gráfico cartesiano de uma função f, pode-se dizer que: 
a ) a projeção da curva sobre o eixo dos $\mathbf{x}$, nos dá o domínio da função.

b ) a projeção da curva sobre o eixo dos $\mathbf{y}$, nos dá o conjunto imagem da função

c ) toda reta vertical que passa por um ponto do domínio da função, intercepta o gráfico da função em no máximo um ponto.

Veja a figura a seguir:

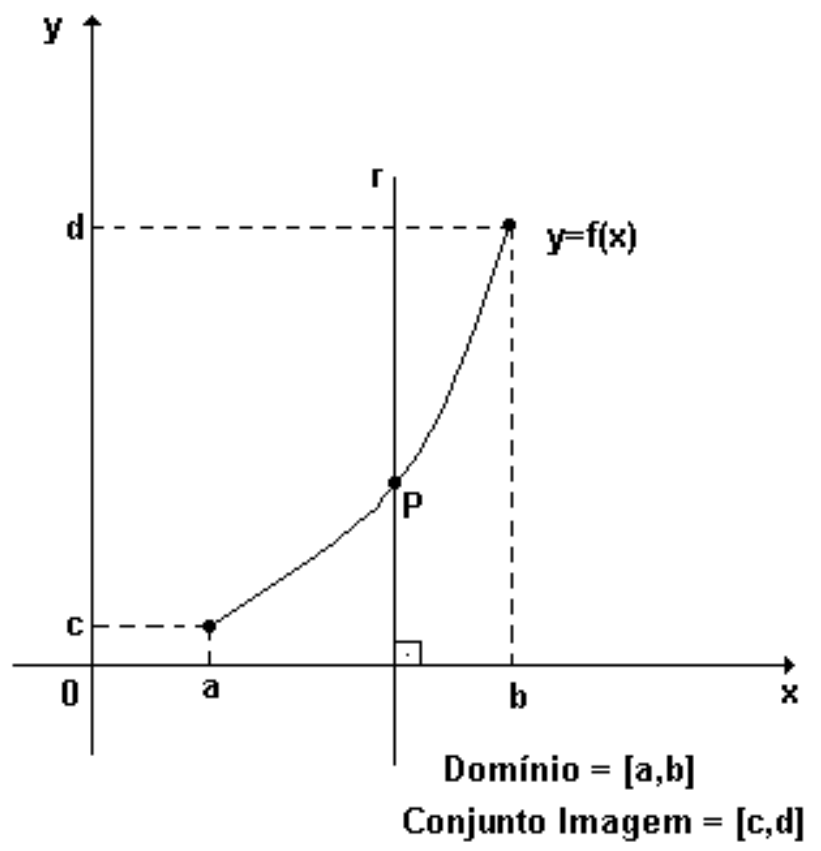

\section{C.2 -Tipos de funções}

C.2.1 - Função sobrejetora

É aquela cujo conjunto imagem é igual ao contradomínio. Exemplo: 


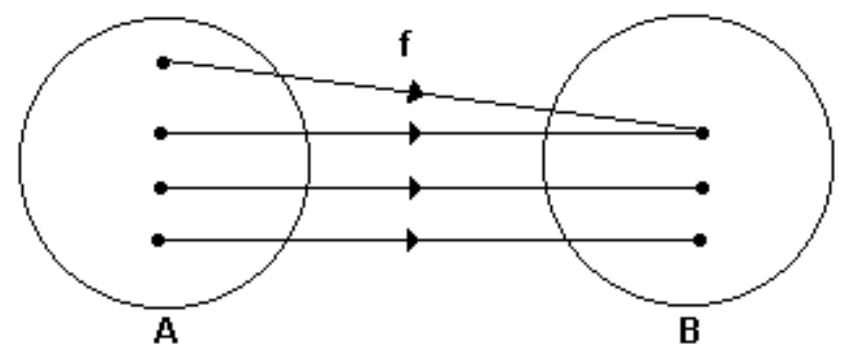

\section{C.2.2 - Função injetora}

Uma função $\mathrm{y}=\mathrm{f}(\mathrm{x})$ é injetora quando elementos distintos do seu domínio possuem imagens distintas, isto é:

- $\quad x_{1} \neq x_{2} \Rightarrow f\left(x_{1}\right) \neq f\left(x_{2}\right)$.

Exemplo:

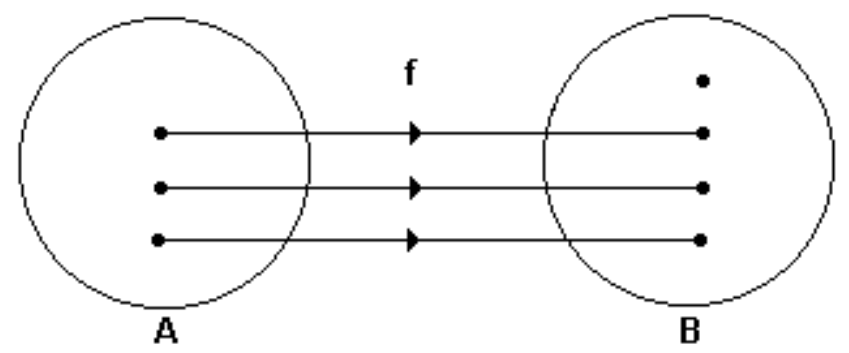

\section{C.2.3 - Função bijetora}

Uma função é dita bijetora, quando é ao mesmo tempo, injetora e sobrejetora.

Exemplo:

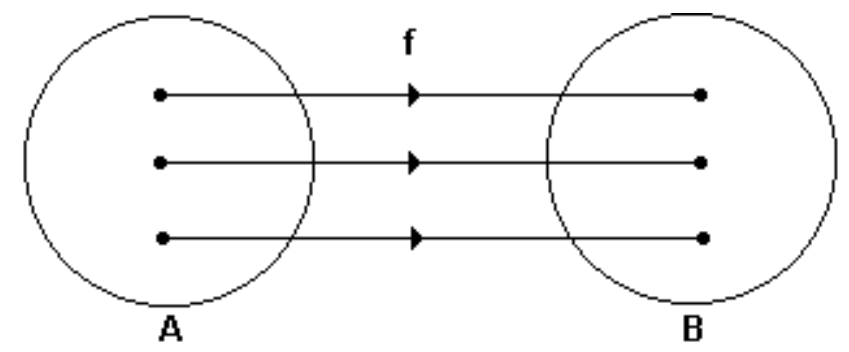




\section{C.3 - Paridade das funções}

\section{C.3.1 - Função par}

A função $\mathbf{y}=\mathbf{f}(\mathbf{x})$ é par, quando $\forall \mathbf{x} \in \mathbf{D ( f )}, \mathbf{f}(-\mathbf{x})=\mathbf{f}(\mathbf{x})$, ou seja, para todo elemento do seu domínio, $\mathbf{f}(\mathbf{x})=\mathbf{f}(-\mathbf{x})$.

Portanto, numa função par, elementos simétricos possuem a mesma imagem. Uma conseqüência desse fato é que os gráficos cartesianos das funções pares são curvas simétricas em relação ao eixo dos y ou eixo das ordenadas.

O gráfico a seguir, é de uma função par.

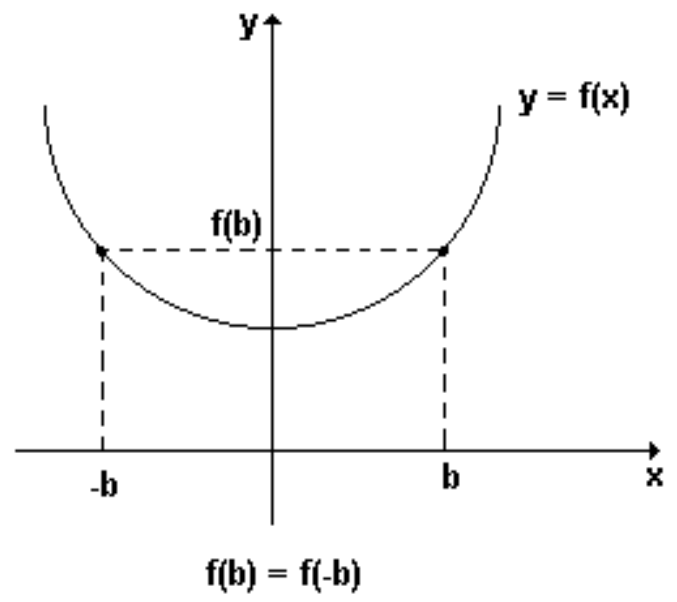

\section{C.4.2 - Função ímpar}

A função $\mathbf{y}=\mathbf{f}(\mathbf{x})$ é ímpar, quando.. $\forall \mathbf{x} \in \mathbf{D}(\mathbf{f}), \mathbf{f}(-\mathbf{x})=-\mathbf{f}(\mathbf{x})$, ou seja, para todo elemento do seu domínio, $\mathbf{f}(-\mathbf{x})=-\mathbf{f}(\mathbf{x})$. Portanto, numa função ímpar, elementos simétricos possuem imagens simétricas. Uma conseqüência desse fato é que os gráficos cartesianos das funções ímpares são curvas simétricas em relação ao ponto $(0,0)$, origem do sistema de eixos cartesianos.

O gráfico s seguir é de uma função ímpar: 


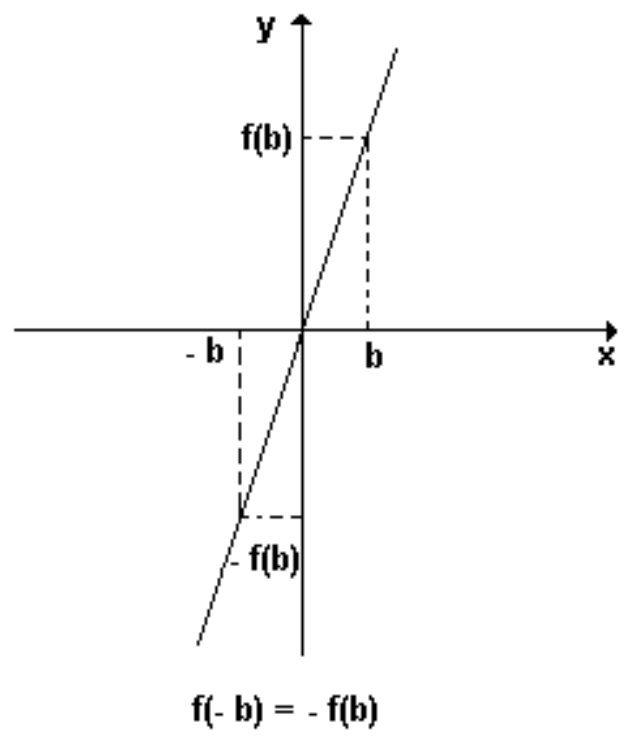

Nota: se uma função $\mathrm{y}=\mathrm{f}(\mathrm{x})$ não é par nem ímpar, diz-se que ela não possui paridade.

Exemplo:

O gráfico abaixo, representa uma função que não possui paridade, pois a curva não é simétrica em relação ao eixo dos x e, não é simétrica em relação à origem.

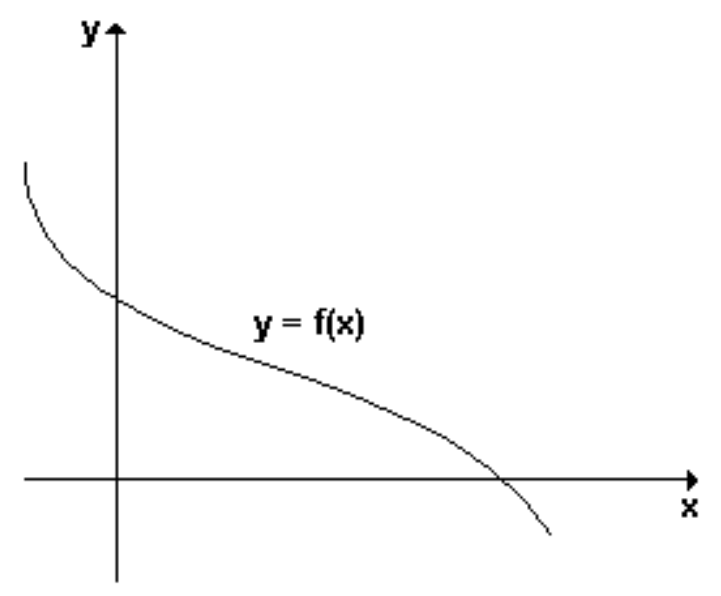

